\title{
Molekulare Analyse des Biotin-regulatorischen Netzwerks in Sinorhizobium meliloti durch Proteomanalyse, Expressionsstudien und Mutagenesen
}

\author{
Dissertation \\ zur Erlangung des Doktorgrades \\ der Mathematisch-Naturwissenschaftlichen Fakultäten \\ der Georg-August-Universität zu Göttingen
}

vorgelegt von

Elke Heinz

aus Arad/Rumänien

Göttingen 2002 
Die vorliegende Arbeit wurde am Institut für Mikrobiologie und Genetik der Georg-AugustUniversität zu Göttingen angefertigt.

D7

Referent:

Prof. Dr. W. Liebl

Korreferent:

Prof. Dr. G. Gottschalk

Tag der mündlichen Prüfung: $\quad 30.10 .2002$ 


\section{INHALTSVERZEICHNIS}

1 EINLEITUNG 1

1.1 Sinorhizobium (Rhizobium) meliloti und die symbiontische StickstoffFixierung

1.2 Rhizobielles Überleben unter limitierenden Bedingungen und die stationäre Wachstumsphase

1.3 Rhizobielles Wachstum in Abhängigkeit von Biotin

1.4 Intention der Arbeit

2 MATERIAL UND METHODEN

2.1 Bakterienstämme und Plasmide $\quad 8$

$\begin{array}{lll}2.2 & \text { Bakterienanzucht } & 10\end{array}$

$\begin{array}{ll}2.2 .1 \text { Nährmedien } & 10\end{array}$

2.2.2 Antibiotika und andere Medienzusätze 13

2.2.3 Wachstumsbedingungen und Stammhaltung 13

$\begin{array}{ll}\text { 2.2.3.1 Zellanzucht } & 13\end{array}$

2.2.3.2 Anzucht von S. meliloti zur Gewinnung von Biotin-limitierten

Kulturen 14

2.2.3.3 Anzucht von Agrobacterium tumefaciens NTL4 zur Detektion von Autoinduktoren $\quad 14$

2.2.3.4 Anlegen von Stammplatten 14

$\begin{array}{ll}\text { 2.2.3.5 Anlegen von Glycerinkulturen } & 14\end{array}$

$\begin{array}{ll}\text { 2.2.3.6 Trübungsmessungen } & 15\end{array}$

2.2.3.7 Anzucht für Überexpressionsversuche mit dem T7-RNA-Polymerase/ $\begin{array}{ll}\text { Promotor-System } & 15\end{array}$

2.3 Basistechniken für das Arbeiten mit Nukleinsäuren $\quad \mathbf{1 5}$

2.3.1 Behandlung von Geräten und Lösungen für das Arbeiten mit Nukleinsäuren $\quad 15$

2.3.2 Reinigung und Konzentrierung von Nukleinsäuren 15

2.3.2.1 Fällung von DNA mit Ethanol oder Isopropanol 15

2.3.2.2 Phenol/Chloroform-Extraktion 16

2.3.2.3 Konzentrationsbestimmung von DNA 16

2.4 Methoden zur Charakterisierung von DNA-Fragmenten 16

2.4.1 Agarosegelelektrophorese und Ethidiumbromid-Färbung von DNA 16

$\begin{array}{ll}\text { 2.4.2 Fragmentlängenbestimmung von DNA } & 17\end{array}$

$\begin{array}{lll}2.5 & \text { Isolierung von DNA } & \mathbf{1 8}\end{array}$

2.5.1 Isolierung von Plasmid-DNA (Birnboim und Doly, 1979, mod.) 18

2.5.2 Isolierung von Plasmid-DNA durch QIAprep Spin Miniprep-Kit 19

2.5.3 Isolierung von Gesamt-DNA aus S. meliloti 20 
2.5.4 Elution von DNA-Fragmenten aus Agarosegelen 21

2.6 Enzymatische Modifikationen von Nukleinsäuren 21

2.6.1 Spaltung von DNA durch Restriktionsendonukleasen 21

2.6.2 Dephosphorylierung von DNA-Enden $\quad 22$

2.6.3 Ligation von DNA-Fragmenten 22

$\begin{array}{lll}2.7 & \text { Transformationsverfahren } & \mathbf{2 3}\end{array}$

2.7.1 Herstellung elektrokompetenter E. coli Zellen 23

2.7.2 Transformation von E. coli durch Elektroporation 23

2.7.3 Herstellung von kompetenten $E$. coli Zellen mit Hilfe der $\mathrm{CaCl}_{2}$-Methode $\quad 24$

2.7.4 Transformation von kompetenten Zellen 24

2.7.5 Selektion rekombinanter E. coli Klone durch X-Gal-Test 25

2.8 DNA-Übertragung durch Konjugation 25

2.9 Herstellung von $S$. meliloti-Mutanten mit Hilfe des sacB-Systems 26

2.10 In vitro Amplifikation von DNA durch Polymerase-Kettenreaktion 26

2.11 Southern-Hybridisierung (Southern, 1975, mod.) 28

2.11.1 Vakuum-Blotting 28

2.11.2 Hybridisierung 29

2.11.3 Sondenherstellung $\quad 30$

2.11.4 Antikörperbindung und colorimetrische Detektion 30

2.12 Proteinbestimmung 31

2.13 SDS-Polyacrylamidgelelektrophorese (SDS-PAGE) 32

2.13.1 Probenvorbereitung 33

2.14 Nativ-Polyacrylamidgelelektrophorese $\quad 34$

2.14.1 Probenvorbereitung für native Gele 35

2.15 2D-PAGE (O'-Farell, 1975, mod.)

2.15.1 Probenvorbereitung 35

2.15.2 Isoelektrische Fokussierung $\quad 37$

2.15.3 Equilibrierung 38

2.15.4 SDS-Gelelektrophorese als 2. Dimension 39

2.16 Probenpräparation für die MALDI-TOF-Massenspektrometrie 40

2.17 Färbung von Proteinen $\quad 41$

2.17.1 Coomassie-Färbung 41

2.17.2 Silberfärbung (Blum et al., 1987, mod.) 42

2.18 Proteinaufreinigung durch Ni-NTA-Affinitätschromatographie 43

2.18.1 Zellaufschluß und Aufreinigung unter nativen Bedingungen 43

2.18.2 Zellaufschluß und Aufreinigung unter denaturierenden Bedingungen $\quad 44$

2.19 B-Glucuronidase-Messungen $\quad 45$ 
2.20 Dünnschichtchromatographie 46

2.21 Chemikalien, Biochemikalien und Enzyme 46

2.22 Geräte, Kits und andere Materialien 48

3 EXPERIMENTE UND ERGEBNISSE

3.1 2D-Gelelektrophorese $\quad \mathbf{5 1}$

3.1.1 Vergleichende 2D-Gelanalyse von S. meliloti Proteinextrakten 51

3.1.2 Ausgewählte Proteine mit erhöhter Expression nach Biotinsupplementation 55

3.1.3 Auswertung der MALDI-TOF-MS-Analyse 59

3.1.4 Identifizierte Proteine aus S. meliloti mit erhöhter Expression nach Biotinsupplementation $\quad 62$

3.2 Konstruktion von Reportergenfusionen $\quad 66$

3.2.1 Aktivitätsmessungen der nodD1- und nodD3-Promotorregionen 69

3.2.2 Aktivitätsmessungen der putativen Promotorregion von ORF SMc04882, eines $\begin{array}{ll}\text { möglichen LysR-Typ-Transkriptionsregulators } & 71\end{array}$

3.2.3 Aktivitätsmessungen der putativen Promotorregion des bioM-Operons $\quad 73$

3.2.4 Aktivitätsmessungen der putativen Promotorregion des plsX-Gens 75

3.2.5 Promotoraktivitätsmessungen einer Autoinduktor Synthase und eines AcylHomoserin-Lacton-abhängigen Transkriptionsregulators 77

3.2.6 Aktivitätsmessungen der putativen Promotorregion des copC-Gens 85

3.2.7 Sequenzanalyse von Biotin-regulierten Promotoren 87

3.2.8 Detektion von S. meliloti 1021 Acyl-HSL durch Dünnschichtchromatographie 90

3.3 Charakterisierung des surE- und pcm-Gens aus $S$. meliloti 92

3.3.1 Klonierung und heterologe Überexpression der surE- und $\mathrm{pcm}$-Gene von

S. meliloti und Aufreinigung der Genprodukte 94

3.3.2 Phosphataseaktivität des SurE-Proteins $\quad 97$

3.3.3 Konstruktion der pcm-Mutante Rm1021-EH45 und der surE-Mutante Rm1021EH47

3.3.3.1 Konstruktion von $\mathrm{pEH} 40 \quad 99$

3.3.3.2 Konstruktion von pEH40-6 99

3.3.3.3 Konstruktion von pEH40-9 101

3.3.3.4 Expression des surE-Gens 103

3.3.3.5 Transkriptionsanalyse des $p c m$-Gens in TY-Vollmedium 103

3.3.3.6 Transkriptionsanalyse des $p c m$-Gens in GTS-Minimalmedium 104

3.3.3.7 Überleben von Rm1021-EH45, Rm1021-EH47 und Rm1021 in TYVollmedium 106

3.3.3.8 Wachstumsversuche der pcm-Mutante Rm1021-EH45, der surE-Mutante Rm-EH47 und Rm1021 in GTS-Minimalmedium 108

3.3.3.9 Komplementation der pcm-Mutante Rm1021-EH45 110 
3.3.3.10 Wachstumsversuche von Rm1021-EH45, Rm1021-EH47 und Rm1021 unter verschiedenen Streßbedingungen

4 DISKUSSION

4.1 S. meliloti 1021-Proteine mit erhöhter Expression nach Biotinsupplementation des Mediums

4.2 Expressionsanalysen

4.2.1 Erhöhte Expression von $\sin I$ und $\sin R$ unter Biotin-limitierenden Bedingungen 122

4.2.2 Expression der nodD1- und nodD3-Reportergenfusion

4.2.3 Expression des bioM-Operons

4.3 Charakterisierung des surE- und pcm-Gens aus $S$. meliloti 1021

4.3.1 SurE- und pcm-Gene und ihre Funktion

4.3.2 Expressionsanalyse des $p c m$-Gens

4.3.3 Überleben der pcm- und surE-Mutante Rm1021-EH45 und Rm1021-EH47

4.3.4 Überleben unter Streß

4.3.5 Phosphataseaktivität des SurE-Proteins

4.3.6 Wachstum von S. meliloti unter Biotin-limitierenden Bedingungen

4.4 Biotinlimitierung als ein spezielles Streß-Signal für S. meliloti ? 


\section{ABKÜRZUNGEN}

$\alpha-N P$

A

AA

Abb.

A.

Amp

APS

AS

ATP

$b(p)$

BCIP

bidest.

Bis

bzw.

C

cAMP

CHAPS

$\mathrm{Cm}$

d

Da

DIG

DNA

DNase

dNTP

DTT

E.

EC

E-Cup

EDTA

et al.

$\mathrm{g}$

GFP

$\mathrm{h}$

IPTG

$\mathrm{kb}$

$\mathrm{Km}$

1

LB

$\mu$

$\mathrm{m}$

$\mathrm{M}$

MALDI-TOF

$\max$

$\min$

$\mathrm{MM}$

mod.

MS
$\alpha$-Naphtyl-Phosphat

Ampere

Acrylamid

Abbildung

Agrobacterium

Ampicillin

Ammoniumpersulfat

Aminosäure

Adenosin-5'-triphosphat

Basenpaare (DNA)/Basen (RNA)

5-Brom-4-chlor-3-indolylphosphat

zweifach destilliert

N,N-Methylen-bis-Acrylamid

beziehungsweise

Celsius; Kohlenstoff

zyklisches Adenosinmonophosphat

3-[(3-Cholamodopropyl)-dimethylammonio]-1-propansulfonat Hydrat

Chloramphenicol

Desoxy-, Küvettenschichtdicke

Dalton

Digoxygenin

Desoxyribonukleinsäure

Desoxyribonuclease

Desoxynukleosidtriphosphat

Dithiothreitol

Escherichia

Enzyme Commission (Enzymkommission)

Eppendorf-Reaktionsgefäß

Ethylendiamintetraessigsäure

et alteri (und andere)

Gramm, Erdbeschleunigung

Green fluorescent protein (grün fluoreszierendes Protein)

Stunde

Isopropyl- $\beta$-d-thiogalactopyranosid

Kilobasen(paare)

Kanamycin

Liter

Luria Bertani

Mikro

Milli

Molar

Matrix assisted laser desorption ionisation-time of flight

maximal

Minute

Minimalmedium

modifiziert

Massenspektrometrie 
n

NBT

OD

ORF

PAGE

PCR

$\mathrm{pH}$

PHB

pI

PMF

pNPP

ppGpp

rel.

RNA

RNase

RT

$\mathrm{s}$

S

$S$.

SDS

$\mathrm{Sm}$

$\mathrm{Sp}$

SSC

Tab.

TAE

TBE

Tc

TEMED

Tris

TY

U

Upm

UV

V

$\mathrm{v} / \mathrm{v}$

Vol

W

w/v

WT

X-Gal

X-Gluc

z.B. nano

Nitroblautetrazolium

Optische Dichte

Open reading frame (Offener Leserahmen)

Polyacrylamid-Gelelektrophorese

Polymerase chain reaction (Polymerase Kettenreaktion)

negativer dekadischer Logarithmus der

Hydroniumionenkonzentration

Poly-3-hydroxybutyrat

Isoelektrischer Punkt

Peptide mass fingerprint

p-Nitrophenyl-Phosphat

Guanosintetraphosphat

Resistenz

relativ

Ribonukleinsäure

Ribonuclease

Raumtemperatur

Sekunde

Svedberg

Sinorhizobium

Natriumdodecylsulfat

Streptomycin

Spectinomycin

Standard-Saline-Citrat

Tabelle

Tris-Acetat-EDTA

Tris-Borat-EDTA

Tetracyclin

$\mathrm{N}, \mathrm{N}, \mathrm{N}^{\prime}, \mathrm{N}^{\prime}-$ Tetramethylendiamin

Tris-hydroxymethyl-aminomethan

Trypton-Yeast-Medium

Unit (Einheit der Enzymaktivität)

Umdrehung pro Minute

Ultraviolett

Volt

Volumen pro Volumen

Volumen

Watt

Gewicht pro Volumen

Wildtyp

5-Brom-4-chlor-3-indolyl- $\beta$-D-Galaktopyranosid

5-Brom-4-chlor-3-indolyl- $\beta$-D-Glucuronsäure-

Cyclohexylammonium-Salz

zum Beispiel 


\section{EINLEITUNG}

\subsection{Sinorhizobium (Rhizobium) meliloti und die symbiontische Stickstoff- Fixierung}

Das Gram-negative Bodenbakterium Sinorhizobium meliloti gehört zu der Familie der Rhizobiaceae und ist in der Lage, eine Symbiose mit Leguminosen einzugehen und dabei molekularen Stickstoff zu fixieren. S. meliloti induziert bei seiner Wirtspflanze die Entwicklung von Wurzelknöllchen, in denen die $\mathrm{zu}$ Bacteroiden differenzierten Mikrosymbionten den atmosphärischen Stickstoff zu Ammonium reduzieren. Jede Rhizobienart hat ein individuelles Wirtsspektrum. Symbiosepartner von S. meliloti ist unter anderem die Luzerne (Medicago sativa L.), die in der Agrarwirtschaft als Gründünger oder Futtermittel eingesetzt wird (Schultze et al., 1992). Durch die Symbiose erlangt die Pflanze einen Wachstumsvorteil, da sie von der Stickstoff-Fixierung in Form von zur Verfügung gestellten Ammoniumionen profitiert. Die Pflanze ist daher weitestgehend unabhängig vom Stickstoffgehalt des Bodens und damit zur Besiedlung stickstoffarmer Böden geeignet. Landwirtschaftlich genutzte Flächen können auf diese Weise mit stickstoffhaltigen Verbindungen angereichert werden, was die Zugabe von kostenintensiven Nitrat- oder Ammoniumdünger in den folgenden Anbaujahren verringert bzw. eliminiert. Die Mikrosymbionten erhalten im Austausch von der Pflanze C4Dicarbonsäuren als Kohlenstoffquelle und leben in einem abgegrenzten Habitat, dem Wurzelknöllchen, welches auch als „induzierte ökologische Nische“ bezeichnet wird.

$\mathrm{Zu}$ den Stickstoff-Fixierern gehören ausschließlich Prokaryoten, da nur diese über die notwendige Enzymausstattung zur Reduktion des molekularen Stickstoffs, den Nitrogenase-Komplex, verfügen. Anders als Bakterien aus den Gattungen Azotobacter, Clostridium oder Klebsiella können Rhizobien nur in Symbiose Stickstoff reduzieren.

Man geht davon aus, daß weltweit jährlich 60-80 Mio. Tonnen Stickstoff durch die Rhizobien-Leguminosen Symbiose fixiert werden (Vance, 1998). Gerade die Symbiose mit der Luzerne stellt mit durchschnittlich $250 \mathrm{~kg}$ fixiertem Stickstoff pro Jahr und Hektar eine sehr leistungsfähige Interaktion dar, während z.B. in der Symbiose von Bradyrhizobium mit der Sojabohne durchschnittlich nur $80 \mathrm{~kg}$ Stickstoff pro Hektar und Jahr fixiert werden (Peoples et al., 1995; Marquard, 2000).

Die molekularen und genetischen Grundlagen der Symbiose wurden in den letzten Jahren detailliert untersucht aber noch nicht vollständig aufgeklärt. In den verschiedenen Stadien der Symbiose kommt es $\mathrm{zu}$ einem Signalaustausch, bei welchem spezifische 
Genexpressionen bei beiden Symbiosepartnern letztlich zur Ausbildung symbiosespezifischer Eigenschaften auf physiologischer und morphologischer Ebene führen. Eine weitergehende molekularbiologische Analyse dieser Interaktionen und der daran beteiligten Signaltransduktion könnte die Effektivität bereits bestehender Symbiosen optimieren und die symbiontische Stickstoff-Fixierung möglicherweise auch auf andere Pflanzen übertragbar machen.

Die Mehrzahl der symbiosespezifischen Gene sind bei $S$. meliloti auf den beiden Megaplasmiden lokalisiert, die aufgrund ihrer Größe von 1,35 Mb (pSymA) und 1,68 Mb (pSymB) auch als zweites und drittes Chromosom neben dem Hauptchromosom (3,65 Mb) bezeichnet werden (Honeycutt et al., 1993; Capela et al., 2001). Die Nodulationsgene (nod-Gene), die essentiell für die Synthese des Nodulationsfaktors und somit der Knöllchenentwicklung sind, und die Stickstoff-Fixierungsgene (nif und fix-Gene) befinden sich auf dem Plasmid pSymA (Barnett et al., 2001). Letztere codieren unter anderem für die Komponenten des komplexen Nitrogenase-Enzymsystems. Auf Megaplasmid pSymB sind neben den Genen für den Dicarbonsäuretransport (dct-Gene) die exo-Gene lokalisiert, die für Enzyme der Exoploysaccharidsynthese codieren und eine Rolle bei der Infektion der Pflanze spielen (Gonzales et al., 1996; Finan et al., 2001).

\subsection{Rhizobielles Überleben unter limitierenden Bedingungen und die stationäre Wachstumsphase}

Rhizobien sind in der Lage, Phasen unter Nährstofflimitierung und in Abwesenheit ihrer Wirtspflanze für einige Jahre im Boden zu überdauern (Bottomley, 1992; Sadowsky et al., 1998). Die Fähigkeit unter limitierenden Wachstums- und Umweltbedingungen zu überleben und auf ein verbessertes Nährstoffangebot mit schnell einsetzendem Wachstum $\mathrm{zu}$ reagieren ist eine Grundvoraussetzung für Bakterien, nahezu alle Lebensräume erfolgreich zu besiedeln. Generell passen sich Gram-negative Mikroorganismen durch das Eintreten in die Stationärphase an das Überleben unter limitierenden Bedingungen an (Matin et al., 1989). Anders als bei einigen Gram-positiven Bakterien wie Bacillus subtilis kommt es dabei nicht zur Differenzierung der Zellen zu Sporen. Dennoch ist die stationäre Wachstumsphase durch physiologische und morphologische Veränderungen charakterisiert und sie wurde besonders bei Bakterien wie Escherichia coli, Salmonella typhimurium und Vibrio sp. untersucht (siehe Übersichtsartikel: Wai et al., 1999; Spector, 1998; Siegele et al., 1993; Loewen et al., 1998). Morphologisch kennzeichnend für Stationärphase-Zellen 
ist ein verkleinertes Zellvolumen und eine kokkoide Form. Die physiologischen Veränderungen sind vielfältig und zeigen sich durch eine allgemein verringerte Stoffwechselaktivität, welche eine verminderte Nukleinsäure- und Protein-Synthese nach sich zieht, Akkumulation von Speicherstoffen, Umstrukturierung der Zellwand oder durch eine veränderte Zusammensetzung der Zellmembran. Die Bakterien besitzen eine erhöhte Resistenz gegenüber verschiedenen Streßfaktoren wie Hitze, osmotischen Veränderungen der Umwelt, UV-Bestrahlung oder Schwermetallen. Stationärphase-Kulturen von E. coli weisen eine hohe genetische Diversität auf und es kommt zur Entwicklung von sogenannten GASP-Mutanten (growth advantage in stationary-phase), welche einen Überlebensvorteil gegenüber Zellen aus jüngeren Kulturen haben (Finkel und Kolter, 1999). Auf molekularer Ebene aktiviert der Stationärphase-Sigmafaktor RpoS in E. coli die Expression von mindestens hundert Genen (Lange und Hengge-Aronis, 1991; HenggeAronis, 1999). In Vibrio cholerae führt die Mutation des rpoS-Gens zu einer verminderten Überlebensfähigkeit unter diversen Streßbedingungen (Yildiz und Schoolink, 1998). Vermutlich sind aber noch weitere Faktoren daran beteiligt, die Anpassung an die stationäre Wachstumsphase oder generell die Anpassung an limitierende Umweltbedingungen zu regulieren. In E. coli ist die Induktion vieler RpoS-abhängiger Promotoren nur in Anwesenheit von ppGpp (Guanosintetraphosphat) möglich (Kvint et al., 2000; Chatterji und Ojha, 2001). Dieses Effektormolekül wird während verschiedener limitierender Nährstoffbedingungen produziert und leitet die sogenannte stringente Kontrolle ein, welche u. a. zur Inhibierung der RNA-Polymerase, rRNA- und tRNASynthese und zur Aktivierung katabolischer Gene oder zur Chaperonin-Synthese führt. Desweiteren kann cAMP rpoS-unabhängige Gene in der Stationärphase induzieren (Hengge-Aronis, 1993). Signalmoleküle wie Acyl-Homoserinlactone (Acyl-HSL), welche am sogenannten quorum sensing beteiligt sind, spielen ebenfalls eine Rolle beim Eintritt in die stationäre Wachstumsphase (Lazazzera, 2000). In Pseudomonas aeruginosa wird die Expression des Stationärphase-Sigmafaktors in lasR-Mutanten verhindert, wobei las $R$ für einen Acyl-HSL abhängigen Transkriptionsaktivator codiert (Latifi et al., 1996). In Ralstonia solanacearum wiederum führt die Mutation eines rpoS-homologen Gens zur verminderten Expression der soll- und solR-Gene, welche an der Produktion von AcylHSL beteiligt sind (Flavier et al., 1998).

Bei Rhizobien werden ebenfalls solche Anpassungsmechanismen in der Stationärphase beobachtet. So bleibt die Überlebensfähigkeit von $R$. leguminosarum nach 55-tägigem Entzug von Kohlenstoff-, Stickstoff- oder Phosphat-Quellen bei nahezu $100 \%$. Die Zellen 
nehmen eine kokkoide Form an und besitzen Resistenz gegenüber verschiedenen Streßfaktoren (Thorne und Williams, 1997). Desweiteren hängt das Überleben von der Populationsdichte beim Eintreten in die Stationärphase ab, wobei Acyl-HomoserinLactone Zelldichte-abhängiges Überleben fördern (Thorne und Williams, 1999). S. meliloti reagiert auf andauernde Inkubation unter Nährstoffmangel mit eingeschränkter Motilität und erhöhter Sensitivität gegenüber chemotaktisch wirksamen Verbindungen. Diese erhöhte Sensitivität ist für das Austreten aus der Stationärphase von Bedeutung (Wei und Bauer, 1998; Sourjik et al., 2000). Es konnten auch verschiedene Gene identifiziert werden, die unter Nährstoff-limitierenden Bedingungen induziert werden oder die für die Wiederaufnahme von exponentiellen Wachstum essentiell sind (Uhde et al., 1997; Davey und de Bruijn, 2000). Unter Stickstoff- und Kohlenstoff-Mangel wird in S. meliloti beispielsweise das $h m g A-G e n$ induziert, dessen Genprodukt beim Abbau von Tyrosin beteiligt ist. HmgA-Mutanten zeigen eine verminderte Überlebensfähigkeit in der stationären Wachstumsphase (Milcamps und de Bruijn, 1999). In diesem Zusammenhang sind auch Untersuchungen unserer Arbeitsgruppe interessant, in denen bereits zwei Gene aus dem sogenannten Survival-Locus aus S. meliloti charakterisiert wurden, welche am Überleben in der Stationärphase $(n l p D)$ oder bei der Wiederaufnahme von Wachstum unter limitierenden Bedingungen (bioS) beteiligt sind (Heinz et al., 1999; Streit et al., 2000). Die Genomsequenzierung zeigte, daß es in S. meliloti kein dem Stationärphase-Sigmafaktor homologes Gen gibt, wobei aber nicht auszuschließen ist, daß andere Sigmafaktoren oder Regulatoren die Funktion dieses Proteins übernehmen.

\subsection{Rhizobielles Wachstum in Abhängigkeit von Biotin}

Vor der Etablierung einer Symbiose muß S. meliloti zunächst die stationäre Wachstumsphase verlassen und die Rhizosphäre der Wirtspflanze besiedeln. Dies erfordert die Wahrnehmung pflanzenspezifischer Signalmoleküle. Eine keimende Leguminose gibt eine Vielzahl von Verbindungen in den Boden ab, darunter phenolische Komponenten wie Flavonoide, Zucker, Aminosäuren organische Säuren oder Vitamine (Phillips und Streit 1996; Rovira und Harris, 1961). Diese Verbindungen können nicht nur als Nährstoffquelle dienen, sondern üben auch regulatorische Funktionen aus, was sich beispielsweise in der Induktion der nod-Gene durch Flavonoide zeigt (Peters et al., 1986). Eine Verbindung, welche eine Schlüsselfunktion bei der Rhizosphärenkolonisierung übernimmt, ist Biotin (Streit et al., 1996). Dieses Vitamin wird von Pflanzen der Familie der Leguminosen in den Boden abgegeben (Rovira und Harris, 1961) und in Rhizosphärentests konnte gezeigt 
werden, daß Biotin stimulierend auf Wachstum von S. meliloti wirkt (siehe Abb. 1). Die Bindung des von der Pflanze exsudierten Biotins durch Avidin führt zu einer schlechteren Besiedlung der Rhizosphäre (Streit et al., 1996). Offensichtlich stellt pflanzliches Biotin bei Wachstum in der Rhizosphäre die wichtigste Biotinquelle dar und ist möglicherweise eine der Komponenten, die den Bakterien die Anwesenheit eines potentiellen Symbiosepartners vermitteln. Der stimulierende Effekt von Biotin auf Wachstum von Rhizobien auch außerhalb der Rhizosphäre ist bereits seit längerem bekannt und auch in neueren Studien wurde die Abhängigkeit des Wachstums von S. meliloti 1021 und weiteren $26 \mathrm{~S}$. meliloti-Stämmen von exogenem Biotin unter Laborbedingungen gezeigt (Watson et al., 2001). Somit scheint der stimulierende Effekt von Biotin in der Gruppe von S. meliloti ein generelles Prinzip darzustellen.

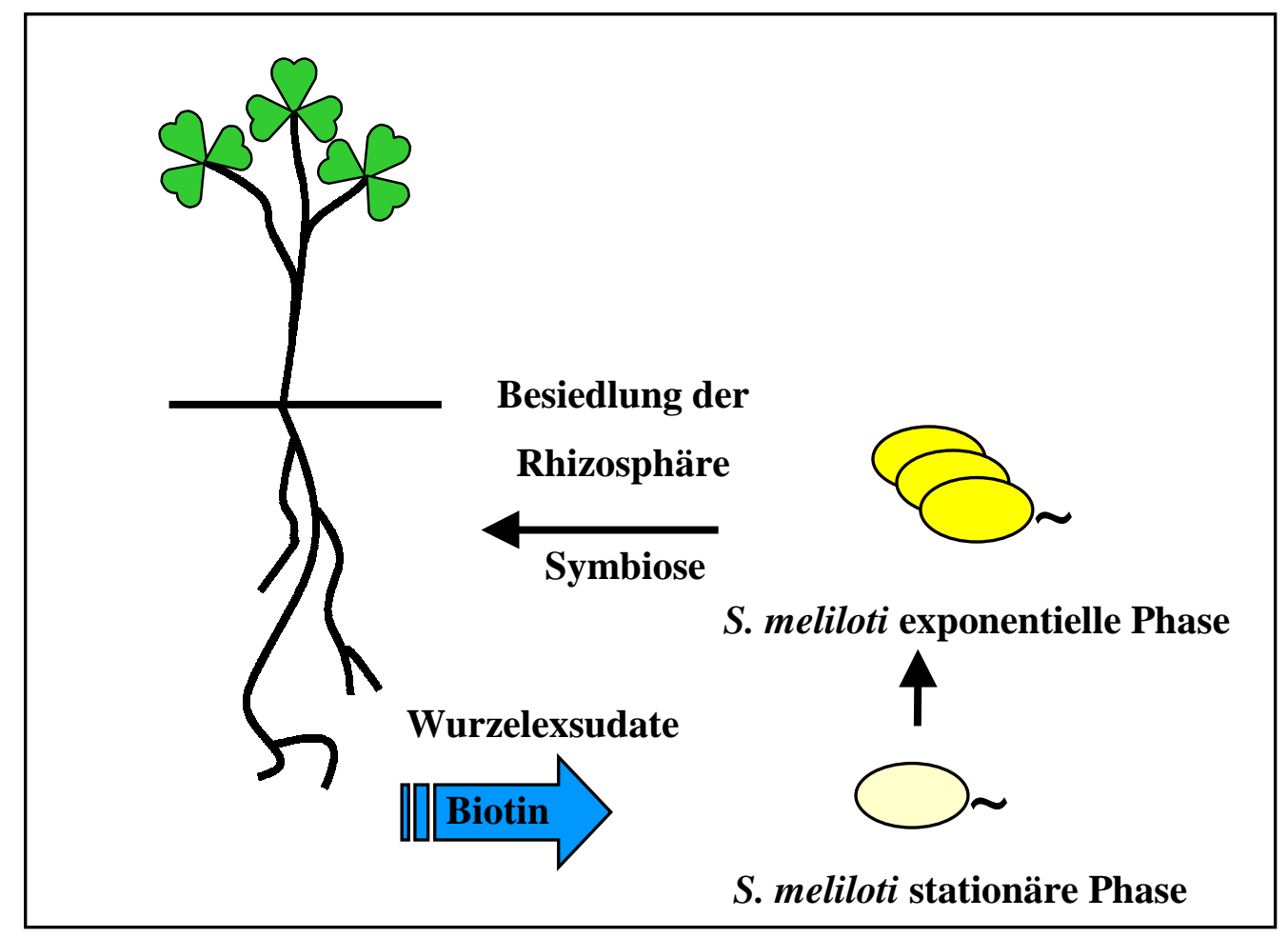

Abb. 1 Darstellung der stimulierenden Wirkung von pflanzlichen Biotin

Biotin wird durch die Wirtspflanze in den Boden exsudiert und fördert rhizobielles Wachstum. Dieses Vitamin stellt eine Schlüsselkomponente für die Besiedelung der Rhizosphäre durch $S$. meliloti dar und ist damit daran beteiligt die ruhenden Bodenbakterien zu schnell wachsenden Rhizosphärenkolonisierern umzuwandeln (Streit et al., 1996).

Im Genom von $S$. meliloti wurden einige der bekannten Biotinbiosynthesegene identifiziert, jedoch konnte nur für drei dieser Gene die Funktionalität durch Komplementationsstudien gezeigt werden (Entcheva et al., 2002). Daher nimmt man an, daß die endogene Biotinbiosynthese unzureichend und damit limitierend für Wachstum 
von S. meliloti ist. Bemerkenswert ist das gute Aufnahmesystem von S. meliloti für Biotin, an welchem die bioM- und bioN-Gene beteiligt sind (Entcheva et al., 2002). Biotin ist als Kofaktor für verschiedene Carboxylasen an der vorübergehenden Bindung von $\mathrm{CO}_{2}$ beteiligt. In S. meliloti und Rhizobium etli führt Biotinlimitation zu einer verminderten Aktivität der Biotin-abhängigen Pyruvatcarboxylasen (Dunn et al., 1997; Dunn et al., 2001).

Zur Identifizierung Biotin-regulierter Gene und zum besseren Verständnis der Prozesse, welche an der Wahrnehmung des pflanzlichen Biotins in der Rhizosphäre beteiligt sind, wurden Transposonmutagenesen durchgeführt. Dabei konnte das bioS-Gen identifiziert werden, welches bereits durch picomolare Konzentrationen an Biotin induzierbar ist und in der Stationärphase maximal exprimiert wird (Streit und Phillips, 1997). Sehr hohe Biotinkonzentrationen reprimieren dagegen die Expression. Mutationen des bioS-Gens führen zu einer verlängerten lag-Phase nach Biotinsupplementation einer unter Biotinlimitierenden Bedingungen angezogenen Kultur und $\mathrm{zu}$ einer erhöhten Aufnahme von exogenem Biotin. Das BioS-Protein reguliert seine eigene Expression und zeigt Ähnlichkeiten zu Proteinen aus der Familie der LysR-Typ-Regulatoren (Streit und Phillips, 1997; Heinz et al., 1999). Bisher wurde das bioS-Gen nur in weiteren S. meliloti-Stämmen und Rhizobium NGR234 nachgewiesen. Interessanterweise befindet sich das bioS-Gen in S. meliloti im sogenannten Survival-Locus. Diese Region umfaßt in vielen Gram-negativen Bakterien die surE-, pcm- und nlpD/lppB-Gene. Das surE-Gen anderer Bakterien codiert für eine saure Phosphatase, wobei die physiologischen Substrate und damit auch die biologische Funktion bisher nicht aufgeklärt sind (Zhang et al., 2001; Lee et al., 2001). Pcm-Gene (auch pcmt-Gene genannt) codieren für L-Isoaspartyl-Protein-Carboxymethyltransferasen, welche spontan durch Deamidierung von Asparagin- und AspartatResten entstehende L-Isoaspartylreste durch Methylierung reparieren können (siehe Übersichtsartikel Visick und Clarke, 1995). In E. coli werden die surE- und pcm-Gene maximal in der Stationärphase exprimiert (Li et al., 1997). NlpD/lppB-Gene codieren für Lipoproteine und in S. meliloti führt die Mutation des $n l p D$-Gens zu einer verminderten Überlebensfähigkeit in der stationären-Wachstumsphase (Streit et al., 2000). Bei manchen Organismen wie $E$. coli befindet sich unmittelbar stromabwärts dieser Gene das $r p o S$-Gen, welches für den Stationärphase-Sigmafaktor codiert. Allein in S. meliloti ist diese konservierte Anordnung durch das bioS Gen, welches unmittelbar in 5'-Richtung des pcmGens lokalisiert ist, aufgehoben. Auf der Suche nach einem übergeordneten Regulator des bioS-Gens wurde das birS-Gen identifiziert. In birS-Mutanten kommt es zur von Biotin 
unabhängigen Expression von bioS (Schmeißer, 2001). Ein weiteres Biotin-reguliertes Gen in S. meliloti ist das $b d h A-G e n$. Es codiert für ein Gen, welches an der Mobilisierung des Speicherstoffes Poly- $\beta$-Hydroxybutyrat (PHB) beteiligt ist. Unter Biotin-limitierenden Bedingungen kommt es zur Synthese dieses Speicherstoffes und bereits durch 0,4 nM Biotin im Anzuchtmedium wird der Abbau von PHB induziert. Reportergenstudien zeigten, daß die Transkription des $b d h A-G e n s$ durch Biotin induziert wird (Hofmann et al., 2000). Zusammenfassend betrachtet ist die Frage offen, ob Biotin einen direkten oder indirekten Einfluß auf die Transkription dieser Gene hat.

\subsection{Intention der Arbeit}

Biotin übernimmt eine Schlüsselfunktion bei der Besiedlung der Rhizosphäre durch S. meliloti und stellt möglicherweise eines der Signale dar, welche den Rhizobien die Anwesenheit eines potentiellen Symbiosepartners vermitteln. Biotinlimitierung dagegen ist mit der Abwesenheit einer Pflanze und damit dem Überdauern in der stationären Wachstumsphase gleichzusetzen. Welche Prozesse auf physiologischer Ebene daran beteiligt sind, exogenes Biotin zu sensen und Wachstum in Abhängigkeit dieses Vitamins wieder aufzunehmen ist bisher weitgehend unbekannt. Daher war es Ziel dieser Arbeit Gene zu identifizieren, welche an der Wahrnehmung von Biotin beteiligt sind. Als zentrale Methode sollte dabei die 2D-Gelelektrophorese angewendet werden, um so die Proteinmuster Biotin-limitierter Kulturen mit denen Biotin-supplementierter Kulturen zu vergleichen. Biotin-induzierte Proteine sollten durch massenspektrometrische Analyse identifiziert werden. Desweiteren sollte mittels Reportergenanalyse die Promotoraktivität von gezielt aus den Datenbanken ausgewählten Genen, welche an Prozessen der Nodulation, Membransynthese oder quorum-sensing beteiligt sind, in Abhängigkeit von Biotin bestimmt werden. Aufgrund der ungewöhnlichen Lokalisation des Biotinregulierten Stationärphasegens bioS im Survival Locus von S. meliloti, sollten die stromaufwärts liegenden surE- und pcm-Gene mutiert und charakterisiert werden, um zu ermitteln, welche Funktion diese Gene für das Überleben von S. meliloti haben. Weiterhin sollte analysiert werden, ob Biotin einen regulatorischen Einfluß auf die Expression dieser Gene ausübt. 


\section{MATERIAL UND METHODEN}

\subsection{Bakterienstämme und Plasmide}

Die in der vorliegenden Arbeit verwendeten Bakterienstämme, Plasmide und Primer sind in den folgenden Tabellen aufgeführt.

Tab. 1 Bakterienstämme

$\begin{array}{lll}\text { Stamm } & \text { Eigenschaften } & \text { Referenz }\end{array}$

\section{Escherichia coli}

$\mathrm{DH} 5 \alpha$

XL1-Blue

BL21(DE3)

S17-1

BL21(DE3)-25

BL21(DE3)-26

Sinorhizobium

meliloti

$\mathrm{Rm} 1021$

Rm1021-B5

Rm1021-EH45

Rm1021-EH47

Rm1021-K-EH45

Agrobacterium

tumefaciens

NTL4

(pCF218)(pCF372)

$\mathrm{KYC}(\mathrm{pCF} 218)$

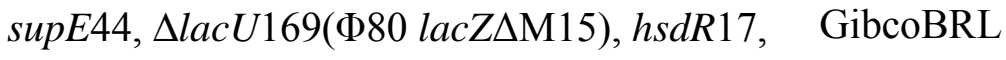

recA1, endA1, gyrA96, thi-1, relA1

recA1, endA1, gyrA96, thi-1, hsdR17, supE44, Bullock et al.,

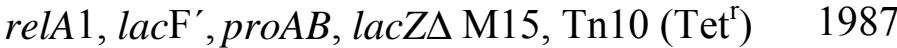

$\mathrm{F}^{-}, o m p T, h s d S_{B}\left(\mathrm{r}_{B}^{-} \mathrm{m}_{B}^{-}\right)$gal, dcm, $\lambda \mathrm{DE} 3 \quad$ Novagen

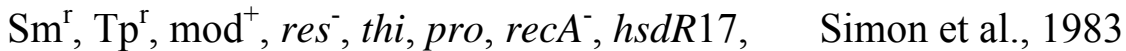
integriertes Plasmid RP4-2-Km::Tn7/Tc::Mu, pEH25 in Überexpressionsstamm diese Arbeit pEH26 in Überexpressionsstamm diese Arbeit

Meade et al., 1982

W. Streit diese Arbeit diese Arbeit diese Arbeit pBBR1MCS::pcm in Rm1021-EH45;

Fuqua und Winans, 1996 Fuqua und Winans, 1996 
Tab. 2 Plasmide

\begin{tabular}{|c|c|c|}
\hline Plasmide & Eigenschaften & Referenz \\
\hline pBluescriptII SK(+) & Kloniervektor, $\mathrm{Amp}^{\mathrm{r}}$, lacPOZ & Stratagene \\
\hline pET19b & Amp $^{\mathrm{r}}$, Expressionsvektor & Novagen \\
\hline pEH25 & pET19b::surE/pcm & diese Arbeit \\
\hline $\mathrm{pEH} 26$ & pET19b::pcm & diese Arbeit \\
\hline pBK3 & $\begin{array}{l}\text { mobilisierbarer Vektor mit lacZ- und gusA- } \\
\text { Reportergenen, } \mathrm{Tc}^{\mathrm{r}}\end{array}$ & Kusian et al., 1995 \\
\hline pk18mobsacB & $\begin{array}{l}\text { mobilisierbarer Vektor zur Konstruktion von } \\
\text { Rm Mutanten }\end{array}$ & $\begin{array}{l}\text { Schäfer et al., } \\
1994\end{array}$ \\
\hline pk18mobsacB-EcoRI & $\begin{array}{l}\text { pk18mobsacB mit entfernter EcoRI } \\
\text { Schnittstelle }\end{array}$ & diese Arbeit \\
\hline $\mathrm{pEH} 40$ & pk18mobsacB-EcoRI::surE/pcm & diese Arbeit \\
\hline pPR-nodD1 & pPR mit 324 bp nodD1-Promotorregion & diese Arbeit \\
\hline pPR-nodD3-kurz & pPR mit 867 bp nodD3-Promotorregion & diese Arbeit \\
\hline pPR-nodD3-lang & pPR mit 1190 bp nodD3-Promotorregion & diese Arbeit \\
\hline pPR-sinI & pPR mit 267 bp sinI-Promotorregion & diese Arbeit \\
\hline $\mathrm{pPR}-\sin R$ & pPRmit 401 bp sinR-Promotorregion & diese Arbeit \\
\hline pPR-bioM & pPR mit 333 bp bioM-Promotorregion & diese Arbeit \\
\hline $\mathrm{pPR}-p l s X$ & pPR mit 273 bp $p l s X$-Promotorregion & diese Arbeit \\
\hline pPR-copC & pPR mit 253 bp copC-Promotorregion & diese Arbeit \\
\hline pPR-tr4882 & pPR mit 176 bp tr4882-Promotorregion & diese Arbeit \\
\hline pBBRMCS-1 & $\mathrm{Km}^{\mathrm{r}}$, mobilisierbar nach $\mathrm{Rm}$ & $\begin{array}{l}\text { Kovach et. al., } \\
1995\end{array}$ \\
\hline pKW120 & Amp ${ }^{\mathrm{r}}$, enthält promotorloses gusA-Fragment & Wilson et al., 1995 \\
\hline pEN322::gfp & Plasmid mit $g f p$-Kassette & Egener et al., 1998 \\
\hline
\end{tabular}


Tab. 3 Primer

\begin{tabular}{|c|c|}
\hline Bezeichnung & Sequenz $\left(5^{\prime}-3^{\prime}\right)$ \\
\hline surE-NdeI-fw & ggg gca tat gcg cat cet gct gac gaa tga cga \\
\hline surE-rev & ata ggg aaa gcc gcg tcc gtc cgt \\
\hline pcm-NdeI-fw & ggg gca tat ggc get gcg get tcg ctc ggg \\
\hline pcm-NdeI-rev & ggg gca tat gtt aaa gga acg acg cta cct gtg \\
\hline gusA-rev & gat ttc acg ggt tgg ggt ttc tac \\
\hline gusA-181-rev & ata cca gac gtt gec cgc ata aat \\
\hline$g u s A-X h o \mathrm{I}-\mathrm{fw}$ & ggg get cga gga gtc cet tat gtt acg tec tgt a \\
\hline gusA-XhoI-rev & ggg get cga gtc att gtt tg cet ccc tg \\
\hline $\sin I-P s t \mathrm{I}-\mathrm{fw}$ & gca agc tgc agc gca cgc tg \\
\hline $\sin I-X b a \mathrm{I}-\mathrm{rev}$ & gaa cat cta gac gat ggc ctg g \\
\hline $\sin R-P s t \mathrm{I}-\mathrm{fw}$ & ggc gct gca ggc gca tat tct $g$ \\
\hline $\sin R-X b a \mathrm{I}-\mathrm{rev}$ & gat gtt cta gac gca tca ggg cg \\
\hline $\operatorname{cop} C-P s t \mathrm{I}-\mathrm{fw}$ & ggt gct gca ggg cat ctc ggc gg \\
\hline $\operatorname{cop} C-X b a \mathrm{I}-\mathrm{rev}$ & tga gtc tag agc cgc ggc aag aag \\
\hline$p l s X-P s t \mathrm{I}-\mathrm{fw}$ & ggt gct gca gga ctg gaa aaa gg \\
\hline$p l s X-X b a \mathrm{I}-\mathrm{rev}$ & gac ttc tag acc ata gtc gec tcc \\
\hline bioM-Pst I-fw & cga cct gca gga agc cga tgt c \\
\hline bioM-XbaI-rev & cca gtc tag aag gat gaa gcg $\mathrm{c}$ \\
\hline $\operatorname{tr} 4882-P s t \mathrm{I}-\mathrm{fw}$ & cgt ctg cag ata cga aac tat tct c \\
\hline $\operatorname{tr} 4882-X b a \mathrm{I}-\mathrm{rev}$ & cac gtc tag aac cag tcg gcg gc \\
\hline nodD1-Pst I-fw & ttc cac tgc agt ttt aag gac atg taa \\
\hline nodD1-XbaI-rev & gac gag gag gtc tag atc tag gec cct \\
\hline nodD3-PstI-fw-kurz & ctt tat ctg cag atc gga gcg acg \\
\hline nodD3-PstI-fw-lang & gca tct gca ggg aca gca tct tc \\
\hline nodD3-XbaI-revl & ctc gtt cta gaa gga gcg tag gcg \\
\hline
\end{tabular}

\subsection{Bakterienanzucht}

\subsubsection{Nährmedien}

Die angegebenen Mengen beziehen sich auf ein Endvolumen von einem Liter im demineralisierten Wasser. Zur Herstellung von Festmedien wurde jeweils noch 1,5\% 
(w/v) Agar hinzugegeben. Alle Lösungen und Medien wurden, sofern nicht anders angegeben, autoklaviert. Die Lagerung erfolgte bei einer Temperatur von $4{ }^{\circ} \mathrm{C}$.

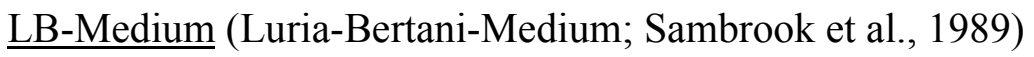

$\begin{array}{lr}\text { Trypton } & 10 \mathrm{~g} \\ \text { Hefeextrakt } & 5 \mathrm{~g} \\ \mathrm{NaCl} & 5 \mathrm{~g} \\ \text { Glucose } & 1,5 \mathrm{~g}\end{array}$

(für LBG-Medium)

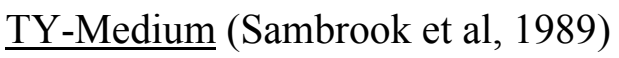

$\begin{array}{lr}\text { Trypton } & 5 \mathrm{~g} \\ \text { Hefeextrakt } & 3 \mathrm{~g} \\ \mathrm{CaCl}_{2} & 0,2 \mathrm{~g}\end{array}$

Agrobacterium tumefaciens-Medium (AT-Medium)

$\underline{20 \times \text { AT-Puffer }}$

$\mathrm{KH}_{2} \mathrm{PO}_{4}$

pH 7 (mit $\mathrm{NaOH}$ einstellen)

$\underline{20 \times \text { AT-Salzlösung }}$

$\begin{array}{lr}\left(\mathrm{NH}_{4}\right)_{2} \mathrm{SO}_{4} & 40 \mathrm{~g} \\ \mathrm{MgSO}_{4} \times 7 \mathrm{H}_{2} \mathrm{O} & 3,2 \mathrm{~g} \\ \mathrm{CaCl}_{2} \times 2 \mathrm{H}_{2} \mathrm{O} & 0,2 \mathrm{~g} \\ \mathrm{FeSO}_{4} \times 7 \mathrm{H}_{2} \mathrm{O} & 0,1 \mathrm{~g} \\ \mathrm{MnSO}_{4} \times \mathrm{H} 2 \mathrm{O} & 0,024 \mathrm{~g}\end{array}$

Für die Herstellung von einem Liter AT-Medium wurden je $50 \mathrm{ml} 20$ x AT-Puffer und 20 x AT-Salzlösung vermischt, mit $10 \mathrm{ml}$ einer 50 \%-igen Glucose-Lösung (w/v) versetzt und auf einen Liter mit autoklaviertem $\mathrm{H}_{2} \mathrm{O}_{\text {bidest }}$ aufgefüllt. 
GTS-Minimalmedium (Kiss et al., 1979)

Komponente 1

$\mathrm{K}_{2} \mathrm{HPO}_{4} \times 3 \mathrm{H}_{2} \mathrm{O}$

$\mathrm{NaCl}$

Tris- $\mathrm{HCl}$

Na-Succinat

$\left(\mathrm{NH}_{4}\right)_{2} \mathrm{SO}_{4}$

$\mathrm{pH} 7,5$

Komponente 2

$\mathrm{MgSO}_{4} \times 7 \mathrm{H}_{2} \mathrm{O}$

$246 \mathrm{mg}$

Komponente 3

$\mathrm{CaCl}_{2} \times 2 \mathrm{H}_{2} \mathrm{O}$

$14,5 \mathrm{mg}$

Komponente 4

$\mathrm{FeCl}_{3} \times 6 \mathrm{H}_{2} \mathrm{O}$

Komponente 5

$\mathrm{Na}_{2} \mathrm{MoO}_{4} \times 2 \mathrm{H}_{2} \mathrm{O}$

$\mathrm{H}_{3} \mathrm{BO}_{3}$

$\mathrm{MnSO}_{4} \times \mathrm{H}_{2} \mathrm{O}$

$\mathrm{ZnSO}_{4} \times 7 \mathrm{H}_{2} \mathrm{O}$

$\mathrm{CuSO}_{4} \times 5 \mathrm{H}_{2} \mathrm{O}$

$\mathrm{CoCl} \times 6 \mathrm{H}_{2} \mathrm{O}$

$\underline{\text { Komponente } 6}$

Biotin

Komponente 7

Glucose

\section{Endkonzentration $\mathrm{x}^{-1}$}

$131 \mathrm{mg}$

$1 \mathrm{~g}$

$3 \mathrm{~g}$

$2,7 \mathrm{~g}$

$2 \mathrm{~g}$

(1)

$\underline{\text { Stammlösungen }}$

$$
655 \mathrm{mg} / 1
$$$$
5 \mathrm{~g} / 1
$$$$
15 \mathrm{~g} / 1
$$

$13 \mathrm{~g} / 1$

$10 \mathrm{~g} / 1$ 
Die Medienbestandteile wurden in MilliQ-Wasser gelöst. Für ein Liter Medium wurden $200 \mathrm{ml}$ der Komponente 1, je $1 \mathrm{ml}$ der Komponenten 2, 3 und 5 und $10 \mathrm{ml}$ der Komponente 4 zusammengefügt, bei Bedarf mit 2 g Glucose und $100 \mu$ l Biotinlösung (Endkonzentration 40,9 nM) versetzt und mit $\mathrm{H}_{2} \mathrm{O}_{\text {bidest }}$ bzw. MilliQ-Wasser auf einen Liter aufgefüllt.

\subsubsection{Antibiotika und andere Medienzusätze}

Von den Antibiotika wurden Stammlösungen angesetzt, sterilfiltriert und bei $-20{ }^{\circ} \mathrm{C}$ gelagert. Die Zugabe der Antibiotika und anderer hitzelabiler Medienbestandteile erfolgte nach Autoklavieren und Abkühlung der Medien auf ca. $55^{\circ} \mathrm{C}$.

Tab. 4 Antibiotika und andere Medienzusätze

\begin{tabular}{lllll}
\hline $\begin{array}{l}\text { Antibiotikum/ } \\
\text { Medienzusatz }\end{array}$ & $\begin{array}{l}\text { Endkonzentration im Medium } \\
(\mu \mathrm{g} / \mathrm{ml})\end{array}$ & & Lösungsmittel \\
\hline & E. coli & S. meliloti & A. tumefaciens & \\
& & & \\
Ampicillin & 100 & 240 & 100 & $\mathrm{H}_{2} \mathrm{O}_{\text {bidest }}$ \\
Kanamycin & 25 & 500 & & $\mathrm{H}_{2} \mathrm{O}_{\text {bidest }}$ \\
Streptomycin & & 2 & 4,5 & $\mathrm{H}_{2} \mathrm{O}_{\text {bidest }}$ \\
Tetracyclin & 10 & & & Ethanol \\
Chloramphenicol & 34 & & Ethanol \\
Spectinomycin & & 80 & $\mathrm{H}_{2} \mathrm{O}_{\text {bidest }}$ \\
Neomycin & & & $\mathrm{H}_{2} \mathrm{O}_{\text {bidest }}$ \\
IPTG & 100 & & $\mathrm{H}_{2} \mathrm{O}_{\text {bidest }}$ \\
X-Gal & 50 & & Dimethylformamid
\end{tabular}

\subsubsection{Wachstumsbedingungen und Stammhaltung}

\subsubsection{Zellanzucht}

Bei E. coli erfolgte die Anzucht über Nacht in LB-Flüssigmedium in Reagenzgläsern oder Erlenmeyerkolben. Dazu wurde mit einer sterilen Impföse von einer Einzelkolonie in das Anzuchtmedium überimpft. Hauptkulturen wurden 1-5 \%-ig (v/v) mit einer über Nacht gewachsenen Vorkultur versetzt. Die Inkubation von E. coli Kulturen erfolgte bei $37^{\circ} \mathrm{C}$ im 
Roller oder auf einem Schüttler. S. meliloti wurde in TY oder GTS-Medium angezogen und mindestens $24 \mathrm{~h}$ bei $28{ }^{\circ} \mathrm{C}$ oder $30^{\circ} \mathrm{C}$ inkubiert. Die Anzucht konnte mit Hilfe von Antibiotika selektiv erfolgen.

\subsubsection{Anzucht von $S$. meliloti zur Gewinnung von Biotin-limitierten Kulturen}

Als Probenmaterial für die 2D-Gelelektrophorese, Promotoraktivitätsmessungen, Wachstums- und Überlebensversuchen war es notwendig, S. meliloti unter Biotinlimitierenden Bedingungen anzuziehen. Dazu wurde S. meliloti in GTS-Medium angeimpft und ein Aliquot dieser 2-3 Tage alten Kultur 0,4-2 \%-ig in frisches GTS-Medium überführt. Nach 2 bis 3 solcher Transfers wurde die Kultur als Biotin-limitiert bezeichnet, sofern nach mindestens $48 \mathrm{~h}$ Inkubation, eine geringere $\mathrm{OD}_{600}$ als $0,8 \mathrm{zu}$ messen war.

\subsubsection{Anzucht von Agrobacterium tumefaciens NTL4 zur Detektion von Autoinduktoren}

Nach Animpfen von $25 \mathrm{ml}$ AT-Minimalmedium mit einer Übernachtkultur des $A$. tumefaciens Reporterstamm NTL4 erfolgte die Inkubation unter Selektionsdruck bis zur späten exponentiellen Phase. Diese Kultur wurde zu $50 \mathrm{ml}$ desselben Mediums, welches nach dem Autoklavieren bei $45^{\circ} \mathrm{C}$ inkubiert wurde und 1,5\% Agar (w/v) und X-Gal (60 $\mu \mathrm{g} / \mathrm{ml})$ enthielt, gegeben und nach guter Durchmischung auf die vorbereiteten Dünnschichtplatten etwa $3 \mathrm{~mm}$ dick gegossen.

\subsubsection{Anlegen von Stammplatten}

Zellen von einer Einzelkolonie wurden von der Platte mit einer steriler Glaspipette oder Platindrahtöse abgenommen und auf einer zweiten Platte mittels Verdünnungsausstrich ausgestrichen.

\subsubsection{Anlegen von Glycerinkulturen}

$500 \mu \mathrm{l}$ einer frischen E. coli Übernachtkultur wurden mit derselben Menge 87 \%-igem Glycerin (w/v) vermischt und bei $-20{ }^{\circ} \mathrm{C}$ oder $-70{ }^{\circ} \mathrm{C}$ gelagert. Für die Anlegung von $S$. meliloti Glycerinkulturen wurde, abgesehen von der länger benötigten Anzuchtzeit, ebenso verfahren. 


\subsubsection{Trübungsmessungen}

Die optische Dichte von Flüssigkulturen wurde bei einer Wellenlänge von $600 \mathrm{~nm}$ mit unbeimpften Medium als Referenz bestimmt (Photometer: Pharmacia Biotech Ultrospec 3000). Dabei wurden die Kulturen so verdünnt, daß die Extinktion nicht größer als 0,8 war. Eine OD von 0,1 entspricht ungefähr einer Konzentration von $10^{8}$ Zellen $/ \mathrm{ml}$. Zur Messung wurden Einmalküvetten mit einer Schichtdicke von $1 \mathrm{~cm}$ verwendet.

\subsubsection{Anzucht für Überexpressionsversuche mit dem T7-RNA-Polymerase/ Promotor-System}

Die E. coli Expressionsstämme BL21(DE3)-25 und BL21(DE3)-26 mit den entsprechenden Plasmiden wurden in LB-Medium mit $100 \mu \mathrm{g} / \mathrm{ml}$ Ampicillin über Nacht angezogen. Mit $5 \mathrm{ml}$ dieser Kultur wurde $100 \mathrm{ml}$ vorgewärmtes LB-Medium mit dem entsprechenden Antibiotikazusatz angeimpft und unter starkem Schütteln bei $37^{\circ} \mathrm{C}$ bis zu einer $\mathrm{OD}_{600}$ von 0,6 inkubiert. Die Expression wurde durch Zusatz von IPTG (Endkonzentration $1 \mathrm{mM}$ ) induziert und die Kulturen weiter bei $37{ }^{\circ} \mathrm{C}$ geschüttelt. Die Zellernte erfolgte nach $3 \mathrm{~h}$ Induktion durch 20 minütige Zentrifugation bei $4000 \mathrm{Upm}$ und $4{ }^{\circ} \mathrm{C}$. Bis zur Lyse konnte das Zellpellet bei $-20^{\circ} \mathrm{C}$ aufbewahrt werden.

\subsection{Basistechniken für das Arbeiten mit Nukleinsäuren}

\subsubsection{Behandlung von Geräten und Lösungen für das Arbeiten mit Nukleinsäuren}

Thermostabile Lösungen, Glaswaren und andere Geräte wurden zur Inaktivierung von Nukleasen autoklaviert. Nicht autoklavierbare Lösungen wurden sterilfiltriert, Geräte mit 70\%-igem Ethanol (v/v) behandelt und wenn möglich abgeflammt.

\subsubsection{Reinigung und Konzentrierung von Nukleinsäuren}

\subsubsection{Fällung von DNA mit Ethanol oder Isopropanol}

Zum Fällen von DNA wurde die DNA-Lösung mit 0,7 Volumen Isopropanol und 0,3 Volumen einer 7,5 M Ammoniumacetat-Lösung bzw. 1/8 Volumen einer $3 \mathrm{M}$ Natriumacetat-Lösung $(\mathrm{pH} \mathrm{5,2)} \mathrm{versetzt.} \mathrm{Alternativ} \mathrm{dazu} \mathrm{konnte} \mathrm{auch} \mathrm{mit} \mathrm{2,5} \mathrm{Volumen}$ unvergälltem Ethanol und $\mathrm{NaCl}$-Lösung mit einer Endkonzentration von 0,3 $\mathrm{M}$ gefällt werden, wonach eine 10 minütige Inkubation bei $-70{ }^{\circ} \mathrm{C}$ oder über Nacht bei $-20{ }^{\circ} \mathrm{C}$ 
angeschlossen wurde. Nach beiden Methoden wurde $20 \mathrm{~min}$ bei 13000 Upm abzentrifugiert, zweimal mit $70 \%$-igem unvergälltem Ethanol (v/v) gewaschen und das getrocknete Pellet im gewünschten Volumen $\mathrm{H}_{2} \mathrm{O}_{\text {bidest }}$ aufgenommen.

\subsubsection{Phenol/Chloroform-Extraktion}

Zur Extraktion von Proteinen wurden die DNA-Lösungen im Verhältnis 1:1 mit einem Phenol/Chloroform-Gemisch (1:1 (v/v)) versetzt und gründlich durchmischt. Zur Phasentrennung wurden die Ansätze 20 min bei 13000 Upm zentrifugiert. Danach konnte die obere wäßrige Phase mit abgeschnittenen $1 \mathrm{ml}$ Spitzen in ein Eppendorfgefäß überführt werden. Die Extraktion wurde zweimal mit dem Phenol/Chloroform-Gemisch und einmal mit Chloroform wiederholt. Anschließend wurde die DNA gefällt.

\subsubsection{Konzentrationsbestimmung von DNA}

Zur Ermittlung der Konzentration wurde die $\mathrm{OD}_{260}$ einer DNA-Lösung in einer Quarzküvette gemessen. Bei dieser Wellenlänge entspricht eine $\mathrm{OD}_{260}$ von 1 einer DNAKonzentration von $50 \mu \mathrm{g} / \mathrm{ml}$. Die Reinheit konnte durch die Bildung der Quotienten von Absorptionswerten bei verschiedenen Wellenlängen ermittelt werden. Für reine DNALösungen gelten folgende Richtwerte:

$\mathrm{OD}_{260}: \mathrm{OD}_{280} \geq 1,8 \quad$ (Sambrook et al., 1989)

\subsection{Methoden zur Charakterisierung von DNA-Fragmenten}

\subsubsection{Agarosegelelektrophorese und Ethidiumbromid-Färbung von DNA}

Eine der am häufigsten angewandten Methoden zur Charakterisierung von DNA ist die Agarosegelelektrophorese. Mit Hilfe dieser Technik können DNA-Moleküle im Gel aufgetrennt werden. Dabei hängt die Laufgeschwindigkeit eines DNA-Fragmentes von mehreren Faktoren ab, wie der Größe des DNA-Moleküls, der Größe der Gelporen die durch die Agarosekonzentration bestimmt wird, der angelegten Spannung und den Salzkonzentrationen des Puffers. Es wurden 0,8 \%-ige Gele für die Analyse von Restriktionsspaltungen und 1,2 \%-ige Gele zur Auftrennung von PCR-Produkten in $1 \mathrm{x}$ TAE-Puffer, der auch als Laufpuffer verwendet wurde, gegossen. Vor Beladen der Geltaschen wurde die DNA mit Ladepuffer im Verhältnis 10:1 vermischt, was zum einen 
der Beschwerung und zum anderen durch den enthaltenen Farbstoff Bromphenolblau der Markierung der Lauffront bei ca. 500 bp diente. Die Auftrennung erfolgte bei einer Spannung von 60-100 V und einer Laufzeit von 45-90 min. Nach Beendigung der Gelelektrophorese erfolgte die Färbung der DNA durch Überführung des Gels in ein Ethidiumbromidbad für 5 min. Das Gel konnte nach anschließender Wässerung bei Bestrahlung mit UV-Licht (254 nm) fotografiert werden.

$\underline{50 \times \text { TAE-Puffer, } \mathrm{pH} \sim 8,5}$

Tris- $\mathrm{HCl}$ $242 \mathrm{~g}$

Eisessig $57,1 \mathrm{ml}$

$\mathrm{Na}_{2}$ EDTA $\times 2 \mathrm{H}_{2} \mathrm{O}$ $37,2 \mathrm{~g}$

$\mathrm{H}_{2} \mathrm{O}_{\text {bidest }}$ ad 11

$10 \times$ DNA-Ladepuffer

Ficoll 400 $20 \mathrm{~g}$

Bromphenolblau $0,25 \mathrm{~g}$

SDS

$1 \mathrm{~g}$

$\operatorname{EDTA}(0,5 \mathrm{M})$

$20 \mathrm{ml}$

$\mathrm{H}_{2} \mathrm{O}_{\text {bidest }}$ ad $100 \mathrm{ml}$

pH 8

Ethidiumbromid-Färbebad

2 Tropfen einer $2 \mathrm{mg} / \mathrm{ml}$ Ethidiumbromidlösung wurden mit $500 \mathrm{ml} \mathrm{H}_{2} \mathrm{O}$ vermischt.

\subsubsection{Fragmentlängenbestimmung von DNA}

Zur Ermittlung der Länge von gelelektrophoretisch aufgetrennten DNA-Molekülen dienten Längenmarker, deren Fragmentgrößen bekannt waren (Gene Ruler ${ }^{\mathrm{TM}} 1 \mathrm{~kb}$ DNA Ladder, Firma MBI Fermentas). Diese Längenstandards wurden parallel zur analysierenden DNA im Agarosegel aufgetrennt. 


\subsection{Isolierung von DNA}

\subsubsection{Isolierung von Plasmid-DNA (Birnboim und Doly, 1979, mod.)}

Diese Methode wurde eingesetzt, wenn eine große Anzahl von Klonen/Transformanten auf das Vorhandensein des richtigen rekombinanten Plasmides hin überprüft werden sollte. Die isolierte Plasmid-DNA konnte dann zur Restriktionsanalyse oder als template für die PCR verwendet werden.

Vorgehensweise:

- $1,5 \mathrm{ml}$ einer Übernachtkultur $1 \mathrm{~min}$ im Eppendorfgefäß bei 13000 Upm abzentrifugieren

- Resuspension des Pellets in $200 \mu 1$ Puffer 1

- Alkalische Lyse der Zellen durch Zugabe von $200 \mu 1$ Puffer 2, dreimaliges invertieren des Eppendorfgefäßes und 5 minütige Inkubation bei RT

- Proteinfällung durch Zugabe von $200 \mu 1$ Puffer 3, 2 s vortexen (bei größeren Plasmiden Eppendorfgefäß vorsichtig dreimal invertieren) und 5-15 minütige Inkubation auf Eis

- Nach 15 minütigem zentrifugieren bei 13000 Upm Überstand in ein neues Eppendorfgefäß überführen

- Bei Bedarf an sehr reiner Plasmid-DNA Durchführung einer Phenol/Chloroform Extraktion zur Verminderung von Proteinkontaminationen; dazu jeden Ansatz mit $200 \mu \mathrm{l}$ eines Phenol/Chloroform-Gemisches versetzen, vortexen und nach $5 \mathrm{~min}$ Abzentrifugieren den Überstand in ein neues Gefäß überführen

- Zugabe von 0,7 Vol Isopropanol und 1/8 Vol einer 3 M Natriumacetat-Lösung (pH5,2)

- 20 min zentrifugieren bei $13000 \mathrm{Upm}$ und Pellet zweimal mit $1 \mathrm{ml} 70 \%$-igem eiskaltem unvergälltem Ethanol waschen

- Trocknen des Pellets bei $37^{\circ} \mathrm{C}$ und Resuspension in $\mathrm{H}_{2} \mathrm{O}_{\text {bidest }}$

\section{Puffer P1 (Resuspensionslösung)}

$\begin{array}{ll}\text { Tris- } \mathrm{HCl} & 50 \mathrm{mM} \\ \text { EDTA } & 10 \mathrm{mM}\end{array}$

$\mathrm{pH} 8$

RNA konnte durch Zusatz von RNaseA (1 mg/ml) zu Puffer 1 entfernt werden. 
Puffer P2 (Lysepuffer)

$\mathrm{NaOH} \quad 0,2 \mathrm{M}$

SDS $1 \%(\mathrm{w} / \mathrm{v})$

Puffer P3 (Neutralisierungslösung)

$\begin{array}{lr}\text { Eisessig } & 29,5 \mathrm{ml} \\ \mathrm{KOH} & \text { ad } \mathrm{pH} 4,8 \\ \mathrm{H}_{2} \mathrm{O}_{\text {bidest }} & \text { ad } 100 \mathrm{ml}\end{array}$

\subsubsection{Isolierung von Plasmid-DNA durch QIAprep Spin Miniprep-Kit}

Dieses Verfahren beruht auch auf der alkalischen Lyse und wurde zur Plasmidisolierung eingesetzt, wenn die Plasmide z. B. für anschließende Transformationen oder Sequenzierungen eingesetzt wurden.

Vorgehensweise:

- 1,5-3 ml einer Übernachtkultur durch einminütige Zentrifugation pelletieren und nach Entfernen des Überstandes in $250 \mu$ l Puffer P1 resuspendieren

- Zugabe von $250 \mu 1$ Puffer P2, vorsichtiges mischen und 5 min Inkubation bei RT

- Zugabe von $350 \mu 1$ Puffer P3, vorsichtiges viermaliges invertieren des Reaktionsgefäßes und Inkubation auf Eis für $5 \mathrm{~min}$

- 10 min Zentrifugation bei $13000 \mathrm{Upm}$ und RT

- Transfer des Überstandes in ein Qiagen-Säulchen und erneute Zentrifugation 1 min bei 13000 Upm, Entfernung des Durchlaufs

- Waschen der Säule mit $750 \mu 1$ Waschpuffer PE

- Zur vollständigen Entfernung des Waschpuffers erneut 2 min bei 13000 Upm zentrifugieren

- Zugabe von $30-50 \mu 1 \mathrm{H}_{2} \mathrm{O}_{\text {bidest }}$ und 1- 10 minütige Inkubation bei RT; Elution der Plasmid-DNA durch Zentrifugation 


\subsubsection{Isolierung von Gesamt-DNA aus $S$. meliloti}

Vorgehensweise:

- 1,5-3 ml von 2 Tage alten Kulturen bei 13000 Upm abzentrifugieren, nach Entfernen des Überstandes in $1 \mathrm{ml} \quad 1 \mathrm{M}$ NaCl-Lösung resuspendieren und $1 \mathrm{~h}$ bei Raumtemperatur stehenlassen

- Abzentrifugieren und Pellet in $200 \mu 1$ TE-Saccharose-Lösung resuspendieren

- Zugabe von $200 \mu 1$ Lysepuffer und Inkubation 45-60 min bei $37^{\circ} \mathrm{C}$

- Versetzen mit $200 \mu \mathrm{l}$ Sarkosyl-ProteinaseK-Lösung, vorsichtig mischen und Inkubation bei $37^{\circ} \mathrm{C}$ für mindestens $60 \mathrm{~min}$

- Extraktion: Zugabe von $200 \mu 1$ eines Chloroform/Phenol-Gemisches im Verhältnis 1:1, gründlich durchmischen und 20 min bei 13000 Upm abzentrifugieren; obere Phase vorsichtig mit abgeschnittenen $1 \mathrm{ml}$ Spitzen in ein neues Eppendorfgefäß überführen; Vorgang zweimal mit einem Chloroform/Phenol-Gemisch und einmal mit reinem Chloroform wiederholen

- Zur Fällung DNA-Lösung mit 0,7 Volumen Isopropanol und 0,3 Volumen einer 7,5 M Ammoniumacetat-Lösung versetzen und über Nacht bei $-20{ }^{\circ} \mathrm{C}$ lagern

- 20 min zentrifugieren bei 13000 Upm; Entfernung des Überstandes und Trocknen; Aufnahme der DNA in $100 \mu 1 \mathrm{H}_{2} \mathrm{O}_{\text {bidest }}$

- Lösung der DNA für $60 \mathrm{~min}$ bei $60^{\circ} \mathrm{C}$

Die Gesamt-DNA wurde bei $4{ }^{\circ} \mathrm{C}$ gelagert.

\section{TE-Saccharose-Puffer}

$20 \%$ Saccharose $(\mathrm{w} / \mathrm{v})$ in TE-Puffer

\section{Lysepuffer}

$10 \mathrm{mg} / \mathrm{ml}$ Lysozym und $1 \mathrm{mg} / \mathrm{ml}$ RNase in TE-Puffer

\section{$\underline{\text { Sarkosyl-ProteinaseK-Lösung }}$}

$25 \mu 1$ einer 20 \%-igen ProteinaseK-Lösung (w/v) wurden in $1 \mathrm{ml} 5$ \%-ige Sarkosyl-Lösung gegeben 


\subsubsection{Elution von DNA-Fragmenten aus Agarosegelen}

Nach PCR oder Restriktionsverdau und Überprüfung des Ergebnisses auf einem Agarosegel konnten DNA-Fragmente, die für eine Ligation benötigt wurden, unter Verwendung des QiaexII-Kits (Qiagen) aus dem Gel eluiert werden.

Vorgehensweise:

- Das Fragment mit einem sauberen Skalpell aus dem Gel schneiden und in ein Eppendorfgefäß mit bekanntem Leergewicht transferieren

- Abwiegen und Bestimmung des Nettogewichtes des Gelblöckchens; pro $100 \mathrm{mg}$ Gewicht $300 \mu 1$ Puffer QX1 in das Gefäß pipettieren

- Zugabe von $30 \mu 1$ QIAEX II und $30 \mathrm{~s}$ vortexen

- Das Eppendorfgefäß 10 min bei $50{ }^{\circ} \mathrm{C}$ inkubieren und alle 2 min kurz vortexen

- $30 \mathrm{~s}$ abzentrifugieren bei 13000 Upm und entfernen des Überstandes

- Das Pellet mit $500 \mu 1$ Puffer QX1 zur Beseitigung von Agarosekontaminationen und zweimal mit je $500 \mu 1$ Puffer PE zur Entfernung von Salzen waschen

- Trocknen des Pellets bei $37^{\circ} \mathrm{C}$ für ca. $20 \mathrm{~min}$

- Zugabe von $20 \mu \mathrm{H} \mathrm{H}_{2} \mathrm{O}_{\text {bidest, }}$, vortexen und 5 min Inkubation bei Raumtemperatur

- $30 \mathrm{~s}$ bei $13000 \mathrm{Upm}$ abzentrifugieren und Überstand mit eluierter DNA in ein neues Eppendorfgefäß überführen

\subsection{Enzymatische Modifikationen von Nukleinsäuren}

\subsubsection{Spaltung von DNA durch Restriktionsendonukleasen}

Restriktionsendonukleasen erkennen kurze DNA-Sequenzen und schneiden doppelsträngige DNA an bestimmten Stellen innerhalb oder benachbart zur Erkennungssequenz, wobei überhängende oder glatte DNA-Enden entstehen können. In der Regel wurden Spaltungsansätze mit einem Gesamtvolumen von $20 \mu 1$ hergestellt.

DNA in TE-Puffer oder

$\begin{array}{lc}\mathrm{H}_{2} \mathrm{O}_{\text {bidest }} & \mathrm{x} \mu \mathrm{l} \\ 10 \mathrm{x} \text { Spaltungspuffer } & 2 \mu \mathrm{l} \\ \text { Restriktionsenzym } & 1-5 \mathrm{U} / \mu \mathrm{g} \text { DNA } \\ \mathrm{H}_{2} \mathrm{O}_{\text {bidest }} & \text { ad } 20 \mu \mathrm{l}\end{array}$


Die Inkubation erfolgte 1-2 $\mathrm{h}$ oder auch über Nacht bei der für das Restriktionsenzym optimalen Temperatur, meist $37^{\circ} \mathrm{C}$. Als Spaltungspuffer wurde entweder One Phor-AllPuffer (Firma Amersham Pharmacia), TAM-Puffer oder der vom Enzymhersteller empfohlene Puffer verwendet.

$10 \times$ TAM-Puffer

$\begin{array}{lr}\text { Kaliumacetat } & 660 \mathrm{mM} \\ \text { Magnesiumacetat } & 100 \mathrm{mM} \\ \text { Tris- } \mathrm{HCl} & 330 \mathrm{mM} \\ \text { DTT } & 5 \mathrm{mM} \\ \text { BSA } & 1 \mathrm{mg} / \mathrm{ml}\end{array}$

mit Eisessig auf pH 7,9 einstellen und sterilfiltrieren

Zur Inaktivierung der Restriktionsenzyme wurden die Ansätze $10-20$ min bei $75{ }^{\circ} \mathrm{C}$ inkubiert.

\subsubsection{Dephosphorylierung von DNA-Enden}

Zur Vermeidung von Selbstligation konnten die 5'-Phosphatgruppen von restriktionsverdauter Vektor-DNA enzymatisch durch alkalische Phosphatase abgespalten werden. Nach der Restriktion wurden zu $20 \mu \mathrm{l}$ eines Restriktionsansatzes $1 \mu 1$ Shrimp alkalische Phosphatase pipettiert und 20 min bei $37^{\circ} \mathrm{C}$ inkubiert. Ein spezieller Puffer war für diese Reaktion nicht nötig. Die Reaktion wurde durch Zugabe von $50 \mu 1$ Chloroform und anschließender Extraktion oder durch Erhitzen für 10 min auf $75{ }^{\circ} \mathrm{C}$ gestoppt. Nach einer Ethanolfällung konnte die DNA für Ligationen eingesetzt werden.

\subsubsection{Ligation von DNA-Fragmenten}

DNA-Ligasen katalysieren die Bildung von Phosphodiester-Bindungen zwischen einem 5'Phosphat- und einem 3'-OH-Ende in doppelsträngiger DNA. Mit Hilfe der T4-DNALigase, dem einzigen Enzym, das effizient glatte Enden ligieren kann, wurden DNAFragmente ligiert. Die Ligationen wurden in möglichst wenig Volumen durchgeführt, mit einem Überschuß an Insert-DNA. Ein $20 \mu$ l-Ansatz war folgendermaßen zusammengesetzt: 
Vektor

T4-Ligase-Puffer $10 \mathrm{x}$

T4-Ligase

Insert
$3-5 \mu 1$

$2 \mu 1$

$0,5 \mu 1(=1 \mathrm{U})$

$12,5-14,5 \mu 1$

\subsection{Transformationsverfahren}

\subsubsection{Herstellung elektrokompetenter $E$. coli Zellen}

- E. coli von einer frischen LB-Platte in eine $30 \mathrm{ml}$ Vorkultur animpfen und 12-14 h auf dem Schüttler bei $37^{\circ} \mathrm{C}$ inkubieren

- Aus der gut angewachsenen Vorkultur 500 ml LB-Medium mit 1-2 \% animpfen und auf dem Schüttler bei $37^{\circ} \mathrm{C}$ bis zu einer $\mathrm{OD}_{600}$ von 0,5-0,6 inkubieren

- Medium möglichst schnell in Eiswasser abkühlen, Zellen in sterilen Zenrifugenbecher ernten $\left(5000 \mathrm{x} \mathrm{g}, 15 \mathrm{~min}, 4{ }^{\circ} \mathrm{C}\right)$ und alle weiteren Arbeitsschritte unter ständiger Kühlung durchführen

- Überstand abgießen, Pellet in $500 \mathrm{ml}$ eiskaltem $\mathrm{H}_{2} \mathrm{O}_{\text {bidest }}$ vollständig resuspendieren und die Zellen erneut ernten (5000 x g, $\left.15 \mathrm{~min}, 4^{\circ} \mathrm{C}\right)$

- Zellen in $40 \mathrm{ml}$ eiskaltem $10 \%$-igem Glycerin aufnehmen, in sterile SS34-Röhrchen überführen und zentrifugieren $\left(5000 \mathrm{x} \mathrm{g}, 15 \mathrm{~min}, 4{ }^{\circ} \mathrm{C}\right)$

- Überstand abgießen, Volumen des Pellets abschätzen und gleiches Volumen 10 \%-iges Glycerin zugeben; etwa $500 \mu 1$

- Zellen resuspendieren, aliquotieren $\left(60 \mu \mathrm{l}\right.$ pro E-Cup) und bei $-70^{\circ} \mathrm{C}$ lagern

\subsubsection{Transformation von $E$. coli durch Elektroporation}

- Kompetente Zellen auf Eis auftauen lassen und mit der DNA-Lösung mischen; bei Bedarf Ligationsansätze zum Entfernen von Salz einer Tropfendialyse gegen $\mathrm{H}_{2} \mathrm{O}_{\text {bidest }}$ unterziehen

- Suspension in eine gekühlte Elektroporationsküvette pipettieren und eventuell vorhandene Luftblasen durch Aufklopfen entfernen

- Küvette außen sorgfältig abtrocknen und bei den Standardbedingungen (Spannung: 1,5 kV, Parallelwiderstand: $200 \Omega$, Kapazität: $25 \mu \mathrm{F}$ ) elektroporieren 
- Zellen nach dem Puls (optimale Entladungszeit: 4,5-5,0 ms) sofort mit $1 \mathrm{ml}$ LBMedium mischen und in einem E-Cup $1 \mathrm{~h}$ bei $37{ }^{\circ} \mathrm{C}$ zur phänotypischen Expression eines Selektionsmarkers inkubieren

- Aliquots unterschiedlicher Größe (20-100 $\mu 1)$ auf LB-Agarplatten unter dem entsprechendem Selektionsdruck ausplattieren und über Nacht bei $37{ }^{\circ} \mathrm{C}$ inkubieren

\subsubsection{Herstellung von kompetenten $\boldsymbol{E}$. coli Zellen mit Hilfe der $\mathbf{C a C l}_{2}$-Methode}

- Einzelkolonie in Flüssigmedium überimpfen und über Nacht bei $37{ }^{\circ} \mathrm{C}$ inkubieren

- $200 \mathrm{ml} \mathrm{LB}-M e d i u m ~ 1 \%$-ig (v/v) mit dieser Kultur animpfen und bis zu einer OD 600 von etwa 0,375 weiter inkubieren

- Nach Aliquotieren der Kultur auf 4 Zentrifugenbecher und 10 min Inkubation auf Eis, Pelletierung der Zellen bei $4{ }^{\circ} \mathrm{C}$ und $4000 \mathrm{Upm}$ für $7 \mathrm{~min}$

- Resuspension jedes Pellets in $10 \mathrm{ml}$ eiskalter $\mathrm{CaCl}_{2}$-Lösung und Zentrifugation für 5 min bei $4{ }^{\circ} \mathrm{C}$ und $4000 \mathrm{Upm}$

- Pellets in $2 \mathrm{ml}$ eiskalter $\mathrm{CaCl}_{2}$-Lösung resuspendieren und jeweils $200 \mu \mathrm{l}$ in vorgekühlte Eppendorfgefäße überführen

- Die Zellen entweder direkt für eine Transformation verwenden oder sofort bei $-70{ }^{\circ} \mathrm{C}$ lagern

\section{Calciumchloridlösung}

$\mathrm{CaCl}_{2}$

$60 \mathrm{mM}$

Glycerin

$15 \%(\mathrm{v} / \mathrm{v})$

PIPES

$10 \mathrm{mM}$

pH 7

\subsubsection{Transformation von kompetenten Zellen}

- Eingefrorene kompetente Zellen 10 min auf Eis auftauen

- Zugabe von 5-8 $\mu 1$ eines Ligationsansatzes, bzw. $1 \mu 1$ ungeschnittenem Plasmid als Positivkontrolle und vorsichtiges mischen

- Zur Adsorption der DNA an die Zellen 30 min auf Eis inkubieren

- $90 \mathrm{~s}$ Hitzeschock bei $42{ }^{\circ} \mathrm{C}$ mit anschließender Inkubation auf Eis für 3-5 min

- Nach Zugabe von 0,8 ml LB-Medium, Zellen zur Ausbildung der Antibiotikaresistenz 45-60 min bei $37^{\circ} \mathrm{C}$ inkubieren 
- Ausplattieren von $100 \mu \mathrm{l}$ auf vorgewärmte Agarplatten mit entsprechendem Antibiotikazusatz zur Selektion und Inkubation über Nacht bei $37^{\circ} \mathrm{C}$

\subsubsection{Selektion rekombinanter $E$. coli Klone durch X-Gal-Test}

Der verwendete E. coli Klonierstamm DH5 $\alpha$ ist durch eine Deletion im lacZ-Gen gekennzeichnet und kann daher keine aktive $\beta$-Galactosidase mehr bilden. Durch Transformation mit Plasmiden wie pBlueskriptII SK+, die über die $\alpha$-Untereinheit der $\beta$ Galactosidase verfügen, in der sich wiederum die Multiklonierungsstelle befindet, kommt es zur Bildung eines aktiven Enzyms. Dies kann auf X-Gal und IPTG haltigen Platten sichtbar gemacht werden, auf denen das lacZ-Gen durch IPTG induziert wird und die ßGalactosidase das Glucoseanalogon X-Gal spaltet wonach durch Luftoxidation ein blauer Farbstoff entsteht. Soll in die Multiklonierungsstelle des Plasmids ein Insert ligiert werden, kann man den Erfolg der Insertion nach Transformation anhand der Kolonienfarbe sehen. Plasmide mit einer Insertion in der Multiklonierungsstelle und damit im lacZ-Gen können keine aktive ß-Galactosidase bilden und erscheinen weiß (Blau/Weiß-Selektion).

\subsection{DNA-Übertragung durch Konjugation}

Da für Rhizobien keine effizienten Transformationssysteme zur Verfügung stehen, wurden Plasmide wie pPR mittels Konjugation mit E. coli als Donorstamm nach S. meliloti mobilisiert. Der verwendete E. coli-Stamm S17-1 verfügt über eine chromosomale Integration des RP4-Plasmids, was den Transfer der $\mathrm{zu}$ mobilisierenden Plasmide ermöglicht. Der Donor sollte sich in der logarythmischen Wachstumsphase befinden, während der Rezipient in der stationären Wachstumsphase geerntet werden sollte.

Durchführung:

- Je 0,5 ml Donor und Rezipient separat für $1 \mathrm{~min}$ bei $13000 \mathrm{Upm}$ zentrifugieren

- Verwerfen des Überstandes und zweimal mit 0,5 ml TY-Medium waschen, dabei die Zellen immer vorsichtig resuspendieren

- Abzentrifugieren und gründliches entfernen des Überstandes

- Pellets von Donor und Rezipient in je $50 \mu \mathrm{l}$ TY-Medium resuspendieren, vereinigen und in die Mitte einer TY-Platte ohne Selektionsdruck pipettieren

- Inkubation ÜN bei $30^{\circ} \mathrm{C}$ 
- Mit einer gelben Spitze Zellen von der Platte abnehmen und in ein Reagenzglas mit GTS-Minimalmedium überführen

- Inkubation für 5-6 h bei $30{ }^{\circ} \mathrm{C}$ auf dem Schüttler und unter Selektionsdruck auf den Rezipienten auf TY oder GTS-Platten in verschiedenen Verdünnungsstufen ausplattieren

\subsection{Herstellung von $S$. meliloti-Mutanten mit Hilfe des sacB-Systems}

Für die Mutationen des surE- und pcm-Gens in S. meliloti wurde das sacB System eingesetzt. Das $s a c B$-Gen codiert für eine Levansucrase aus B. subtilis und ist ein effizienter Gegenselektionsmarker, der sowohl in Gram-negativen und auch Grampositiven Bakterien verwendet werden kann (Jäger et al., 1995; Gay et al., 1983).

Die zu mutierenden DNA-Abschnitte wurden in den Vektor pK18mobsacB kloniert, der über eine Multiklonierungsstelle und das $s a c B$-Gen verfügt. Nach Insertion der entsprechenden Reportergene in die zu mutierenden Gene konnte das Konstrukt mit E. coli S17-1 als Donor nach S. meliloti mobilisiert werden. Durch homologe Rekombination können die mutierten DNA-Abschnitte in die Zielregion integrieren. Dabei unterscheiden sich Transkonjuganten, bei denen nur eine einfache Rekombination und damit eine Integration des Vektors stattgefunden hat gegenüber doppelt homolog rekombinierten Klonen durch die Sensitivität gegenüber Saccharose im Anzuchtmedium. Rezipienten, die das Plasmid nicht enthalten, können im Gegensatz zu $s a c B$ exprimierenden Rezipienten auf LB-Agarplatten mit $10 \%$-iger Saccharose wachsen. Warum die Expression der Levansucrase toxisch ist, ist bisher noch nicht im Detail geklärt.

\subsection{In vitro Amplifikation von DNA durch Polymerase-Kettenreaktion}

Die spezifische Amplifikation von DNA-Abschnitten im Rahmen der Klonierung des surE- und pcm-Gens, der verschiedenen putativen Promotoren und bei der Selektion und Charakterisierung von rekombinanten Plasmiden wurde mit Hilfe der PolymeraseKettenreaktion durchgeführt.

Für die Klonierung der verschiedenen Gene und Promotoren wurde die Pfu-Polymerase verwendet, da sie verglichen mit anderen thermostabilen Polymerasen die geringste Fehlerrate besitzt. PCR-Ansätze wurden auf Eis angesetzt und waren folgendermaßen zusammengesetzt: 
$\mathrm{H}_{2} \mathrm{O} \quad 74 \mu \mathrm{l}$

10 x Puffer für $P f u$ -

Polymerase

$10 \mu 1$

dNTP (je dNTP 2,5 mM) $\quad 8 \mu 1$

Primer fw $(20 \mu \mathrm{M}) \quad 2 \mu \mathrm{l}$

Primer rev $(20 \mu \mathrm{M}) \quad 2 \mu \mathrm{l}$

S. meliloti-Gesamt-DNA $\quad 2 \mu 1$

$(50-100 \mathrm{ng} / \mu \mathrm{l})$

Pfu-Polymerase $\quad 2 \mu 1$

$(2,5 \mathrm{U} / \mu \mathrm{l})$

$\Sigma \quad 100 \mu 1$

Nach einem ersten Denaturierungsschritt von 2 min bei $94{ }^{\circ} \mathrm{C}$ wurden 35 Zyklen nach folgendem Schema durchlaufen, dabei richteten sich die Anlagerungstemperaturen nach den Schmelztemperaturen der Primer.

Denaturierung

$94{ }^{\circ} \mathrm{C}$

$60 \mathrm{sec}$

Anlagerung

$40-58{ }^{\circ} \mathrm{C}$

$60 \mathrm{sec}$

Elongation

$72{ }^{\circ} \mathrm{C}$

$120 \mathrm{sec}$

Nach Ablauf der 35 Zyklen wurde der letzte Elongationsschritt auf 10 min ausgedehnt.

Bei den übrigen PCR-Reaktionen erfolgte die Amplifikation mit Hilfe der Taq-Polymerase nach dem gleichen Schema unter Verwendung eines speziellen Taq-Puffers. Als template wurden die zu untersuchenden Plasmide verwendet. Alternativ dazu konnte auch von den zu untersuchenden Kolonien Zellmaterial mit der Pipettenspitze direkt in den PCR-Ansatz gegeben werden. Die Elongationszeiten richteten sich nach der Größe der zu amplifizierenden Fragmente, wobei man davon ausgeht, daß die Taq-DNA-Polymerase in einer Minute 1000 Basen einbauen kann. Für eine optimale Amplifikation sollten die Schmelztemperaturen der Primer im gleichen Bereich liegen. Der Schmelzpunkt berechnet sich nach folgender Formel: Tm $=$ 69,3 + 0,41 (\% GC-Gehalt des Primers) - 650/L

L gibt die Länge des Primers an (Chester und Marshak, 1993). 


\subsection{Southern-Hybridisierung (Southern, 1975, mod.)}

Bei den in dieser Arbeit durchgeführten Southern-Hybridisierungen zur Analyse von Klonen wurde die DNA nach dem Verfahren des Vakuum-Blotting auf Nylonmembranen (Hybond-N, Firma Amersham Pharmacia) übertragen und anschließend mit DIG markierten DNA-Sonden hybridisiert.

\subsubsection{Vakuum-Blotting}

Die mit Restriktionsenzymen verdaute Gesamt-DNA wurde im 0,8\%-igem Agarosegel $2 \mathrm{~h}$ lang bei $60 \mathrm{~V}$ getrennt, wobei die äußeren Taschen des Gels freigelassen wurden. Nach Färbung im Ethidiumbromidbad erfolgte die Fotografie des Gels mit einem Lineal als Größenstandard, um später die detektierten Banden besser zuordnen zu können.

Die auf Gelgröße zurechtgeschnittene Nylonmembran wurde auf die gut angefeuchtete Unterlage einer Vakuum-Blot-Apparatur (Firma BioRad ${ }^{\circledR}$, Vacuum Blotter) gelegt und mit einer Plastik-Maske bedeckt. Dabei sollte der Ausschnitt der Maske etwas kleiner als Membran und Gel sein, um eine vollständige Abdichtung zu gewährleisten. Nach dem Anschalten der Vakuum-Pumpe (Firma BioRad ${ }^{\circledR}$,Vacuum Regulator) wurde das Gel auf die Membran gelegt und der Deckel der Apparatur geschlossen. Während der folgenden Vorbehandlungen und des Transfers wurde ein Vakuum von 5-10 mm Hg angelegt, wobei das Gel mit den entsprechenden Lösungen überschichtet wurde:

- 10 min Depurinierungslösung

- 20 min Denaturierungslösung

- 30 min Neutralisierungslösung

- $2 \mathrm{~h}$ Transferlösung

Anschließend wurden vor Entfernen des Gels die Taschen zur Markierung mit einer Nadel durchstochen und die noch feuchte Membran zur Fixierung der transferierten DNA mit der DNA Seite direkt auf den UV-Schirm für $45 \mathrm{~s}$ in die Gel-Dokumentationsanlage (Firma BioRad $^{\circledR}$ ) gelegt. Die Membran konnte sofort für die Prähybridisierung verwendet oder auch gelagert werden. 
Depurinierungslösung

$0,25 \mathrm{M} \mathrm{HCl}$

Denaturierungslösung

$0,5 \mathrm{~N} \mathrm{NaOH}$ und $1,5 \mathrm{M} \mathrm{NaCl}$

Neutralisierungslösung

0,5 M Tris- $\mathrm{HCl}, \mathrm{pH} 7,5$ und $3 \mathrm{M} \mathrm{NaCl}$

Transferlösung

20 x SSC; 0,3 M Natriumcitrat, $\mathrm{pH} 7,0$ und $3 \mathrm{M} \mathrm{NaCl}$

\subsubsection{Hybridisierung}

Zur Vermeidung unspezifischer Bindungen wurde mindestens eine Stunde prähybridisiert. Dazu wurde die Membran mit der DNA-Seite nach innen in ein Hybridisierungsröhrchen (Firma Ochs) überführt und mit mind. $20 \mathrm{ml}$ Prähybridisierungslösung pro $100 \mathrm{~cm}^{2}$ Membranfläche versetzt. Die Prähybridisierung erfolgte im Hybridisierungsofen (Firma Biometra) bei $63-68^{\circ} \mathrm{C}$.

Für die Hybridisierung über Nacht bei ebenfalls $63-68{ }^{\circ} \mathrm{C}$ wurde die Sonde aufgetaut, 10 min im Wasserbad zur Denaturierung der DNA gekocht und bis zur Verwendung auf Eis gelagert. Nach erfolgter Hybridisierung konnte die Sondenlösung weggefroren und mehrfach wiederverwendet werden. Die Membran wurde anschließend 2 x 5 min bei RT mit mind. $50 \mathrm{ml}$ Waschpuffer 1 und $2 \times 15$ min bei der Hybridisierungstemperatur mit 50 $\mathrm{ml}$ vorgewärmtem Waschpuffer 2 zur Entfernung ungebundener bzw. unspezifisch gebundener Sonde gewaschen.

Prähybridisierungslösung

$20 \times \mathrm{SSC}$

Blocking-Stammlösung

$10 \%(\mathrm{w} / \mathrm{v})$

N-Lauryl-Sarkosin $10 \%$

$(\mathrm{w} / \mathrm{v})$

SDS $10 \%(\mathrm{w} / \mathrm{v})$

$\mathrm{H}_{2} \mathrm{O}_{\text {bidest }}$

\section{Blocking-Stammlösung}

$12,5 \mathrm{ml} \quad$ Blockierungsreagenz

$10 \mathrm{~g}$

$5,0 \mathrm{ml}$ Maleinsäurepuffer ad $100 \mathrm{ml}$

$0,5 \mathrm{ml}$

$0,1 \mathrm{ml}$

ad $50 \mathrm{ml}$ 
Maleinsäurepuffer

Maleinsäure

$11,6 \mathrm{~g}$

$\mathrm{NaCl}$

$8,76 \mathrm{~g}$

$\mathrm{NaOH}$

$7 \mathrm{~g}$

$\mathrm{H}_{2} \mathrm{O}_{\text {bidest }}$

ad $1000 \mathrm{ml}$

$\mathrm{pH} \mathrm{7,5}$

Waschpuffer 1

$2 \times \mathrm{SSC} / 0,1 \% \operatorname{SDS}(\mathrm{w} / \mathrm{v})$
Waschpuffer 2

$0,1 \times \mathrm{SSC} / 0,1 \% \operatorname{SDS}(\mathrm{w} / \mathrm{v})$

Die Zusammensetzung der Hybridisierungslösung entsprach der der Prähybridisierungslösung mit Ausnahme der zugesetzten Sonde.

\subsubsection{Sondenherstellung}

Die Sonden wurden durch PCR (2.10) hergestellt, wobei chromosomale DNA als template eingesetzt wurde. Dabei wurde ein dNTP-Mix verwendet, das DIG markiertes dUTP enthielt, so daß während der PCR markierte Nukleotide in die amplifizierte DNA eingebaut wurden. Die so hergestellte Sonde wurde auf einem Agarosegel analysiert und konnte direkt aus dem Gel ausgeschnitten und nach Denaturierung dem Prähybridisierungspuffer zugesetzt werden.

Alternativ konnte die Sonde durch Klenow-labelling hergestellt werden. Dazu wurden dem zu markierenden gelgereinigten Fragment $(15 \mu \mathrm{l})$ nach Denaturierung für 10 min bei 100 ${ }^{\circ} \mathrm{C}$ und Transfer auf Eis folgende Komponenten hinzugefügt: $2 \mu 1$ Hexanukleotidgemisch, $2 \mu \mathrm{l}$ dNTP-Mix mit DIG-markiertem dUTP und $1 \mu 1$ Klenow-Fragment (Firma Boehringer). Dieser Ansatz wurde $1 \mathrm{~h}$ bei $37{ }^{\circ} \mathrm{C}$ inkubiert und durch Zugabe von $2 \mu 1$ EDTA (0,2 M, pH 8) gestoppt.

\subsubsection{Antikörperbindung und colorimetrische Detektion}

Zum Blockieren der Membran wurde diese $30 \mathrm{~min}$ in mind. $50 \mathrm{ml}$ Puffer 2 bei RT inkubiert. Nach Zugabe des vorher kurz anzentrifugierten Antikörpers (Anti-DigoxigeninAP Fab-Fragmente (Roche), 1 $\mu \mathrm{l} / 10 \mathrm{ml}$ Puffer 2) und 30 minütiger Inkubation bei RT erfolgte die Entfernung der ungebundenen Antikörper durch zweimaliges Waschen in DIG-Waschpuffer für $15 \mathrm{~min}$. Nach zweiminütigem Äquilibrieren im Detektionspuffer wurde die Membran aus dem Hybridisierungsröhrchen herausgenommen, in eine Folie 
gelegt und mit der Färbelösung versetzt. Nach Zuschweißen der Folie wurde die Membran im Dunkeln inkubiert bis deutlich sichtbare Banden auftraten. Die Membran wurde aus der Folie entfernt, mit Wasser gespült und getrocknet.

Puffer 2

Blocking-Stammlösung $\quad 5 \mathrm{ml}$

Maleinsäurepuffer $\quad 45 \mathrm{ml}$

DIG-Waschpuffer

Tween $20(100 \%) \quad 0,3 \mathrm{ml}$

Maleinsäurepuffer $\quad$ ad $100 \mathrm{ml}$

Detektionspuffer

Tris- $\mathrm{HCl}$

$100 \mathrm{mM}$

$\mathrm{NaCl}$

$100 \mathrm{mM}$

$\mathrm{pH} 9,5$

Färbelösung

NBT-Lösung

$66 \mu 1$

BCIP-Lösung

$33 \mu 1$

Detektionspuffer

ad $10 \mathrm{ml}$

\section{NBT-Lösung}

$75 \mathrm{mg} / \mathrm{ml}$ NBT in Dimethylformamid

\section{BCIP-Lösung}

$50 \mathrm{mg} / \mathrm{ml} \mathrm{BCIP}$ in Dimethylformamid

\subsection{Proteinbestimmung}

Die Bestimmung von Proteinkonzentrationen wurde mit dem BioRad ${ }^{\circledR}$-Protein-Microassay durchgeführt (modifiziert nach Bradford, 1976). Dieser Test beruht auf der Verschiebung des Absorptionsmaximums des Farbstoffes Coomassie-Brilliant-Blau in saurer Lösung von $465 \mathrm{~nm}$ auf $595 \mathrm{~nm}$ beim Binden von Proteinen. Zur Proteinbestimmung wurden $10 \mu 1$ einer Proteinlösung mit $1 \mathrm{ml}$ Farbreagenz versetzt, das entsprechend der Anleitung des Herstellers verdünnt wurde. Nach mind. 5 Minuten wurde die OD bei $595 \mathrm{~nm}$ gemessen. 
Bei einer $\mathrm{OD}_{595}$ von über 0,5 wurde die Messung mit entsprechend verdünnter Proteinlösung wiederholt. Mit Hilfe einer mit Rinderserumalbumin aufgenommenen Eichgeraden im Bereich von 1-20 $\mu \mathrm{g}$ Protein/ml, konnte die Menge an Protein in der jeweiligen Probe bestimmt werden.

\subsection{SDS-Polyacrylamidgelelektrophorese (SDS-PAGE)}

Bei diesem Trennungsverfahren setzt man die Eigenschaften des Detergens SDS (Natriumdodecylsulfat) ein, sich an Proteine zu lagern und fast alle nicht kovalenten Wechselwirkungen in nativen Proteinen zu zerstören. Dabei wird ein SDS-Anion pro zwei Aminosäurereste gebunden, wodurch die Eigenladung des Proteins überlagert wird und die negative Ladung des SDS-Protein-Komplexes der Masse des Proteins ungefähr proportional ist. Daher erfolgt die Auftrennung der Proteine bei dieser Gelelektrophorese in Abhängigkeit von der Masse. Für die Elektrophorese wurde eine MinigelElektrophorese-Kammer verwendet. Es wurden ausschließlich diskontinuierliche Gele gegossen, die aus einem Trenngel und einem darüber liegendem Sammelgel bestehen, was zu einer besseren Auftrennung der Proben führt.

Tab. 5 Zusammensetzung der Minigele

$10 \%$ Trenngel $15 \%$ Trenngel $5 \%$ Sammelgel

\begin{tabular}{lrrr}
\hline $\mathrm{H}_{2} \mathrm{O}_{\text {bidest }}$ & $1,75 \mathrm{ml}$ & $1 \mathrm{ml}$ & $1,05 \mathrm{ml}$ \\
TG & $1,05 \mathrm{ml}$ & $1,0 \mathrm{ml}$ & - \\
$\mathrm{SG}$ & - & - & $0,45 \mathrm{ml}$ \\
$\mathrm{AA}$ & $1,4 \mathrm{ml}$ & $2,5 \mathrm{ml}$ & $1,33 \mathrm{ml}$ \\
APS $10 \%(\mathrm{w} / \mathrm{v})$ & $30 \mu \mathrm{l}$ & $30 \mu \mathrm{l}$ & $30 \mu \mathrm{l}$ \\
TEMED & $3 \mu \mathrm{l}$ & $3 \mu \mathrm{l}$ & $3 \mu 1$ \\
\hline
\end{tabular}

$\underline{\text { Acrylamidlösung (AA) }}$

30 \% (w/v) Acrylamid/Bisacrylamid-Lösung im Verhältnis 37,5:1

Ammoniumpersulfat (APS)

$10 \%(\mathrm{w} / \mathrm{v})$ in $\mathrm{H}_{2} \mathrm{O}_{\text {bidest }}$ 
$\underline{4 \times \text { Trenngelpuffer (TG) }}$

Tris- $\mathrm{HCl}$ $18,2 \mathrm{~g}$

SDS

$$
0,4 \mathrm{~g}
$$

$\mathrm{H}_{2} \mathrm{O}_{\text {bidest }}$

ad $100 \mathrm{ml}$

$\mathrm{pH} 8,8$

$\underline{4 \times \text { Sammelgelpuffer (SG) }}$

Tris-HCl

6,1

SDS

0,4

$\mathrm{H}_{2} \mathrm{O}_{\text {bidest }}$

ad $100 \mathrm{ml}$

pH 6,8

Elektrophorese-Laufpuffer

Tris- $\mathrm{HCl}$

$$
6,04 \mathrm{~g}
$$

Glycin

$28,84 \mathrm{~g}$

SDS

\section{$2 \mathrm{~g}$}

$\mathrm{H}_{2} \mathrm{O}_{\text {bidest }}$

ad $2000 \mathrm{ml}$

Für ein Gel wurden je eine große und eine kleine Glasplatte mit $70 \%$-igem Ethanol gereinigt und mit dazwischen liegenden Abstandhaltern in eine Gelapparatur eingesetzt. Danach wurde das Trenngel zwischen die senkrecht stehenden Glasplatten gegossen und vorsichtig mit $\mathrm{H}_{2} \mathrm{O}$ überschichtet, um eine gerade Geloberfläche zu erhalten. Nach mindestens 45 minütiger Polymerisation des Trenngels wurde das Wasser mit saugfähigem Papier entfernt und das Sammelgel darüber gegossen. Danach wurde der Kamm luftblasenfrei eingesetzt und das Gel nach Polymerisation und Ziehen des Kammes für die Gelelektrophorese verwendet. Die Elektrophorese wurde bei einer konstanten Spannung von 150 Volt im Elektrophoresepuffer durchgeführt und nach 50-70 min beendet.

\subsubsection{Probenvorbereitung}

Die Proben wurden sofern nicht anders angegeben 1:5 mit 5 x SDS-Probenpuffer versetzt und vor dem Auftragen 5 min bei $95^{\circ} \mathrm{C}$ erhitzt. 
5 x SDS-Probenpuffer für denaturierende Gele

$\begin{array}{ll}\mathrm{H}_{2} \mathrm{O}_{\text {bidest }} & 3,8 \mathrm{ml} \\ \text { 0,5 M Tris-HCl, pH 6,8 } & 1,0 \mathrm{ml} \\ \text { Glycerin } & 0,8 \mathrm{ml} \\ \text { SDS 10\% (w/v) } & 1,6 \mathrm{ml} \\ \text { 2-Mercaptoethanol } & 0,4 \mathrm{ml} \\ \text { Bromphenolblau 1\%(w/v) } & 0,4 \mathrm{ml}\end{array}$

\subsection{Nativ-Polyacrylamidgelelektrophorese}

Bei dieser Methode erfolgt die Auftrennung von Proteinen im elektrischen Feld in Abhängigkeit ihrer Ladung und Größe bei gegebenem pH-Wert des Elektrophoresepuffers und gegebenem Vernetzungsgrad des Polyacrylamids. Die nativen Proteingele wurden auf die gleiche Weise wie die SDS-Gele gegossen und waren auch aus einem Trenngel und einem Sammelgel zusammengesetzt. Anstelle von SDS-haltigen Lösungen wurden die unten aufgeführten SDS-freien Lösungen eingesetzt.

$\underline{4 \text { x Trenngelpuffer-Nativ (TG-N) }}$

Tris-HCl

$\mathrm{H}_{2} \mathrm{O}_{\text {bidest }}$ ad $100 \mathrm{ml}$

pH 8,8

$\underline{4 \times \text { Sammelgelpuffer-Nativ (SG-N) }}$

Tris- $\mathrm{HCl}$

$6,1 \mathrm{~g}$

$\mathrm{H}_{2} \mathrm{O}_{\text {bidest }}$ ad $100 \mathrm{ml}$

pH 6,8

$10 \times$ Elektrophorese-Laufpuffer-Nativ

$\begin{array}{lr}\text { Tris- } \mathrm{HCl} & 30,3 \mathrm{~g} \\ \text { Glycin } & 144,1 \mathrm{~g} \\ \mathrm{H}_{2} \mathrm{O}_{\text {bidest }} & \text { ad } 1000 \mathrm{ml} \\ \mathrm{pH} 8,4 & \end{array}$




\subsubsection{Probenvorbereitung für native Gele}

Die Proteinproben wurden 4:1 mit dem Probenpuffer versetzt und ohne vorherige Denaturierung in die Geltaschen gefüllt. Nach einem Vorlauf von $15 \mathrm{~min}$ bei $50 \mathrm{~V}$ erfolgte die elektrophoretische Auftrennung der Proteine bei $100 \mathrm{~V}$ für $2 \mathrm{~h}$.

$\underline{4 \text { x Probenpuffer für native Gele }}$

Glycerin $\quad 7,5 \mathrm{ml}$

Bromphenolblau

(2\% Lösung) $\quad 0,5 \mathrm{ml}$

Tris- $\mathrm{HCl} \quad 0,4 \mathrm{~g}$

$\mathrm{H}_{2} \mathrm{O}_{\text {bidest }} \quad$ ad $25 \mathrm{ml}$

pH 6,8

\subsection{D-PAGE (O'-Farell, 1975, mod.)}

Die zweidimensionale Polyacrylamidgelelektrophorese (2D-PAGE) ermöglicht es Proteine aufgrund ihrer Ladung (isoelektrischer Punkt) durch isoelektrische Fokussierung in der ersten Dimension und aufgrund ihrer molekularen Masse durch SDS-PAGE in der zweiten Dimension aufzutrennen.

\subsubsection{Probenvorbereitung}

Nach Lyse der Bakterienzellen müssen die Proteine so aufbearbeitet werden, daß sie als Probenmaterial für die Isofokussierung einsetzbar sind. Dieser Prozeß umfaßt idealerweise die Solubilisierung, Denaturierung und Reduktion der Proteine, um alle Proteininteraktionen aufzuheben.

Durchführung:

- S. meliloti-Kulturen bei $4{ }^{\circ} \mathrm{C}$ und $10000 \mathrm{Upm} 10 \mathrm{~min}$ abzentrifugieren und bei $-20{ }^{\circ} \mathrm{C}$ ÜN lagern

- Aufnahme des Zellpellets in Lysepuffer; Menge hängt vom Volumen und der $\mathrm{OD}_{600}$ der Ausgangskultur ab; Richtwert: $6 \mathrm{ml}$ Lysepuffer/100 ml gut angewachsener Biotin supplementierter Kultur und 3 ml Lysepuffer /100 ml Biotin limitierter Kultur

- 2 Durchgänge in der gekühlten french pressure cell 
- Lysierte Zellen in SS34 Zentrifugenbecher oder bei kleinen Mengen in E-Cups überführen und bei $4{ }^{\circ} \mathrm{C} 20 \mathrm{~min} 13000 \mathrm{Upm}$ zentrifugieren

- Überstände vereinigen und mit drei Volumen eiskaltem Aceton versetzen und (mindestens $2 \mathrm{~h}$ ) über Nacht bei $-20^{\circ} \mathrm{C}$ präzipitieren

- Bei $4{ }^{\circ} \mathrm{C}, 20$ min und $13000 \mathrm{Upm}$ abzentrifugieren

- Überstand verwerfen und Pellet gut bei RT trocknen lassen

- Pellet in mindestens $1 \mathrm{ml}$ Probenpuffer aufnehmen; zur vollständigen Denaturierung und Lösung Extrakt bis zu einer Stunde bei RT stehen lassen

\section{$\underline{\text { Lysepuffer }}$}

Harnstoff

$8 \mathrm{M} \quad 19,2 \mathrm{~g}$

CHAPS

$2-4 \%(\mathrm{w} / \mathrm{v}) \quad 0,8-1,6 \mathrm{~g}$

Tris- $\mathrm{HCl}$

$40 \mathrm{mM}$

$0,194 \mathrm{~g}$

MilliQ-Wasser

ad $40 \mathrm{ml}$

Frisch zubereiten oder in Aliquots bei $-20^{\circ} \mathrm{C}$ aufbewahren.

Optional: Zusatz von Protease Inhibitor: Pefabloc $5 \mathrm{mM}$; 11,975 mg auf $10 \mathrm{ml}$ Puffer

Probenpuffer

Harnstoff

$8 \mathrm{M} \quad 4,8 \mathrm{~g}$

CHAPS

$2 \%(\mathrm{w} / \mathrm{v}) \quad 200 \mathrm{mg}$

*Pharmalyte

Tris- $\mathrm{HCl}$

$$
0,5 \%(\mathrm{v} / \mathrm{v}) \quad 50 \mu 1
$$

$35 \mathrm{mM} \quad 42,4 \mathrm{mg}$

(Stammlsg.)

*DTT $\quad 1 \%(\mathrm{w} / \mathrm{v}) \quad 100 \mathrm{mg}$

MilliQ-Wasser ad $10 \mathrm{ml}$

*Frischen Probenpuffer ansetzen und nur $1 \mathrm{ml}$ davon mit $5 \mu 1$ Pharmalyte und $10 \mathrm{mg}$ DTT versetzen; restlichen Puffer aliquotieren und nach einmaligem Auftauen und Zugabe von Pharmalyte und DTT nicht wieder einfrieren. 
$\underline{\text { Rehydrierungslösung }}$

Harnstoff

CHAPS

*Pharmalyte

Bromphenolblau

MilliQ-Wasser

$\begin{array}{rr}8 \mathrm{M} & 12 \mathrm{~g} \\ 2 \%(\mathrm{w} / \mathrm{v}) & 0,5 \mathrm{~g} \\ 0,5 \%(\mathrm{v} / \mathrm{v}) & 125 \mu \mathrm{l} \\ \text { wenige } & \text { Körner } \\ & \text { ad } 25 \mathrm{ml}\end{array}$

* In $1 \mathrm{ml}$ Aliquots lagern und direkt vor Gebrauch 2,8 mg DTT und 0,5 $\mu 1$ Pharmalyte hinzufügen.

\subsubsection{Isoelektrische Fokussierung}

Bei diesem Trennungsverfahren wandern die Proteine im elektrischen Feld innerhalb einer Gelmatrix bis zu dem pH-Wert, an dem sich die Summe der positiv und negativ geladenen Aminosäurereste des Proteins gegenseitig aufheben (isoelektrischer Punkt). Am isoelektrischen Punkt ist daher die elektrophoretische Mobilität des Proteins in einem angelegten elektrischen Feld gleich Null.

Die bei den Isofokussierungen eingesetzten Gelstreifen sind dadurch gekennzeichnet, daß der pH-Gradient durch Kopolymerisation definierter Chemikalien, sogenannter Immobiline, an die Acrylamid-Matrix stabil gehalten wird, (Immobilisierte-pHGradienten, Bjellqvist et al.1982) (IPG-Streifen, Firma Amersham Pharmacia).

Nach Bestimmung der Proteinkonzentration wurde die gewünschte Menge des zu trennenden Proteingemisches mit Probenpuffer auf $170 \mu \mathrm{l}$ Probenvolumen aufgefüllt. Danach erfolgte die Zugabe von 170 Rehydrierungslösung. Die Probe wurde gemischt und in die Mitte einer Keramikhalterung pipettiert. Vorteile der gemeinsamen Applikation von Probe und Rehydrierungslösung sind eine bessere Auflösung und die Möglichkeit größere Proteinmengen zu trennen (Sanchez et al. 1997; Rabilloud et al. 1994).

Der IPG-Streifen wurde unmittelbar vor Gebrauch aus dem $-20{ }^{\circ} \mathrm{C}$ Gefrierfach entnommen, die Plastikfolie entfernt und mit der Gelseite nach unten in die Keramikhalterung gelegt. Dabei wurde die Probe vorsichtig mit Hilfe des Streifens in der Halterung verteilt. Vor Überschichtung des Streifens mit $2 \mathrm{ml}$ Silikonöl (Dry-strip-coverfluid, Firma Amersham Pharmacia) wurden Luftblasen zwischen Probenlösung und Gelstreifen mit Hilfe einer Pipettenspitze entfernt. Danach wurde die Halterung mit der spitzen Seite nach oben auf die IPGphor-Apparatur (Firma Amersham Pharmacia) gelegt, so daß Anoden- und Kathodenseite richtig ausgerichtet waren. 
Die Isofokussierungen wurden bei konstant $20{ }^{\circ} \mathrm{C}$ und $50 \mu \mathrm{A}$ pro Streifen durchgeführt. Laufzeiten richteten sich u.a. nach der Probenmenge und dem gewählten $\mathrm{pH}-$ Bereich der Streifen, wobei generell gilt, daß größere Probenmengen und engere $\mathrm{pH}$-Bereiche der Streifen längere Fokussierzeiten benötigen. Folgende Standardprogramme wurden variiert, wenn z. B. Gele im pH-Bereich von 4,5-5,5 gestartet wurden.

Standardprogramm für analytische Fokussierungen (bis zu $150 \mu \mathrm{g}$ Protein/Probe):

$\begin{array}{lcccc}\underline{\text { Stufe }} & \text { Einstellung } & \underline{\text { Dauer }(\mathrm{h})} & \text { Dauer (Vhr) } & \text { Spannung(V) } \\ \text { 1-Rehydrierung } & \text { konstant } & 12 & & 20 \\ 2 & \text { konstant } & 1 & & 200 \\ 3 & \text { konstant } & 1 & & 500 \\ 4 & \text { konstant } & & 1000 & 1000 \\ 5 & \text { Gradient } & 1 & & 8000 \\ 6 & \text { konstant } & & 40000 & 8000\end{array}$

Standardprogramm für präparative Fokussierungen (bis zu $1 \mathrm{mg}$ Protein/Probe):

$\begin{array}{lcccc}\underline{\text { Stufe }} & \text { Einstellung } & \underline{\text { Dauer }(\mathrm{h})} & \text { Dauer (Vhr) } & \text { Spannung(V) } \\ \text { 1-Rehydrierung } & \text { konstant } & 12 & & 20 \\ 2 & \text { konstant } & 2 & & 150 \\ 3 & \text { konstant } & 1 & & 200 \\ 4 & \text { konstant } & 1 & & 500 \\ 5 & \text { konstant } & & 1000 & 1000 \\ 6 & \text { Gradient } & 1 & & 8000 \\ 7 & \text { konstant } & & 60000 & 8000\end{array}$

Nach Durchlauf des Programmes konnten die Streifen direkt für die SDS-PAGE verwendet oder bei $-70{ }^{\circ} \mathrm{C}$ in Plastikfolie eingeschweißt aufbewahrt werden.

\subsubsection{Equilibrierung}

Während der Equilibrierung wurden die IPG-Streifen an das Puffersystem der nachfolgenden SDS-Gelelektrophorese angepaßt. Nach Einschweißen der Streifen in Plastikfolie wurden diese mit je $10 \mathrm{ml}$ Equilibrierungslösung versetzt und $15 \mathrm{~min}$ bei RT unter leichtem Schütteln inkubiert. Auf einen zweiten Equilibrierungsschritt mit 
Iodacetamid wurde weitgehend verzichtet. Vergleiche hatten ergeben, daß ein zusätzlicher Equilibrierungsschritt zum Entfernen des überschüssigen DTT und Verhindern der Reoxidation während der Elektrophorese keinen Effekt auf das Aussehen der Gele hatte.

Equilibrierungslösung

1,5 M Tris-HCl, $\mathrm{pH} 8,8$

Harnstoff

$$
\begin{array}{rr}
50 \mathrm{mM} & 6,7 \mathrm{ml} \\
6 \mathrm{M} & 72,07 \mathrm{~g}
\end{array}
$$

Glycerol $87 \%(v / v)$

SDS

$\begin{array}{lr}30 \%(\mathrm{v} / \mathrm{v}) & 69 \mathrm{ml} \\ 2 \%(\mathrm{w} / \mathrm{v}) & 4,0 \mathrm{~g}\end{array}$

Bromphenolblau

wenige Körner

MilliQ-Wasser

$\operatorname{ad} 200 \mathrm{ml}$

Die Equilibrierungslösung wurde in $10 \mathrm{ml}$ Aliquots gelagert und unmittelbar vor Gebrauch mit je 100 mg DTT versetzt.

\subsubsection{SDS-Gelelektrophorese als 2. Dimension}

Zur weiteren Auftrennung der isofokussierten Proteine in Abhängigkeit ihrer Massen wurde eine SDS-Gelelektrophorese in einem vertikalen System durchgeführt. Die Gele wurden mit Hilfe einer Gießapparatur nach Angaben des Herstellers angefertigt. Nach Equilibrierung der IPG-Streifen wurden diese auf mit Wasser getränktes Filterpapier gelegt, um überschüssigen Equilibrierungspuffer zu entfernen. Die Streifen wurden dann einmal durch den SDS-Laufpuffer gezogen, mit Hilfe einer Pinzette vorsichtig auf die Oberfläche des auspolymerisierten SDS-Gels gelegt und mit einem flachen Spatel ebenmäßig auf die Oberfläche gedrückt. Bei Bedarf konnten die Plastikenden der Streifen abgeschnitten werden, um so noch genügend Platz zur Auftragung eines Markers zur Verfügung zu haben. Als Gelkammer diente die PROTEAN ${ }^{\circledR}$ II xi-Cell von BioRad ${ }^{\circledR}$.

Die Laufzeit bei zwei gleichzeitig laufenden Gelen betrug $5 \mathrm{~h}$ bei $60 \mathrm{~mA}$ oder $15 \mathrm{~h}$ bei 20 mA. Der Laufpuffer wurde immer frisch angesetzt.

Für ein $12 \%$-iges Gel mit einer Größe von 20 x $20 \mathrm{~cm}$ und einer Dicke von $1 \mathrm{~mm}$ wurden folgende Komponenten benötigt. 
Trenngel $(12 \%)$

AA (siehe 2.13)

Trenngelpuffer

(siehe 2.13)

$\mathrm{H}_{2} \mathrm{O}_{\text {bidest }}$

SDS $10 \%(\mathrm{w} / \mathrm{v})$

APS $10 \%(\mathrm{w} / \mathrm{v})$

TEMED

$\Sigma$

\begin{tabular}{rlr} 
& \multicolumn{2}{l}{ Sammelgel (4\%) } \\
$120 \mathrm{ml}$ & AA (siehe 2.13) & $1,33 \mathrm{ml}$ \\
& Sammelgelpuffer & $2,5 \mathrm{ml}$ \\
$16,75 \mathrm{ml}$ & $\mathrm{H}_{2} \mathrm{O}_{\text {bidest }}$ & \\
$500 \mu \mathrm{l}$ & SDS $10 \%(\mathrm{w} / \mathrm{v})$ & $6,1 \mathrm{ml}$ \\
$200 \mu \mathrm{l}$ & APS $10 \%(\mathrm{w} / \mathrm{v})$ & $100 \mu \mathrm{l}$ \\
$50 \mu \mathrm{l}$ & TEMED & $50 \mu \mathrm{l}$ \\
$50 \mathrm{ml}$ & $\Sigma$ & $10 \mu \mathrm{l}$ \\
& & $10 \mathrm{ml}$
\end{tabular}

Laufpuffer: siehe 2.13 .

Nach Durchlauf der Gele und Herauslösen aus der Apparatur erfolgte die Färbung. Gele, die mit bis zu $150 \mu \mathrm{g}$ Protein in der ersten Dimension beladen wurden, wurden einer Silberfärbung (2.16.2) unterzogen. Wurden die Gele als Probenmaterial für die MALDITOF-MS angefertigt, wurde $1 \mathrm{mg}$ Proteinlösung aufgetragen und mit Coomassie (2.16.1) gefärbt.

\subsection{Probenpräparation für die MALDI-TOF-Massenspektrometrie}

Zur Identifizierung der regulierten Proteine wurde eine MALDI-TOFMassenspektrometrie durchgeführt (matrix assisted laser desorption ionisation-time of flight). Dazu schnitt man zunächst die entsprechenden Coomassie-gefärbten Proteinspots mit Hilfe eines sauberen Skalpells aus dem Gel aus und unterzog sie einem Trypsinverdau.

Durchführung:

- Vorwaschen der E-Cups mit $500 \mu 10,1 \%$ TFA/60 \% $\mathrm{CH}_{3} \mathrm{CN}$

- Ausgeschnittenes Gelstück kleinschneiden und in vorgewaschenes E-Cup transferieren

- Ein ungefärbtes Stück des Gels zur Herstellung eines Hintergrundes für die Messung ebenso behandeln

- Zugabe von $250 \mu 150 \% \mathrm{H}_{2} \mathrm{O} / 50 \% \mathrm{CH}_{3} \mathrm{CN}$ auf ein E-Cup und 5 min waschen

- Entfernen des Waschpuffers und Zugabe von $250 \mu \mathrm{l} 50 \% \mathrm{CH}_{3} \mathrm{CN} / 50 \mathrm{mM} \mathrm{NH} \mathrm{NCO}_{3}$ $\mathrm{zu}$ allen Proben

- 30 min bei RT unter Schütteln waschen; Entfernen des Waschpuffers 
- Zugabe von $250 \mu 150 \% \mathrm{CH}_{3} \mathrm{CN} / 10 \mathrm{mM} \mathrm{NH}_{4} \mathrm{HCO}_{3}$ und bei RT 30 min waschen

- Entfernen des Waschpuffers und in der Vakuumzentrifuge trocknen

- Zugabe von 0,1 $\mu \mathrm{g}$ modifiziertem Trypsin (Promega) pro $15 \mathrm{~mm}^{3}$ Gelfläche in $15 \mu 110$ $\mathrm{mM} \mathrm{NH}_{4} \mathrm{HCO}_{3} \mathrm{zu}$ allen Proben und zur Hintergrund-Probe Achtung: Trypsin muß vorher zur Aktivierung in saurem Puffer aufgenommen werden: $200 \mu 1$ des mitgelieferten Puffers (50 mM Essigsäure) wurden auf 1 E-Cup Trypsin (20 $\mu \mathrm{g})$ gegeben, aliquotiert und vor Gebrauch bei $30^{\circ} \mathrm{C} 10-15$ min aktiviert.

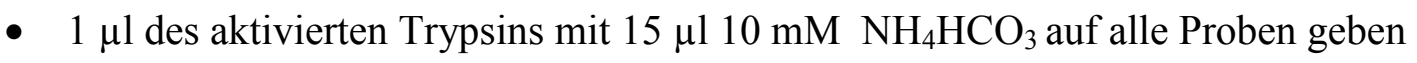

- 5-10 min stehen lassen

- Zugabe von $20 \mu 110 \mathrm{mM} \mathrm{NH}_{4} \mathrm{HCO}_{3}$ ohne Enzym

- Inkubation für $24 \mathrm{~h}$ bei $37^{\circ} \mathrm{C}$

- Aufbewahren der Proben bis zur Messung bei $4{ }^{\circ} \mathrm{C}$

Die Proben wurden vor der Analyse mit Ultraschall behandelt, um die Peptide aus der Gelmatrix herauszulösen. Als Matrix bei der Massenspektrometrie dienen im allgemeinen leichte organische Säuren. Im folgenden wurde $\alpha$-Cyano-4-hydroxy Zimtsäure verwendet. Das Probenmaterial wurde 1:1 mit der Matrix vermischt und $2 \mu \mathrm{l}$ des Gemisches auf eine Probenträgerplatte mit eingravierten Ringen zur Markierung der Probenposition pipettiert. Durch Hitze (Föhn) konnte die Kristallisation gefördert werden. Eine Probe wurde dreimal auf dieselbe Stelle aufgetragen. Der Probenträger wurde in das Gerät gegeben (MALDITOF, mit Reflektor (RETOF); Bruker Reflex II) und jede einzelne Probenposition konnte mit dem Laser angesteuert werden. Der Laser wurde auf ein Kristall gerichtet, welches über einen Monitor überprüft werden konnte, und mit dem Laser pro Messung 20 mal beschossen. Dann wählte man von derselben Probe 3-4 weiter Kristalle und verfuhr genauso. Die gemessenen Massenpeaks einer Probe wurden übereinandergelegt. Zur Kalibrierung wurden die Massen dreier bekannter Peptide bestimmt.

\subsection{Färbung von Proteinen}

\subsubsection{Coomassie-Färbung}

Nach Beendigung der Elektrophorese wurden die SDS-Gele mit Coomassie-BlauFärbelösung versetzt und 30-60 min lang darin leicht geschüttelt. Entfärbt wurden die Gele mit einer Entfärberlösung, die mehrmals gewechselt wurde, solange bis der Hintergrund 
der Gele nahezu farblos war. Die Gele wurden in Folie eingeschweißt und bei $4{ }^{\circ} \mathrm{C}$ aufbewahrt oder bis zum Trocknen mit dem BioRad ${ }^{\circledR}$ Geltrockner in $\mathrm{H}_{2} \mathrm{O}_{\text {bidest }}$ aufbewahrt.

Färbelösung

Coomassie-Brilliant-Blau $\quad 1,2 \mathrm{~g}$

$\mathrm{R}-250$

Coomassie-Brilliant-Blau $\quad 1,2 \mathrm{~g}$

G-250

Methanol

$455 \mathrm{ml}$

Eisessig

$80 \mathrm{ml}$

$\mathrm{H}_{2} \mathrm{O}_{\text {bidest }}$

ad $1000 \mathrm{ml}$

\section{Entfärberlösung}

Methanol

$400 \mathrm{ml}$

Essigsäure

$100 \mathrm{ml}$

$\mathrm{H}_{2} \mathrm{O}_{\text {bidest }}$

ad $1000 \mathrm{ml}$

\subsubsection{Silberfärbung (Blum et al., 1987, mod.)}

Die unspezifische Färbung von Proteinen mit Silber wird unter leichtem Schwenken auf dem Schüttler durchgeführt. Die Inkubationen und das Waschen erfolgten nach folgender Anleitung:

- Mind. $1 \mathrm{~h}$ Inkubation des Gels in Fixierlösung; bei länger andauerndem Fixieren zum Beispiel über Nacht (bis max. 24 h) vor weiteren Schritten das Gel für $30 \mathrm{~min}$ in frische Fixierlösung legen

- $3 \times 10-20 \mathrm{~min}$ in $50 \%$-igem Ethanol inkubieren

- $60 \mathrm{~s}$ Thiosulfatlösung

- Waschen 3 x $20 \mathrm{~s}$ in $\mathrm{H}_{2} \mathrm{O}_{\text {bidest }}$

- 20 min in Imprägnierlösung inkubieren

- 2 × $20 \mathrm{~s}$ in $\mathrm{H}_{2} \mathrm{O}_{\text {bidest }}$ waschen

- Schwenken in Entwicklerlösung bis Proteinbanden bzw. Spots gut erkennbar sind

- Kurz mit $\mathrm{H}_{2} \mathrm{O}_{\text {bidest }}$ spülen und 15 min in Stopplösung aufbewahren

- Zweimal mit $\mathrm{H}_{2} \mathrm{O}_{\text {bidest }}$ spülen und in Wasser oder $10 \%$-iger Glycerinlösung (v/v) bis zum Trocknen aufbewahren 
$\underline{\text { Fixierlösung }}$

Methanol

Eisessig

Formaldehyd 37\% (v/v)

$\mathrm{H}_{2} \mathrm{O}_{\text {bidest }}$

Imprägnierlösung

$\mathrm{AgNO}_{3}$

Formaldehyd 37\% (v/v)

$\mathrm{H}_{2} \mathrm{O}_{\text {bidest }}$

$\underline{\text { Stoplösung }}$

EDTA

$\mathrm{H}_{2} \mathrm{O}_{\text {bidest }}$

$\mathrm{pH} 7,5$
Entwicklerlösung

$\begin{array}{rlr}50 \mathrm{ml} & \mathrm{Na}_{2} \mathrm{CO}_{3} & 3,4 \mathrm{~g} \\ 12 \mathrm{ml} & \text { Formaldehyd 37\% (v/v) } & 50 \mu \\ 0,1 \mathrm{ml} & \text { Thiosulfatlösung } & 2 \mathrm{ml} \\ 100 \mathrm{ml} & \mathrm{H}_{2} \mathrm{O}_{\text {bidest }} & \text { ad } 100 \mathrm{ml}\end{array}$

Thiosulfatlösung

$0,2 \mathrm{~g} \quad \mathrm{Na}_{2} \mathrm{SO}_{3} \times 5 \mathrm{H}_{2} \mathrm{O}$

$20 \mathrm{mg}$

$75 \mu \mathrm{l} \quad \mathrm{H}_{2} \mathrm{O}_{\text {bidest }} \quad$ ad $100 \mathrm{ml}$
$1,86 \mathrm{~g}$

ad $100 \mathrm{ml}$

Zur Färbung zweier 20 x 20 cm großen SDS-Gele im Rahmen der 2D-Gelelektrophorese wurden je $300 \mathrm{ml}$ aller Lösungen frisch angesetzt.

\subsection{Proteinaufreinigung durch Ni-NTA-Affinitätschromatographie}

Die überexprimierten SurE- und Pcm-Proteine konnten aufgrund der 6 N-terminalen Histidinreste durch Nickel-NTA Metall-Affinitätschromatographie aufgereinigt werden. Die 6 Histidinreste haben eine hohe Affinität zu den immobilisierten Nickelionen der Matrix, wodurch die Proteine an das Säulenmaterial gebunden wird.

Nach Anzucht, Induktion und Zellernte wurde versucht, die Proteine sowohl unter nativen als auch unter denaturierenden Bedingungen anzureichern. Bei beiden Verfahren wurde das Zell-Lysat mit einer Ni-NTA-Matrix inkubiert, ungebundene Proteine ausgewaschen und die gebundenen Proteine eluiert.

\subsubsection{Zellaufschluß und Aufreinigung unter nativen Bedingungen}

Vorgehensweise:

- Frisch geerntete oder auf Eis aufgetaute Zellen in Lysepuffer aufnehmen, wobei die Menge sich nach dem Naßgewicht der Zellen richtet (3 ml Lysepuffer/g Naßgewicht) 
- Zellaufschluß durch Zugabe von 1mg/ml Lysozym und 30 min Inkubation auf Eis

- DNase Behandlung ( $5 \mu \mathrm{g}$ DNaseI/ml) 15 min auf Eis und Zellen in einer gekühlten Druckzelle in 3 Durchgängen vollständig aufschließen

- Zentrifugation des Lysates bei $10000 \mathrm{Upm}$ für 30 min bei $4{ }^{\circ} \mathrm{C}$

- Überstand für die Aufreinigung einsetzen

- $1 \mathrm{ml}$ der $50 \%$-igen Ni-NTA Matrix mit $4 \mathrm{ml}$ Überstand in ein verschließbares Plastikgefäß füllen und für $60 \mathrm{~min}$ bis über Nacht bei $4{ }^{\circ} \mathrm{C}$ unter ständigem Schütteln inkubieren

- Beladen einer $10 \mathrm{ml}$ Säule mit dem Ni-NTA-Lysat Mix. Zur Sedimentation der NiNTA-Matrix Lysat mit den nicht an die Matrix gebundenen Bestandteilen durchlaufen lassen und zweimal mit je $4 \mathrm{ml}$ Waschpuffer waschen

- Zur Elution Säule mit 4 x 0,5 ml Elutionspuffer versetzen und die Fraktionen in Eppendorfgefäßen sammeln

\section{Lysepuffer/ Waschpuffer/ Elutionspuffer}

$\begin{array}{lr}\mathrm{NaH}_{2} \mathrm{PO}_{4} & 50 \mathrm{mM} \\ \mathrm{NaCl} & 300 \mathrm{mM} \\ \mathrm{pH} 8 & \end{array}$

Die Puffer enthielten die gleiche Menge an Natriumdihydrogenphosphat und Natriumchlorid und unterschieden sich in der Konzentration an Imidazol, wobei der Lysepuffer $10 \mathrm{mM}$, der Waschpuffer $20 \mathrm{mM}$ und der Elutionspuffer $250 \mathrm{mM}$ Imidazol enthielt.

\subsubsection{Zellaufschluß und Aufreinigung unter denaturierenden Bedingungen}

Vorgehensweise:

- Aufgetaute oder frisch geerntete Zellen pro g Naßgewicht in $5 \mathrm{ml}$ Puffer B aufnehmen

- Zellen durch 60 min Inkubation bei Raumtemperatur lysieren, dabei mehrmals leicht schütteln

- Nach Zentrifugation des Lysates bei 10000 Upm für 30 min bei Raumtemperatur den Überstand für die Aufreinigung einsetzen

- Binden der Proteine mit den Histidinsequenzen an die Nickel-NTA-Matrix durch 60 min Inkubation unter leichtem Schütteln bei RT (1 ml der Matrix auf 4 ml Überstand) 
- Das Gemisch in eine leere $10 \mathrm{ml}$ Säule überführen und nach Sedimentation der Matrixpartikel zweimal mit $4 \mathrm{ml}$ Puffer $\mathrm{C}$ waschen

- Elution mit Elutionspuffern verschiedener pH-Werte D und E, (4 x 0,5 ml von jedem Puffer)

\section{Puffer B,C,D,und E}

Harnstoff

$\mathrm{NaH}_{2} \mathrm{PO}_{4}$

Tris- $\mathrm{HCl}$

$\begin{array}{rll}8 \mathrm{M} & \text { Puffer B } & \mathrm{pH} \mathrm{8,0} \\ 0,1 \mathrm{M} & \text { Puffer C } & \mathrm{pH} \mathrm{6,3} \\ 0,01 \mathrm{M} & \text { Puffer D } & \mathrm{pH} \mathrm{5,9} \\ & \text { Puffer E } & \mathrm{pH} 4,5\end{array}$

Die Puffer B,C,D und E unterschieden sich nur durch ihre pH-Werte, die aufgrund der Eigendissoziation von Harnstoff unmittelbar vor Gebrauch der Puffer mit $\mathrm{HCl}$ eingestellt wurden.

\subsection{B-Glucuronidase-Messungen}

Die Aktivität der ß-Glucuronidase wurde in einem fluorimetrischen Test bestimmt, in dem die Umsetzung des Substrates 4-Methyl-Umbelliferyl-ß-D-Glucuronid (MUG) zu 4Methyl-umbelliferon (MU) verfolgt wurde (Jefferson et al., 1986).

Durchführung:

- $\quad 100 \mu \mathrm{zu}$ untersuchende Bakterienkultur, bzw. entsprechend verdünnte Aliquots, mit $900 \mu \mathrm{lgusA}$-Extraktionspuffer für $2 \min$ bei $37^{\circ} \mathrm{C}$ vorinkubieren

- Zugabe von $100 \mu$ l Substratlösung im Abstand von $15 \mathrm{~s}$ und Inkubation für 20 min bei $37^{\circ} \mathrm{C}$

- Abstoppen der Reaktion durch Zugabe von $200 \mu$ Stoppuffer im Abstand von $15 \mathrm{~s}$

- Messen der Fluoreszenz mit dem Fluorimeter (Minifluorimeter TKO 100, Firma Hoefer) nach Bestimmung des Leerwertes (Reaktionspuffer, Medium und Substratlösung)

Die Glucuronidaseaktivitäten wurden als relative Einheiten bestimmt. Dazu wurde die Fluoreszenz von $100 \mu 1$ Kultur bzw. verdünnter Kultur nach oben angegebener Methode bestimmt. Verdünnt wurden Kulturen mit hoher optischer Dichte oder Kulturen von denen Vorversuche gezeigt hatten, daß Meßwerte außerhalb des Meßbereiches zu erwarten sind. 
Diese Fluoreszenz-Meßwerte wurden zur Standardisierung unter Berücksichtigung des Verdünnungsfaktors der Kulturen auf die optischen Dichte bezogen $\left(\mathrm{OD}_{600}=1\right)$.

gusA-Extraktionspuffer

$0,5 \mathrm{M}(\mathrm{Na})_{x}(\mathrm{H})_{y} \mathrm{PO}_{4}-\mathrm{Puffer}$

$\mathrm{pH} 7,5$

ß-Mercaptoethanol

$0,5 \mathrm{M} \mathrm{Na}_{2}$ EDTA

$5 \%$ N-Lauryl-Sarkosin

$(\mathrm{w} / \mathrm{v})$

$10 \%$ Triton-X-100

$\mathrm{H}_{2} \mathrm{O}_{\text {bidest }}$

Stoppuffer

$(0,2 \mathrm{M}) \mathrm{Na}_{2} \mathrm{CO}_{3}$

\section{$\underline{\text { Substratlösung }}$}

$5 \mathrm{ml}$ 4-Methyl-Umbelliferyl-ß-

$11 \mathrm{mg}$

D-Glucuronid (MUG)

0,07 $\mathrm{ml}$ gusA-Extraktionspuffer

ad $20 \mathrm{ml}$

$2 \mathrm{ml}$

$2 \mathrm{ml}$

$1 \mathrm{ml}$

ad $100 \mathrm{ml}$

\subsection{Dünnschichtchromatographie}

Zur Isolierung von Acyl-Homoserinlactonen wurden jeweils $25 \mathrm{ml}$ S. meliloti-Kulturen abzentrifugiert und der Überstand dreimal mit einem Volumen Ethylacetat extrahiert. Die Ehylacetatfraktionen wurden gesammelt und bis zur Trockne eingedampft. Der Rückstand wurde in $1 \mathrm{ml}$ Ethylacetat aufgenommen, erneut evakuiert, mit $100 \mu \mathrm{l}$ desselben Lösungsmittels versetzt und bis zur Verwendung bei $-20^{\circ} \mathrm{C}$ aufbewahrt. Aliquots $(2 \mu \mathrm{l})$ wurden auf eine RP-18W Dünnschichtplatte aufgetragen (Firma Macherey und Nagel) und mit 60\% Methanol: $40 \% \mathrm{H}_{2} \mathrm{O}(\mathrm{v} / \mathrm{v})$ als Laufmittel in zwei Durchgängen aufgetrennt. Nach Trocknen der Dünnschichtplatten erfolgte die Überschichtung mit dem Agrobacterium tumefaciens Reporterstamm NTL4 und Inkubation bei $30^{\circ} \mathrm{C}$. Die Isolierung der Homoserinlactone aus dem Überstand von A. tumefaciens KYC6, ein Stamm der die Autoinduktoren in hohem Maße produziert und als Positivkontrolle diente, erfolgte nach der gleichen Methode.

\subsection{Chemikalien, Biochemikalien und Enzyme}

Anorganische Salze wurden von den Firmen Roth, Sigma oder Merck bezogen. 
Chemikalien

Acrylamid/Bisacrylamid

Agar

Agarose

Ammoniumpersulfat

Ampicillin

BCIP

Blocking Reagenz

Biotin

Bromphenolblau

BSA

Chloramphenicol

Coomassie-Blau R-250/G-250

Chloroform

Eisessig

Essigsäure

Ethidiumbromid

Ethanol

EDTA

Ficoll 400

Glucose

Glycin

Glycerol

Harnstoff

Hefeextrakt

Isopropanol

IPTG

Kanamycin

2-Mercaptoethanol

Methanol

$\alpha$-Naphtyl-Phosphat

NBT

p-Nitrophenyl-Phosphat $\underline{\text { Hersteller }}$

$\operatorname{BioRad}^{\circledR} /$ Roth

Merck/ Oxoid

Biozym/ Gibco BRL

Sigma

Sigma

Biomol

Boehringer

Sigma

Serva

Sigma

Sigma

Serva

Merck

Merck

Merck

Serva

Merck

Merck

Sigma-Aldrich

Merck/ Fluka

Merck

Fluka

Serva

Oxoid

Merck

Sigma

Sigma

Merck

Merck

Sigma

Biomol

Simga 
Pefabloc

Pharmalyte

Phenol

PIPES

Saccharose

Salzsäure

SDS

Streptomycin

TEMED

Tris-HCl

Trypsin

Trypton

Tween-20

X-Gal/ X-Gluc
Merck

Amersham Pharmacia

Merck

Sigma

Merck

Merck

Fluka

Sigma

Biomol/ BioRad ${ }^{\circledR}$

Sigma

Promega

Oxoid

Serva

Sigma

$\underline{\text { Hersteller }}$

Boehringer

Serva

Sigma

Pharmacia/ MBI/

New England Biolabs/ Boehringer

Boehringer

Boehringer

Boehringer

Boehringer/ Qiagen/

Eigenherstellung

Stratagene

Pfu-Polymerase/ Pfu-Puffer

\subsection{Geräte, Kits und andere Materialien}

Sofern unter Material und Methoden nicht anders angegeben wurden folgende Geräte, Kits und andere Materialien verwendet. 
DNA-Gelextraktionskit,

Qiagen

Qiaquick-Gel-Extraktion-Kit

DNA-Größenstandard

Gibco BRL/ MBI

Filtermembran

Schleicher \& Schuell

Gelkammern/

$\operatorname{BioRad}^{\circledR}$

Agarosegelelektrophorese

Geltrockner

$\operatorname{BioRad}^{\circledR}$

Kamera/

$\operatorname{BioRad}^{\circledR}$

Geldokumentationsanlage

Ni-NTA-Matrix

Qiagen

Nitrocellulosemembran

Sartorius

Nylonmembran

Schleicher \& Schuell/ (Hybond-N, Amersham

Pharmacia)

PCR-Maschine

Perkin Elmer/ MWG Biotech

Fotometer

Ameraham Pharmacia Ultrospec 3000

Plasmid-Isolationskit

Qiagen

Proteinbestimmungs-Reagenz

BioRad $^{\circledR}$

Protein-Größenstandard

Sigma, Novex

SDS-Gelelektrophoresekammer

BioRad $^{\circledR}$

Zentrifugen

Sorvall Instruments (Du Pont)/ Biofuge Heraeus 


\section{EXPERIMENTE UND ERGEBNISSE}

Leguminosen exsudieren Biotin in signifikanten Mengen über die Wurzel und dieses Vitamin übernimmt eine Schlüsselfunktion bei der Besiedlung der Rhizosphäre durch S. meliloti. In Rhizosphärentests und auch bei Anzucht unter Laborbedingungen konnte bereits die Abhängigkeit des rhizobiellen Wachstums durch exogenes Biotin demonstriert werden (Streit et al., 1996; Watson et al., 2001; Entcheva et al., 2002). Da die endogene Biotinbiosynthese des Mikrosymbionten limitierend ist, stellt pflanzenexsudiertes Biotin im natürlichen Habitat die wichtigste Quelle für dieses Vitamin dar und könnte möglicherweise daran beteiligt sein, S. meliloti die Anwesenheit eines potentiellen Symbiosepartners zu signalisieren. Welche Prozesse auf physiologischer Ebene an der Wahrnehmung von exogenem Biotin involviert sind und letztlich dazu führen, Wachstum in Abhängigkeit von Biotin wieder aufzunehmen, ist weitgehend unbekannt. Bisher wurden erst zwei Gene in S. meliloti charakterisiert (bioS und bdhA), deren Expression direkt oder indirekt durch Biotin beeinflußt wird. Daher war es Ziel dieser Arbeit, mit Hilfe unterschiedlicher Methoden weitere Biotin-regulierte Gene zu identifizieren und so den Einfluß von exogenem Biotin auf rhizobielles Wachstum zu analysieren.

i) Als zentrale Methode wurde die 2D-Gelelektrophorese gewählt. Dabei wurden die Proteinmuster von S. meliloti 1021-Zellen, die zunächst unter Biotin-limitierenden Bedingungen inkubiert wurden, mit den Proteinmustern von Zellen verglichen, die nach Inkubation unter Biotin-limitierenden Bedingungen mit Biotin supplementiert wurden. Ausgewählte Proteine, deren Expression nach Biotinzugabe deutlich erhöht war, wurden durch MALDI-TOF-MS analysiert.

ii) In einem zweiten Ansatz wurden gezielt Gene aus Datenbanken ausgewählt und deren Expression in Abhängigkeit von Biotin im Medium durch Promotoraktivitätsmessungen bestimmt. Dadurch wurde der potentielle regulatorische Einfluß von Biotin auf Gene, die an Prozessen wie Nodulation, Phospholipidsynthese oder Autoinduktion beteiligt sind, untersucht.

iii) In einem dritten Ansatz wurde durch Mutagenese die Bedeutung von Genen aus dem Survival-Locus für das Überleben in der stationären Wachstumsphase untersucht. 


\subsection{D-Gelelektrophorese}

Die zweidimensionale Gelelektrophorese bietet die Möglichkeit, mehrere hundert bis tausend Proteine einer Zelle zu trennen und gleichzeitig auf einem Gel darzustellen. Dabei werden die Proteine in der ersten Dimension isoelektrisch fokussiert, d.h. aufgrund ihrer Ladung getrennt. In der zweiten Dimension erfolgt die Separation aufgrund der unterschiedlichen molekularen Massen im SDS-Polyacrylamidgel. Auf diese Weise können Proteinextrakte von Zellen, die unter verschiedenen Wachstumsparametern angezogen wurden oder Proteinextrakte von Mutanten und Wildtyp-Zellen miteinander verglichen werden. Durch diese sogenannte Proteomanalyse läßt sich die Gesamtheit aller Proteine in einer Zelle zu einem bestimmten Zeitpunkt untersuchen. Interessante Proteine können nach Isolation aus dem Gel und proteolytischem Verdau massenspektrometrisch analysiert und identifiziert werden.

Ein Ziel der Arbeit war es, den Einfluß externen Biotins auf rhizobielles Wachstum zu untersuchen und Proteine zu identifizieren, deren Expression direkt oder indirekt durch Biotin induziert wird. Daher wurden die Proteinmuster von Zellen, die unter Biotin limitierenden Bedingungen angezogen worden waren mit denen verglichen, die nach Biotinsupplementation angefertigt wurden. Ausgewählte Proteine, die nach Biotinsupplementation im 2D-Gel reproduzierbar stärker exprimiert waren, wurden aus dem Gel ausgeschnitten und einem Verdau durch Trypsin unterzogen. Die Peptidgemische wurden durch MALDI-TOF-Massenspektrometrie analysiert und die resultierenden Peptidmassen eines Proteins durch Datenbankanalysen identifiziert. In dieser Arbeit wurden 12 Proteine aus S. meliloti identifiziert, die eine erhöhte Expression nach Biotinzugabe zeigten.

\subsubsection{Vergleichende 2D-Gelanalyse von $S$. meliloti Proteinextrakten}

Mit Hilfe der 2D-Gelelektrophorese sollten Proteine identifiziert werden, deren Expression in Abhängigkeit von Biotin induziert wird. Dazu mußte S. meliloti zunächst unter Biotinlimitierenden Bedingungen angezogen werden, was durch mehrere Passagen in nicht Biotin-supplementiertes GTS-Minimalmedium erreicht wurde. Da die vermutlich fehlende endogene Biotinbiosynthese limitierend auf rhizobielles Wachstum wirkt, führte der sukzessive Transfer von S. meliloti in frisches nicht Biotin-supplementiertes Medium zu einer Verarmung an Biotin im Medium und damit $\mathrm{zu}$ einem reduzierten Wachstum, meßbar durch geringere optische Dichten. Ein Aliquot einer solchen Biotin-limitierten 
Kultur wurde abzentrifugiert und das Pellet bei $-20{ }^{\circ} \mathrm{C}$ aufbewahrt. Die restliche Kultur wurde durch Biotinzugabe (40 nM Endkonzentration) komplementiert, bis zur Wiederaufnahme von Wachstum weiter inkubiert und in der logarithmischen Phase geerntet. Die Zellpellets der unter Biotinlimitierung angezogenen Kultur und der Biotinsupplementierten Kultur wurden parallel zur Herstellung des Proteinextraktes aufbearbeitet. Die isoelelektrische Fokussierung, SDS-PAGE und die Färbung wurden für ein Probenpaar immer gleichzeitig durchgeführt.

In Vorversuchen wurden Zellen bereits sechs Stunden nach Biotinzugabe geerntet. Bei dieser Kultur wurde nach der kurzen Inkubationszeit nach Biotinsupplementation keine höhere $\mathrm{OD}_{600}$ gemessen, als vor Biotinsupplementation. Die Zellen wurden aufbearbeitet und mit den Proteinmustern der nicht supplementierten Biotinkultur verglichen. Es zeigte sich, daß unter diesen Versuchsbedingungen keine starken Änderungen auf Proteinebene in den 2D-Gelen $\mathrm{zu}$ sehen waren (nicht dargestellt). Daher wurden für die folgenden Versuche die Zellen nach deutlicher Wachstumszunahme geerntet, was abhängig von der Länge der vorangegangenen Inkubation unter Biotin-limitierenden Bedingungen war. Je älter die Biotin-limitierten S. meliloti Stationärphase-Kulturen waren, desto länger dauerte die lag-Phase nach Biotinsupplementation. Bei den im folgenden dargestellten Experimenten wurden die Zellen 32-37 Tage lang unter Biotin-limitierenden Bedingungen inkubiert. Die Zellernte erfolgte 64-90 h nach Biotinsupplementation.

Wie auf den vergleichenden Gesamtansichten der Gele im pI-Bereich 4-7 zu sehen ist (Abb. 2), wurde ein Großteil der etwa 600 Proteine unter beiden Wachstumsbedingungen exprimiert. Manche Proteine lagen verstärkt exprimiert unter Biotin-limitierenden Bedingungen vor (etwa 50), andere zeigten eine erhöhte Expression nach Zugabe von Biotin (etwa 70). Während auf den Gelen der unter Biotin-limitierenden Bedingungen angezogenen Kulturen vor allem kleine Proteine im unteren pI-Bereich vermehrt zu beobachten waren, befanden sich auf den Gelen der Biotin-supplementierten Kulturen verstärkt Proteine mit großen Massen im pI-Bereich von 5,5-6,5. Da der Großteil der Proteine im pI-Bereich 4,5-5,5 lokalisiert war, wurden zur besseren Auflösung Isofokussierungen in diesem pI-Bereich durchgeführt (Abb. 3). Insgesamt wurden 18 Proteine, deren Expression reproduzierbar nach Biotinzugabe induziert oder deutlich erhöht war und deren Positionen auch im Coomassie gefärbten SDS-Gel eindeutig zuzuordnen war, massenspektrometrisch untersucht. 12 dieser 18 Proteine konnten eindeutig als S. meliloti Proteine identifiziert werden. Wie unter 2.16 angegeben, wurden die entsprechenden Proteinspots aus dem Gel herausgeschnitten und einem Trypsinverdau 
unterzogen, bevor sie als Probenmaterial für die MALDI-TOF-MS Analyse eingesetzt werden konnten.

a) Biotin $40(\mathrm{nM})$

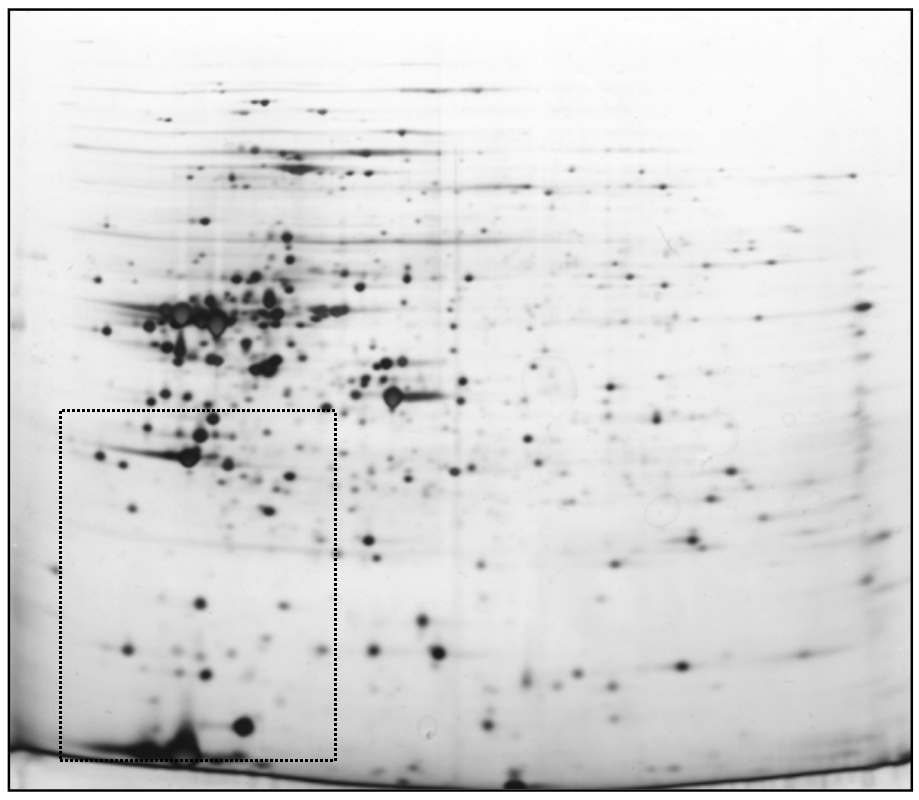

pI 4

pI 7

\section{b) Biotin-limitiert}

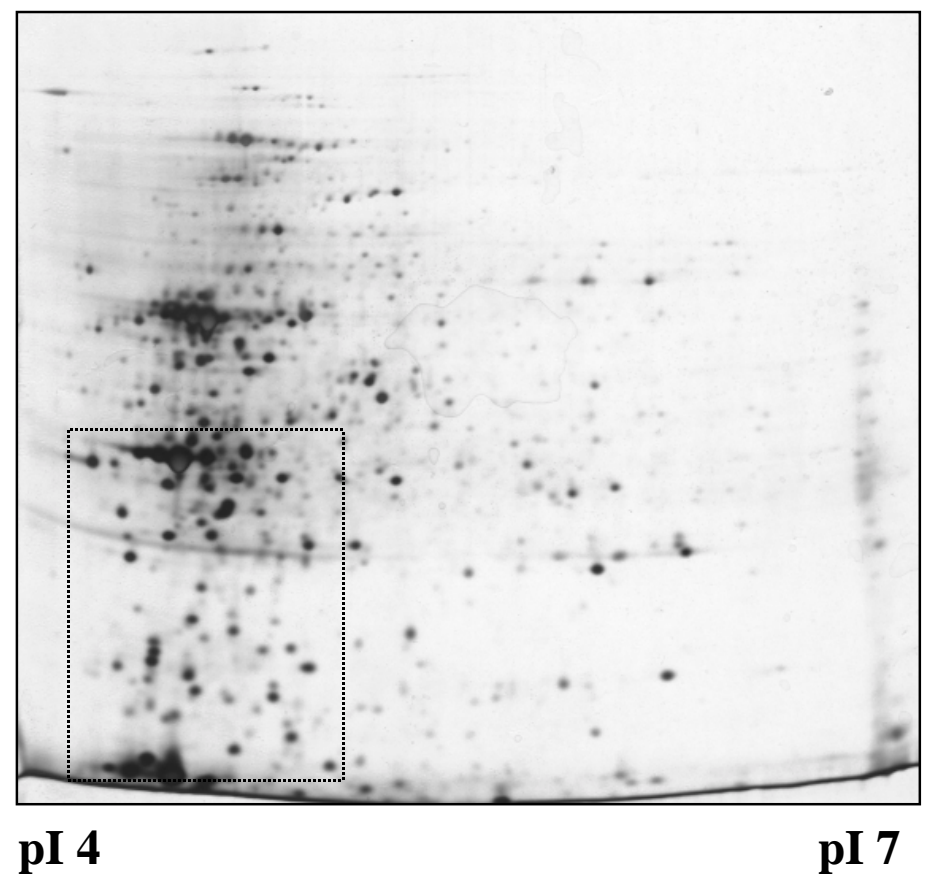

Abb. 2 Vergleichende Gesamtansicht von S. meliloti Proteinextrakten

Vor allem unter Biotin-limitierenden Bedingungen b) waren im unteren pIBereich viele kleine Proteine detektierbar, die unter Biotinsupplementation a) nicht $\mathrm{zu}$ sehen waren (siehe markierten Bereich). Es wurden jeweils $100 \mu \mathrm{g}$ Protein für die Isofokussierung aufgetragen. Die SDS-PAGE wurde in einem $12 \%$-igem (w/v) Gel durchgeführt, woran sich eine Silberfärbung anschloß. 

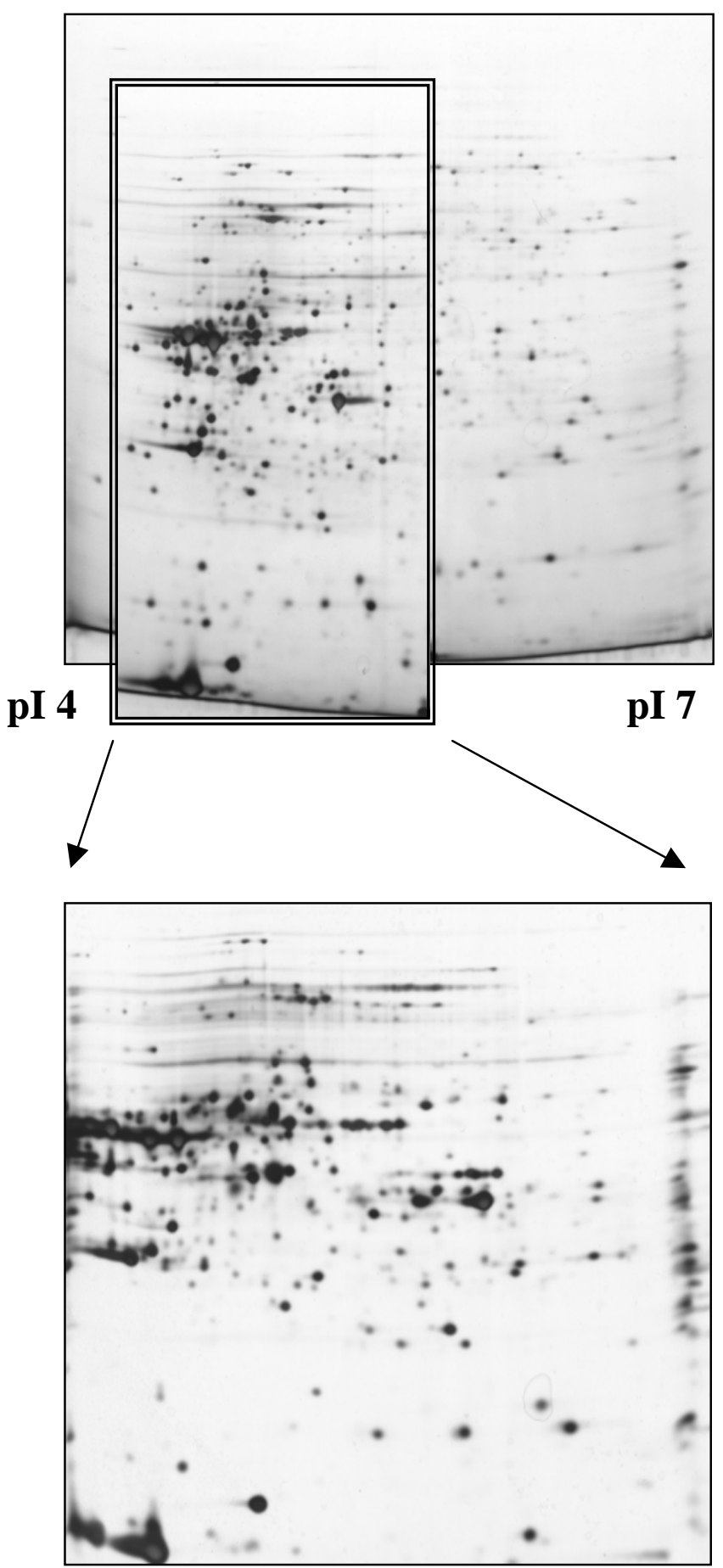

pI 4,5

pI 5,5

Abb. 3 Darstellung der verbesserten Auflösung durch Verwendung von IPGStreifen mit engerem pI-Bereich $\mathbf{( 4 , 5 - 5 , 5 )}$ für die Isofokussierung

Bei beiden Gelen wurde als Probenmaterial Proteinextrakt Biotinsupplementierter Kulturen aufgetragen. Durch die Isofokussierung im engeren pI-Bereich wurde eine bessere Auflösung für Regionen mit einer hohen Anzahl an Proteinen erreicht. Es wurden jeweils $100 \mu \mathrm{g}$ Protein in der ersten Dimension aufgetragen und eine SDS-PAGE in einem $12 \%$-igem (w/v) Gel durchgeführt. 


\subsubsection{Ausgewählte Proteine mit erhöhter Expression nach Biotinsupplementation}

Zur besseren Veranschaulichung der Proteine, die nach Biotinsupplementation eine erhöhte Expression aufwiesen und durch MALDI-TOF-MS identifiziert wurden, sind im folgenden Ausschnitte aus den entsprechenden 2D-Gelen dargestellt. Dabei werden die Gele, in denen Proteinextrakte Biotin-supplementierter Kulturen aufgetrennt wurden, den Gelen gegenübergestellt, die die Proteinextrakte der unter Biotinlimitierung inkubierten Kulturen zeigen. Regulierte Proteine werden durch Pfeile markiert. Die Bezeichnung der Proteine wird auf den Gelen durch Buchstaben angegeben. Anhand der entsprechenden Tabellen 7 und 8 kann ermittelt werden, um welche Proteine es sich dabei handelt.

\section{a) Biotin (40 $\mathrm{nM})$}

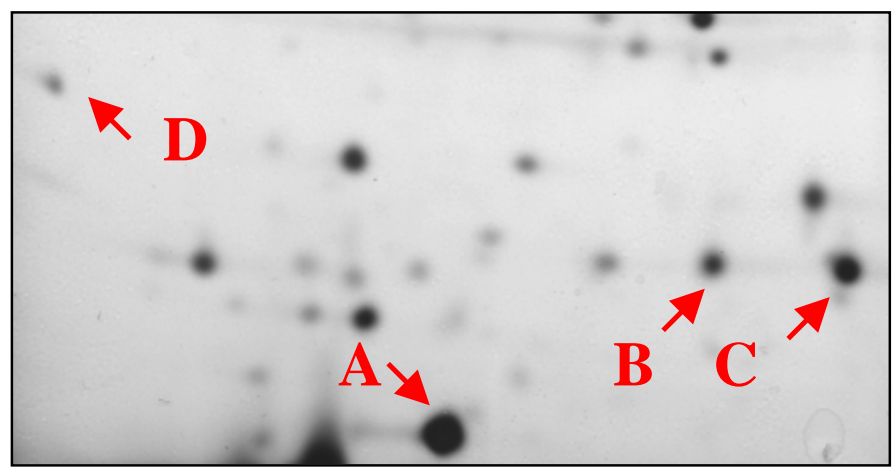

\section{b) Biotin-limitiert}

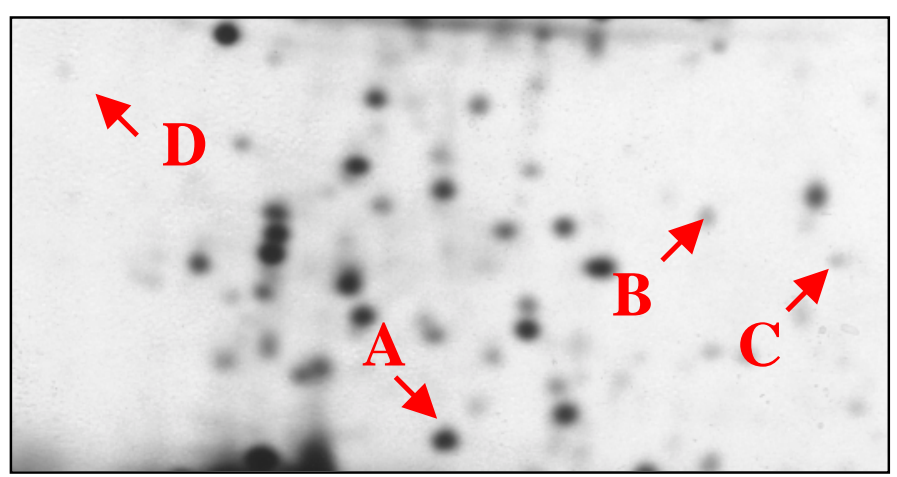

Abb. 4 Ausschnittsvergrößerung aus Gelen des pI-Bereiches 4-7 zur Darstellung der Proteine A, B, C und D

Proteine, die nach Biotinsupplementation stärker exprimiert (Abb. 4 a) und massenspektrometrisch analysiert wurden, sind durch Pfeile und Buchstaben markiert. Bei Protein A handelte es sich um das 50S ribosomale Protein L7/L12 und bei Protein D um die Omega-Untereinheit der RNA-Polymerase. B und C wurden beide als CopC-Protein identifiziert, welches möglicherweise an der Resistenz gegenüber Kupfer beteiligt ist. Die Laufunterschiede sind auf Modifikationen zurückzuführen. 


\section{a) Biotin (40 $\mathrm{nM})$}

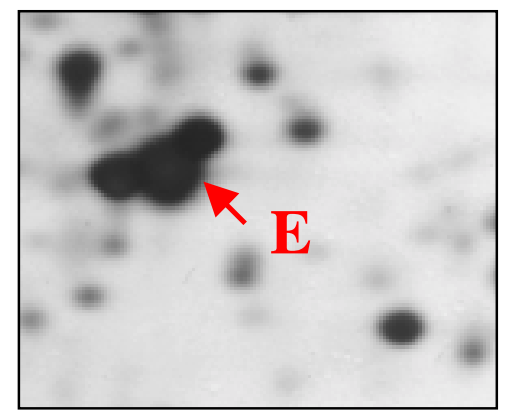

b) Biotin-limitiert

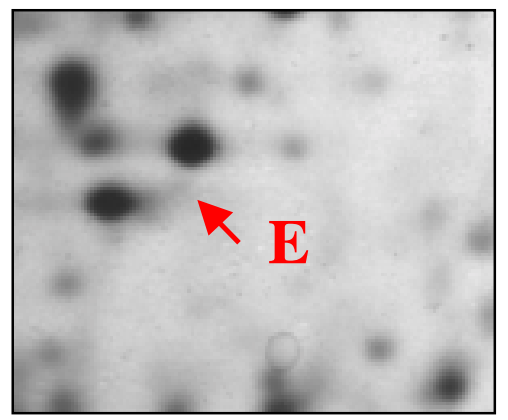

Abb. 5 Ausschnittsvergrößerung zur vergleichenden Darstellung des Proteins E Die Ausschnitte stammen aus Gelen der Proteinextrakte Biotin-supplementierter Kulturen a) und Biotin-limitierter Kulturen b) des pI-Bereiches 4-7. Protein E wurde als ABC-Transporter-Bindeprotein für L-Aminosäuren identifiziert.

a) Biotin $40 \mathrm{nM}$

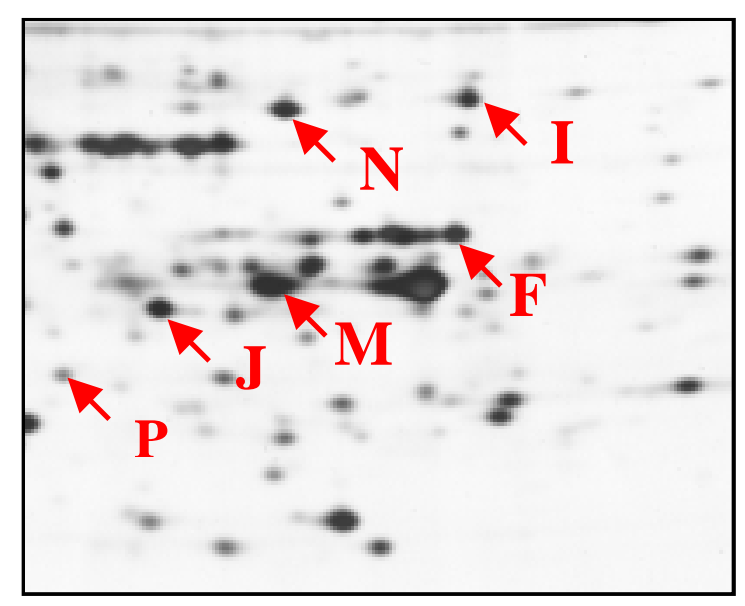

b) Biotin-limitiert

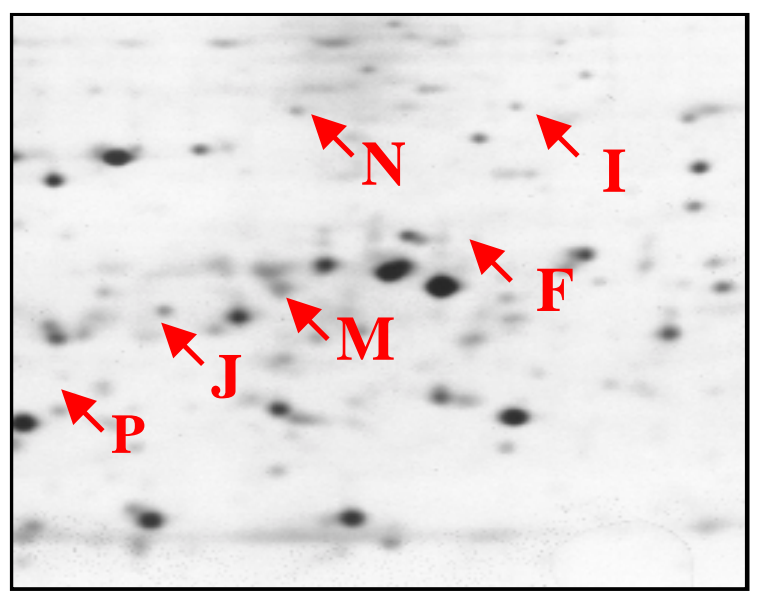

Abb. 6 Ausschnittsvergrößerung zur Darstellung der Proteine F, I, J, M, N und P Die Ausschnitte sind aus den Gelen des pI-Bereiches 4,5-5,5 a) unter Biotinsupplementation und b) unter Biotinlimitierung. Bei Protein $\mathrm{F}$ handelte es sich um ein ABC-Transporter-Bindeprotein für Zucker, bei Protein I um ein ABC-Transporter-Bindeprotein für Glycerol-3-Phosphat und bei Protein J um ein konserviertes hypothetisches Protein. M zeigte Ähnlichkeiten zu einem ABC-Transporter-Bindeprotein aus $M$. loti. $\mathrm{N}$ und $\mathrm{P}$ konnten nicht identifiziert werden, zeigten aber Ähnlichkeiten zu einer Guanylat-Kinase bzw. zu einem Chromosomen-Trennungs-Protein (siehe Tab. 8). 


\section{a) Biotin $40 \mathrm{nM}$}

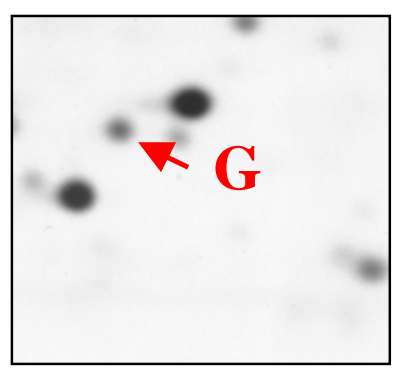

b) Biotin-limitiert

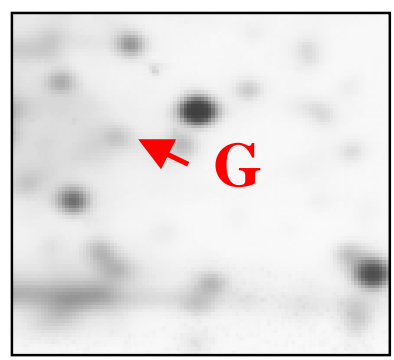

Abb. 7 Ausschnittsvergrößerung zur vergleichenden Darstellung des Proteins G Die Ausschnitte sind aus den Gelen des pI-Bereiches 4,5-5,5 a) unter Biotinsupplementation und $\mathrm{b}$ ) unter Biotinlimitierung. Bei $\mathrm{G}$ handelte es sich um eine Aldolase des 2-Keto-3-desoxy-6-phosphogluconat-Weges, einem Schlüsselenzym des Entner-Doudoroff-Weges.

\section{a) Biotin $40 \mathrm{nM}$}

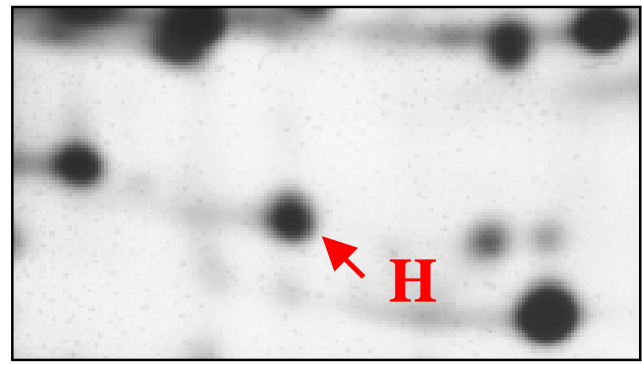

b) Biotin-limitiert

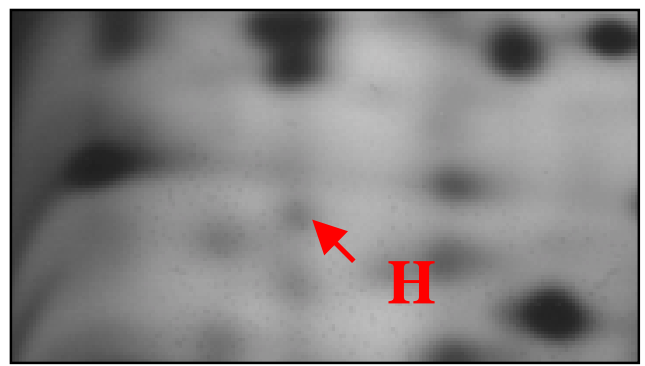

\section{Abb. 8 Ausschnittsvergrößerung zur Darstellung des Protein H}

Die Ausschnitte stammen aus Gelen der Proteinextrakte Biotin-supplementierter Kulturen a) und Biotin-limitierter Kulturen b) des pI-Bereiches 4,5-5,5. Protein $\mathrm{H}$ wurde als $\mathrm{ABC}-$ Transporter-Bindeprotein identifiziert, wobei die Art des gebundenen Moleküls nicht näher spezifiziert werden konnte. 


\section{a) Biotin $40 \mathrm{nM}$}

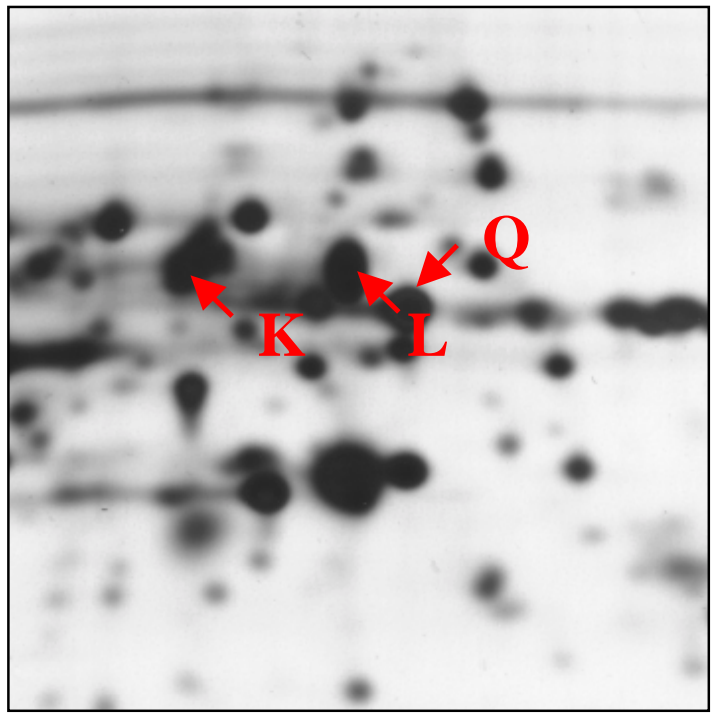

b) Biotin-limitiert

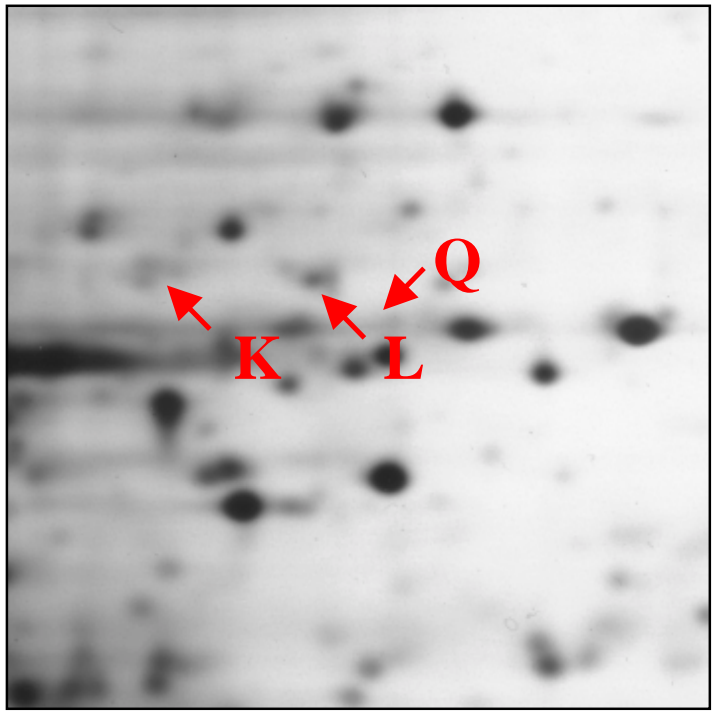

Abb. 9 Ausschnittsvergrößerung zur vergleichenden Darstellung der Proteine K, L und $\mathbf{Q}$

Die Ausschnitte stammen aus Gelen der Proteinextrakte Biotin-supplementierter Kulturen a) und Biotin-limitierter Kulturen b) des pI-Bereiches 4,5-5,5. Die Proteine $\mathrm{K}$ und $\mathrm{L}$ wurden als Leucin spezifisches Bindeprotein identifiziert, zeigten etwa das gleiche Laufverhalten in der zweiten Dimension, unterschieden sich jedoch geringfügig durch den pI-Wert, was auf Modifikationen des Proteins schließen läßt. Protein Q konnte nicht identifiziert werden (siehe Tab. 8).

a) Biotin $40 \mathrm{nM}$

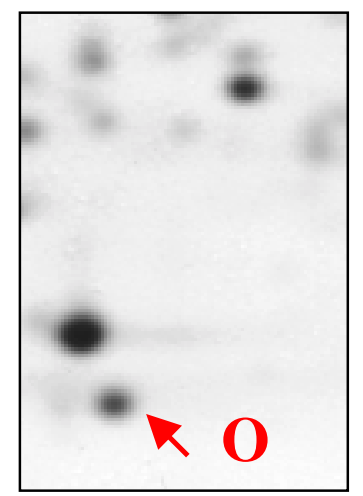

b) Biotin-limitiert

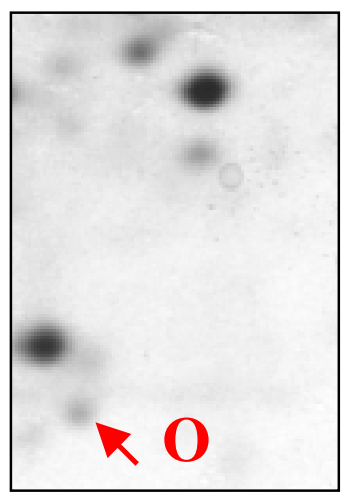

Abb. 10 Ausschnittsvergrößerung zur Darstellung des Proteins O

Die Ausschnitte stammen aus Gelen der Proteinextrakte Biotin-supplementierter Kulturen a) und Biotin-limitierter Kulturen b) des pI-Bereiches 4-7. Das Protein O konnte bisher nicht eindeutig identifiziert werden, zeigte aber Ähnlichkeiten zu einem Chromosomen-Trennungs-Protein aus Lactococcus lactis subsp. lactis (siehe Tab. 8). 


\section{a) Biotin $40 \mathrm{nM}$}

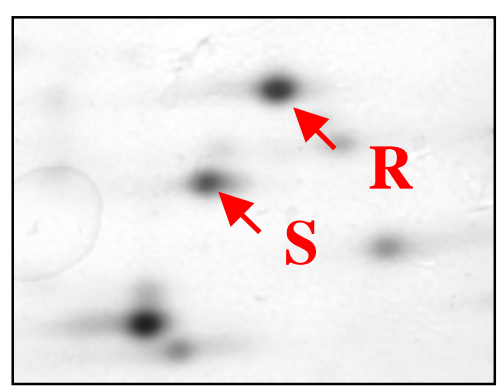

b) Biotin-limitiert

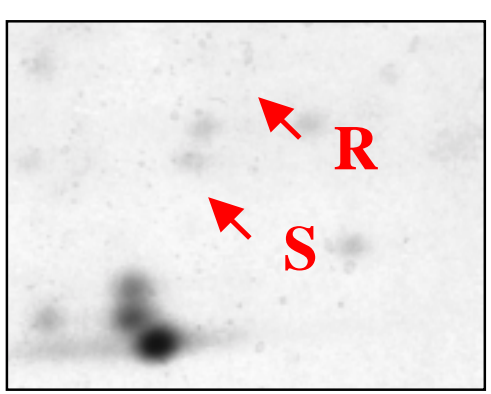

Abb. 11 Ausschnittsvergrößerung zur vergleichenden Darstellung der Proteine $\mathbf{R}$ und $S$

Die Ausschnitte stammen aus Gelen der Proteinextrakte Biotin-supplementierter Kulturen a) und Biotin-limitierter Kulturen b) des pI-Bereiches 4,5-5,5. Beide Proteine konnten nicht identifiziert werden, zeigten aber Ähnlichkeiten zu einem Protein zur Initiation der Replikation des Plasmids aus Bacillus subtilis (Protein $\mathrm{R}$ ) und $\mathrm{zu}$ einem hypothetischem Protein aus Staphylococcus aureus subsp. aureus Mu50 (Protein S)(siehe Tab. 8).

\subsubsection{Auswertung der MALDI-TOF-MS-Analyse}

Bei Aufnahme eines Massenspektrums erzeugt jedes detektierte Ion ein Ereignis an der Position im Spektrum, die seinem $\mathrm{m} / \mathrm{z}$ Wert (Masse/Ladung) entspricht. Im Spektrum selbst ist die relative Intensität der aufsummierten Signale gegen das $\mathrm{m} / \mathrm{z}$ Verhältnis aufgetragen. Aus den Peaks, die im Spektrum auftreten, können die Massen der Peptide abgelesen werden. Die Massen aller Peptide, die nach Analyse einer Proteinprobe auftreten, werden als peptide mass fingerprint (PMF) bezeichnet, was bedeutet, daß die Zusammensetzung der Peptidmassen eines bestimmten Proteins einem Fingerabdruck gleicht. Zur Identifikation der Proteine wurden die PMF mit Peptidmassen, die sich theoretisch bei einem Verdau der in Datenbanken gespeicherten Proteinsequenzen ergeben würden, verglichen. Die Datenbankanalyse erfolgte mit Hilfe des Mascot-Programmes (www.matrixscience.com). In die Suchmaske wurden dabei die beobachteten Massen in Form einer Peakliste einer Probe eingegeben. Die Standardeingabeparameter sind in Tabelle 6 wiedergegeben. 
Tab. 6 Standardeingabeparameter des Mascot-Suchprogrammes

\begin{tabular}{|c|c|}
\hline Parameter & Einstellung \\
\hline Enzym & Trypsin \\
\hline missed cleavages ${ }^{1}$ & 1 \\
\hline Suchart & PMF \\
\hline Massenwerte & monoisotopisch \\
\hline Peptidmassentoleranz & $1 \mathrm{Da}$ oder $0.5 \%$ \\
\hline Ladung des Peptides & $\mathrm{MH}^{+}$ \\
\hline fixierte und variable Modifizierungen & ohne \\
\hline Datenbank & NCBInr \\
\hline Proteinmasse & nicht eingeschränkt \\
\hline
\end{tabular}

${ }^{1}$ maximale Anzahl zu erwartender ausgelassener Spaltungsstellen beim Verdau des Proteins

Peaks im vorderen Bereich des Spektrums bis 800 Da wurden aus den Peaklisten entfernt, da diese oft unspezifisch und die selteneren größeren Peptide für eine Identifizierung am aussagekräftigsten sind (Schrattenholz, 2001). In Tabelle 7 sind die Proteine aufgeführt, die nach Biotinzugabe eine erhöhte Expression zeigten und identifiziert werden konnten. Dabei wurden die Proteine als identifiziert eingestuft, wenn unter Standardbedingungen mit dem Mascot-Suchprogramm ein signifikanter Score-Wert erreicht wurde. Dieser lag bei den gewählten Suchbedingungen bei 66. Das entsprechende Protein wurde in der $S$. meliloti Datenbank (http://sequence.toulouse.inra.fr/meliloti.html) ermittelt, einem theoretischem tryptischen Verdau mit dem Programm peptidemass (http:// www.expasy.ch/ tools/peptide-mass.html) unterzogen und die entstehenden Peptidmassen mit den Peaklisten und den Spektren verglichen. Außerdem wurden die theoretischen Massen und pI-Werte, der nach dem Suchprozeß erhaltenen Proteine, mit der Position des zugehörigen Proteinspots im Gel verglichen. Desweiteren wurden Proteine mit einem Scorewert unter 66 als identifiziert eingestuft (Proteine D, G, I und J), wenn unter Standardsuchbedingungen als erster Treffer ein S. meliloti Protein gefunden wurde und die Peptidmassen des theoretisch tryptisch verdauten Proteins in den Spektren auftraten. So war beispielsweise das Spektrum von Protein G durch Hintergrundpeaks gekennzeichnet, die möglicherweise durch Verunreinigungen des Probenmaterials verursacht wurden. Das Suchprogramm differenziert nicht zwischen großen Peaks und Hintergrundpeaks. Das bedeutet, daß die zugehörigen Peptidmassen der großen Peaks und der kleinen 
Hintergrundpeaks den gleichen Stellenwert bekommen und Hintergrundpeaks daher die Signifikanz eines Suchergebnisses erniedrigen. So wurde für das Protein G kein signifikanter Treffer gefunden. Betrachtet man jedoch die herausragenden großen Peaks des Spektrums, so tauchten die zugehörigen Peptidmassen alle im theoretisch tryptisch verdauten Protein G auf.

In Abb. 12 ist das Ergebnis einer mit dem Mascot-Programm durchgeführten Suche exemplarisch für Protein-Spot A dargestellt. Balken im linken Teil des Bildes geben die Proteine wieder, die zwar Ähnlichkeiten zu den eingegebenen Proteindaten haben, aber nicht signifikant ähnlich sind. Je höher die Balken sind, desto mehr Proteine wurden gefunden. Balken, die nicht farbig hinterlegt sind, zeigen die Proteine auf, die als signifikant eingestuft wurden. Da nur ein Protein im signifikanten Bereich gefunden wurde ist dieser Balken niedrig.

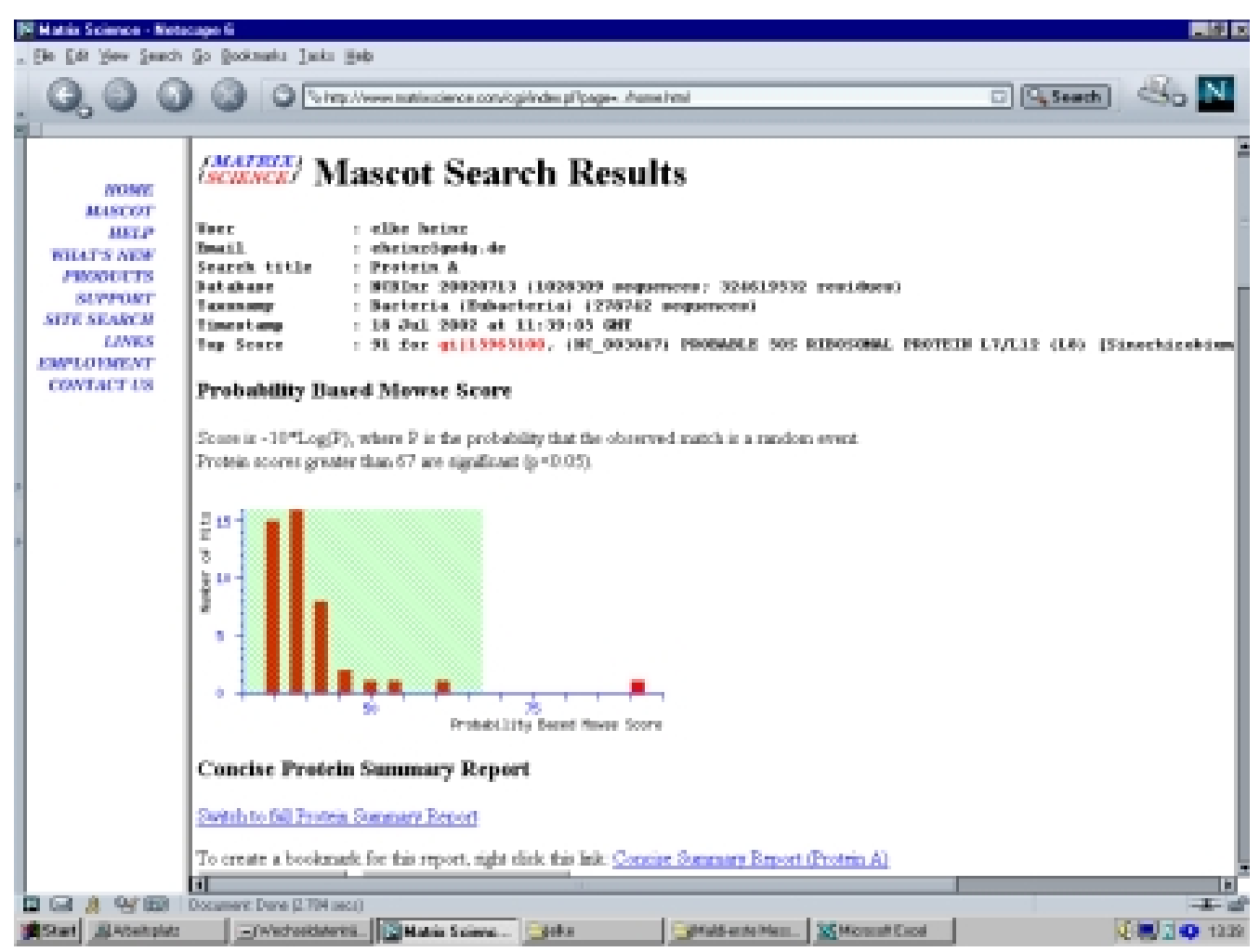

\section{Abb. 12 Darstellung eines Suchresultates des Mascot-Programmes}

Die Abbildung zeigt exemplarisch das Ergebnis der Mascot-Analyse für das Protein A. Nach Eingabe der Peptidmassen in die Suchmaske wurde ein Protein -das ribosomale Protein L7/L12 aus S. meliloti- mit einem Score-Wert von 91 signifikant identifiziert. Nicht signifikante Proteine sind farblich hinterlegt. 


\subsubsection{Identifizierte Proteine aus $S$. meliloti mit erhöhter Expression nach Biotinsupplementation}

In ihrer Expression durch Biotin regulierte Proteine sind in Tabelle 7 unter Angabe der theoretisch berechneten Massen und pI-Werte zusammengefaßt. Angegeben wurden die entsprechende Bezeichnung der Proteine oder der ORF-Nummern.

Bei Protein A handelte es sich das um 50S ribosomales Protein L7/L12. Dies deutet darauf hin, daß die Proteinsynthese nach Biotinsupplementation erhöht war.

Die Proteine B und C wurden beide als ORF [SMc02283] identifiziert. Blast-Analysen der Proteinsequenz zeigten, daß dieser ORF Ähnlichkeiten zu CopC aus Agrobacterium tumefaciens C58 (64\% identische Aminosäuren und $81 \%$ ähnliche Aminosäuren) und Aeromonas veronii (37\% identische AS und $51 \%$ ähnliche AS) aufweist. CopC-Proteine sind Kupfer bindende Proteine, die zusammen mit anderen Genprodukten mikrobieller cop-operons an der Resistenz gegenüber Kupfer beteiligt sind und auch Kupfer

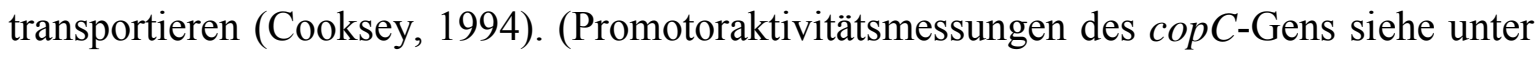
3.2.6). Beide Proteine zeigten im SDS-Gel dieselbe Masse und einen schwach voneinander abweichenden pI-Wert, was auf eine natürliche oder durch die Aufbearbeitung artifizielle Modifikation hindeutet, durch die der pI-Wert des Proteins geändert wurde (z.B. Phosphorylierung). Durch Scan-Prosite-Analyse wurden mehrere potentielle Phosphorylierungsstellen durch Proteinkinasen gefunden (www.expasy.ch/cgibin/scanprosite). Bei Protein D handelte es sich um das RpoZ-Protein (EC 2.7.7.6), der Omega-Untereinheit der RNA-Polymerase. Dies zeigt, daß die Transkription nach Biotinsupplementation verstärkt wird. Die Proteine E, F, H, und I wurden als Komponenten von ABC-Transportern identifiziert. Es handelte sich bei allen vier Proteinen um Bindeproteine für verschiedene Moleküle wie L-Aminosäuren oder Zucker. Protein G wurde als 2-Keto-3-Desoxy-6-Phosphogluconat-Aldolase, einem Schlüsselenzym des Entner-Doudoroff Weges, identifiziert. Es katalysiert die Spaltung von 2-Keto3-Desoxy-6-Phosphogluconat zu Pyruvat und Glycerinaldehyd-3-Phosphat. Protein J konnte als konserviertes hypothetisches Protein identifiziert werden. Blast-Analysen zeigten, daß das Protein aus S. meliloti 77 \% Identität zu einem Protein aus Agrobacterium tumefaciens und 53 \% Identität zu einem Protein aus Agrobacterium vitis hat. Bei diesen beiden Organismen ist die Funktion des Proteins bisher ebenso unbekannt wie bei $S$. meliloti. Proteine K und L wurden beide als Leucin spezifisches Bindeprotein (Vorläufer) LivK identifiziert. Wie auch bei den Proteinen B und C beobachtet, liefen Proteine K und L auf gleicher Höhe im SDS-Gel und unterschieden sich durch den pI-Wert (siehe Abb. 9), 
was auf Modifikationen schließen läßt. Auch in der Proteinsequenz des LivK Proteins konnten durch Scan-Prosite-Analyse potentielle Phosphorylierungsstellen gefunden werden. LivK gehört zu den bakteriellen Aminosäuren bindenden Proteine und ist am spezifischen Transport verzweigter Aminosäuren beteiligt.

Tab. 7 Proteine aus $S$. meliloti, deren Expression durch Zugabe von 40 nM Biotin signifikant erhöht wurde

\begin{tabular}{|c|c|c|c|c|}
\hline Protein & $\begin{array}{c}\text { Identifikation } \\
\text { ORF/Bezeichnung }\end{array}$ & Funktion & $\begin{array}{l}\text { Score } \\
- \text { Wert }^{2}\end{array}$ & $\begin{array}{c}\mathrm{pI} / \\
\mathrm{Mr}[\mathrm{Da}]^{3}\end{array}$ \\
\hline $\mathrm{A}$ & $\begin{array}{l}\text { 50S ribosomales Protein L7/L12, } \\
\text { [SMc01318/RplL] }\end{array}$ & Translation & 91 & $4,79 / 12827$ \\
\hline $\mathrm{B} / \mathrm{C}$ & $\begin{array}{l}\text { CopC, [SMc02283] } \\
\text { Anmerkung: Im SDS-Gel B und C mit gleichen Massen; } \\
\text { pI-Wert verschieden; Modifikation }\end{array}$ & $\begin{array}{l}\text { Kupfer- } \\
\text { bindendes } \\
\text { Protein }\end{array}$ & $88 / 80$ & $5,30 / 17182$ \\
\hline $\mathrm{D}$ & $\begin{array}{l}\omega \text {-UE DNA-abhängige RNA-Polymerase, } \\
\text { [SMc02408/RpoZ] }\end{array}$ & Transkription & 63 & $4,19 / 14893$ \\
\hline $\mathrm{E}$ & $\begin{array}{l}\text { generelles ABC-Transporter-Bindeprotein für L- } \\
\text { Aminosäuren, periplasmatisch, } \\
{[\mathrm{SMc} 02118 / \mathrm{AapJ}]}\end{array}$ & Transport & 70 & $5,00 / 36833$ \\
\hline $\mathrm{F}$ & $\begin{array}{l}\text { ABC-Transporter-Bindeprotein für Zucker, } \\
\text { periplasmatisch, } \\
\text { [SMb20484] }\end{array}$ & Transport & 87 & $5,40 / 34865$ \\
\hline G & $\begin{array}{l}\text { KHG-KDPG Aldolase, } \\
\text { [SMc03153/Eda2] }\end{array}$ & $\begin{array}{l}\text { Hexose- } \\
\text { Abbau }\end{array}$ & 56 & $4,73 / 21626$ \\
\hline $\mathrm{H}$ & $\begin{array}{l}\text { ABC-Transporter-Bindeprotein, } \\
\text { periplasmatisch, [SMc02774] }\end{array}$ & Transport & 67 & $5,06 / 34010$ \\
\hline I & $\begin{array}{l}\text { ABC-Transporter-Bindeprotein für Glycerol-3-Phosphat, } \\
\text { periplasmatisch (Vorläufer), [SMb20416/UgpB] }\end{array}$ & Transport & 60 & $5,20 / 46612$ \\
\hline $\mathrm{J}$ & konserviertes hypothetisches Protein, [SMb20025] & unbekannt & 54 & $5,34 / 34080$ \\
\hline $\mathrm{K} / \mathrm{L}$ & $\begin{array}{l}\text { Leucin-spezifisches Bindeprotein (Vorläufer), } \\
\text { [SMc01946/LivK] } \\
\text { Anmerkung: Im SDS-Gel K und L mit gleichen Massen } \\
\text { pI-Wert verschieden; Modifikation }\end{array}$ & Transport & $74 / 76$ & $5,00 / 39024$ \\
\hline
\end{tabular}

\footnotetext{
${ }^{1}$ S. meliloti Kulturen wurden 64-90 h nach Biotinsupplementation geerntet

${ }^{2}$ unter Standard-Eingabeparameter ermittelter Score-Wert; Score-Werte ab 66 gelten als signifikant (vgl. Erläuterung im Text)

${ }^{3}$ anhand der Proteinsequenz theoretisch berechnete pI-und Mr-Werte, die mit der Position der Protein-Spots im Gel verglichen wurden
} 
Desweiteren wurden 3 Proteine massenspektrometrisch analysiert und identifiziert, deren Expression unter den getesteten Versuchsbedingungen nicht signifikant verändert war. Es handelte sich um das Chaperonin A [GroES oder SMc00912], einer NukleosidDiphosphat-Kinase [SMc00595], und einem 5'-Nukleotidase-Vorläufer-Protein [SMc01228]. Diese Proteine dienten als interne Markerproteine zur Größen- und pI-WertBestimmung. Zwei dieser Proteine konnten bereits durch andere Arbeitsgruppen identifiziert werden (GroES-Protein und Nukleosid-Diphosphat-Kinase; Guerreiro et al., 1999). Einige Proteine, die eine erhöhte Expression nach Biotinzugabe aufwiesen, wurden durch MALDI-TOF-MS bisher nicht eindeutig als $S$. meliloti Proteine identifiziert. Bei den in der Tabelle 8 zusammengefaßten Proteinen konnte kein signifikanter Score-Wert erreicht werden. Die ersten drei als nicht signifikant eingestuften Proteine der Liste, bzw. Proteine aus nahe verwandten Organismen wie Agrobacterium tumefaciens oder M. loti, die das Suchprogramm als Ergebnis lieferte, wurden dennoch daraufhin überprüft, ob es entsprechende Proteine in S. meliloti gab. Traten in der S. meliloti Datenbank keine entsprechenden Proteine dem Namen nach auf, wurde mit Hilfe des blastp-Programmes nach ähnlichen Proteinen gesucht und die Position im Gel überprüft. In der folgenden Tabelle sind jeweils nur die Proteine aufgeführt, die an erster Stelle nach Analyse mit dem Mascot-Suchprogramm in der Liste der besten aber nicht signifikanten Treffer angezeigt wurden. 
Tab. 8 Proteine, mit erhöhter Expression nach Biotinzugabe, die nicht eindeutig identifiziert werden konnten

\begin{tabular}{|c|c|c|c|}
\hline Protein & beste Übereinstimmung zu & $\begin{array}{l}\text { Vergleich mit } S . \text { meliloti } \\
\text { Datenbank }^{1}\end{array}$ & $\begin{array}{l}\text { Score- } \\
\text { Wert }^{2}\end{array}$ \\
\hline M & ABC-Transporter-Bindeprotein [M. loti $]$ & $\begin{array}{l}44 \text { \% Identität/ } 61 \% \text { Ähnlichkeit zu } \\
\text { LEU/ILE/VAL-bindendes Protein aus } \\
\text { S. meliloti [SMc00078 oder LivJ] }\end{array}$ & 46 \\
\hline $\mathrm{N}$ & $\begin{array}{l}\text { Guanylat Kinase } \\
\text { [Streptococcus pyogenes M1 GAS] }\end{array}$ & $\begin{array}{l}43 \% \text { Identität/ } 62 \% \text { Ähnlichkeit zur } \\
\text { Guanylat-Kinase aus S. meliloti, }\end{array}$ & 50 \\
\hline $\mathrm{O}$ & $\begin{array}{l}\text { Chromosomen-Trennungs-Protein } \\
\text { [Lactococcus lactis subsp. lactis] }\end{array}$ & $\begin{array}{l}34 \text { \% Identität/ } 58 \text { \% Ähnlichkeit zu } \\
\text { [SMc02801 oder ParB] }\end{array}$ & 53 \\
\hline $\mathrm{P}$ & Malat-Dehydrogenase $[E$. coli $]$ & $\begin{array}{l}30 \% \text { Identität/ } 49 \% \text { Ähnlichkeit zur } \\
\text { Malat-Dehydrogenase aus S. meliloti }\end{array}$ & 48 \\
\hline Q & MucB-Protein [Salmonella typhimurium] & $\begin{array}{l}\text { kein homologes Protein in S. meliloti } \\
\text { vorhanden }\end{array}$ & 53 \\
\hline $\mathrm{R}$ & $\begin{array}{l}\text { Protein zur Initiation der Plasmidreplikation } \\
\text { [Bacillus subtilis] }\end{array}$ & $\begin{array}{l}\text { kein homologes Protein in S. meliloti } \\
\text { vorhanden }\end{array}$ & 46 \\
\hline $\mathrm{S}$ & $\begin{array}{l}\text { hypothetisches Protein [Staphylococcus } \\
\text { aureus subsp. aureus] }\end{array}$ & $\begin{array}{l}\text { kein homologes Protein in S. meliloti } \\
\text { vorhanden }\end{array}$ & 56 \\
\hline
\end{tabular}




\subsection{Konstruktion von Reportergenfusionen}

Neben der Analyse Biotin-regulierter Proteine durch 2D-Gelelektrophorese wurden zur Identifikation von weiteren Genen, deren Expression durch Biotin beeinflußt wird, in diesem Teil der Arbeit Promotoraktivitäten ausgewählter Gene in An- oder Abwesenheit von Biotin untersucht. Dabei wurden 8 Gene anhand der vorliegenden Genomsequenz ausgesucht. Entscheidend bei der Auswahl war die Beteiligung dieser Gene in verschiedenen Bereichen des Stoffwechsels und der Regulation, nämlich bei der Phospholipidsynthese, der Nodulation und Autoinduktion. Die Sequenzen der Gene wurden aus den S. meliloti Datenbanken erhalten (http://sequence.toulouse.inra.fr) und die Transkriptionsrichtung ermittelt. Die stromaufwärts liegenden Bereiche der verschiedenen ORFs mit den putativen Promotorregionen wurden durch PCR unter Verwendung der PfuPolymerase amplifiziert. Dabei enthielten die Fragmente auch den 5'-Bereich des zu untersuchenden Gens und den 3'-Bereich des unmittelbar stromaufwärts gelegenen Gens. Die Primer wurden so gewählt, daß an das 5'-Ende der putativen Promotorregion eine PstISchnittstelle und an das 3'-Ende eine XbaI-Schnittstelle eingefügt wurde. Diese XbaI-PstIFragmente wurden in den ebenso geschnittenen Vektor pBK3 inseriert, so daß die putativen verschiedenen Promotorregionen unmittelbar stromaufwärts einer gusAReportergenkassette lokalisiert waren (Abb. 13). Bei den hergestellten Reportergenfusionen handelte es sich um Transkriptionsfusionen, da das gusA-Gen eine eigene ribosomale Bindestelle besitzt. Nach Mobilisation der Konstrukte nach S. meliloti durch den Donorstamm E. coli S17-1 wurden die relativen gusA-Aktivitäten nach Anzucht unter Biotin-limitierenden Bedingungen und Biotinsupplementation $(40 \mathrm{nM})$ bestimmt (siehe 2.19). Dabei wurden jeweils 3 Parallelkulturen in den verschiedenen Medien angezogen und während verschiedener Wachstumsphasen gemessen. Als Vorkultur diente eine bereits unter Biotin-limitierenden Bedingungen angezogene Kultur.

In der Tabelle 9 sind alle getesteten putativen Promotorregionen zusammengefaßt. Um auszuschließen, daß der leere pBK3 Vektor bereits eine von der Biotinkonzentration im Medium abhängige Grundaktivität besitzt, wurde das Plasmid ohne inserierte Promotorregion nach S. meliloti mobilisiert und die ß-Glucuronidaseaktivitäten zur Kontrolle bestimmt. Die Mittelwerte dieser Messungen lagen mit 398 rel. ß-Glucuronidaseeinheiten für die Biotin-supplementierten Kulturen im selben Bereich wie die der Biotin-limitierten Kulturen (387 rel. ß-Glucuronidaseeinheiten). 
Tab. 9 Übersicht über die untersuchten putativen Promotorregionen

\begin{tabular}{|c|c|c|}
\hline $\begin{array}{l}\text { Promotorregion } \\
(\mathrm{Gen} / O R F)\end{array}$ & Funktion & Fragmentgröße (bp) \\
\hline \multirow[t]{3}{*}{ nodD1 } & übergeordneter & 324 \\
\hline & Transkriptionsregulator & \\
\hline & Nodulation & \\
\hline \multirow{3}{*}{ nodD3-kurz/ nodD3-lang } & übergeordneter & $867 / 1190$ \\
\hline & Transkriptionsregulator & \\
\hline & Nodulation & \\
\hline $\sin I$ & Autoinduktor-Synthase & 267 \\
\hline \multirow[t]{2}{*}{$\sin R$} & HSL-abhängiger & 401 \\
\hline & Transkriptionsregulator & \\
\hline$p l s X$ & Phospholipid Biosynthese & 273 \\
\hline bioM [SMc00962] & $\begin{array}{l}\text { putativer ABC-Transporter bioM } \\
\text { aus dem bioMNB-Operon }\end{array}$ & 333 \\
\hline SMc04882 & putativer Transkriptionsregulator & 176 \\
\hline $\operatorname{copC}[\mathrm{SMc} 02283]$ & $\begin{array}{l}\text { Kupfer bindendes Protein/ Kupfer- } \\
\text { Resistenz }\end{array}$ & 253 \\
\hline
\end{tabular}




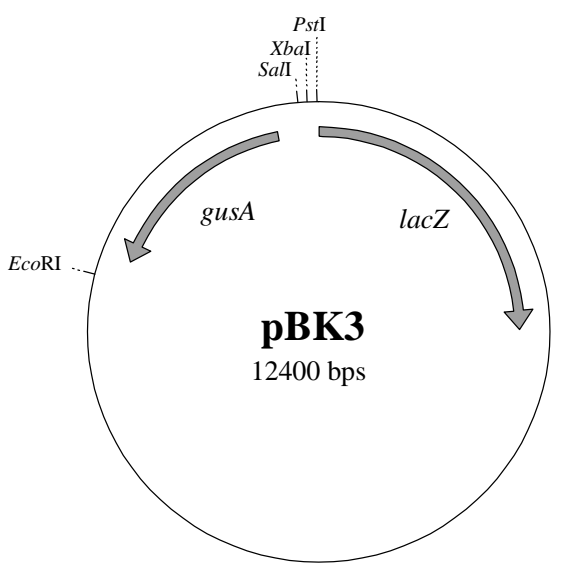

Amplifikation der putativen

Promotorregionen mit terminalen

3'-XbaI und 5'-PstI Schnittstellen

durch PCR mittels $P f u$-Polymerase
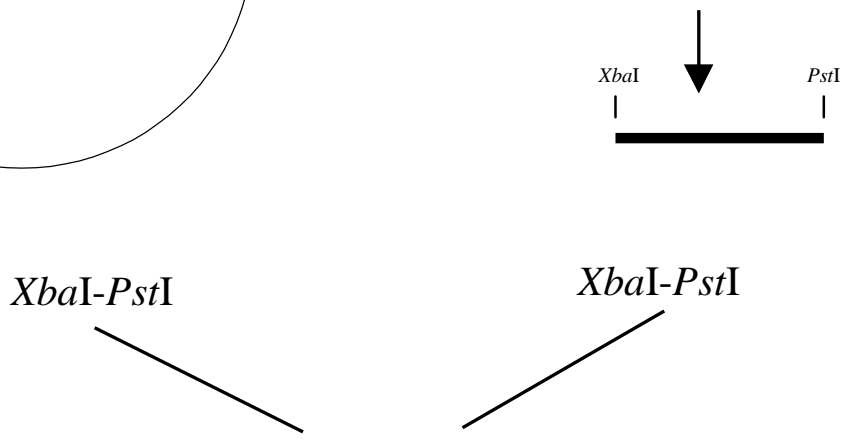

Ligation

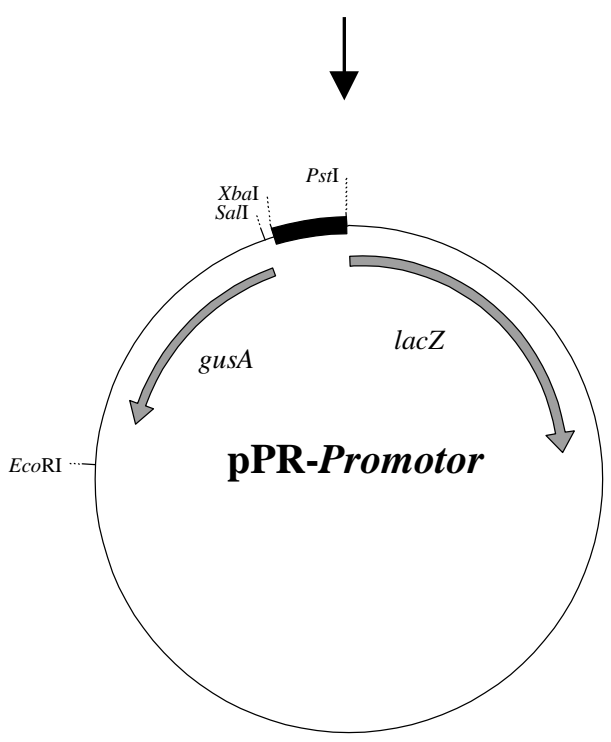

Abb. 13 Darstellung der generellen Klonierungsstrategie zur Konstruktion von Promotorfusionen der in Tabelle 9 aufgeführten Gene im Replikon pBK3 Die putativen Promotorregionen wurden als XbaI-PstI-Fragmente nach PCRAmplifikation in 5'-Richtung des gusA-Reportergens des Vektors pBK3 kloniert. Alle Konstrukte wurden durch Sequenzierung überprüft. 


\subsubsection{Aktivitätsmessungen der nodD1- und nodD3-Promotorregionen}

Rhizobielle nod-Genprodukte sind an der Bildung des Nod-Faktors (Nodulationsfaktor) beteiligt, der die frühe Antwort der Wirtspflanze während der Etablierung der Symbiose induziert. Die Expression der nod-Gene ist nicht nur von Flavonoiden und anderen von der Wirtspflanze sekretierten Komponenten abhängig, sondern wird auch durch NodD induziert, einem Regulatorprotein aus der Familie der LysR-Typ-Transkriptionsaktivatoren. In S. meliloti 1021 gibt es drei NodD Proteine, NodD1, NodD2 und NodD3. Während NodD1 und NodD2 die Expression der Nodulationsgene in Anwesenheit eines pflanzlichen Induktors aktivieren, erfolgt die Expression der nod-Gene durch NodD3 unabhängig davon. Auch Biotin ist eine der Verbindungen, welche die Pflanze über die Wurzel in den Boden abgibt und die Wachstum von S. meliloti in der Rhizosphäre fördert. Daher sollte analysiert werden, ob das Vorhandensein von Biotin möglicherweise einen Einfluß auf die Expression der Regulatorproteine NodD1 und NodD3 ausübt und somit auch an der frühen Entwicklung der Symbiose beteiligt ist. Es wurde untersucht, ob die Expression der Transkriptionsregulatoren auch unter Biotinlimitierung möglich ist.

Für die Analyse des nodD1-Promotors wurde ein 324 bp umfassendes stromaufwärts gelegenes und den 5'-Bereich des nodD1-Gens überlappendes Fragment amplifiziert und in den Vektor pBK3 kloniert (siehe Primer Tab. 3). Das resultierende Plasmid wurde als pPR-nodD1 bezeichnet. Da bereits bekannt war, daß das nodD3-Gen zwei Transkriptionsstartpunkte besitzt, wurden zwei verschieden lange Fragmente amplifiziert und kloniert. In pPR-nodD3-kurz war ein 867 bp Fragment mit dem ersten Transkriptionsstartpunkt inseriert worden, und in pPR-nodD3-lang ein 1189 bp großes Fragment mit beiden Transkriptionsstartpunkten (siehe Primer Tab. 3). Zusätzlich zur Bestimmung der rel. ß-Glucuronidaseeinheiten in Abhängigkeit von Biotin im Medium wurden auch Messungen durchgeführt, bei denen der pflanzliche Induktor Luteolin (Endkonzentration 3,5 nM) zu den Kulturen gegeben wurde.

Abb. 14 zeigt die Meßwerte für pPR-nodD1. Unter den getesteten Bedingungen war der Promotor immer auf relativ hohem Niveau angeschaltet. Gegenüber der logarithmischen Wachstumsphase waren die Werte, die in der stationären Wachstumsphase gemessen wurden, leicht erhöht. Unter Biotin-limitierenden Bedingungen (schwarze Balken) oder Biotinsuffizienz (graue Balken) waren die gusA-Aktivitäten in keiner Wachstumsphase signifikant verschieden. Nach Messungen der gusA-Aktivität in der Stationärphase wurde Luteolin zu den Kulturen hinzugefügt, für weitere 45 min bei $30{ }^{\circ} \mathrm{C}$ unter Schütteln inkubiert und erneut gemessen. Eine signifikante $\mathrm{Zu}$ - oder Abnahme konnte hier nicht 
gemessen werden (Abb. 14). Auch Zugabe von Luteolin beim Animpfen der Zellen oder zu Beginn der logarithmischen Wachstumsphase hatte keinen Effekt auf die Aktivität (nicht gezeigt).

A

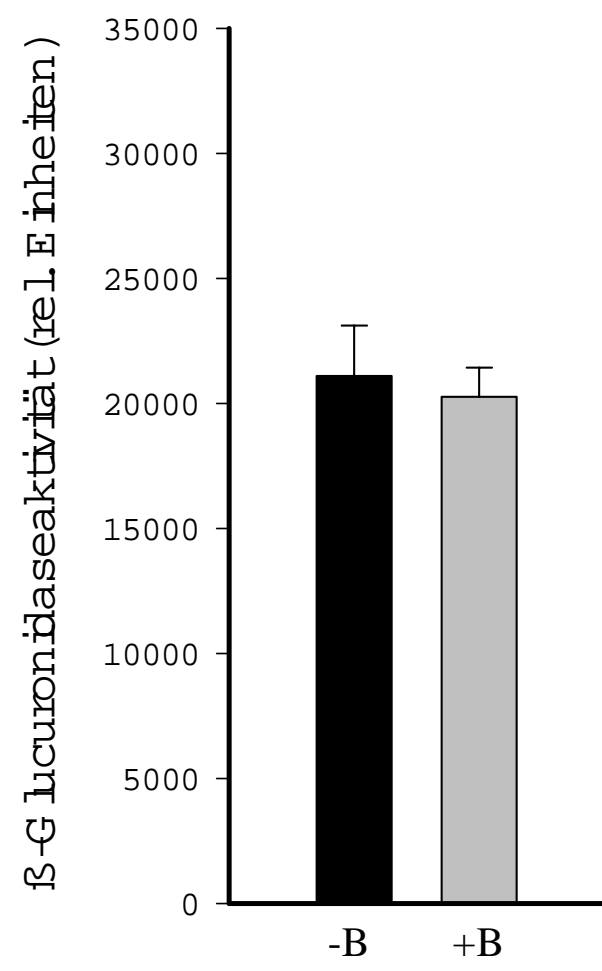

B

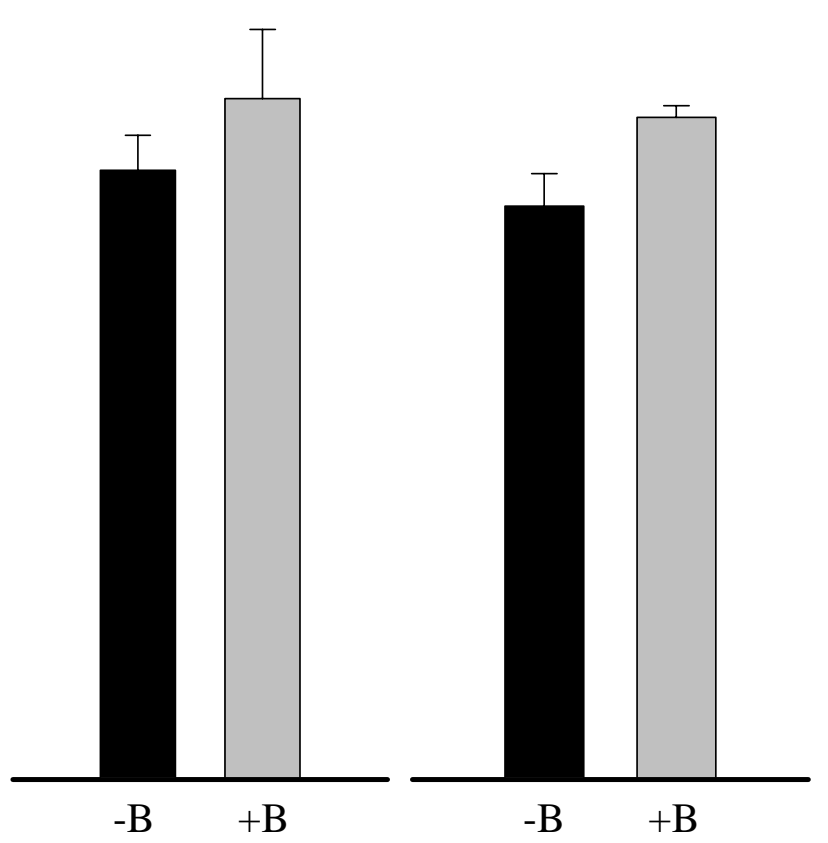

Abb. 14 Darstellung der relativen B-Glucuronidaseaktivität des pPR-nodD1 Konstruktes in S. meliloti 1021

Unter A sind die Meßwerte der logarithmischen Wachstumsphase und unter $\mathbf{B}$ der stationären Wachstumsphase dargestellt. C zeigt die Ergebnisse der Messungen, die nach 45 minütiger Inkubation von Stationärphasezellen nach Luteolinzugabe angefertigt wurden. Alle Werte stellen Mittelwerte aus drei parallel durchgeführten Messungen mit Standardabweichungen dar. -B: Kulturen wurden unter Biotinlimitierung angezogen; +B: Kulturmedium enthielt Biotin in einer Endkonzentration von $40 \mathrm{nM}$.

Die Ergebnisse der Untersuchungen des nodD3-Promotors sind in Abb. 15 dargestellt. Die durchschnittlichen Aktivitäten in der stationären Wachstumsphase lagen bei pPR-nodD3lang sowohl unter Biotin-limitierenden Bedingungen (417 zu 274) als auch bei Biotinsuffizienz (363 zu 222) leicht über denen des kurzen Promotorabschnittes. Unter 
Berücksichtigung der Hintergrundaktivität des leeren pBK3 Vektors von 387 (-Biotin) und 389 (+Biotin) ist jedoch davon auszugehen, daß beide Konstrukte unter den getesteten Bedingungen, wie auch in der logarithmischen Wachstumsphase nicht oder nur schwach induziert waren. Zugabe von Luteolin zu Kulturen, die sich in unterschiedlichen Wachstumsphasen befanden, bewirkte keine signifikante Änderung der Expression (nicht gezeigt).

A

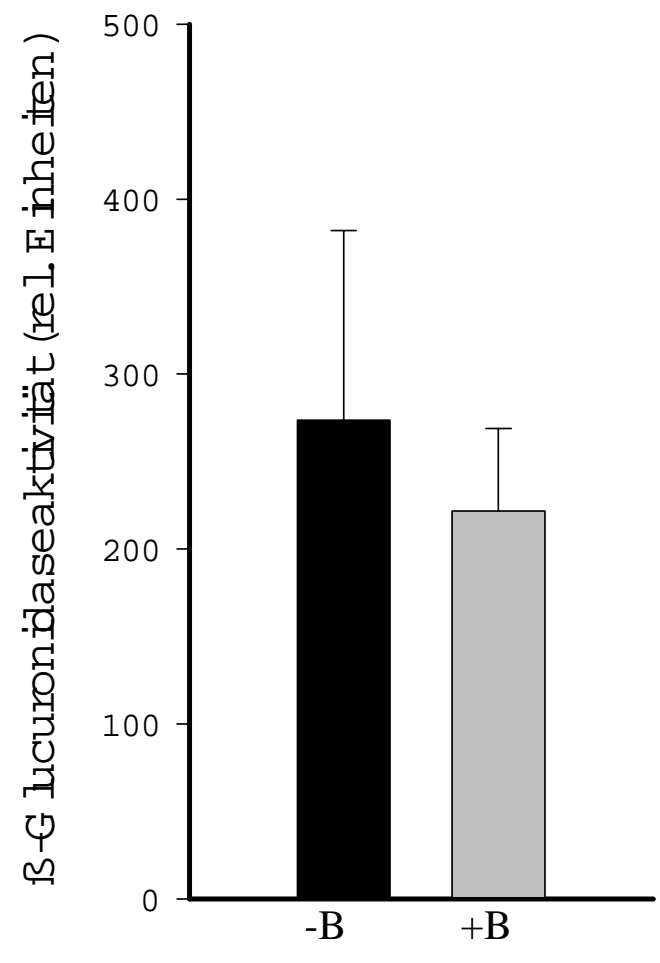

B

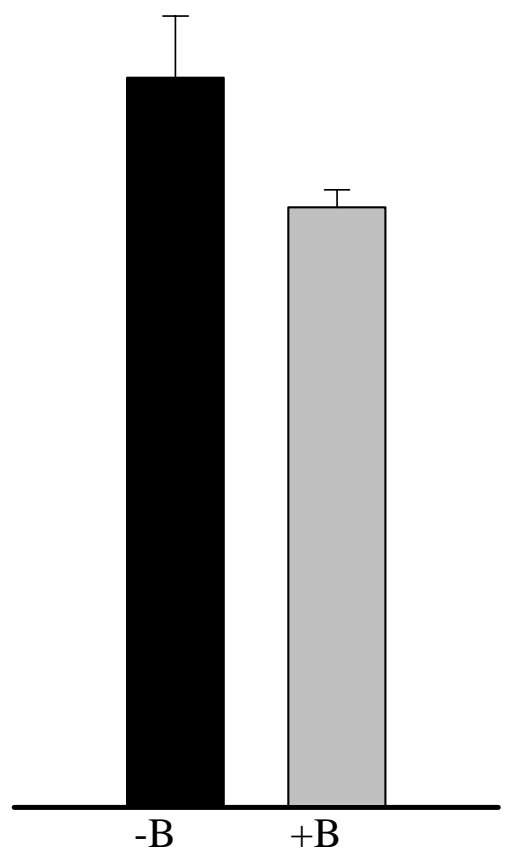

Abb. 15 Darstellung der relativen B-Glucuronidaseaktivität der pPR-nodD3-kurz (A) und pPR-nodD3-lang (B) Konstrukte in S. meliloti 1021

Die Messungen wurden in der stationären Wachstumsphase durchgeführt. Die Daten stellen Mittelwerte aus drei parallel durchgeführten Messungen mit Standardabweichungen dar. -B: Kulturen wurden unter Biotinlimitierung angezogen; +B: Kulturmedium enthielt Biotin in einer Endkonzentration von 40 nM.

\subsubsection{Aktivitätsmessungen der putativen Promotorregion von $O R F$ SMc04882, eines möglichen LysR-Typ-Transkriptionsregulators}

In früheren Arbeiten wurde in S. meliloti das bioS-Gen identifiziert, dessen Expression in der stationären Wachstumsphase durch Biotin induziert wird (Streit und Phillips, 1997). 
Biotinbindestudien zeigten, daß das heterolog in E. coli überexprimierte BioS-Protein nicht direkt Biotin bindet. Auf der Suche nach einem übergeordneten Regulator des bioS-Gens wurde eine Transposonmutagenese in der bioS-Mutante Rm1021-B5 durchgeführt und auf die veränderte Expression des bioS-Gens selektioniert. Bei einer der Transposonmutanten war das Transposon in den $O R F$ SMc04882 gesprungen und das bioS-Gen wurde unter allen getesteten Bedingungen exprimiert, unabhängig vom Biotingehalt des Mediums. Zur Charakterisierung des Gens SMc04882, das Ähnlichkeit zu einem Transkriptionsregulator zeigt, wurde die putative Promotorregion vor die gusA-Reportergenkassette des Vektors pBK3 kloniert (Primer siehe Tab. 3). Die Größe des inserierten Fragmentes betrug 176 bp. Die gusA-Aktivität wurde in Abhängigkeit der Biotinkonzentration im Medium gemessen, um zu untersuchen, ob die Expression des putativen Regulators durch Biotin induziert oder reprimiert werden kann.

Wie Abb. 16 zeigt, wird die Expression nicht durch das Vorhandensein von Biotin im Medium beeinflußt, weder wie hier dargestellt in der stationären Wachstumsphase noch in anderen Phasen des Wachstums (nicht gezeigt). Die Expression des putativen Transkriptionsregulators erfolgte unter den getesteten Bedingungen konstitutiv. 


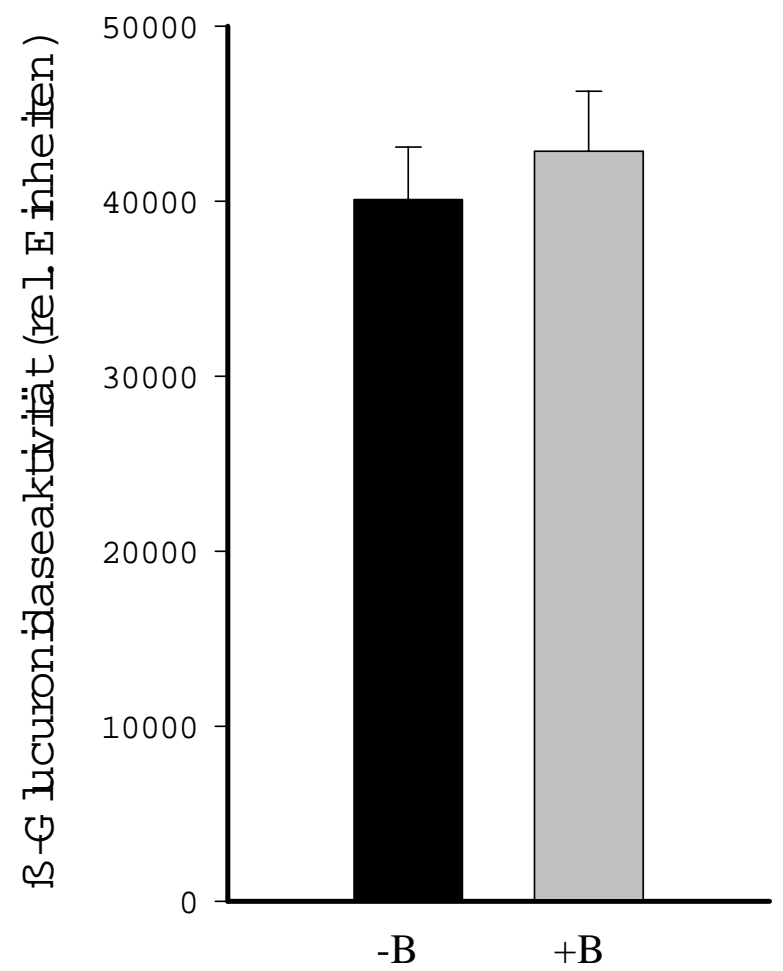

\section{Abb. 16 Darstellung der relativen Glucuronidaseaktivität des pPR-tr4882- Konstruktes in S. meliloti 1021 \\ Sowohl unter Biotin-limitierenden Bedingungen (-B; schwarzer Balken) als auch unter Biotinsuffizienz (+B; grauer Balken) wurden sehr hohe rel. gusA-Werte gemessen, die nicht signifikant verschieden waren. Die Daten stellen Mittelwerte aus drei parallel durchgeführten Messungen mit Standardabweichungen dar.}

\subsubsection{Aktivitätsmessungen der putativen Promotorregion des bioM-Operons}

Mit Hilfe von Transposonmutagenese war in früheren Arbeiten eine S. meliloti-Mutante isoliert worden, die phänotypisch durch stark eingeschränktes Wachstum im nicht Biotinsupplementierten Minimalmedium gekennzeichnet war. Dagegen war bei Anzucht im Biotin-haltigen Minimalmedium kein Unterschied im Wachstumsverhalten zum Wildtyp festzustellen. Bei dieser Mutante (Rm1021-bioM) war das Transposon Tn5B30 in einen ORF inseriert, der als bioM bezeichnet wurde. Sequenzanalysen ergaben, daß BioM Ähnlichkeiten zu ATP-bindenden Proteinen zeigt, die zu der Familie der ABC-Transporter gehören und am Transport von Kobalt beteiligt sind. Neuere Arbeiten zeigten, daß bioMMutanten zwar ${ }^{14} \mathrm{C}$-Biotin im gleichen Maße in die Zelle aufnehmen wie der Wildtyp, jedoch das Biotin schlechter in der Zelle halten können (Entcheva et al., 2002). 
Stromabwärts des bioM-Gens liegt ein weiteres ABC-Transporter-Protein [SMc00963] unmittelbar gefolgt von einem ORF [SMc00964], der Ähnlichkeiten zu dem bioB-BiotinBiosynthesegen aus Agrobacterium tumefaciens zeigt. Das BioB-Protein katalysiert bei Gram-negativen Bakterien den letzten Schritt der Biotinsynthese vom Dethiobiotin zum Biotin. In 3'-Richtung von bioB liegt ein Gen, welches möglicherweise für eine AcetylCoA-Acetyltransferase codiert.

Zur weiteren Charakterisierung des bioM-Gens wurde die putative Promotorregion in 5'Richtung der gusA-Reportergenkassette des Vektors pBK3 kloniert, um so die Abhängigkeit der Expression von Biotin im Anzuchtmedium zu messen. Das klonierte Fragment war 333 bp lang (Primer siehe Tab. 3).

In Abb. 17 sind die relativen B-Glucuronidase-Aktivitäten dreier Parallelkulturen des pPRbioM Konstruktes unter den beiden Bedingungen dargestellt. Die Messungen wurden in verschiedenen Wachstumsphasen durchgeführt und der Zeitpunkt des Überimpfen aus einer nicht Biotin-supplementierten Vorkultur als 0 gesetzt. In Anwesenheit von $40 \mathrm{nM}$ Biotin im Medium wurde eine 2,1-fach (nach 48 h) bis 2,4-fach (nach 120 h) höhere Aktivität gemessen, als unter Biotin-limitierenden Bedingungen. Daher ist davon auszugehen, daß die Expression des bioM-Gens in Anwesenheit von Biotin im Medium leicht induziert wurde. 


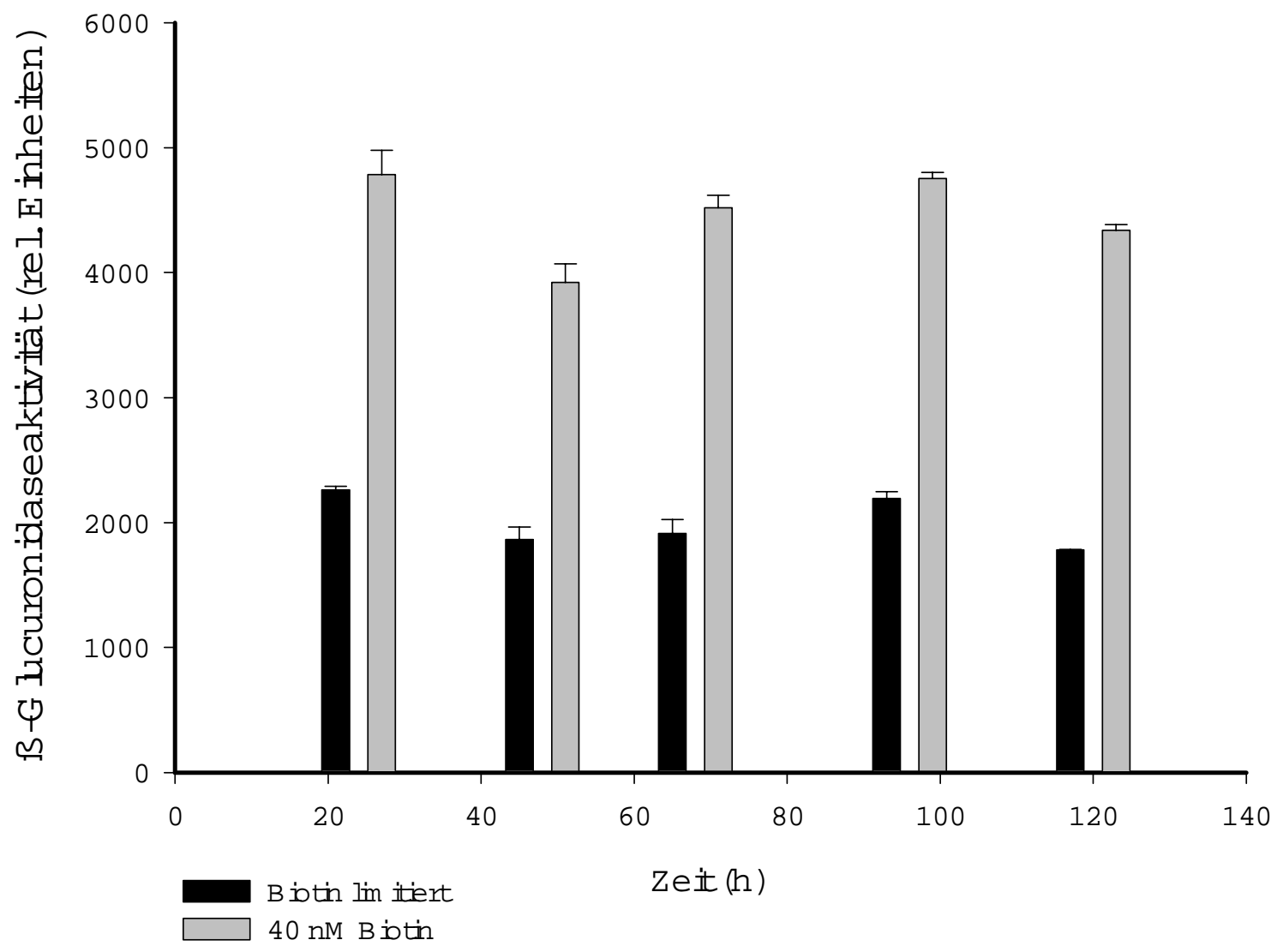

Abb. 17 Relative B-Glucuronidaseaktivität des pPR-bioM-Konstruktes in S. meliloti 1021

Gemessen wurde nach Anzucht unter Biotin-limitierenden Bedingungen (schwarzer Balken) und Biotinsuffizienz (grauer Balken). Wachstum in Anwesenheit von $40 \mathrm{nM}$ Biotin führte zu einer 2,1-2,4-fach erhöhten Expression der Promotorfusion.

\subsubsection{Aktivitätsmessungen der putativen Promotorregion des $p l s X$-Gens}

Das $p l s X$-Gen codiert für ein Protein, welches eine Rolle in der Phospholipid-Biosynthese spielt. Welche genaue Funktion es dabei übernimmt und wie es reguliert wird, ist bisher unbekannt (Kutchma et al., 1999). Während das $p l s X$-Gen bei E. coli das erste Gen des fab-Clusters (fatty acid biosynthesis) ist, das für mehrere Schlüsselenzyme der Fettsäuresynthese codiert (Zhang und Cronan, 1998), liegt es bei S. meliloti anders angeordnet vor. Hier ist es unmittelbar stromaufwärts des fabH-Gens lokalisiert, das für eine B-Ketoacyl-Acyl-Carrier Protein Synthase codiert. Interessanterweise hat dieses Protein Ähnlichkeiten zu dem Protein BioZ aus Mesorhizobium sp. R7A, welches an der Synthese des Biotin-Vorläufers Pimeolyl-CoA beteiligt ist. Unter diesen Voraussetzungen 
schien es möglich, daß Biotin eine regulatorische Funktion auf die Expression des pls $X$ Gens ausübt. Deshalb wurde die putative Promotorregion als 273 bp langes Fragment vor das gusA-Reportergen des Vektors pBK3 kloniert und die Expression des resultierenden Konstruktes pPR-plsX in S. meliloti gemessen. Die rel. B-Glucuronidaseeinheiten, die nach Inkubation der Kulturen im Biotin-limitierten und im Biotin-haltigen Medium in der logarithmischen Wachstumsphase gemessen wurden, sind in Abb. 18 dargestellt. Biotin hatte unter den getesteten Bedingungen keinen Einfluß auf die Expression der putativen $p l s X$-Promotorregion. Auch Messungen, die in der frühen stationären Wachstumsphase durchgeführt wurden, zeigten keine veränderte gusA-Aktivitäten im Vergleich zu denen der logarithmischen Wachstumsphase. Die Expression erfolgte unter den getesteten Bedingungen konstitutiv.

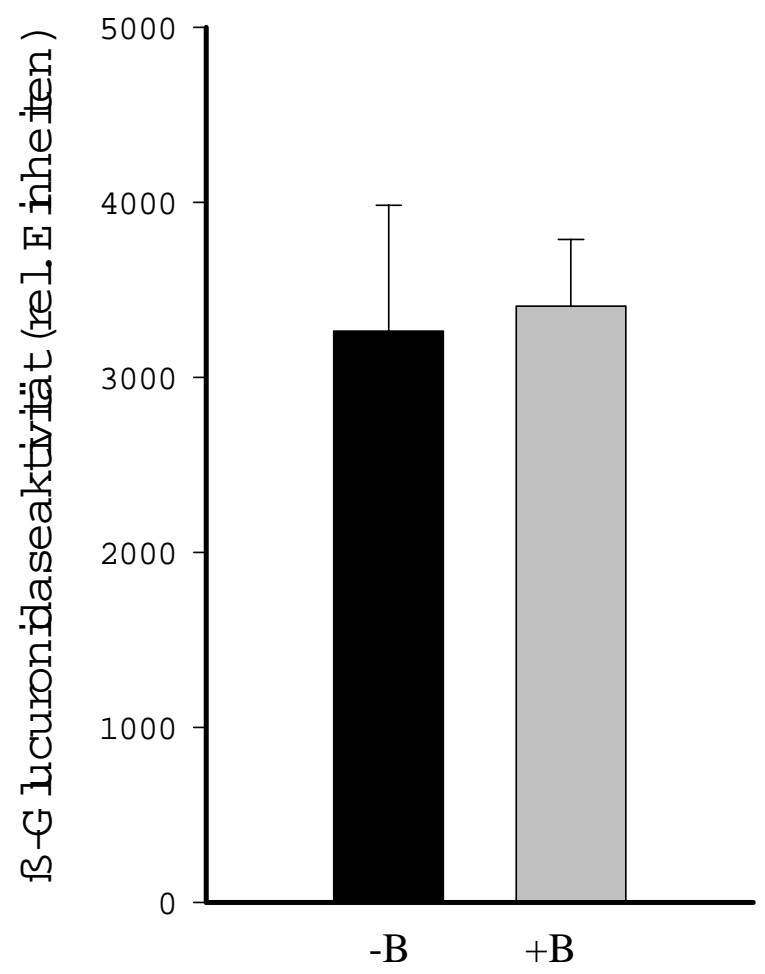

Abb. 18 Relative B-Glucuronidaseaktivität des pPR-plsX-Konstruktes in S. meliloti 1021

Dargestellt sind die gusA-Aktivitäten, die in der logarithmischen Wachstumsphase nach Anzucht im Biotin-limitierten Medium (-B) und Biotinsupplementierten Medium (+B) gemessen wurden. Die Daten stellen Mittelwerte aus drei parallel durchgeführten Messungen mit Standardabweichungen dar. 


\subsubsection{Promotoraktivitätsmessungen einer Autoinduktor Synthase und eines Acyl- Homoserin-Lacton-abhängigen Transkriptionsregulators}

Viele Bakterien können mit Hilfe kleiner Signalmoleküle kommunizieren und ihre Aktivität auf diese Weise koordinieren. Gram-negative Bakterien setzen verschiedene Signalstoffe ein. Gut untersucht sind die Systeme, in denen Acyl-Homoserin-Lactone (Acyl-HSL) synthetisiert werden. Diese als Autoinduktoren bezeichneten Signalmoleküle werden durch die Aktivität eines Enzyms katalysiert, welches als Substrate S-Adenosylmethionin und Intermediate der Fettsäure-Biosynthese verwendet und zur Familie der LuxI-Acyl-HSL Synthasen gehört. Die Acyl-HSL der unterschiedlichen Bakterien variieren in der Länge und Substitution der Acyl-Seitenkette. In der Regel diffundiert der Autoinduktor ins Medium, akkumuliert während des Wachstums und kann nach Überschreiten eines Schwellenwertes an einen spezifischen Rezeptor binden, der zur Familie der LuxR-Transkriptionsregulatoren gehört. Durch die Bindung des Acyl-HSL wird dieser Regulator aktiviert, welches die Repression oder Induktion verschiedener Zielgene zur Folge hat.

Allgemein tritt diese Art der Acyl-HSL-abhängigen Zellkommunikation bei solchen Gramnegativen Bakterien auf, die in Assoziation mit höheren Organismen wie Pflanzen oder dem menschlichen Organismus stehen. Dabei können die Mikroorganismen pathogen sein oder symbiontisch mit dem Wirtsorganismus leben.

Während bereits seit längerem bekannt ist, daß S. meliloti L5-30, S. meliloti 1021 und S. meliloti YA2 ein Acyl-HSL-Molekül produzieren (Shaw, 1997; Gray et al., 1997; Cha et al., 1998), zeigten neuere Arbeiten, daß bis zu sieben verschiedene Autoinduktoren durch S. meliloti 1021 synthetisiert werden (Marketon und Gonzales, 2002). Die durch die AcylHSL regulierten Zielgene und damit die Funktion dieser Moleküle ist bisher noch nicht aufgeklärt. In S. meliloti 1021 wurden die Gene, welche für die Autoinduktor-Synthase und den HSL-abhängigen Transkriptionsregulator codieren, als $\operatorname{sinI}$ und $\sin R$ bezeichnet.

In der Regel ist die Autoinduktion ein Phänomen, welches in Abhängigkeit von zunehmender Populationsdichte steht. In E. coli wurde jedoch beobachtet, daß Homoserinlactone auch unter Nährstoffmangel unabhängig von einer hohen optischen Dichte im Medium gebildet werden und möglicherweise als intrazelluläre Signale von Bedeutung sind. Bei Vibrio harveyi kontrolliert das LuxR Regulator Protein die Synthese des Speicherstoffes Poly-ß-Hydroxybutyrat (PHB) (Miyamoto et al., 1998). Durch Versuche in unserer Arbeitsgruppe konnte gezeigt werden, daß S. meliloti bei Anzucht unter Biotinmangel im Medium große Mengen des Reservepolysaccharids PHB bildet. Da 
Biotinmangel auch limitierend auf rhizobielles Wachstum wirkt und zur Bildung von PHB führt, schien es interessant, den Einfluß von Biotinmangel auf die Expression der Autoinduktor Synthase und des Transkriptionsregulators in S. meliloti zu untersuchen. Diese mögliche Beteiligung sollte mit Hilfe von Promotoraktivitätsmessungen analysiert werden. Daher wurden die beiden putativen Promotorregionen des $\sin I$ - und $\sin R$-Gens in den pBK3 Vektor stromaufwärts des B-Glucuronidase-Reportergens kloniert, wobei das $\operatorname{sinI-Promotorfragment~} 267$ bp und das $\sin R$-Promotorfragment 401 bp groß war (Primer siehe Tab. 3). Die beiden Konstrukte wurden als pPR-sinI und pPR-sinR bezeichnet und nach S. meliloti mobilisiert. Nach Anzucht unter Biotin-limitierenden Bedingungen und unter Biotinsuffizienz in Minimalmedium wurden die relativen B-Glucuronidaseaktivitäten bestimmt. Als Kohlenstoffquelle enthielt das Anzuchtmedium entweder Succinat (9,6 mM) und Glucose $(10,1 \mathrm{mM})$ oder nur Succinat in verschiedenen Konzentrationen.

In Abb. 19 sind die Mittelwerte mit Standardabweichungen der relativen gusA-Aktivitäten dreier Parallelkulturen dargestellt, die nach Anzucht von S. meliloti 1021-pPR-sinI unter Biotin-limitierenden Bedingungen und Biotinsuffizienz in Minimalmedium mit Succinat als einziger Kohlenstoffquelle in verschiedenen Wachstumsphasen gemessen wurden. Es konnte gezeigt werden, daß unter Biotin-limitierenden Bedingungen die rel. gusA-Aktivität während der verschiedenen Messpunkte höher war als unter Biotinsuffizienz; dabei war dieser Effekt in der frühen Wachstumsphase am deutlichsten. $48 \mathrm{~h}$ nach Anzucht aus einer unter Biotin-limitierenden Bedingungen angezogenen Vorkultur war die Expression des Reportergens in den Biotin-limitierten Kulturen um das 4,3-fache höher als in den entsprechenden Kulturen, die 40 nM Biotin enthielten, nach 72 h 1,7-fach und nach 120 h 1,4-fach höher. Generell nahm mit zunehmender Inkubationsdauer die Expression der Gene zu. Ebenso ließ sich bei Anwesenheit von Glucose und Succinat im Medium beobachten, daß Biotinlimitierung zu einer erhöhten Promotoraktivität führte, jedoch war dieser Effekt nicht so gravierend wie im Medium, das nur Succinat als C-Quelle enthielt (Abb. 20). Nach 48 h Wachstum war die rel. gusA-Aktivität, die in den Biotin-limitierten Kulturen gemessen wurde, um den Faktor 2,9 höher gegenüber den Werten, die für die Biotin-supplementierten Kulturen bestimmt wurden. Insgesamt waren die rel. gusAAktivitäten im Minimalmedium, welches beide C-Quellen enthielt, geringer als in Medium welches nur Succinat enthielt. 
A

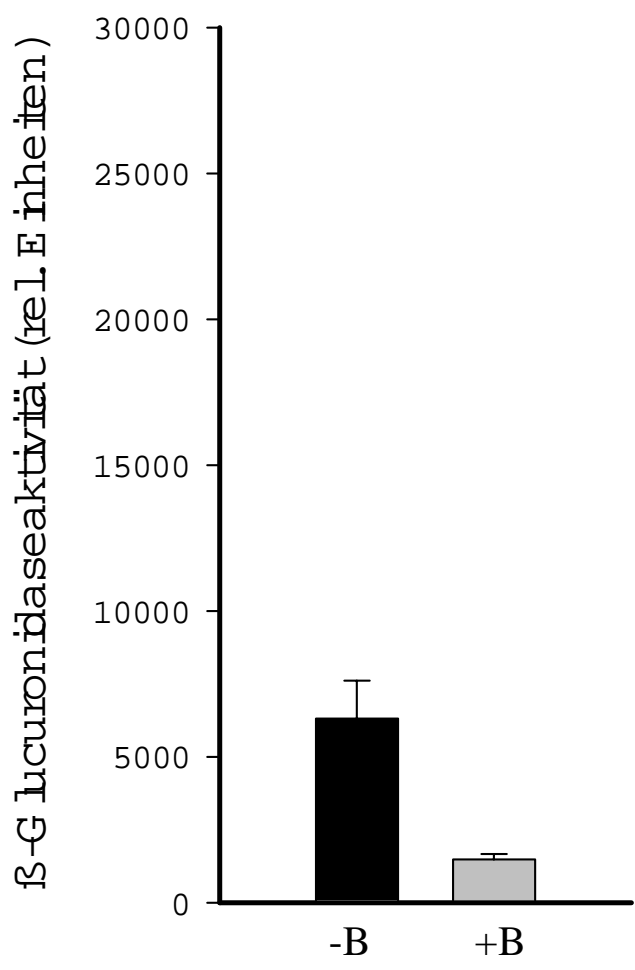

B

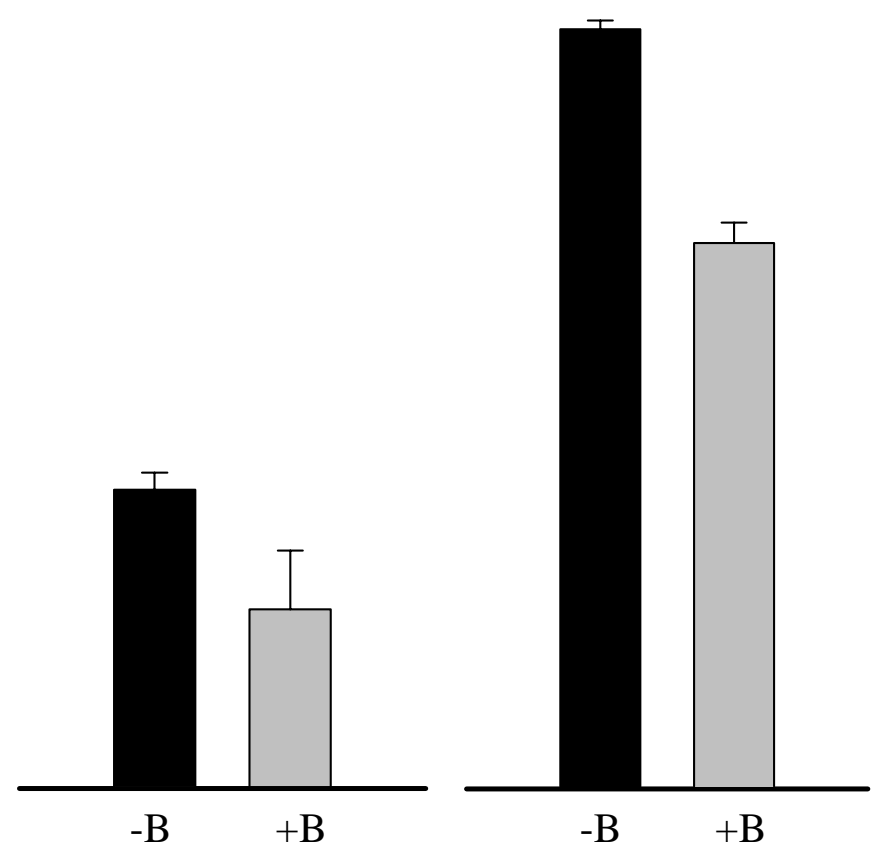

$\mathbf{C}$

Abb. 19 Relative B-Glucuronidaseaktivität des pPR-sinI-Konstruktes in S. meliloti 1021 nach Anzucht in Minimalmedium mit Succinat als C-Quelle

Biotinlimitierung (-B) führte bis $\mathrm{zu}$ einer 4,3-fach erhöhten BGlucuronidaseaktivität im Vergleich zu Kulturen, die unter Biotinsuffizienz (+B) angezogen worden waren. Dargestellt sind die Mittelwerte inklusive ihrer Standardabweichungen der Meßwerte aus jeweils drei Parallelkulturen nach (A) $48 \mathrm{~h},(\mathbf{B}) 72 \mathrm{~h}$ und (C) $120 \mathrm{~h}$ Anzucht in Minimalmedium mit Succinat als einziger Kohlenstoff-Quelle. 
A

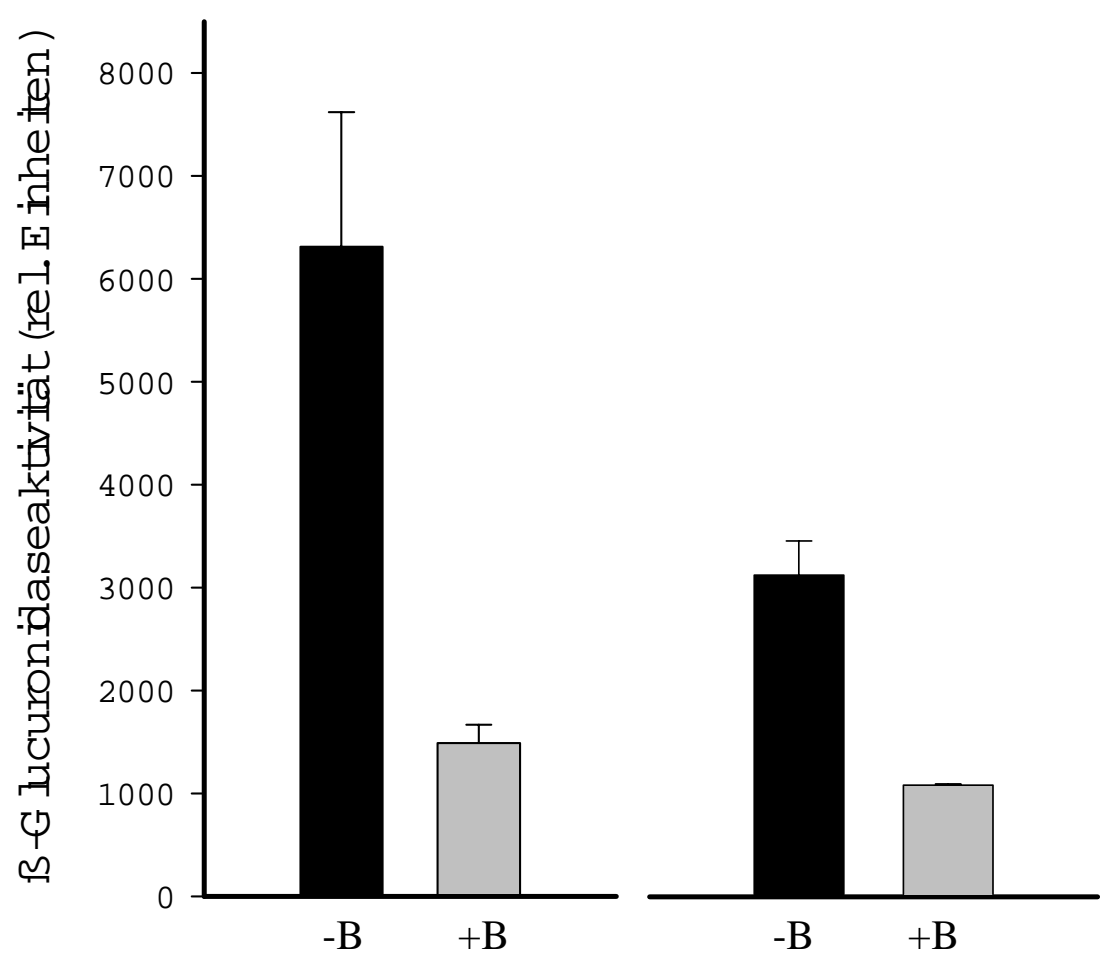

Abb. 20 Relative B-Glucuronidaseaktivität des pPR-sinI-Konstruktes in S. meliloti 1021 nach Anzucht in Minimalmedium mit (A) Succinat als C-Quelle und (B) Succinat und Glucose als C-Quellen

Anzucht von S. meliloti unter Biotin-limitierenden Bedingungen (-B) führte in beiden Medien zu einer erhöhten B-Glucuronidasaktivität im Vergleich zu Kulturen, die unter Biotinsuffizienz $(+\mathrm{B})$ angezogen wurden. Unter Biotinlimitierung mit Succinat als einziger C-Quelle (A) konnte eine 4,3-erhöhte Aktivität und mit Succinat und Glucose als C-Quellen (B) eine 2,9-fach erhöhte Aktivität gegenüber den entsprechenden Biotin-supplementierten Kulturen gemessen werden. Die Werte stellen Daten aus drei parallel durchgeführten Messungen mit Standardabweichungen nach $48 \mathrm{~h}$ Wachstum dar.

Um den Einfluß der Konzentration der C-Quelle im Medium auf die Aktivität des Promotors des sinI-Gens weiter $\mathrm{zu}$ charakterisieren, wurden Messungen unter Biotinlimitierenden Bedingungen nach 48 und $72 \mathrm{~h}$ Wachstumszeit in GTS-Medium mit Glucose $(10,1 \mathrm{mM})$ und Succinat $(9,6 \mathrm{mM})$ (Abb. 21, schwarze Balken) und in GTS-Medium mit verschiedenen Succinatkonzentrationen $(9,6 \mathrm{mM} ; 4,8 \mathrm{mM} ; 0,96 \mathrm{mM})$ durchgeführt (Abb 21). Dabei zeigte sich, daß mit abnehmender Succinatkonzentration im Medium in der Regel die Aktivität des sinI-Promotors anstieg. Lediglich nach $72 \mathrm{~h}$ Wachstumszeit waren nach Anzucht in GTS-Medium mit nur 0,96 mM Succinat verringerte gusA-Aktivitäten im 
Vergleich zu den zwei anderen nur Succinat-haltigen Medien meßbar (durchschnittlich 11200 rel. gusA-Einheiten), was möglicherweise an dem wiederholten sehr schlechten Wachstum dieser Kulturen lag. Die durchschnittliche $\mathrm{OD}_{600}$ dreier Parallelkulturen betrug 0,21 in Anwesenheit von 0,96 mM Succinat, während die Durchschnittswerte der unter den anderen Bedingungen angewachsenen Kulturen höher waren (10,1 mM Glucose/ 9,6 mM Succinat: $\mathrm{OD}_{600}=0,44 ; 9,6 \mathrm{mM}$ Succinat: $\mathrm{OD}_{600}=0,43 ; 4,8 \mathrm{mM}$ Succinat: $\mathrm{OD}_{600}=0,41$ ). Nach 48 h Wachstumszeit dagegen waren noch keine signifikanten Unterschiede in den gemessenen optischen Dichten der verschiedenen Kulturen beobachtbar.

A

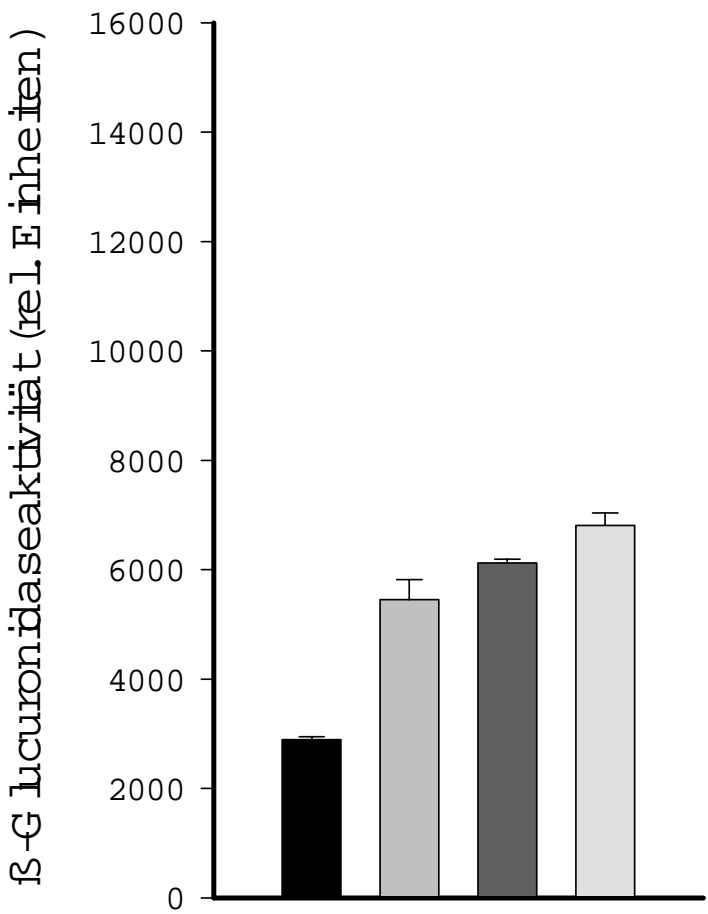

Glucose (mM)

Succinat $(\mathrm{mM})$
10,1
9,6

$9,6 \quad 4,8 \quad 0,96$

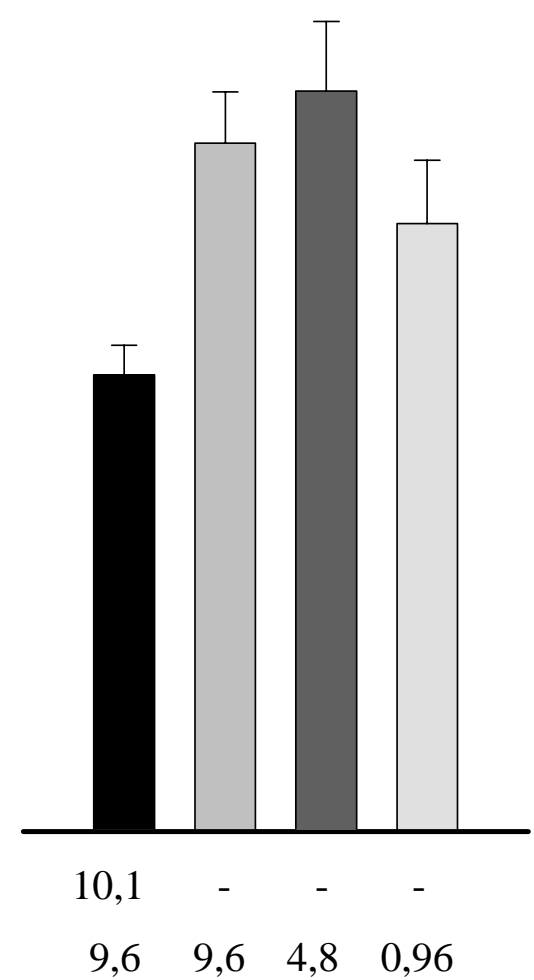

Abb. 21 Relative B-Glucuronidaseaktivität des pPR-sinI-Konstruktes in S. meliloti 1021 nach Anzucht in Minimalmedium mit unterschiedlichen C-Quellen unter Biotin-limitierenden Bedingungen nach (A) $48 \mathrm{~h}$ und (B) $72 \mathrm{~h}$

Je geringer der C-Quellen-Anteil des Mediums war, desto höhere gusAAktivitäten wurden bestimmt (Ausnahme siehe Text). Die Daten stellen Mittelwerte mit Standardabweichungen aus je drei Parallelkulturen dar. Der Gehalt der jeweiligen C-Quelle im Medium wurde unterhalb der Balken aufgeführt; $(-)=$ keine Glucose im Medium. 
In einem weiteren Ansatz wurde der Effekt von Avidin, welches spezifisch an Biotin bindet, im Anzuchtmedium untersucht. Dazu wurde eine $48 \mathrm{~h}$ alte Vorkultur von $S$. meliloti-pPR-sinI abzentrifugiert, dreimal mit GTS-Medium ohne supplementiertes Biotin gewaschen und resuspendiert. Mit diesen resuspendierten Zellen wurden je drei Parallelkulturen GTS-Minimalmedium ohne Biotin (Abb. 22 A), mit 40 nM Biotin (B) und mit $40 \mathrm{nM}$ Biotin und Avidin (C) (0,61 Units/ $\mathrm{ml}^{-1}$ ) angeimpft, welche Glucose und Succinat als C-Quellen enthielten. Die Aktivitäten des sinI-Promotors in den Biotinlimitierten Kulturen waren mit durchschnittlich 3280 rel. Einheiten vergleichbar mit denen der Biotin und Avidin supplementierten Kulturen (3438 rel. Einheiten). Durch das zugegebene Avidin wurde das Biotin im Medium gebunden und stand den Zellen nicht mehr zur Verfügung, so daß Biotin auch in diesem Medium limitierend war. In den Biotinsupplementierten Kulturen waren die Aktivitäten erwartungsgemäß mit durchschnittlich 1099 rel. Einheiten um den Faktor 3 bzw. 3,1 geringer.

Diese Untersuchungen mit der sinI-Promotorfusion zeigten, daß Wachstum unter Biotinlimitierenden Bedingungen im Vergleich zu Wachstum unter Biotinsuffizienz bis zu einer 4,3-fach erhöhten Expression der Autoinduktor-Synthase in S. meliloti führten. Ebenso ließ die zunehmende Limitierung von C-Quellen im Medium die Promotoraktivität ansteigen. 
A $\quad$ B $\quad$ C

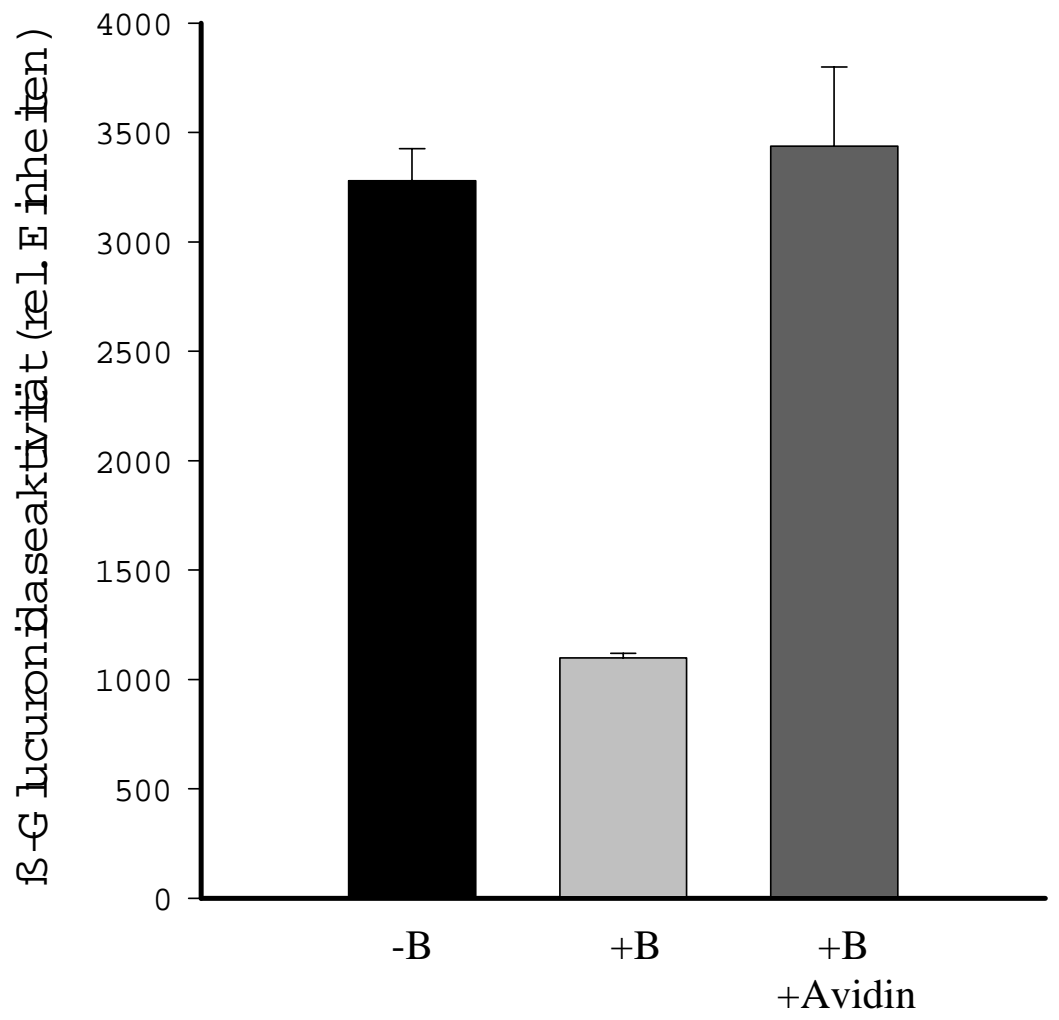

Abb. 22 Relative B-Glucuronidaseeinheiten des pPR-sinI-Konstruktes in S. meliloti in Gegenwart von Avidin im Medium

Wachstum im Biotin-haltigen Medium (B) $(40 \mathrm{nM})$ führte zu einer verminderten Aktivität des sinI-Promotors im Vergleich zu Wachstum in Biotinsupplementierten Kulturen (A). Bei Zugabe von spezifisch an Biotin-bindendes Avidin zum Anzuchtmedium (0,61 Units $\left./ \mathrm{ml}^{-1}\right)$, entsprachen die relativen gusAWerte denen der Biotin-limitierten Kulturen (C). Die Abbildung zeigt Daten dreier Parallelkulturen je Anzuchtmedium mit den entsprechenden Standardabweichungen.

Die relativen $\beta$-Glucuronidaseaktivitäten des pPR-sinR-Konstruktes in $S$. meliloti sind in Abb. 23 und 24 dargestellt. Insgesamt waren die gemessenen Werte höher als bei dem sinIPromotorkonstrukt, jedoch war die Expression weniger abhängig von der Biotinkonzentration im Medium. Nach 48 h Inkubation waren die Werte der Kulturen, die unter Biotinlimitierung angezogen worden waren, um den Faktor 1,4 erhöht gegenüber denen der Biotin-supplementierten Kulturen, nach 54 h um den Faktor 1,5 und nach 72 h um den Faktor 1,2. Dabei waren die Bakterien in Minimalmedium angezogen worden, das Succinat und Glucose als Kohlenstoffquelle enthielt. Wie in Abb. 24 dargestellt, wurde 
sowohl in Biotin-limitierten als auch in Biotin-supplementierten Kulturen die Aktivität durch Inkubation von $S$. meliloti pPR-sinR in GTS-Minimalmedium mit Succinat als einziger C-Quelle (9,6 mM) erhöht. Unter Biotinlimitierung waren die Werte nach $48 \mathrm{~h}$ Wachstum in Minimalmedium mit Succinat als C-Quelle 1,5-fach höher als unter Biotinsuffizienz.

A

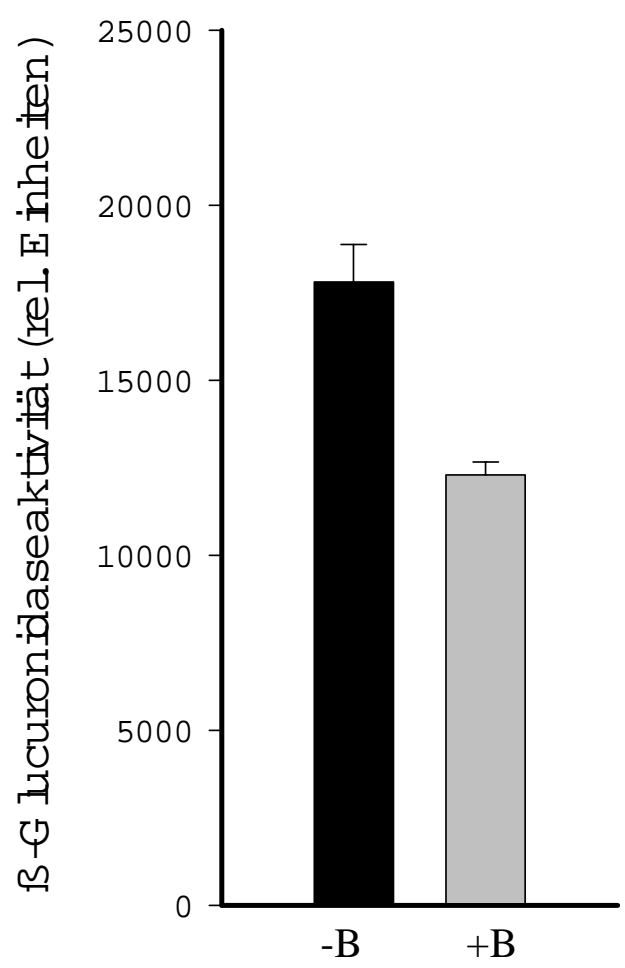

B

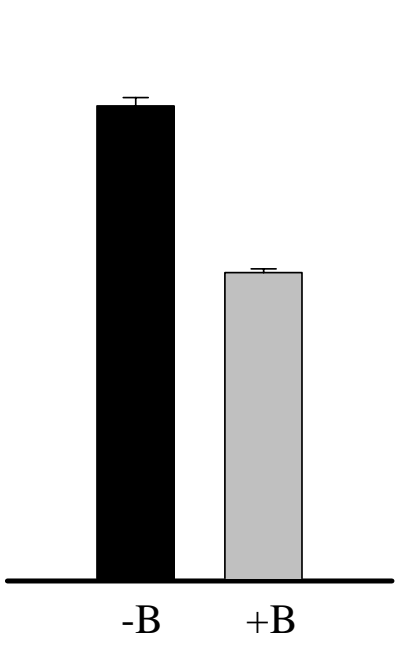

C

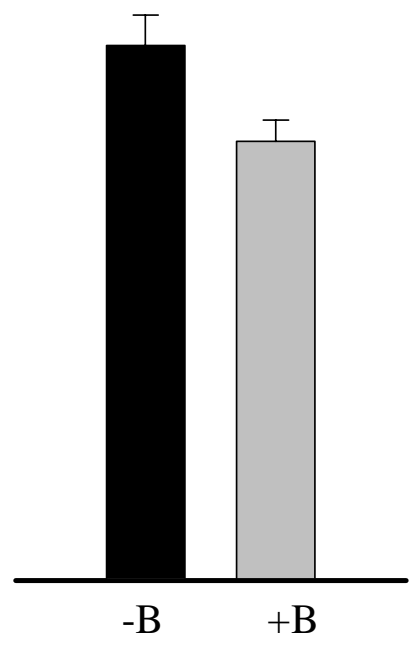

Abb. 23 Relative B-Glucuronidaseaktivität des pPR-sinR-Konstruktes in S. meliloti 1021

In Biotin-limitierten Kulturen (-B) konnte im Vergleich $\mathrm{zu}$ den Biotinsupplementierten Kulturen (+B). Zu allen drei Zeitpunkten (A) 48 h, (B) $54 \mathrm{~h}$ und (C) $72 \mathrm{~h}$ der Messung eine erhöhte gusA-Aktivität beobachtet werden. Die Werte stellen Mittelwerte aus drei parallel durchgeführten Messungen mit Standardabweichungen dar. 
A

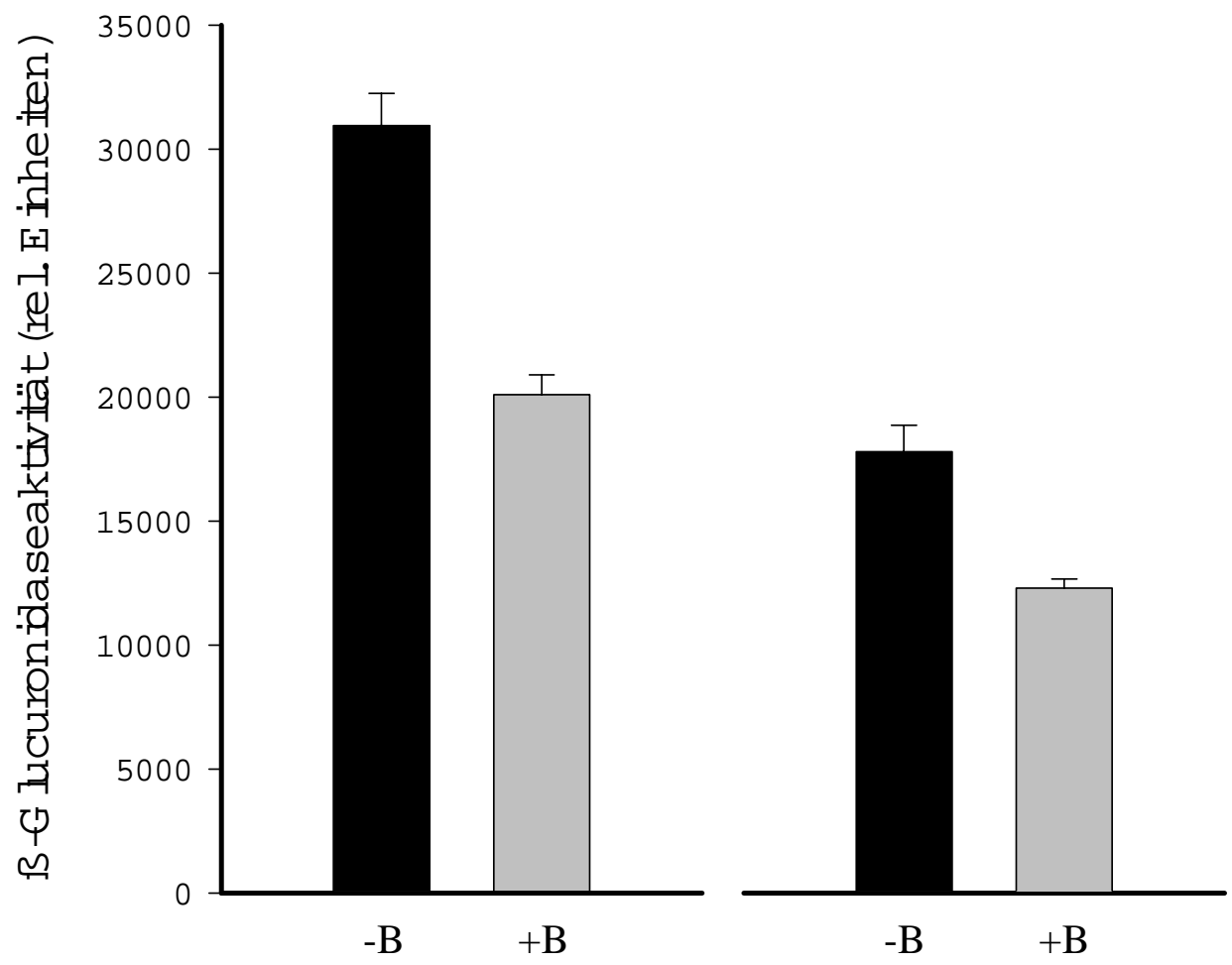

Abb. 24 Relative B-Glucuronidaseaktivität des pPR-sinR-Konstruktes in S. meliloti 1021 nach Anzucht in Minimalmedium mit (A) Succinat als C-Quelle und (B) Succinat und Glucose als C-Quellen

Wurden die Konstrukte in Minimalmedium mit Succinat als einziger Kohlenstoffquelle angezogen (A), konnten die Aktivitäten nach 48 h Wachstum gegenüber denen des Glucose und Succinat haltigen Mediums (B) gesteigert werden. In beiden Fällen führte Biotinlimitierung zu einer erhöhten Expression der putativen sinR-Promotorregion. Die Werte stellen Mittelwerte aus drei parallel durchgeführten Messungen mit Standardabweichungen dar.

\subsubsection{Aktivitätsmessungen der putativen Promotorregion des copC-Gens}

Eines der Proteine, welches in dieser Arbeit mit Hilfe der Proteomanalyse als Biotinreguliert identifiziert werden konnte, war das CopC-Protein. Supplementation des Mediums mit Biotin führte $\mathrm{zu}$ einer erhöhten Expression von CopC (Tab. 7). In Pseudomonas syringae ist das Kupfer bindende CopC-Protein Teil des cop-Operons, 
welches an der Resistenz des Organismus gegenüber Kupfer aber auch am Transport von Kupfer in die Zelle beteiligt ist. In S. meliloti wurde $\operatorname{copC}$ bisher nicht charakterisiert.

Die erhöhte Expression des CopC-Proteins nach Biotinsupplementation des Anzuchtmediums sollte mit Hilfe von Promotoraktivitätsmessungen überprüft werden. Die putative Promotorregion des $\operatorname{copC}$-Gens wurde als 253 bp langes PCR Produkt mit terminalen XbaI und PstI Schnittstellen in den Vektor pBK3 kloniert. Nach Mobilisierung des resultierenden Plasmides pPR-copC nach S. meliloti 1021 wurde die gusAReportergenaktivität in An- oder Abwesenheit von Biotin im Medium gemessen. Dazu wurden jeweils drei Parallelkulturen mit Biotin-supplementiertem und nicht supplementiertem GTS-Minimalmedium mit einer unter Biotin-limitierenden Bedingungen gewachsenen Vorkultur angeimpft, inkubiert und die gusA-Aktivitäten bestimmt. Der Zeitpunkt des Überimpfens wurde als 0 gesetzt. Wie in Abb. 25 dargestellt, zeigten die unter Biotinsuffizienz angezogenen Zellen eine gegenüber den unter Biotinlimitation inkubierten Zellen eine 1,5- bis 5-fach erhöhte relative gusA-Aktivität. In einem weiteren Experiment erfolgte die Anzucht der S. meliloti-pPR-copC Kulturen analog zu den gewählten Anzuchtbedingungen der 2D-Gelelektrophorese. Nach 35 Tage andauernder Inkubation unter Biotin-limitierenden Bedingungen und Bestimmung der gusA-Aktivität wurden die Zellen mit $40 \mathrm{nM}$ Biotin versetzt, weiter inkubiert und die gusA-Aktivität nach $72 \mathrm{~h}$ erneut gemessen. Auch hier zeigte sich nach Biotinzugabe eine 18-fach erhöhte gusAAktivität (nicht dargestellt). Diese Ergebnisse bestätigten, daß $\operatorname{copC~im~Biotin-~}$ supplementierten Medium verstärkt exprimiert wird, wie es bereits mit Hilfe der 2DGelanalyse beobachtet worden war. 


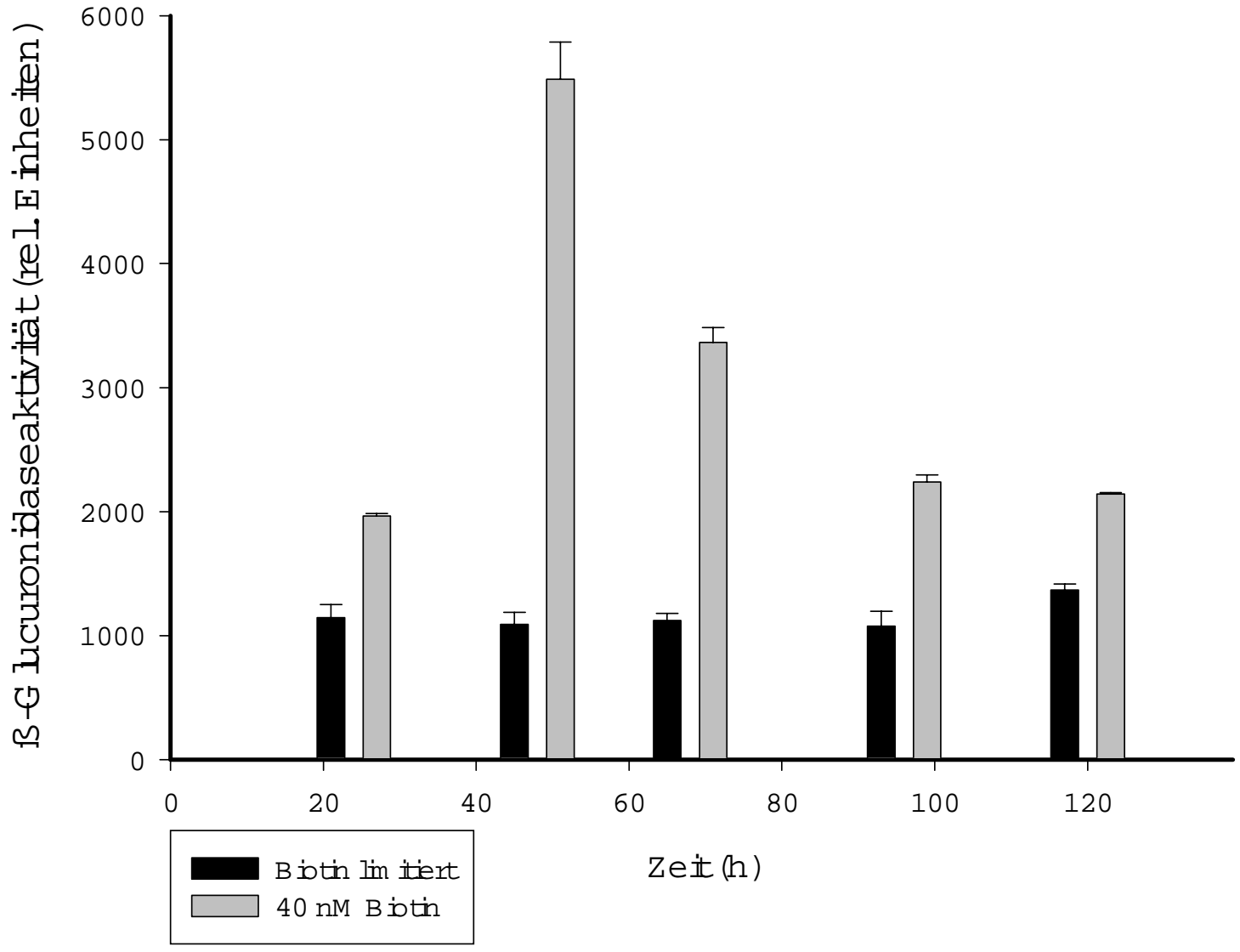

Abb. 25 Relative B-Glucuronidaseaktivität des pPR-copC-Konstruktes in S. meliloti 1021

Unter Biotin-limitierenden Bedingungen (schwarze Balken) waren die rel. ßGlucuronidaseaktivitäten in den getesteten Wachstumsphasen nahezu konstant, während die Aktivitäten in Biotin-supplementiertem Medium (graue Balken) in der logarithmischen Wachstumsphase anstiegen und bis zu 5,0-fach gegenüber denen der Biotin-limitierten Kulturen erhöht waren. Die Daten stellen Mittelwerte aus jeweils drei Parallelkulturen inklusive der Standardabweichungen dar.

\subsubsection{Sequenzanalyse von Biotin-regulierten Promotoren}

Durch Promotoraktivitätsmessungen konnten drei Gene $\sin I$, $\sin R$ und bioM identifiziert werden, deren Expression durch das Vorhandensein von Biotin im Medium beeinflußt wurde. Desweiteren wurden mit Hilfe dieser Methode die Ergebnisse der Proteomanalyse, nämlich eine erhöhte Expression des CopC-Proteins unter Biotinsuffizienz im Medium, bestätigt. Im folgenden wird die physikalische Anordnung der als Biotin-reguliert 
identifizierten Gene innerhalb des S. meliloti Genoms und die Sequenz der klonierten Bereiche dargestellt. Sequenzen, welche in der Promotorregion des sinI-Gens und des sinR-Gens zu finden sind und deren Bedeutung bisher nicht untersucht wurde, sind blau hinterlegt. Weitere mögliche regulatorische Motive sind gelb hinterlegt.

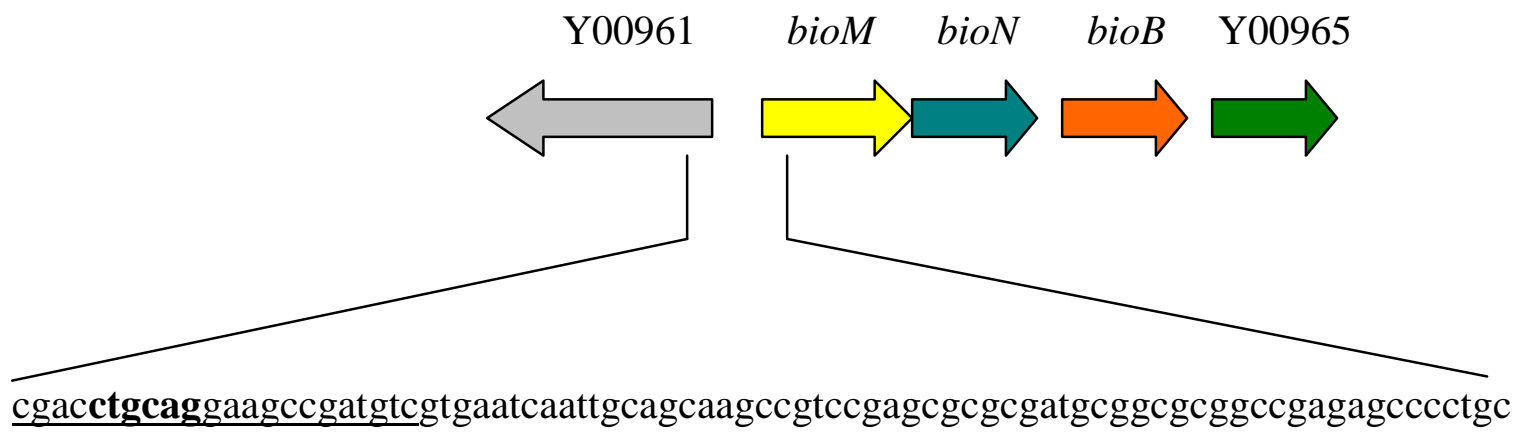

ttggcgagaaagatgcgccgggcatcgcgattggaaaggcgaatcgtcatgaacagagagtaggcttttattcccaagtttcaaa cgtcagacggcaatagatgtatagtccgcgetacattgccetttacgatcgacttgtcctatagagcgatcacgcaaaacatcgcg aggaccgacggcttggaaatccgctttaccgattgctcggtcagcttcggcgaacgggtcgcgcttcatccttctagacct

Abb. 26 Physikalische Anordnung des bioM-Gens und schematische Darstellung des Promotorbereiches

Dargestellt wurde die für die Klonierung des bioM-Promotorbereiches amplifizierte Region. Unterstrichene Sequenzen: Bindestellen der Primer, in denen durch PCR eingefügte Schnittstellen für die Restriktionsenzyme PstI bzw. $X b a I$ hervorgehoben wurden; grau unterlegte Sequenzen: Stopcodons der stromaufwärts liegenden Gene; rot markierte Sequenzen: Startcodons; Unmittelbar stromaufwärts der Startcodons wurde die putative Shine-DalgarnoSequenz hervorgehoben. 


\section{A}

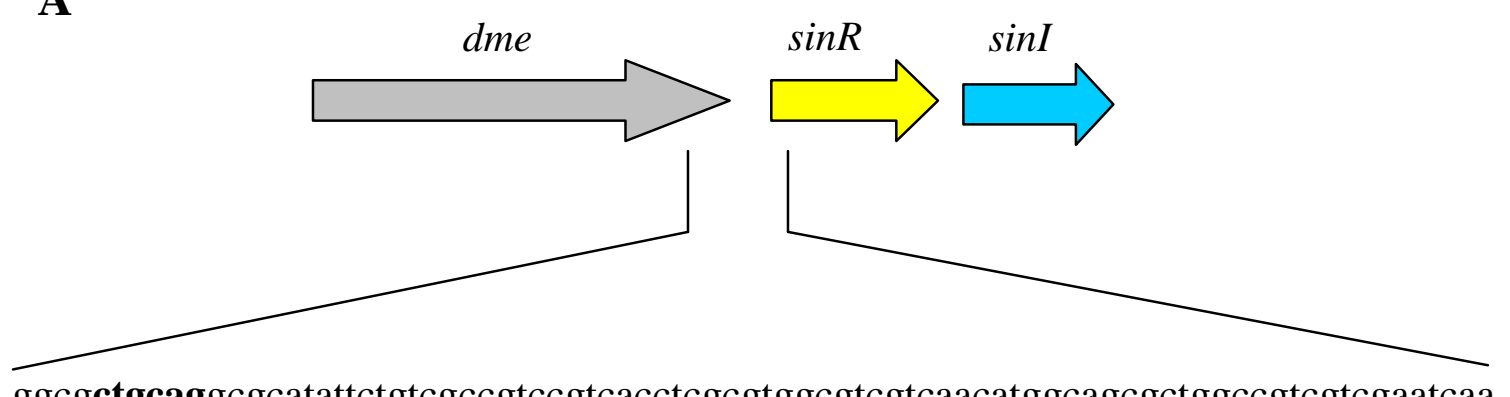

ggcgctgcaggcgcatattctgtcgccgtccgtcacctcgcgtggcgtcgtcaacatggcagcgctggccgtcgtcgaatcaa gccatcccgtctgaggggtggcgcgcctcctcattcactggagggcggaaaaaacgccgcttccacgggaccgacgcagcc gcgtcagcgatatttggctaaaaagtcaacttatgattgcataagcgggattactgcaccgtttatgaaatattgcactagacaaaa ccggccgccgtaaaccatgtttattataggggcaagtttcggtgttacggcatggctaatcaacaggctgtcctcaatttgctgga tatcgtggaatatggaggttgcgcagacccegagcgcttcttcgccetgatgcgtctagacttc

B

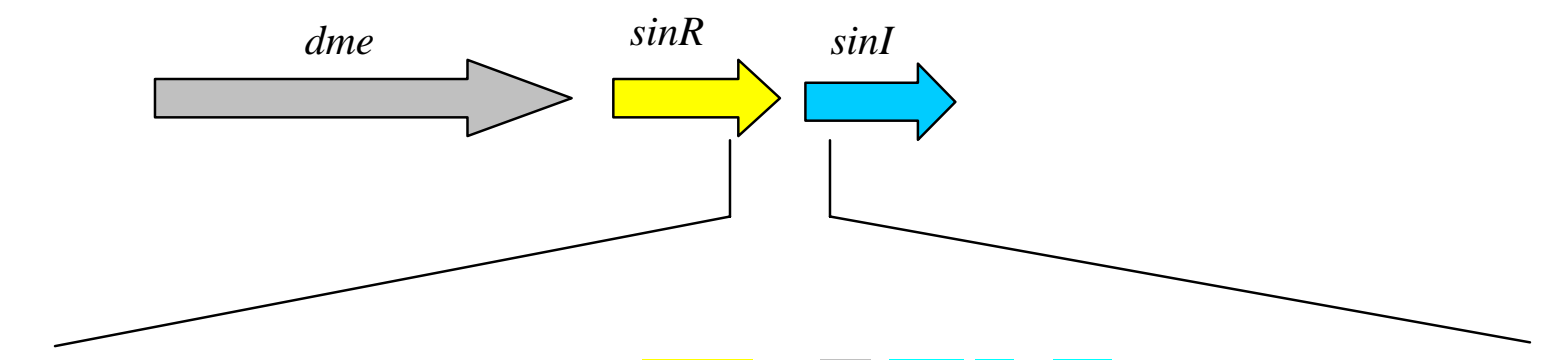

gcaagctgcagcgcacgctgttcgacatgctctgatcccaccatctgacgggttgccggecegggacaggaccggccacc cgcagattccccacaaatctattgggaaaaatgaggaaataaactgtcactatagacagttacatgtgtcatccgagcctgac agcatcgctacatcgcgtaatcacgcatggagcgaaaaaatgatcaggatagtgaacggaaacggtcgcagccagcaccce caggccatctctagatgttc

Abb. 27 Physikalische Anordnung des sinI- bzw. sinR-Gens und schematische Darstellung der klonierten Promotorregionen

Die abgebildeten Sequenzen geben die für die Klonierung der Promotorregionen amplifizierten Bereiche wieder. A: Promotorregion des sinI-Gens. Promotoraktivitätsmessungen zeigten eine bis $\mathrm{zu}$ 4,3-fach erhöhte Expression unter Biotin-limitierenden Bedingungen. B: Promotorregion des sinR-Gens, dessen Expression unter Biotin-limitierenden Bedingungen leicht erhöht war (bis 1,7-fach). Unterstrichene Sequenzen: Bindestellen der Primer, in denen durch PCR eingefügte Schnittstellen für die Restriktionsenzyme PstI bzw. XbaI hervorgehoben wurden; grau unterlegte Sequenzen: Stopcodons der stromaufwärts liegenden Gene; rot markierte Sequenzen: Startcodons; Unmittelbar stromaufwärts der Startcodons wurden die putativen ShineDalgarno-Sequenzen hervorgehoben. Mögliche konservierte Motive sind gelb hinterlegt. Sequenzen, die in beiden Promotorbereichen auftreten, deren Bedeutung aber nicht untersucht wurde, sind hellblau hinterlegt. 


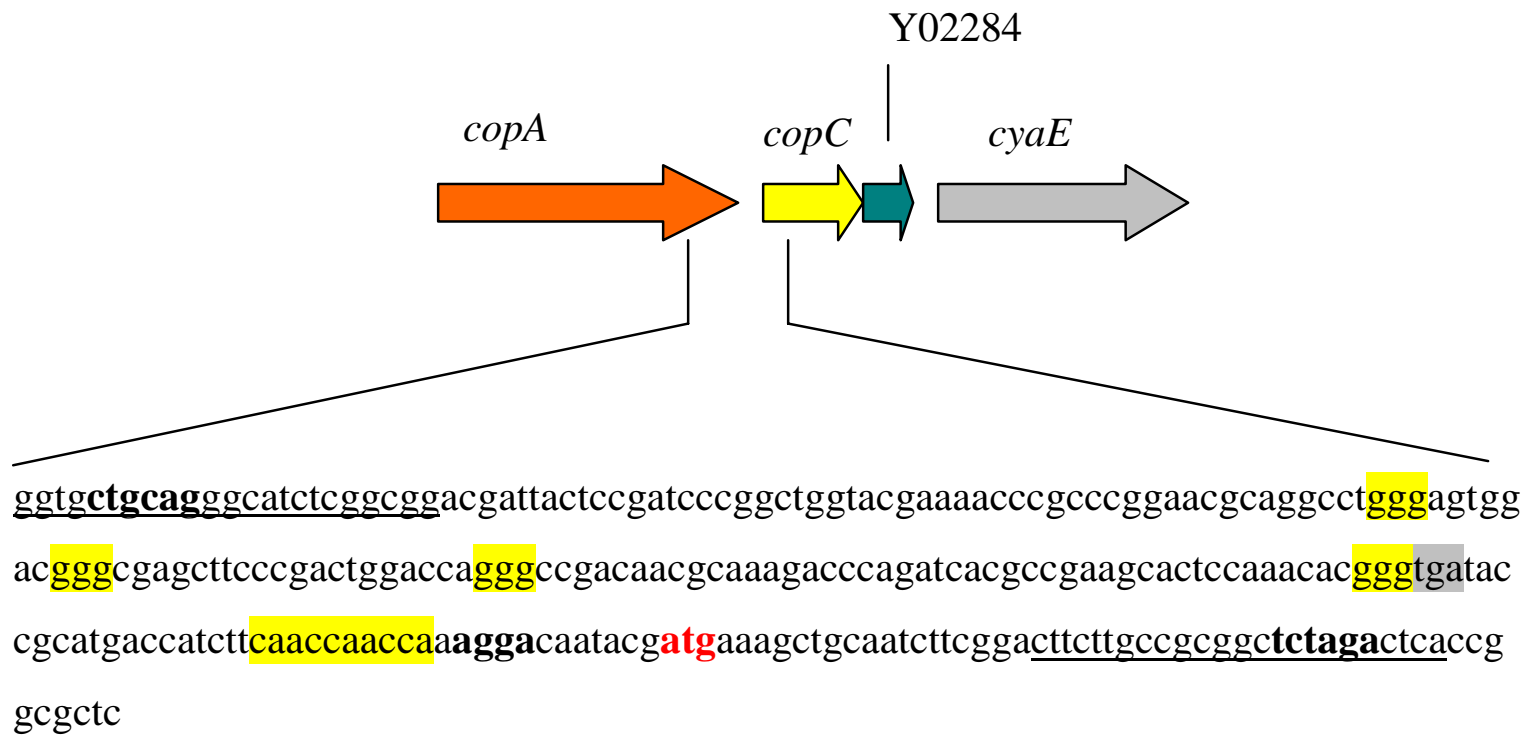

Abb. 28 Physikalische Anordnung des $\operatorname{cop} C$-Gens und schematische Darstellung des Promotorbereiches

Das für die Klonierung des $\operatorname{copC}$-Promotorbereiches amplifizierte 253 bpFragment, dessen Genprodukt möglicherweise an der Resistenz gegenüber Kupfer beteiligt ist, wurde hier dargestellt. Stromaufwärts des $\operatorname{cop} C$-Gens liegt das copA-Gen, welches in anderen Mikroorganismen an der Translokation von Kupfer beteiligt ist. Die Binderegionen der verwendeten Primer wurden unterstrichen und die eingefügten Schnittstellen markiert.

grau unterlegte Sequenzen: Stopcodon des stromaufwärts liegenden Gens; rot markierte Sequenz: Startcodon; unmittelbar stromaufwärts der Startcodons wurde die putative Shine-Dalgarno-Sequenz hervorgehoben. Gelb markierte Sequenzen: potentielle regulatorisch wichtige Sequenzen.

\subsubsection{Detektion von $S$. meliloti 1021 Acyl-HSL durch Dünnschichtchromatographie}

Mit Hilfe der sinI-Promotorfusion konnte gezeigt werden, daß die Expression der Autoinduktor-Synthase bei Anzucht von S. meliloti-pPR-sinI unter Biotin-limitierenden Bedingungen bis um das 4,3-fache erhöht gegenüber Wachstum im Biotinsupplementierten Medium war. Daher wurde untersucht, ob sich aus einer definierten Menge Zellüberstand von S. meliloti 1021-Kulturen, die unter Biotin-limitierenden Bedingungen angezogen worden waren, auch eine größere Menge an Acyl-HSL isolieren und detektieren ließ, als aus einem Zellüberstand Biotin-supplementierter Rhizobien. Zum Nachweis von langkettigen Acyl-Homoserinlactonen aus dem Überstand verschiedener Mikroorganismen eignet sich der Reporterstamm Agrobacterium tumefaciens NTL4 (pCF218) (pCF372), der durch eine Deletion der endogenen Autoinduktor-Synthase (traI) und einer plasmidcodierten traI-lacZ Fusion gekennzeichnet ist. Dieser Stamm kann selbst 
keine Acyl-HSL bilden, jedoch können externe Acyl-HSL-Moleküle mit dem Transkriptionsregulator TraR interagieren, der die Expression der traI-lacZ Fusion induziert. Die Acyl-HSL wurden aus dem Überstand der unter den verschiedenen Bedingungen angezogenen Kulturen extrahiert und dünnschichtchromatographisch aufgetrennt (siehe 2.20). Die Platten wurden dann mit agarhaltigem A. tumefaciens NTL4 (pCF218) (pCF372) Kulturmedium überschichtet und inkubiert. Durch die Aktivität des traI-lacZ-Konstruktes erfolgte die Umsetzung des im Agar enthaltenen Substrates X-Gal an den Stellen der Dünnschichtchromatographie-Platte, an denen sich die extrahierten $S$. meliloti HSL-Moleküle befanden. In Abb. 29 ist das Ergebnis einer Dünnschichtchromatographie dargestellt. In Spur 1 wurden $2 \mu$ eines Extraktes aufgetragen, der aus dem Zellüberstand unter Biotin-limitierenden Bedingungen angezogenen Kulturen stammt und unter 2 dieselbe Menge eines Extraktes, der aus dem Zellüberstand Biotin-supplementierter Kulturen gewonnen wurde. Beide Kulturen hatten etwa dieselbe optische Dichte $\left(\mathrm{OD}_{600}\right.$ : -Biotin 0,29 und + Biotin 0,30) wurden aber nach verschieden langer Wachstumsszeit zur Herstellung der Extrakte geerntet (-Biotin 48 h; +Biotin 28 h nach Animpfen). Wie in Abb. 29 dargestellt, trat in Spur 1 eine stärkere Blaufärbung des überschichteten Agars als in Spur 2 auf. Offensichtlich ließ sich aus dem Überstand Biotin-limitierter Kulturen eine größere Menge an Autoinduktoren extrahieren als aus dem Überstand Biotin-supplementierter Kulturen mit annähernd identischer optischer Dichte, was darauf hindeutet, daß Autoinduktion nicht nur ein Phänomen der Populationsdichte darstellt. Erfolgte die Extraktion der Autoinduktoren aus dem Überstand Biotin-supplementierter Kulturen, die ebenfalls nach $48 \mathrm{~h}$ geerntet wurden und damit auch eine höhere optische Dichte hatten $\left(\mathrm{OD}_{600}\right.$ : 0,84), war die Intensität dieser Proben im Test höher als von Biotin-limitierten Kulturen mit gleich langer Wachstumszeit (nicht gezeigt). Da keine Acyl-Homoserin-Lacton-Moleküle als Standard zur Verfügung standen, wurde als Positivkontrolle (Spur P) Extrakte des Zellüberstandes von A. tumefaciens KYC6 aufgetragen, der Autoinduktoren im hohen Maße produziert. Laufunterschiede der Autoinduktoren sind im allgemeinen auf verschieden lange Acyl-Seitenketten und Art der Substitutionen am C3-Atom der Acylseitenkette zurückzuführen. Dabei haben langkettige und unsubstituierte Seitenketten die geringsten $\mathrm{R}_{\mathrm{f}}$-Werte. Da unbekannt ist, um welches Acyl-HSL Molekül es sich in der Positivkontrolle handelte, konnten die Signale von $S$. meliloti 1021 nicht exakt eingeordnet werden. Die detaillierte Struktur des S. meliloti 1021 Autoinduktors wurde bisher noch nicht aufgeklärt. Durch einen Chromobacterium violaceum Reporterstamm, der im allgemeinen zum Nachweis von Acyl-HSL Molekülen 
mit kürzeren Seitenketten eingesetzt wird, konnten keine Autoinduktoren von S. meliloti 1021 detektiert werden (nicht dargestellt).

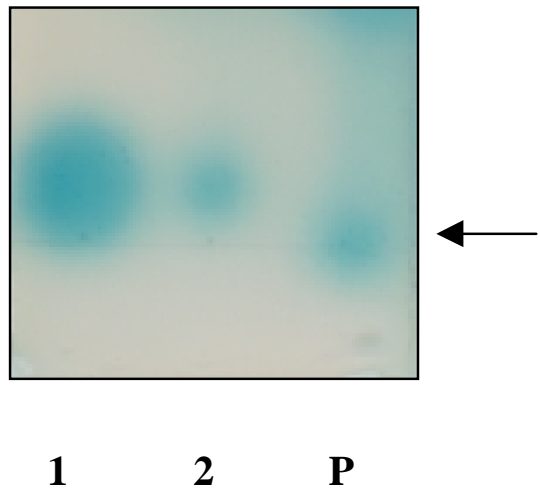

Abb. 29 Detektion von Autoinduktoren aus $S$. meliloti durch Dünnschichtchromatographie

Die Proben wurden auf eine RP-18W Dünnschichtplatte aufgetragen und mit 60\% Methanol: $40 \% \mathrm{H}_{2} \mathrm{O}(\mathrm{v} / \mathrm{v})$ als Laufmittel chromatographiert. Acyl-HSL wurden durch Überschichtung mit dem Reporterstamm A. tumefaciens NTL4 (pCF218) (pCF372) sichtbar gemacht. Aufgetragen wurden jeweils $2 \mu$ Probe, welche aus der Extraktion von Überständen Biotin-limitierter Kulturen (Spur 1) bzw. Biotin-supplementierter Kulturen (Spur 2) gewonnen wurde. Zur Extraktion wurde dasselbe Kulturvolumen eingesetzt und die optische Dichte der Kulturen war nahezu identisch. Spur 3: Positivkontrolle; Der Pfeil markiert die Auftragungslinie.

\subsection{Charakterisierung des surE- und pcm-Gens aus $S$. meliloti}

Das pcm-Gen, das surE-Gen und auch das schon in Vorarbeiten charakerisierte $n l p D$-Gen (Streit et al., 2000) sind weit verbreitet und ihre Anordnung ist bei vielen Mikroorganismen konserviert (siehe Abb. 30). Bei einigen Bakterien wie E. coli liegt in 3'Richtung dieser Gene das rpoS-Gen, welches für den Stationärphase-Sigmafaktor codiert. Man nimmt an, daß die genannten Gene beim Überleben in der Stationärphase von Bedeutung sind, daher wurde die gesamte Region als survival operon bezeichnet. Das besondere des S. meliloti survival operons ist das bioS-Gen (Abb. 30). Es wird durch Biotin in der Stationärphase induziert und Mutanten zeigen eine verlängerte lag-Phase nach Biotinsupplementation zu einer Biotin-limitierten Stationärphasekultur. Dieses Gen war bereits wie das $n l p D$-Gen in Vorarbeiten charakterisiert worden und daher sollten in dieser Arbeit die beiden anderen Gene des survival operons untersucht werden (Heinz et al., 1999; Streit et al., 2000). Die Proteine wurden zunächst kloniert, überexprimiert und aufgereinigt. Durch Erzeugung von Mutanten der beiden Gene sollte anhand von 
Wachstumsversuchen die Bedeutung der Proteine für das Überleben in der stationären Wachstumsphase untersucht werden.

Sinorhizobium meliloti

Mesorhizobium loti

Rhodobacter capsulatus

Vibrio cholerae El Tor N16961

Caulobacter crescentus

Escherichiacoli

Pseudomonas aeruginosa

Xylella fastidiosa

Agrobacterium tumefaciens
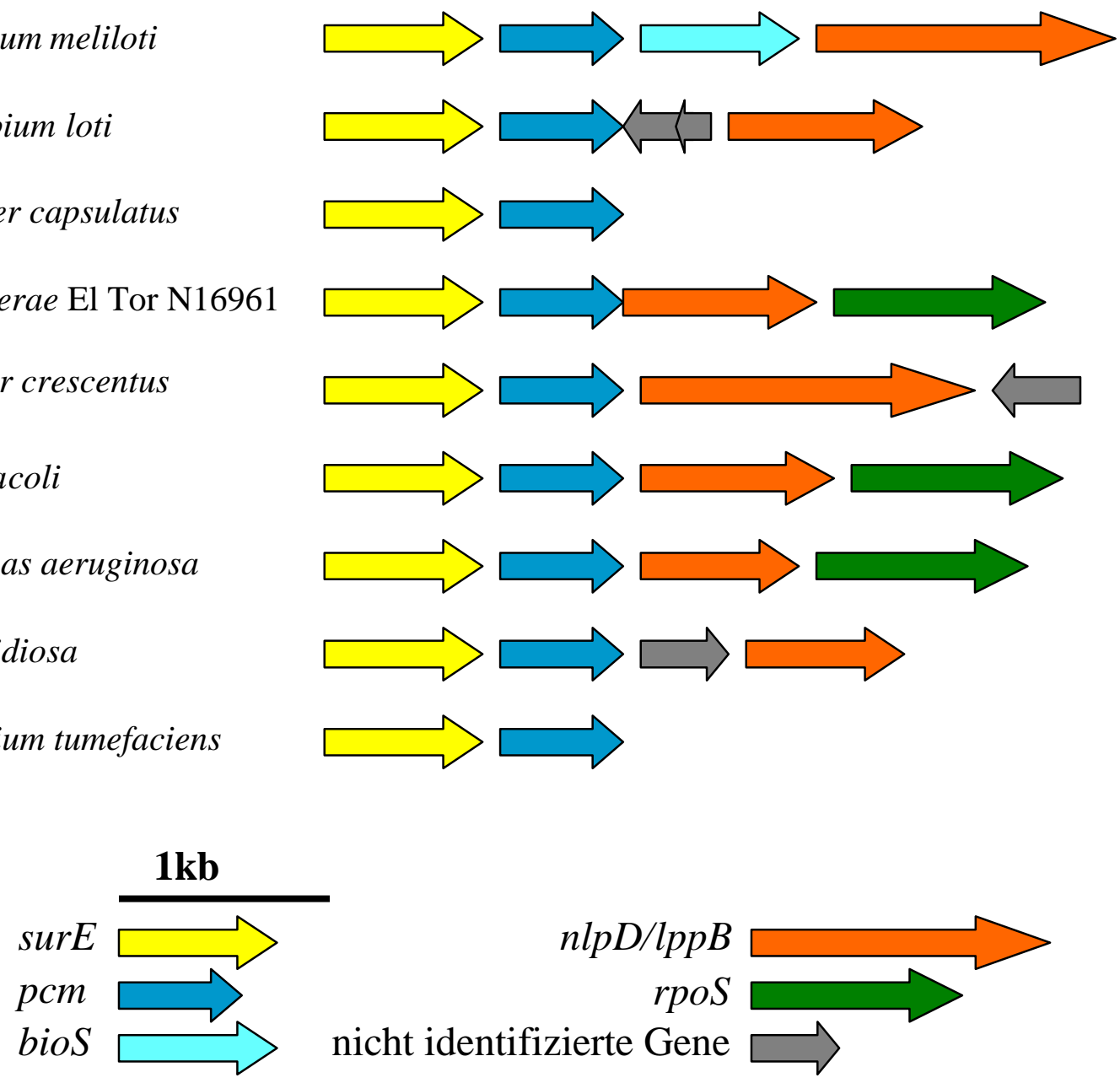

\section{Abb. 30 Anordnung von Genen im survival operon}

Die Anordnung der surE-, pcm- und $n l p D / l p p B-G e n e$ ist in vielen Organismen konserviert. Bei einigen Bakterien, wie z.B. hier dargestellt bei $V$. cholerae, $E$. coli, oder $P$. aeruginosa befindet sich im 3'-Bereich des nlpD/lppB-Gens das rpoS-Gen, welches für den Stationärphase-Sigmafaktor codiert. Das Biotinregulierte bioS Gen findet man nur bei S. meliloti.

Das pcm-Gen codiert für eine L-Isoaspartyl-Protein-Carboxymethyltransferase (EC 2.1.1.77), ein Reparaturenzym für degenerierte Proteine. Durch spontane Deamidierung können in Proteinen aus Asparaginresten oder L-Aspartatresten L-Isoaspartylreste entstehen. Die Methyltransferase bindet spezifisch an L-Isoapartylreste und methyliert das C-Atom der neu gebildeten Seitenkette, wobei S-Adenosylmethionin als MethylgruppenDonor dient. Über einen L-Isoaspartylmethylester entsteht dann ein Zwischenprodukt, welches durch hydrolytische Spaltung wieder zu Aspartyl oder Isoaspartyl umgesetzt werden kann. 
Da unter Mangelbedingungen wie auch in der stationären Wachstumsphase die Proteinsynthese limitiert ist, erscheint es offensichtlich, daß Proteinerhaltung und Reparatur wichtig sind, um lange Perioden unter solchen limitierenden Bedingungen zu überdauern. Welche Bedeutung dabei das pcm-Gen für das Überleben von S. meliloti hat, ein Organismus der in der Lage ist in seinem natürlichen Habitat lange Perioden unter limitierenden Bedingungen zu überleben, sollte in dieser Arbeit untersucht werden.

Stromaufwärts des pcm-Gens liegt das surE-Gen (sur=survival), dessen physiologische Funktion bisher noch nicht aufgeklärt wurde. Zwar konnte gezeigt werden, daß das SurE Protein aus Thermotoga maritima eine Magnesium-abhängige Phosphataseaktivität besitzt, jedoch ist bisher unbekannt, welche Substrate das Enzym in der Zelle verwendet (Zhang et al., 2001; Lee et al., 2001). Aufgrund der Lokalisation wird spekuliert, daß das Genprodukt auch an Prozessen beteiligt ist, die eine Anpassung an ein Leben unter limitierenden Bedingungen erlauben. Daher schien es interessant auch dieses Gen zu untersuchen. Nach Klonierung, Überexpression und Aufreinigung wurde eine surE-Mutante generiert, um mit Hilfe von Wachstumsversuchen die Bedeutung des Gens für das rhizobielle Überleben zu untersuchen.

\subsubsection{Klonierung und heterologe Überexpression der surE- und pcm-Gene von S. meliloti und Aufreinigung der Genprodukte}

Das surE-Gen wurde als surE-pcm-Fragment mit terminalen NdeI-Schnittstellen (Primer surE-NdeI-fw und pcm-NdeI-rev, Tab. 3) unter Verwendung der Pfu-Polymerase durch PCR amplifiziert. Das PCR-Produkt wurde zunächst mit glatten Enden in den mit EcoRV geschnittenen Vektor pBluescriptII SK(+) ligiert, der eine Blau-Weiß-Selektion ermöglichte. Das resultierende Plasmid wurde als pSK::surE/pcm bezeichnet. Nach NdeIVerdau dieses Konstruktes wurde das surE-pcm-Fragment in den ebenso verdauten Überexpressionsvektor pET19b ligiert, wobei das resultierende Plasmid mit pEH25 bezeichnet wurde. Letzteres ist in Abb. 31 dargestellt.

Die Klonierung von pEH26, dem Überexpressionsvektor für das pcm-Gen, wurde nach dem gleichen Verfahren durchgeführt (Abb. 31). Für die Amplifikation des pcmFragmentes wurden die Primer $p c m-N d e \mathrm{I}-\mathrm{fw}$ und $p c m-N d e \mathrm{I}-\mathrm{rev}$ eingesetzt (Tab. 3).

Die Klonierung der Gene in den Überexpressionsvektor pET19b ermöglichte es an den NTerminus der $\mathrm{zu}$ exprimierenden Proteine 10 Histidinreste anzuhängen, was die Aufreinigung durch Nickel-NTA-Affinitätschromatographie erlaubte. Die Überexpression erfolgte mit Hilfe des T7-RNA-Polymerase/Promotor-Systems. Die Plasmide pEH25 und 
pEH26 wurden in den E. coli Expressionsstamm BL21(DE3) transformiert, der durch ein chromosomales T7-RNA-Polymerase-Gen gekennzeichnet ist, das unter Kontrolle eines durch IPTG induzierbaren lacUV5 Promotors steht. Die Aufreinigung der Proteine wurde nach Induktion mit $1 \mathrm{mM}$ IPTG und anschließender weiterer drei-stündiger Inkubation durchgeführt.

Das überexprimierte SurE-Protein ließ sich sowohl unter nativen als auch denaturierenden Bedingungen aufreinigen und zeigte im SDS-Polyacrylamidgel eine Größe von etwa 28 kDa, was der anhand der Aminosäuresequnz berechneten Größe von 27,7 kDa zuzüglich des N-terminal fusionierten Vektoranteils und den Histidinresten entsprach. Bei Analyse des nativ aufgereinigten SurE-Proteins im Nativ-PAGE war eine zusätzliche Bande bei etwa $60 \mathrm{kDa}$ zu sehen (Abb. 32 B), was auf eine Dimerisierung unter nativen Bedingungen schließen läßt.

Das Pcm-Protein sollte eine Größe von 24,9 kDa haben (errechnete Größe: 22,4 kDa + 2,5 kDa Vektoranteil), was mit der Proteinbande im SDS-Polyacylamidgel übereinstimmte (Abb. 32 A). Unter nativen Bedingungen konnte das Pcm-Protein nicht aufgereinigt werden, da das Protein offensichtlich in inclusion bodies vorlag. Daher konnten auch keine Tests zum Nachweis der Methyltransferase-Aktivität des Pcm-Proteins durchgeführt werden. 


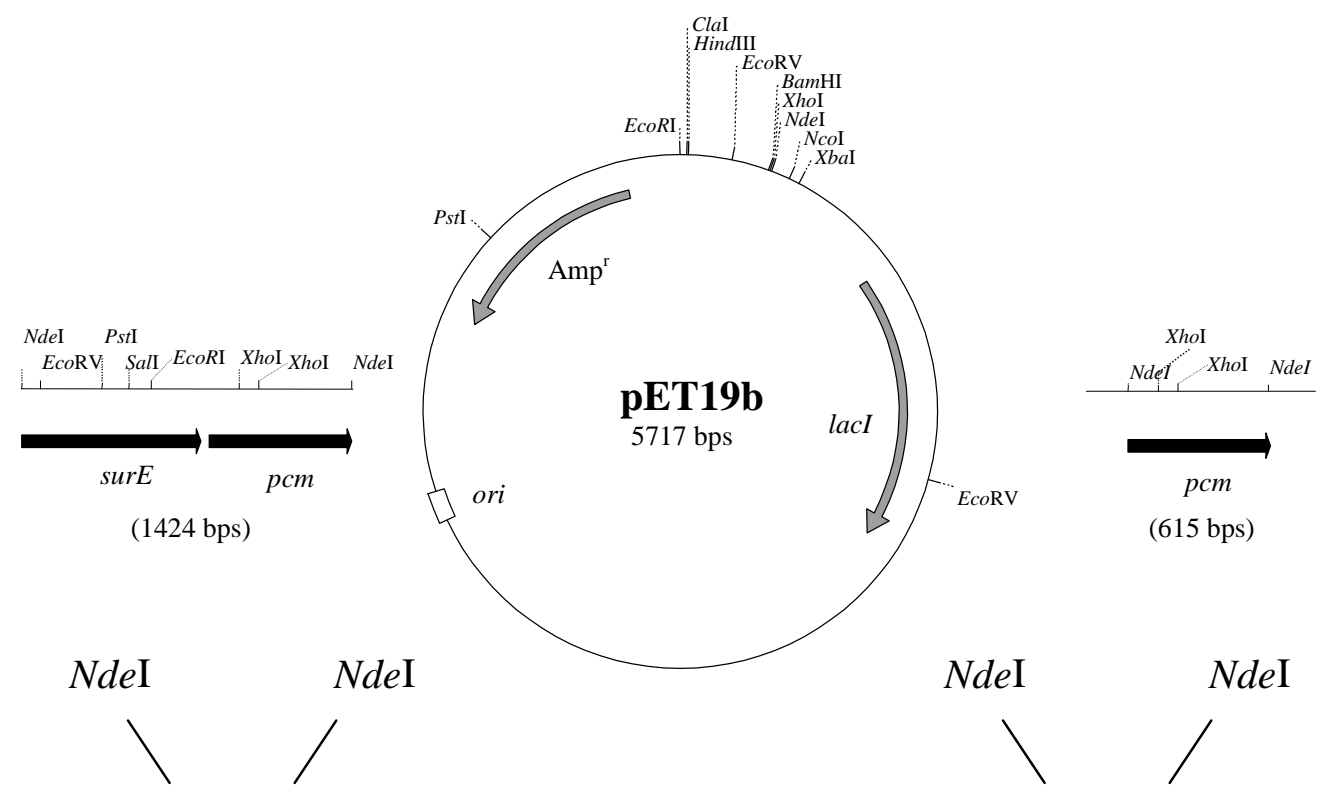

Ligation

Ligation
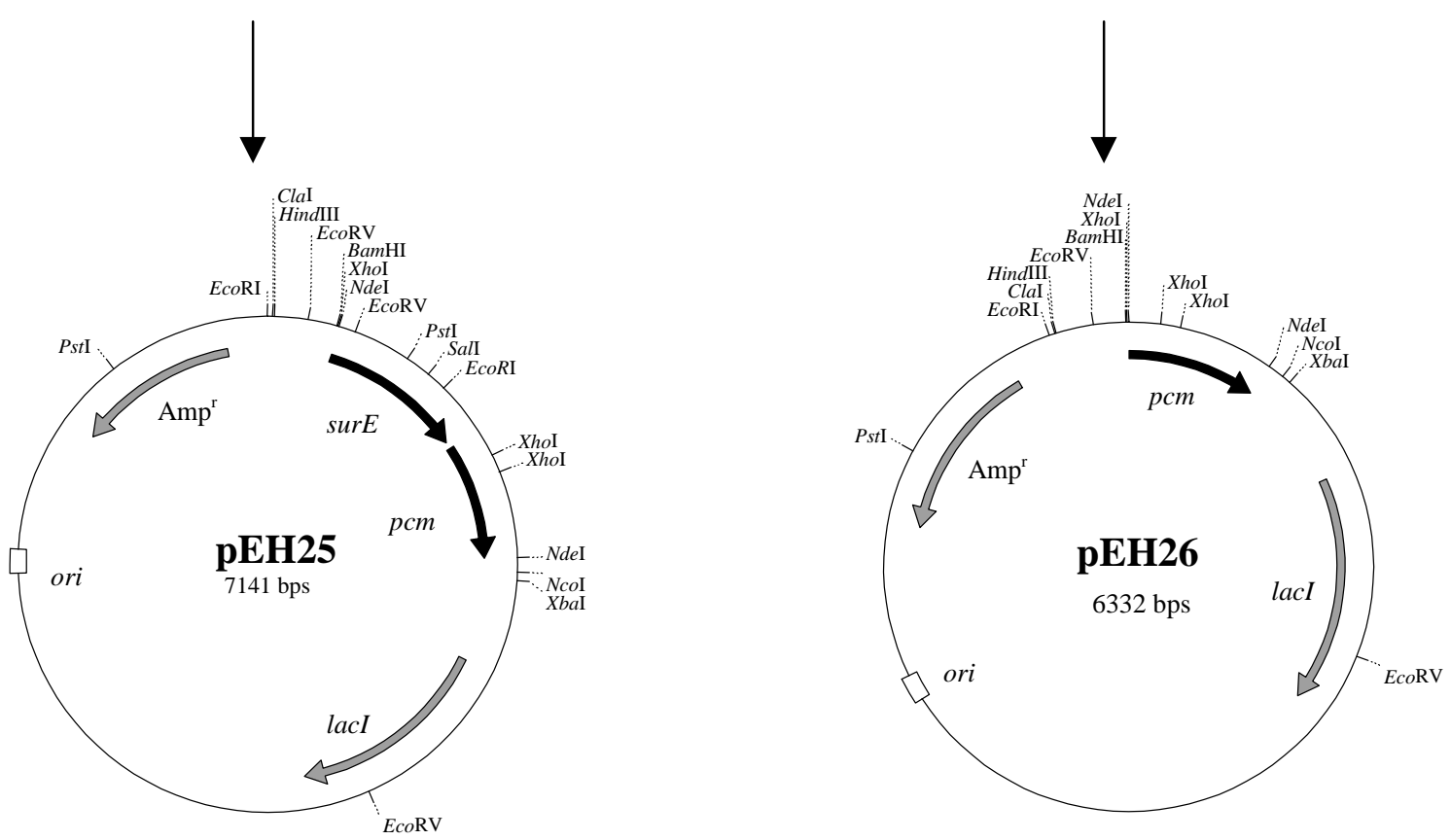

Abb. 31 Darstellung der Klonierungsstrategie zur Überexpression der surE- und pcm-Gene

Die Gene wurden durch PCR amplifiziert, blunt end in den Vektor pBluscriptII $\mathrm{SK}(+)$ kloniert (nicht dargestellt) und nach NdeI-Verdau in den entsprechend geschnittenen Überexpresionsvektor pET19b kloniert. Die resultierenden Konstrukte wurden als pEH25 und pEH26 bezeichnet. 
A

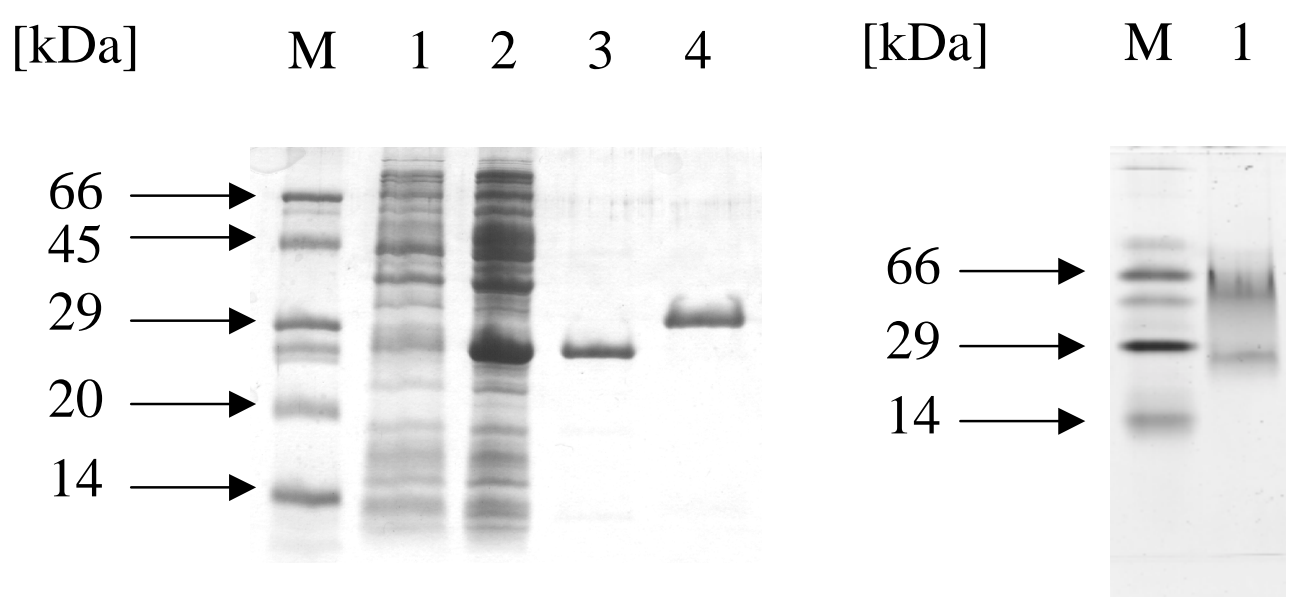

Abb. 32 Polyacrylamid-Gelelektrophorese der heterolog in $E$. coli überexprimierten SurE- und Pcm-Proteine

(A) Gelelektrophoretische Auftrennung der unter denaturierenden Bedingungen aufgereinigten Proteine SurE und Pcm in einem $12 \%$-igem (w/v) SDSPolyacrylamidgel.

M: Marker; 1: pEH26 in BL21(DE3) vor Induktion; 2: pEH26 in BL21(DE3) nach 3h Induktion mit IPTG (1 mM Endkonzentration); 3: aufgereinigtes PcmProtein $(2 \mu \mathrm{g})$; 4: aufgereinigtes SurE-Protein $(2 \mu \mathrm{g})$

(B) Nativ-PAGE (12\%-iges Gel) des nativ aufgereinigten SurE-Proteins. Unter diesen Bedingungen konnte eine zweite Bande, neben der bereits im SDS-Gel zu sehenden Bande bei $28 \mathrm{kDa}$, mit einer Größe von etwa $60 \mathrm{kDa}$ beobachtet werden. M: Nativ-Marker; 1: nativ aufgereinigtes SurE-Protein $(2 \mu \mathrm{g})$

\subsubsection{Phosphataseaktivität des SurE-Proteins}

Untersuchungen von SurE aus T. maritima zeigten, daß das Protein eine von divalenten Metallionen abhängige Phosphataseaktivität besitzt und eine neue Familie von Phosphatasen repräsentiert. Die Struktur wurde aufgeklärt und die Bindestellen der divalenten Metallionen innerhalb des Proteins bestimmt (Lee et al., 2001; Zhang et al., 2001). Mit dem heterolog überexprimierten SurE-Protein, welches am N-Terminus noch die Histidinreste des Vektoranteils trug, wurden daher Aktivitätsmessungen durchgeführt, um zu überprüfen, ob das Protein ebenfalls Phosphataseaktivität besitzt. In Abb. 33 ist die Enzymaktivität in Abhängigkeit des pH-Wertes des Reaktionsansatzes dargestellt. Es wurde nur das pH-Optimum bestimmt. Im pH-Bereich 5,0-6,5 wurde in $50 \mathrm{mM}$ Bis-Tris Puffer und im pH-Bereich 6,5-8,5 in $50 \mathrm{mM}$ Tris-Puffer gemessen. Als Substrat diente pNitrophenyl-Phosphat, was in einer Endkonzentration von $6 \mathrm{mM}$ im Ansatz enthalten war. 
Alle Reaktionsansätze wurden bei $37{ }^{\circ} \mathrm{C}$ inkubiert. In Anwesenheit von $20 \mathrm{mM} \mathrm{MgCl}_{2}$ konnte eine maximale Enzymaktivität von 5,05 $\mu \mathrm{mol}^{*} \mathrm{~min}^{-1} * \mathrm{mg}^{-1}$ bei $\mathrm{pH}$ 6,5 gemessen werden. Ohne $\mathrm{MgCl}_{2}$ wurden geringere Enzymaktivitäten ermittelt (max. 2,48 $\mu \mathrm{mol}^{*} \min ^{-1}$ * $\mathrm{mg}^{-1}$ bei $\mathrm{pH}$ 6,5). Die Rate der Hydrolyse war proportional zur Inkubationszeit und Enzymkonzentration (nicht dargestellt). Auch das Substrat $\alpha$-Naphtyl-Phosphat wurde durch SurE umgesetzt, wobei die Menge nicht quantifiziert wurde (nicht dargestellt).

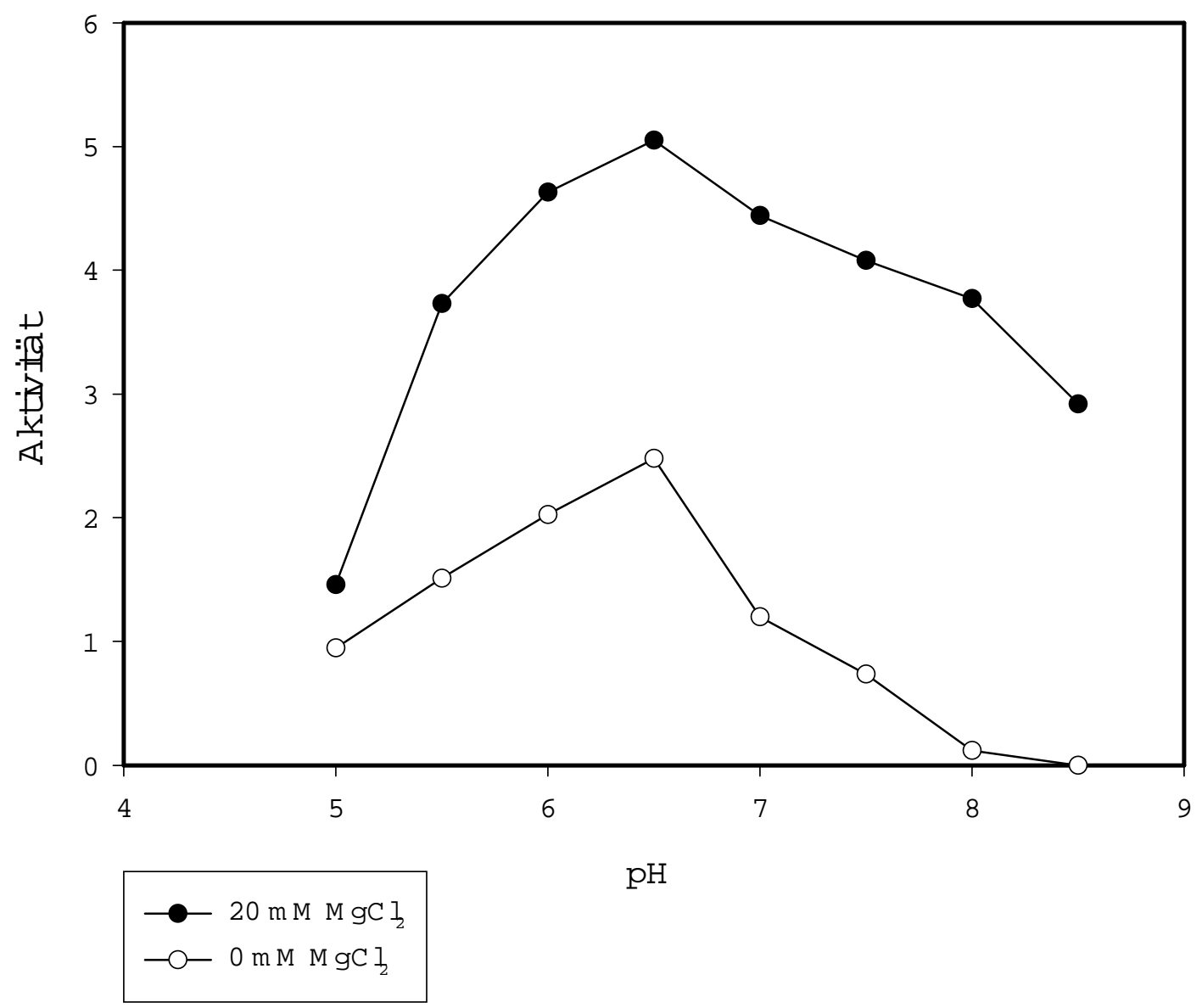

Abb. 33 SurE-Phosphataseaktivität in Abhängigkeit des pH-Wertes in Gegenwart von $20 \mathrm{mM} \mathrm{MgCl}_{2}$ und ohne $\mathrm{MgCl}_{2}$ im Reaktionsansatz

Die höchsten Aktivitäten wurden bei $\mathrm{pH}$ 6,5 gemessen. $\mathrm{MgCl}_{2}$ führte zu einer Steigerung der Enzymaktivität. Als Substrat diente p-Nitrophenyl-Phosphat (6 $\mathrm{mM})$. Die Daten stellen Mittelwerte aus Messungen dreier paralleler Reaktionsansätze dar. 


\subsubsection{Konstruktion der pcm-Mutante Rm1021-EH45 und der surE-Mutante Rm1021-EH47}

Die Mutagenese des pcm-Gens und des surE-Gens erfolgte mit Hilfe des sacB-Systems (siehe 2.9). Die Mutante Rm1021-EH45 zeichnet sich durch die Insertion eines promotorlosen gusA-Reportergens in das pcm-Gen aus. Da die Insertion eines gusA-Gens in das surE-Gen aus unbekannten Gründen nicht erfolgreich war, wurde die Mutante Rm1021-EH47 durch die Insertion einer promotorlosen gfp-Kassette (grün fluoreszierendes Protein) in das surE-Gen konstruiert. Bei beiden Konstrukten handelt es sich um transkriptionale Fusionen.

\subsubsection{Konstruktion von pEH40}

Zur Konstruktion der Mutanten wurden die Gene surE und pcm durch PCR unter Verwendung der Pfu-Polymerase und den Primern surE-NdeI-fw und $p c m-N d e I-r e v$ mit $S$. meliloti 1021 Gesamt-DNA als template amplifiziert. Das resultierende 1434 bp große Produkt wurde blunt-end in die SmaI-Schnittstelle des mobilisierbaren Vektors pk18mobsacB-E kloniert. Dieser Vektor entspricht dem Vektor pk18mobsacB mit der Ausnahme, daß die EcoRI-Schnittstelle innerhalb der Multiklonierungsstelle, die bei der Insertion der $g f p$-Kassette in die EcoRI-Schnittstelle des surE-Gens gestört hätte, durch Restriktion mit EcoRI, Auffüllung mit dem Klenow-Fragment und Ligation entfernt wurde. Das so entstandene Konstrukt wurde als pEH40 bezeichnet (Abb. 34).

\subsubsection{Konstruktion von pEH40-6}

Die gusA-Kassette wurde mittels PCR amplifiziert, wobei das Plasmid pCam140 als template diente, welches das Reportergen aus E. coli enthält. Mit Hilfe der Primer wurde an das 5'- und 3'-Ende eine XhoI-Schnittstelle eingefügt. Außerdem war der 5'-Primer so gewählt, daß die Sequenz der ribosomalen Bindestelle und ihr Abstand zum ATGStartcodon unverändert zur Originalsequenz in E. coli blieb. Die Klonierung des gusAGens erfolgte als XhoI-Fragment in den Vektor pEH40 in die erste XhoI-Schnittstelle des pcm-Gens, die sich an Basenpaarposition 129 befindet. Da es noch eine weitere XhoISchnittstelle an Basenpaarposition 213 im pcm-Gen gibt, wurde das Zwischenstïck von 84 bp während der Klonierung deletiert. Die Orientierung des inserierten gusA-Gens in Leserichtung des $p c m$-Gens wurde durch PCR unter Verwendung der Primer surE-NdeI-fw und gusA-181-rev untersucht. 


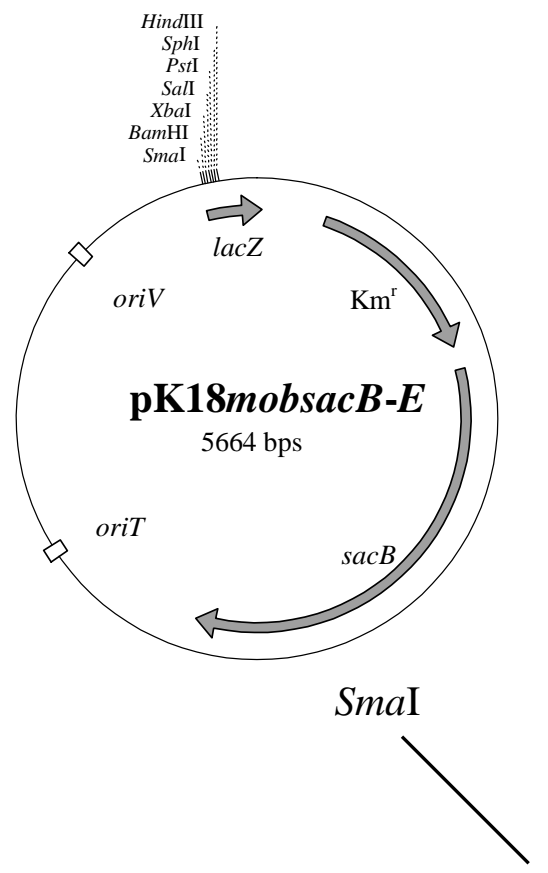

Amplifikation des surE- und pcm-

Gens
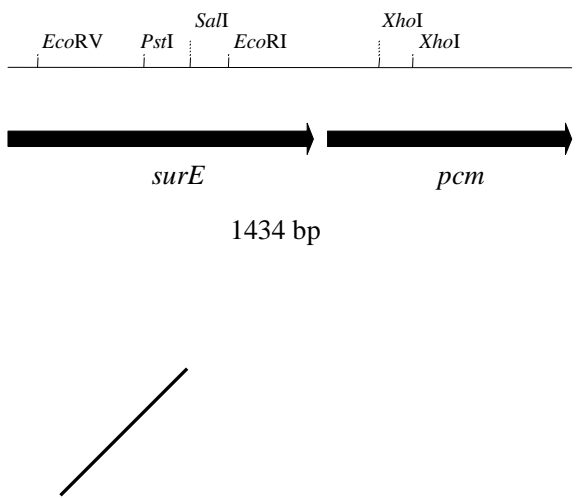

blunt-end Ligation

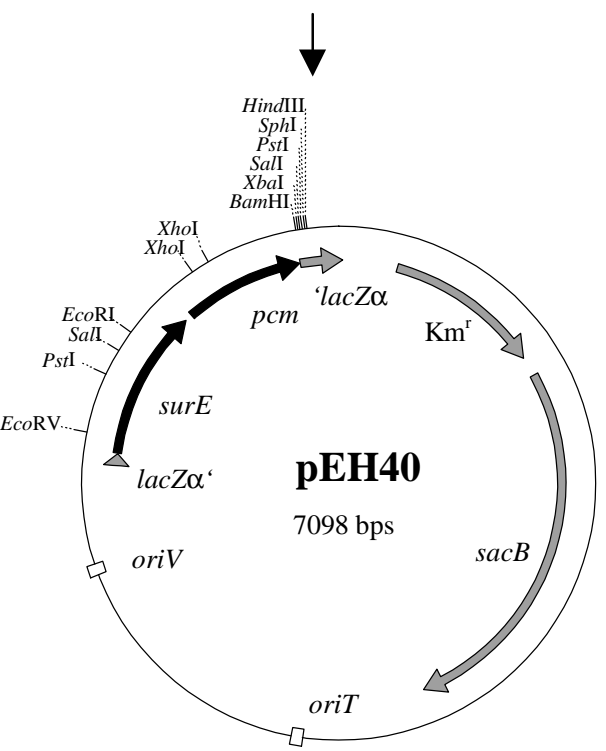

Abb. 34 Klonierung des surE- und pcm-Gens in den Vektor pk18mobsacB-E

Das surE- und pcm-Gen wurde mit Hilfe von PCR unter Verwendung der PfuPolymerase amplifiziert und blunt-end in den SmaI geschnittenen Vektor pk18mobsacB-E ligiert. Das Produkt wurde als pEH40 bezeichnet. 


\subsubsection{Konstruktion von pEH40-9}

Das $g f p$-Gen wurde durch EcoRI-Verdau aus dem Vektor pEN322 geschnitten und in den EcoRI verdauten Vektor pEH40 in das surE-Gen ligiert. In 5'-Richtung vor dem ATGStartcodon des $g f p$-Gens befinden sich translationale Stopsignale in allen drei Leserahmen und eine ribosomale Bindestelle. Die Orientierung der $g f p$-Kassette in Leserichtung des surE-Gens wurde durch PCR überprüft. Desweiteren wurden die beiden Plasmide pEH406 und pEH40-9 durch Sequenzierungsreaktionen überprüft und nach Transformation in den E. coli Stamm S17-1 nach S. meliloti mobilisiert. Mittels Selektion durch das sacB-System konnten die Mutanten Rm1021-EH45 und Rm1021-EH47 isoliert werden, bei denen durch doppelt homologe Rekombination die WT-Gene durch die mutierten Abschnitte ausgetauscht worden waren. Die Klone wurden wiederum durch PCR-Analysen und durch Southern-Hybridisierungen, bei denen das surE-bzw. das pcm-Gen als Sonde eingesetzt wurden, überprüft. 


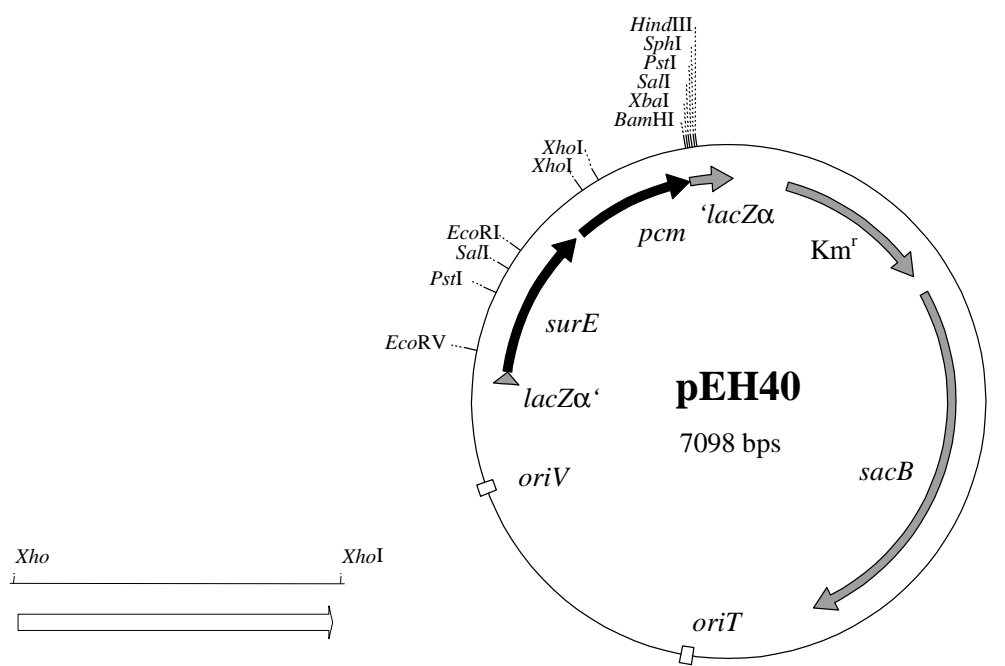

gusA

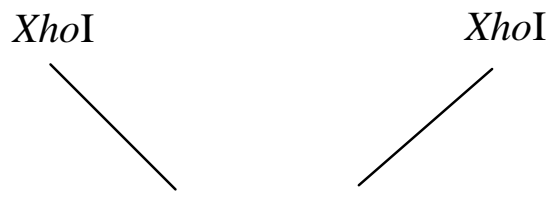

Ligation

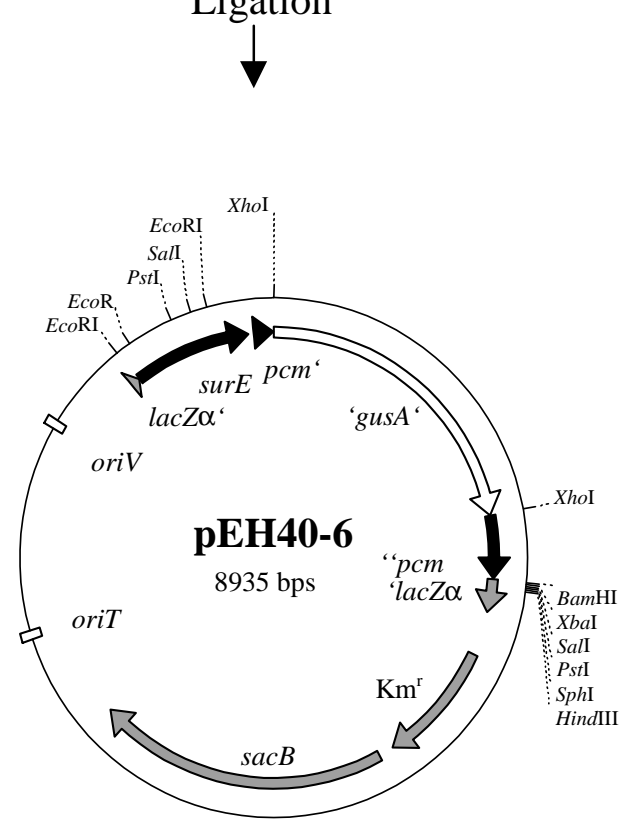

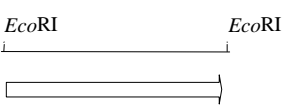

$g f p$
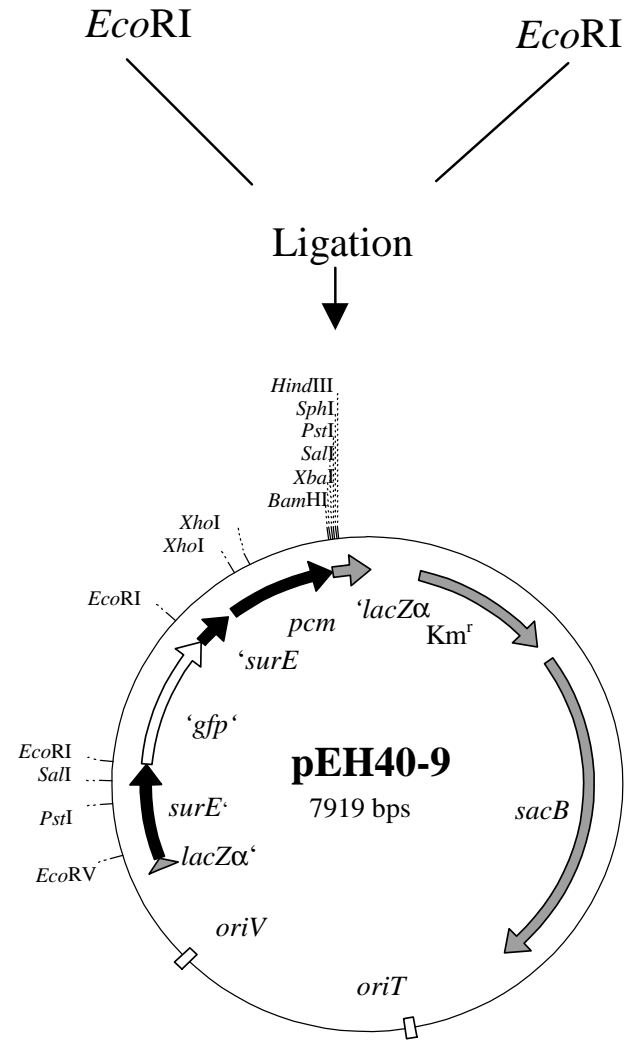

Abb. 35 Darstellung der Klonierungsstrategie zur Insertion der Reportergene gusA und $\boldsymbol{g} \boldsymbol{f} \boldsymbol{p}$ in den Vektor pEH40

Das gusA-Gen wurde als XhoI-Fragment in die 5'-XhoI-Schnittstelle des $\mathrm{pcm}$ Gens und das $g f p$-Gen als EcoRI-Fragment in die EcoRI-Schnittstelle des surEGens kloniert. Die erhaltenen Produkte wurden als pEH40-6 und pEH40-9 bezeichnet. 


\subsubsection{Expression des surE-Gens}

In der Mutante Rm1021-EH47 war ein $g f p$-Reportergen inseriert worden, welches eine eigene ribosomale Bindestelle besitzt. Mit Hilfe eines Fluoreszenzphotometers wurde die Fluoreszenz während verschiedener Wachstumsphasen in TY-Vollmedium und GTSMinimalmedium bestimmt. Da die Zellen selber auch fluoreszierten, wurden die zu messenden Kulturen immer bis $\mathrm{zu}$ einer maximalen optischen Dichte $\mathrm{OD}_{600}$ von 0,1 verdünnt. Unter den getesteten Bedingungen konnte für Rm1021-EH47 keine Fluoreszenz bestimmt werden, die sich signifikant von der der Negativkontrolle (Wildtyp) unterschied. Auch Variation der Emissions- und Excitations-Wellenlängen führte zu keiner meßbaren erhöhten Fluoreszenz bei der Mutante. Mit Hilfe der surE-gfp-Reportergenfusion konnte daher nicht ermittelt werden, unter welchen Bedingungen das surE-Gen exprimiert wird.

\subsubsection{Transkriptionsanalyse des pcm-Gens in TY-Vollmedium}

Mit Hilfe des gusA-Reportergens, welches in das $p c m$-Gen inseriert wurde, konnte die Expression des pcm-Gens quantitativ als relative ß-Glucuronidaseaktivität unter verschiedenen Bedingungen bestimmt werden (siehe 2.19). Messungen, die nach Anzucht von Rm1021-EH45 in TY-Vollmedium durchgeführt wurden, zeigten, daß die Expression mit Beginn der stationären Wachstumsphase am höchsten war und daß sie mit durchschnittlichen relativen ß-Glucuronidase-Werten von 1979 um den Faktor 3,8 gegenüber den Werten der frühen logarithmischen Phase erhöht waren (siehe Abb 36). 


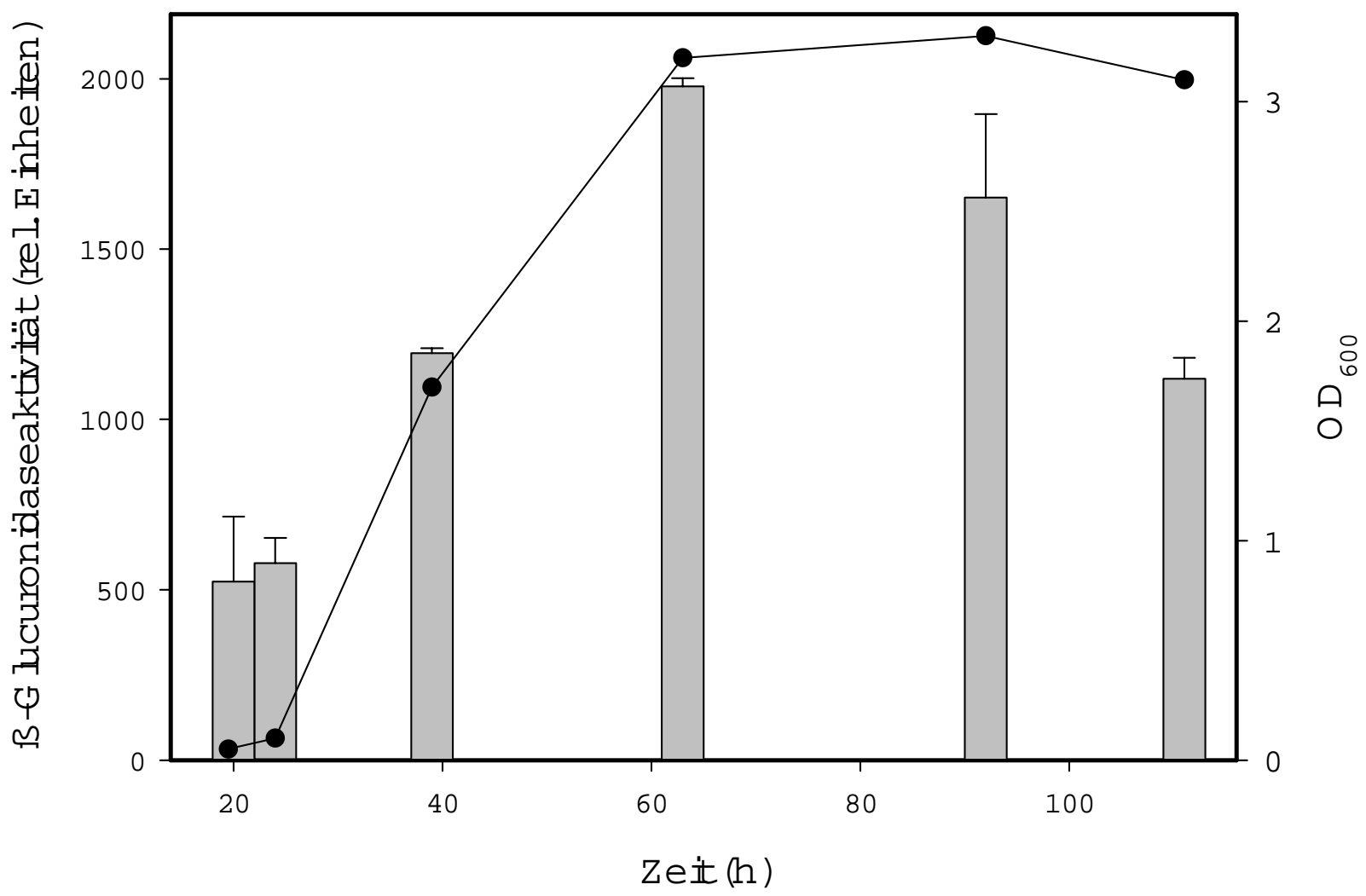

Abb. 36 Expression des pcm-Gens in TY-Vollmedium

Dargestellt wurden die rel. B-Glucuronidaseaktivitäten (graue Balken) und die optischen Dichten $\left(\mathrm{OD}_{600}\right.$; Kurve) der Kulturen in Abhängigkeit von der Wachstumszeit (Bestimmung der relativen B-Glucuronidaseaktivität siehe 2.19) Die Expression des pcm-gusA-Konstruktes war in der frühen stationären Wachstumsphase am höchsten.

\subsubsection{Transkriptionsanalyse des pcm-Gens in GTS-Minimalmedium}

Da das pcm-Gen unmittelbar stromaufwärts des Biotin-regulierten bioS-Gens lokalisiert ist, sollte auch die Abhängigkeit der Expression des pcm-Gens durch Biotin untersucht werden. Rm1021-45 wurde durch zwei Passagen im nicht Biotin-supplementierten GTSMedium ausgehungert und eine solche Biotin-limitierte Kultur diente dann als Vorkultur mit der jeweils drei Kulturgefäße GTS-Minimalmedium ohne Biotin und GTSMinimalmedium mit $40 \mathrm{nM}$ Biotin beimpft wurden. Wie in Abb. 37 dargestellt ist, nahm die pcm-gusA-Transkription in GTS Medium mit Biotin in den ersten Tagen der Inkubation zu und fiel dann auf ein niedrigeres Niveau zurück. Nach 49, 50 bzw. 70 Tagen Inkubation im Biotin-supplementierten GTS-Medium war nahezu keine Aktivität mehr meßbar. 
Auch die pcm-gusA-Transkription der unter Biotin-limitierenden Bedingungen angezogenen Kulturen stieg zunächst an. Messungen, die am 10. und 12. Tag der Inkubation durchgeführt wurden, zeigten noch keine signifikanten Unterschiede zwischen den beiden Anzuchtbedingungen. Nach 14 Tagen fielen die Aktivitäten der Biotinsupplementierten Kulturen ab während die der Biotin-limitierten Kulturen noch weiter anstiegen und mit Werten von durchschnittlich 2029 rel. gusA-Einheiten nach 20 Tagen Inkubation ihren Maximalwert erreichten. Danach fielen die Werte ab, blieben aber immer deutlich über denen der Biotin-supplementierten Kulturen. Nach 14 Tagen war die gusAAktivität der Biotin-limitierten Kulturen um den Faktor 2,2, nach 20 Tagen um den Faktor 5,5, und nach 70 Tagen Inkubation um den Faktor 13,6 erhöht. Die Ergebnisse zeigen, daß die Aktivität des Reportergens und damit auch die Transkription des pcm-Gens durch die Anwesenheit von Biotin im Medium beeinflußt wurden. 


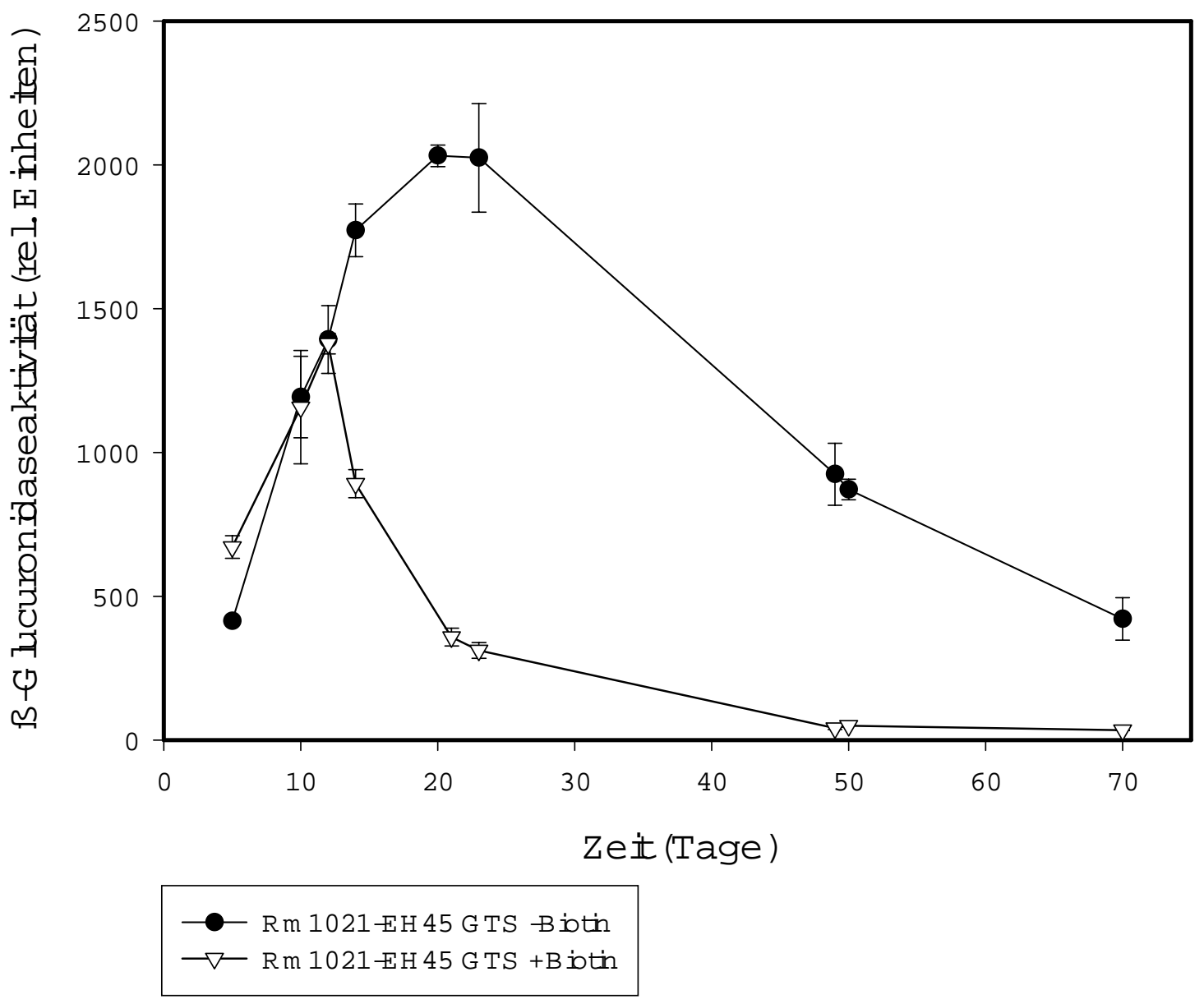

Abb. 37 Transkriptionsanalyse des pcm-Gens in GTS-Minimalmedium mit und ohne Biotin

Dargestellt wurden die rel. B-Glucuronidaseeinheiten (siehe 2.19), die in der pcm-gusA-Mutante Rm1021-EH45 nach Anzucht im Biotin-supplementierten und Biotin-limitierten GTS-Minimalmedium gemessen wurden. Die Werte stellen Mittelwerte aus drei parallel durchgeführten Messungen mit Standardabweichungen dar.

\subsubsection{7 Überleben von Rm1021-EH45, Rm1021-EH47 und Rm1021 in TY- Vollmedium}

Mit Hilfe von Wachstumsstudien wurde überprüft, ob die Mutanten Rm1021-EH45 und Rm1021-EH47 eine verminderte Überlebensfähigkeit im Vergleich zum Wildtyp haben. Dazu wurden die Mutanten und der WT in TY-Medium in jeweils drei Parallelkulturen angezogen, nach verschiedenen Zeitpunkten ein Aliquot der Kultur entnommen und die optische Dichte bestimmt. Nach Anlegen von Verdünnungsreihen wurden verschiedene Verdünnungsstufen ausplattiert, inkubiert und ausgezählt. Wie in Abbildung 38 dargestellt, 
zeigten die beiden Mutanten keine signifikante Einschränkung in der Wachstumsfähigkeit. Daher ist davon auszugehen, daß die mutierten Gene unter den getesteten Bedingungen keine Bedeutung für das Überleben weder in der logarithmischen noch in der stationären Wachstumsphase für $S$. meliloti haben.

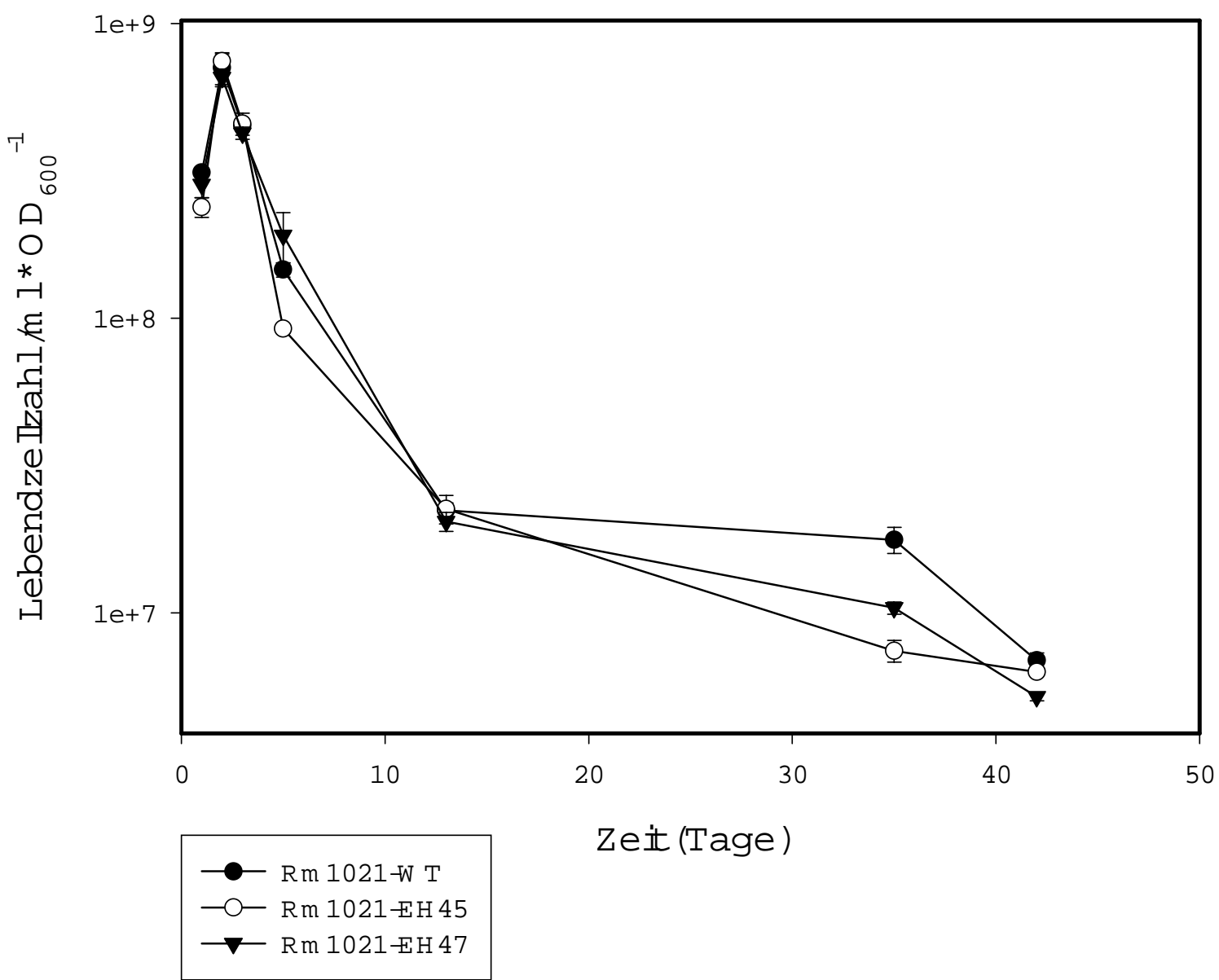

Abb. 38 Überleben von Rm1021, Rm1021-EH45 und Rm-EH47 in TY-Vollmedium Dargestellt ist die Anzahl der Kolonien bildenden Einheiten/ml bezogen auf die optische Dichte der Kulturen nach Ausplattierung nach verschieden langen Wachstumszeiten. Dabei zeigten die Mutanten Rm1021-EH45 und Rm1021EH47 keinen veränderten Phänotyp im Vergleich zum Wildtyp. Dargestellt wurden die Mittelwerte dreier Parallelkulturen inklusive Standardabweichung. 


\subsubsection{Wachstumsversuche der pcm-Mutante Rm1021-EH45, der surE-Mutante Rm-EH47 und Rm1021 in GTS-Minimalmedium}

Analog zu den Wachstumsversuchen in TY-Vollmedium wurden auch Überlebensstudien in GTS-Minimalmedium durchgeführt. Da die Expression des pcm-gusA-Konstruktes unter Biotin-limitierenden Bedingungen in GTS-Minimalmedium um ein Vielfaches erhöht war, gegenüber den Werten, die für die Biotin-supplementierten Kulturen gemessen wurden, erschien es interessant, das Überleben unter Biotin-limitierenden Bedingungen zu untersuchen. Erste Wachstumsstudien hatten gezeigt, daß die pcm-Mutante im Gegensatz zu der surE-Mutante RM1021-EH47 und der ebenfalls untersuchten bioS-Mutante Rm1021-B5 einen Überlebensphänotyp zeigte. Daher wurden für Langzeitexperimente nur noch die pcm-Mutante Rm1021-EH45 und der Wildtyp detaillierter untersucht. Nach Anzucht der Vorkulturen von Rm1021-EH45 und des Wildtyps Rm1021 unter Biotinlimitierenden Bedingungen wurden je drei 2 1-Erlenmeyerkolben mit 200 ml GTSMinimalmedium ohne und mit Biotinsupplementation (40 $\mathrm{nM})$ beimpft und auf dem Rundschüttler bei $30{ }^{\circ} \mathrm{C}$ inkubiert. Die Bestimmung des Titers erfolgte durch Anlegen von Verdünnungsreihen und Ausplattierung auf GTS-Agarplatten. Diese wurden ohne Zugabe von Biotin angesetzt, jedoch ist nicht auszuschließen, daß der zugegebene Agar Biotinkontaminationen enthielt. Durch Kolonie-PCR wurde stichprobenartig die Stabilität der pcm-Mutante überprüft, um auszuschließen, daß es zu Reversionen oder Kontaminationen während der langen Versuchsdauer kam.

In Abb. 39 sind die Ergebnisse der Überlebensversuche dargestellt. Die Anzahl der Kolonien bildenden Einheiten pro ml Medium wurden bestimmt, die Werte auf $\mathrm{OD}_{600}=1$ umgerechnet und gegen die Zeit aufgetragen. Dabei zeigte sich, daß die pcm-Mutante Rm1021-EH45 nach 2 Tagen Inkubation einen nicht signifikant unterschiedlichen Titer im Vergleich zum Wildtyp hatte. Nach 6 Tagen Inkubation dagegen, lag der Titer der Mutante um den Faktor 3,7 unter dem des Wildtyps, nach 12 Tagen um den Faktor 3,9 und nach 20 Tagen Inkubation um den Faktor 6,2. Die größte Diskrepanz wurde nach 35 Tagen gemessen, als der Durchschnittswert des Titers des Wildtyps bei $1,97 * 10^{8}$ Lebendzellzahl $/ \mathrm{ml} * \mathrm{OD}_{600}{ }^{-1}$ und der der Mutante bei $6,71 * 10^{6}$ Lebendzellzahl $/ \mathrm{ml} *$ $\mathrm{OD}_{600}{ }^{-1}$ lag. Die Titer der Kulturen nahmen bei beiden Stämmen im Laufe der Inkubationszeit ab, jedoch konnte bei der Mutante in der Stationärphase eine verminderte Überlebensfähigkeit im Vergleich zum Wildtyp beobachtet werden. Diese Ergebnisse zeigten, daß die Mutation des $p c m$-Gens zu einem Überlebensphänotyp führte und das 
pcm-Gen eine Rolle beim Überleben in der stationären Wachstumsphase unter Biotinlimitierenden Bedingungen spielt.

Wurden der Wildtyp und die Mutante Rm1021-EH45 im Biotin-supplementierten GTSMinimalmedium inkubiert, konnten dagegen nach bis zu 33 Tagen andauernder Inkubation keine voneinander signifikant abweichenden Titer bestimmt werden.

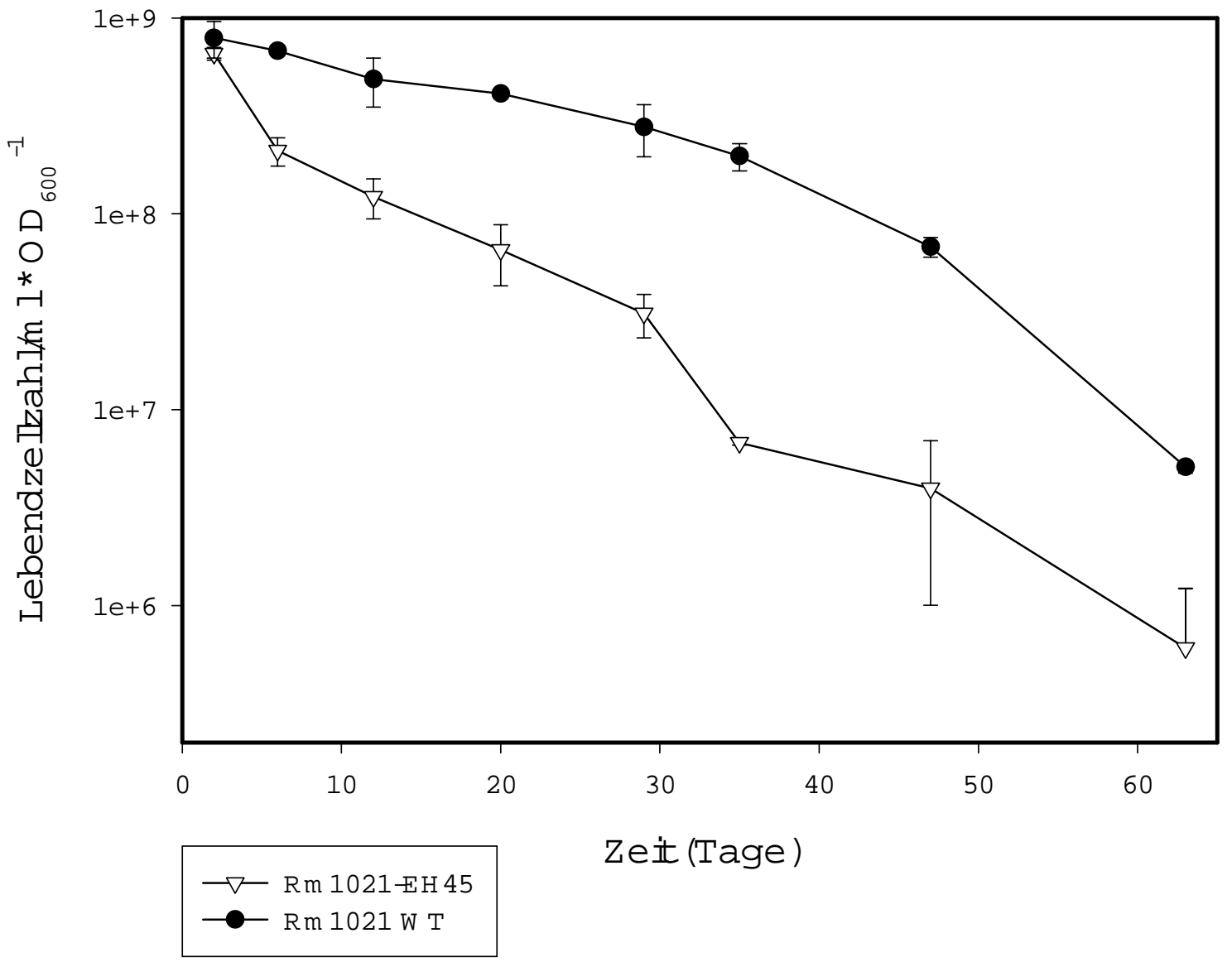

Abb. 39 Überleben von Rm1021-EH45 und Rm1021 in GTS-Minimalmedium unter Biotin-limitierenden Bedingungen

Dargestellt ist die Anzahl der Kolonien bildenden Einheiten pro ml Kultur bezogen auf die optische Dichte der Kulturen nach Ausplattierung nach verschieden langen Inkubationszeiten. Dargestellt wurden die Mittelwerte dreier Parallelkulturen inklusive Standardabweichung. Die pcm-Mutante Rm1021EH45 zeigte dabei bereits nach 6 Tagen Wachstum in GTS-Minimalmedium ohne Biotin gegenüber dem Wildtyp eine verminderte Fähigkeit, Kolonien zu bilden. 


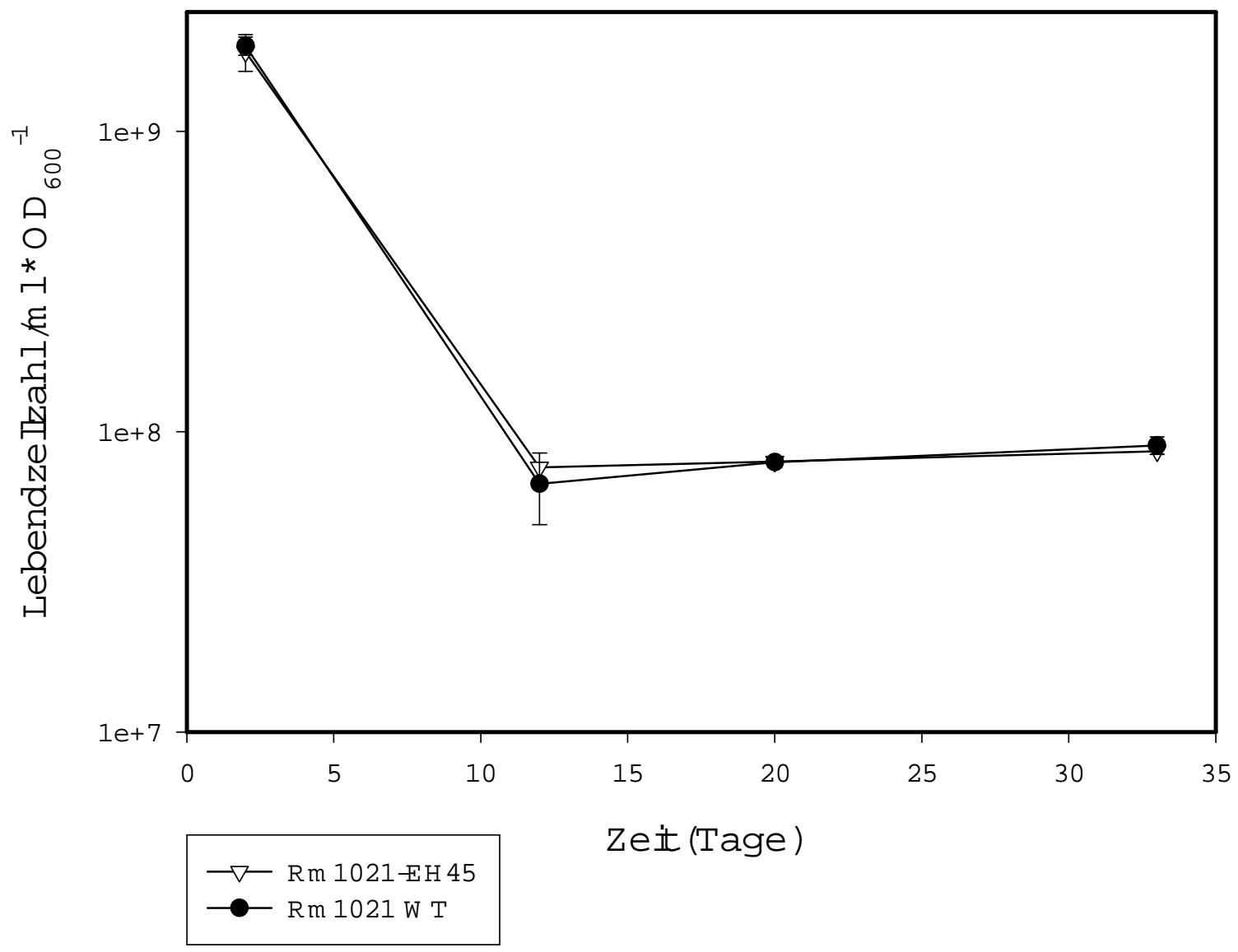

Abb. 40 Überleben von Rm1021-EH45 und Rm1021 im Biotin-supplementierten GTS-Minimalmedium

Unter diesen Versuchsbedingungen war das Überleben der pcm-Mutante Rm1021-EH45 im Vergleich zum WT Rm1021 nicht eingeschränkt.

\subsubsection{Komplementation der pcm-Mutante Rm1021-EH45}

Mit der Komplementation der $p c m$-Mutante durch das S. meliloti $\mathrm{pcm}$-Gen sollte überprüft werden, ob der beobachtete Phänotyp durch eine intakte Version des Gens aufgehoben werden kann. Das pcm-Gen wurde als 859 bp EcoRI-Fragment aus pSK::surE/pcm herausgeschnitten. Die 5'-Schnittstelle befand sich an Basenpaar-Position 556 des surEGens und die 3'-Schnittstelle im Vektoranteil. Das intakte pcm-Gen wurde in den EcoRI geschnittenen Vektor pBBRMCS1 kloniert und das resultierende Konstrukt mit E. coli S17-1 als Donorstamm nach Rm1021-EH45 mobilisiert. Der Vektor pBBRMCS1 trägt eine Kanamycinresistenz und ist replizierbar in $S$. meliloti. Mit dem 
Komplementationsstamm Rm1021-K-EH45, der Mutante Rm1021-EH45 und dem Wildtyp Rm1021 wurden Wachstumsversuche unter Biotin-limitierenden Bedingungen durchgeführt. Die Mutante und der Wildtyp zeigten nach 12 Tagen Inkubation und Ausplattierung ein den Erwartungen entsprechendes Wachstumsverhalten (Rm1021=4,98* $10^{8}$ und $\mathrm{Rm} 1021-\mathrm{EH} 45=9,7 * 10^{7}$ Lebendzellzahl $/ \mathrm{ml}^{*} \mathrm{OD}_{600}{ }^{-1}$ ) der Komplementationsstamm dagegen wuchs schlechter $\left(3,02 * 10^{7}\right.$ Lebendzellzahl $\left./ \mathrm{ml} * \mathrm{OD}_{600}{ }^{-1}\right)$. Um zu überprüfen, ob die zusätzliche Kopie des pcm-Gens oder das Vorhandensein des Plasmids selbst zu vermindertem Wachstum führten, wurde das Plasmid pBBRMCS1 in den WT Rm1021 mobilisiert und in drei Parallelkulturen unter Biotin-limitierenden Bedingungen inkubiert. Analog dazu wurden auch die pcm-Mutante und der Komplementationsstamm mitgeführt. Erneut wurde nach 12 Tagen ausplattiert und die Lebendzellzahlen bestimmt. Der Komplementationsstamm wuchs wieder sehr schlecht $\left(1,41 * 10^{7}\right.$ Lebendzellzahl/ml * $\left.\mathrm{OD}_{600}{ }^{-1}\right)$ und auch der Wildtyp zeigte mit 9,6 *10 $0^{7}$ Lebendzellzahl/ml $* \mathrm{OD}_{600}{ }^{-1}$ eine um den Faktor 5,07 bzw. 5,19 verminderte Zellzahl gegenüber vorangegangenen Untersuchungen $\left(4,87\right.$ und 4,98*10 $10^{8}$ Lebendzellzahl $\left./ \mathrm{ml}^{*} \mathrm{OD}_{600}{ }^{-1}\right)$. Das heißt, daß das Vorhandensein des Plasmids pBBRMCS1 unter den genannten Wachstumsbedingungen zu einer verminderten Lebendzellzahl führte. Für die pcm-Mutante wurde ein Wert von 1,92* $10^{8}$ Lebendzellzahl $/ \mathrm{ml}^{*} \mathrm{OD}_{600}{ }^{-1}$ bestimmt, der leicht über dem vorangegangener Werte lag $\left(1,22 * 10^{8}\right.$ und $9,7 * 10^{7}$ Lebendzellzahl $\left./ \mathrm{ml}^{*} \mathrm{OD}_{600}{ }^{-1}\right)$. Bei allen Werten handelt es sich um Mittelwerte dreier Parallelkulturen.

Durch Mobilisation des in das Plasmid pBBRMCS1 inserierten $\mathrm{pcm}$-Gens in die Mutante Rm1021-EH45 konnte der Überlebensphänotyp der Mutante nicht komplementiert werden, da das Vorhandensein des Plasmids selbst offensichtlich $\mathrm{zu}$ verminderter Wachstumsfähigkeit führte, wie hier für den WT gezeigt wurde.

\subsubsection{Wachstumsversuche von Rm1021-EH45, Rm1021-EH47 und Rm1021 unter verschiedenen Streßbedingungen}

In E. coli wurde bereits gezeigt, daß pcm-Mutanten, die in der stationären Wachstumsphase mit 0,5\% (v/v) Methanol oder 0,1 mg/ml Paraquat (Oxidationsmittel) versetzt werden, eine verminderte Überlebensfähigkeit zeigen (Visick und Clarke, 1998). Auch bei Pflanzen wird die Methyltransferaseaktivität in Abhängigkeit von Dehydrierung und anderen Streßbedingungen aktiviert. Da das $p c m-G e n$ in der Stationärphase induziert wird und unter Biotin-limitierenden Bedingungen, offensichtlich auch eine Streßsituation 
für die Rhizobien, ein vermindertes Überleben beobachtet wurde, sollte in diesem Teil der Arbeit der Einfluß von anderen potentiellen Streßfaktoren untersucht werden.

In ersten Versuchen wurden die Mutanten Rm1021-EH45, Rm1021-EH47 und der Wildtyp in TY-Medium angezogen und jeweils drei $5 \mathrm{ml}$ Parallelkulturen in der stationären Wachstumsphase (4 Tage Inkubation) mit $\mathrm{MeOH}$ (Endkonzentration 0,5\% (v/v)) und $\mathrm{H}_{2} \mathrm{O}_{2}$ (Endkonzentration $27 \mathrm{mM}$ ) versetzt oder 2 min lang bei $38^{\circ} \mathrm{C}$ bzw. $41^{\circ} \mathrm{C}$ inkubiert. Die Bestimmung der Titer durch Ausplattierung 2,5 h bis 7 Tage nach Zugabe der Agenzien bzw. Hitzeinkubation zeigte keine signifikante Abnahme der Zellzahl der Mutanten im Vergleich zum Wildtyp. Auch die Verdopplung der zugegebenen $\mathrm{MeOH}$ bzw. $\mathrm{H}_{2} \mathrm{O}_{2}$-Konzentration zeigten keine Veränderungen. Dieselben Versuche wurden ebenfalls im Biotin-supplementierten GTS-Minimalmedium mit 4 Tage alten Stationärphasekulturen durchgeführt. Auch hier war kein Phänotyp zu beobachten. Schließlich wurden die Mutanten und der Wildtyp in GTS und TY-Medium mit verschiedenen Mengen an $\mathrm{NaCl}$ inkubiert. Während in TY-Medium mit $0,2 \mathrm{M} \mathrm{NaCl}$ alle drei Stämme uneingeschränkt wachsen konnten, war das Wachstum im Biotin-haltigen GTS-Medium nur bis zu einer Salzkonzentration von 0,1 M möglich.

In weiteren Versuchen wurden der Wildtyp und die pcm-Mutante über zwei Passagen im nicht Biotin-supplementierten GTS-Medium inkubiert. Mit einer solchen Biotin-limitierten Vorkultur wurden jeweils sechs nicht Biotin-supplementierte und sechs GTS-Röhrchen mit $40 \mathrm{nM}$ Biotin je Stamm angeimpft und bei $30{ }^{\circ} \mathrm{C}$ inkubiert. $72 \mathrm{~h}$ nach Animpfen der Kulturen wurden je drei supplementierte und nicht supplementierte Kulturen 20 min bei 39 ${ }^{\circ} \mathrm{C}$ inkubiert und unmittelbar danach, zusammen mit den unbehandelten Kontrollen, ausplattiert. Die Anzahl der Kolonien bildenden Einheiten bezogen auf die OD $_{600}$ wurde durch Auszählen ermittelt. Dabei zeigte sich, daß sowohl der Wildtyp, als auch die Mutante Rm1021-EH45 in den hitzegeschockten Biotin-limitierten Kulturen wesentlich besser anwuchsen als die unbehandelten Kontrollen (siehe Abb. 41).

Der Mittelwert der Titer, die für die Kontrollen bestimmt wurde, wurde als $100 \%$ festgesetzt, so daß für den Wildtyp nach Hitzeschock unter Biotin-limitierenden Wachstumsbedingungen ein durchschnittlicher Titer von $185 \%$ und für die pcm-Mutante von $207 \%$ bestimmt werden konnte. In den Biotin-supplementierten Kulturen wurden nach Hitzebehandlung leicht erhöhte Titer bestimmt, diese waren aber weniger stark von den Kontrollen abweichend (113\% bei Rm1021 und $115 \%$ Rm1021-EH45). Für die gewählten Streßbedingungen konnte für Rm1021-EH45 kein vom Wildtyp abweichender Phänotyp gefunden werden. Interessant ist aber, daß Hitzestreß, der unter Biotin- 
limitierenden Bedingungen erfolgte, in S. meliloti zu einem deutlich besseren Überleben führte, als das für Kulturen $\mathrm{zu}$ beobachten war, welche im Biotin-haltigen Medium angezogen worden waren.
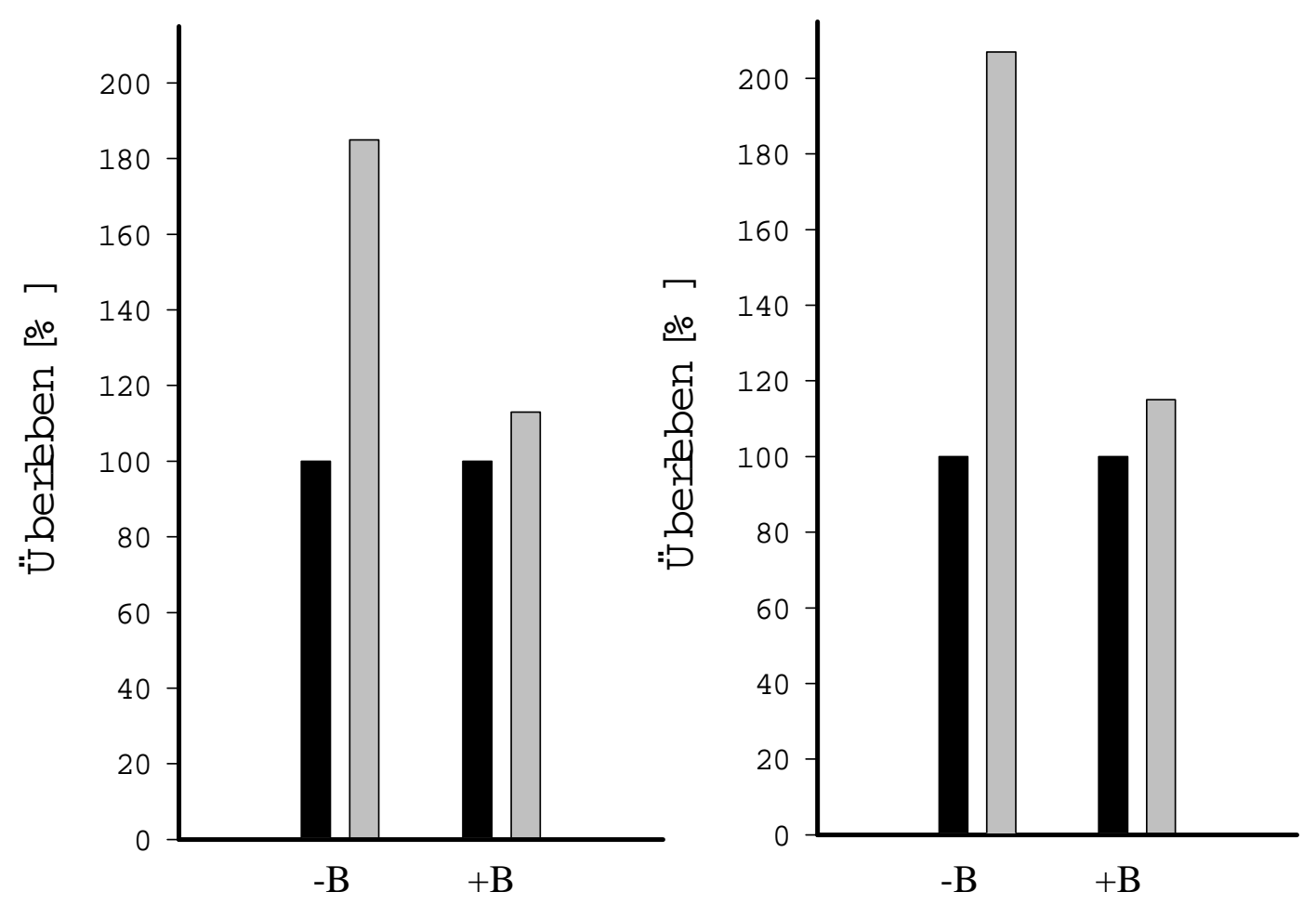

unbehande lte Kontrollen

$\mathrm{H}$ itzegeschockte Kulturen

Abb. 41 Überleben von Rm1021 und Rm1021-EH45 nach Anzucht in GTSMinimalmedium mit und ohne Biotin nach Hitzeschock

Der Mittelwert der Titer der unbehandelten drei Kontrollen unter jeder Bedingung wurde jeweils für den Wildtyp und die pcm-Mutante Rm1021-EH45 als $100 \%$ festgesetzt. Sowohl beim WT als auch bei der Mutante konnte unter Biotin-limitierenden Bedingungen (-B) nach Hitzeschock eine starke Zunahme der Titer beobachtet werde, während unter Biotinsuffizienz (+B) der Titer nur leicht anstieg. 


\section{DISKUSSION}

Im Rahmen dieser Arbeit wurden verschiedene Strategien verfolgt, um weitere Biotinregulierte Gene in S. meliloti 1021 zu identifizieren. Dazu zählten die 2D-Gelelektrophorese und die Expressionsanalyse von gezielt aus den Datenbanken ausgewählten Genen, welche an Prozessen wie der Nodulation, Autoinduktion oder Phospholipidbiosynthese involviert sind. Desweiteren wurden die surE- und pcm-Gene aus dem Survival-Locus charakterisiert und deren Bedeutung für das Überleben in der stationären Wachstumsphase untersucht.

Die 2D-Gelelektrophorese bietet die Möglichkeit unter verschiedenen Bedingungen die Proteinexpression eines Organismus oder Gewebes zu analysieren. Zur Identifizierung von Biotin-induzierbaren Genen bzw. Genprodukten in S. meliloti 1021 wurde in dieser Arbeit die vergleichende Proteomanalyse durchgeführt. Dabei wurde das Proteinmuster von zunächst unter Biotinlimitierung inkubierten Rhizobien mit dem Proteinmuster Biotinsupplementierter Kulturen verglichen. Durch den wiederholten Transfer von S. meliloti in nicht Biotin-supplementiertes GTS-Minimalmedium erreichten die Kulturen nur geringe optische Dichten und durch die lange Inkubation unter diesen Bedingungen (32-37 Tage) befanden sich die Bakterien stets in der stationären Wachstumsphase. Durch die Zugabe von $40 \mathrm{nM}$ Biotin kam es nach einer lag-Phase, deren Dauer vom Alter der unter Biotinlimitierung inkubierten Kulturen abhing, zu erneutem Wachstum. Die optische Dichte der Kulturen nahm zu und die Kulturen wurden in der exponentiellen Phase geerntet.

Die 2D-Gel Analyse ergab, daß ein Großteil der etwa 600 Protein-Spots unter beiden Bedingungen $\mathrm{zu}$ sehen war. Unter Biotin-limitierenden Bedingung traten etwa 50 zusätzliche Spots auf, die nach Biotinsupplementation nicht oder kaum zu sehen waren. Diese befanden sich vor allem im niedermolekularen Bereich bei relativ geringen pIWerten (siehe Abb. 2). Biotinsupplementation führte zur Induktion von etwa 70 Proteinen. 18 Proteine, die nach Biotinsupplementation verstärkt exprimiert wurden und auch im Coomassie gefärbten Gel eindeutig zuzuordnen waren, wurden massenspektrometrisch untersucht. Dabei wurden 12 Proteine identifiziert.

In mehreren Studien wurden bereits früher bei verschiedenen Rhizobien mit Hilfe der vergleichenden Proteom-Analyse Proteine identifiziert, die unter definierten Bedingungen induziert oder reprimiert waren. Natera et al. (2000) verglichen unter anderem die Proteinmuster von nicht pflanzenassoziierten S. meliloti 1021-Zellen, die in Flüssigkultur 
in der frühen exponentiellen Phase geerntet wurden, mit denen von Bacteroiden. In den Bacteroiden waren 130 Proteine verstärkt exprimiert oder induziert und mindestens 350 Proteine in ihrer Expression vermindert oder überhaupt nicht vorhanden. Von den in den freilebenden Rhizobien erhöht exprimierten Proteinen konnten insgesamt 27 identifiziert werden, darunter das SurE-Protein, periplasmatische Bindeproteine für Sorbitol und Dipeptide und ein periplasmatisches Bindeprotein eines ABC-Transporters, welcher nicht näher definiert wurde. In den Bacteroiden wurden u.a. die Enzyme der PHB-Synthese herunterreguliert. Die vergleichende Proteomanalyse von S. meliloti 1021-Zellen aus der frühen exponentiellen Phase $\left(\mathrm{OD}_{600}=0,3\right)$ und der späten exponentiellen Phase $\left(\mathrm{OD}_{600}=1,2\right)$ ergab, daß mindestens 52 Proteine mit verändertem Expressionsniveau in den 2D-Gelen zu sehen waren. Letztlich wurden davon nur zwei Proteine mit erhöhter Expression in der späten exponentiellen Phase identifiziert. Desweiteren wurde das Proteinmuster von Zellen analysiert, die mit dem pflanzlichen Induktor Luteolin versetzt wurden. Sechs und 17 Stunden nach Luteolinsupplementation konnten keine Veränderungen im Proteom beobachtet werden (Guerreiro et al., 1999). Dagegen zeigten Versuche in $R$. leguminosarum, daß die Zugabe des pflanzlichen Induktors Dihydroxyflavon zwar auch nicht die generelle Expression der Proteine beeinflußte, aber zumindest 4 Proteine neu induziert waren. Zwei dieser Proteine konnten identifiziert werden (Guerreiro et al., 1997). Proteomanalysen dieser Arbeit demonstrierten, daß sechs Stunden nach Biotinzugabe noch keine eindeutig reproduzierbaren neuen Spots auf den 2D-Gelen auftraten. Dies kann viele Ursachen haben. Unwahrscheinlich ist, daß die Zellen das Biotin aus der Umgebung noch nicht wahrgenommen haben. Vermutlich führen eher technische Probleme der Proteinaufarbeitung und Visualisierung dazu, daß keine Veränderungen in der Expression auf den 2D-Gelen sichtbar sind. Generell werden während der Proteinaufarbeitung Proteine verloren, darunter vor allem hydrophobe Proteine wie Membranproteine aufgrund der schlechten Löslichkeit im Probenpuffer oder Präzipitation in der ersten Dimension. Desweiteren ist die Kopienzahl der Proteine innerhalb der Zelle ein limitierender Faktor. In analytischen Gelen sind nach Silberfärbung nur die Proteine sichtbar, die in einer Anzahl von mindestens mehreren tausend Kopien pro Zelle vorhanden sind (Wilkins et al., 1998). Dabei gingen die Forscher davon aus, daß $100 \mu \mathrm{g}$ Protein pro Gel geladen werden, einer Menge, die auch bei den Gelen dieser Arbeit eingesetzt wurde. Nur bei Beladung des Gels mit 5 mg könne man auch Proteine nach Silberfärbung sehen, die in einer Anzahl von 1000 Kopien pro Zelle vorhanden sind. Gerade aber Regulatorproteine, die an der Wahrnehmung des exogenen Biotins und Weiterleitung und Verarbeitung des „Biotin- 
Signals“ beteiligt sein könnten, sind vermutlich in einer geringeren Kopienzahl in der Zelle vorhanden und daher auf den Gelen nicht detektierbar.

\subsection{S. meliloti 1021-Proteine mit erhöhter Expression nach Biotin- supplementation des Mediums}

Insgesamt wurden 18 Proteine mit erhöhter Expression nach Biotinsupplementation aus den Gelen ausgeschnitten, tryptisch verdaut und massenspektrometrisch analysiert. 12 Proteine konnten dabei eindeutig identifiziert werden (siehe Tab. 7). Im folgenden wird auf die Rolle dieser Proteine eingegangen.

Protein A: Protein A, welches unter Biotin-limitierenden Bedingungen im geringen Maße und nach Biotinsupplementation stark induziert wird, ist das 50S ribosomale Protein L7/L12, welches durch das rplL-Gen codiert wird. Generell gibt es eine Korrelation zwischen der Ribosomenkonzentration und der Wachstumsrate in E. coli (Nomura, 1999). In anderen Studien wurde die Genexpression der ribosomalen Proteine in Streptomyces coelicolor während verschiedener Wachstumsphasen mit Hilfe der 2D-Gelelektrophorese untersucht (Blanco et al., 1994). Man konnte zeigen, daß die meisten ribosomalen Proteine in allen Wachstumsphasen synthetisiert werden, in frühen Wachstumsphasen ist die Syntheserate jedoch erhöht. Interessanterweise gibt es auch ribosomale Proteine, deren Expression nach 20-24 h Inkubation zu Beginn der stationären Wachstumsphase stark abnimmt und die nach $28 \mathrm{~h}$ und $48 \mathrm{~h}$ Wachstum nicht mehr detektierbar sind. Dabei handelt es sich um L7/L12 und L10. Bisher konnte nicht geklärt werden, warum dieser Effekt nur bei diesen ribosomalen Proteinen auftritt. In S. meliloti ist die Expression von L7/L12 auch unter Biotin-limitierenden Bedingungen in der Stationärphase herunterreguliert und wird mit Wachstumsbeginn offensichtlich induziert. Generell wird die ribosomale Proteinsynthese durch ppGpp im Rahmen der stringenten Kontrolle reguliert. Allgemein geht man davon aus, daß die Regulation durch ppGpp einer der Faktoren ist, der es Bakterien erlaubt sich an limitierende Nährstoffbedingungen (starvation) anzupassen. In E. coli und Vibrio angustum wurde nachgewiesen, daß nach Fettsäure (FS)-Aushungerung eine SpoT (SpoT=ppGpp-Synthetase und ppGpp-Hydrolase) vermittelte ppGpp-Akkumulation auftritt und man spekulierte, daß SpoT ein Signal wahrnimmt, welches im FS-Stoffwechsel eine Rolle spielt, um die Verfügbarkeit von CQuellen zu erfassen (Gong et al., 2002). Damit einhergehend sind Beobachtungen von Seyfzadeh und Mitarbeitern (1993). E. coli Zellen mit einer Mutation des accD-Gens, 
welches für eine Untereinheit der Acetyl-CoA-Carboxylase codiert, einem Schlüsselenzym der FS-Synthese, zeigen unter anderem eine veränderte ppGpp Akkumulation und den Verlust der Fähigkeit schnell auf die Zugabe von Nährstoffen zu reagieren. Das ist insofern interessant, als daß Biotin als Cofaktor für dieses Enzym benötigt wird. Somit läßt sich vermuten, daß es durch Biotinlimitation in $S$. meliloti zu einer Inhibierung der Fettsäuresynthese kommt. Ob dies letztlich auch ein Signal ist, die ppGpp-Synthese in $S$. meliloti $\mathrm{zu}$ stimulieren und damit die stringente Kontrolle einzuleiten, wodurch beispielsweise die verringerte Expression von L7/L12 unter Biotin-limitierenden Bedingungen verursacht werden könnte, muß noch geklärt werden. Während man zunächst annahm, daß in Rhizobium sp. die ppGpp-Synthese nur durch C-Quellen-Mangel induziert werden kann, zeigten neuere Arbeiten, daß in S. meliloti 1021, im Gegensatz zu zwei weiteren Rhizobienstämmen, auch Aminosäuren- und Ammonium-Mangel die Akkumulation von ppGpp stimuliert (Howorth und England, 1999). In S. meliloti gibt es nur ein RelA/SpoT-Protein [SMc02659] (RelA=ppGpp-Synthetase) und die stringente Kontrolle spielt eine Rolle bei der Knöllchenbildung und der Bildung des Exopolysaccharides Succinoglycan (Wells und Long, 2002).

Letztlich führt Biotinlimitierung $\mathrm{zu}$ verminderten Wachstum, damit einhergehend offensichtlich zu einer eingeschränkten Proteinsynthese, was sich in verringerter Expression ribosomaler Proteine widerspiegelt.

Proteine B/C: Beide Proteine wurden als CopC-Protein bestimmt und waren leicht unter Biotinlimitierung und stark nach Biotinsupplementation induziert (siehe Abb. 4). CopCGene sind Teile von cop-Operons, welche in vielen pflanzenpathogenen Bakterien zu finden sind und an der Resistenz gegenüber Kupfer aber auch an der Akkumulation von Kupfer involviert sind. In diesen Organismen codiert $\operatorname{copC}$ für ein periplasmatisches Kupfer-bindendes Protein, welches möglicherweise am Transport des Kupfers in die Zelle beteiligt ist, um somit genug Kupfer für Kupfer-abhängige Enzyme in die Zelle zu transportieren (Cooksey, 1994). Die Expression des cop-operons ist durch Kupfer induzierbar und wird durch die Regulatorproteine CopR und CopS kontrolliert, die selber konstitutiv exprimiert werden. CopC wurde bisher in S. meliloti 1021 noch nicht charakterisiert. Durch Analyse der Proteinsequenz (Scan-prosite: www.expasy.ch/cgibin/scanprosite) wurde in dieser Arbeit eine Multi-Kupfer-Oxidase-Signatur identifiziert, welche sich an Position 134-154 des Peptides befindet (konservierte Aminosäuresequenz: $\mathrm{G}-\mathrm{x}-[\mathrm{F}]-\mathrm{x}-[\mathrm{I}]-\mathrm{x}(8)-\mathrm{G}-[\mathrm{M}]-\mathrm{x}(3)-[\mathrm{V}])$ und welche auch in anderen Cop-Proteinen wie CopA vorkommt. Desweiteren findet man durch Sequenzanalyse im N-Terminus ein 
Signalpeptid, welches als Indiz für die Sekretion des CopC-Proteins in das Periplasma bewertet werden kann (iPSORT-prediction: http://hypothesiscreator.net/ipsort/predict.cgi) Das copC-Gen ist in S. meliloti im 3'-Bereich von copA lokalisiert, jedoch befinden sich stromabwärts der beiden Gene keine weiteren cop-Gene wie in Pseudomonas spp. (copB, copD, copR und copS). Da copB aus Enterococcus hirae copA aus E. coli komplementiert kann man vermuten, daß nicht alle cop-Gene für die Funktionalität des Resistenz- oder Transport-Systems essentiell sind. CopR und CopS aus Pseudomonas spp. zeigen Ähnlichkeit zu einem Transkriptionsregulator und einer Sensor-Histidin-Kinase aus $S$. meliloti. Dabei handelt es sich um ORF SMc02366 (45\% identische AS und $61 \%$ ähnliche AS zu copR aus Pseudomonas fluorescens) und dem unmittelbar stromabwärts gelegenen $O R F$ SMc02367 (27\% identische AS und $46 \%$ ähnliche AS zu copS aus $P$. fluorescens). Für copB und $c o p D$ wurden keine homologen Gene durch blast-Analysen des S. meliloti-Genoms gefunden. Letztlich muß die Organisation und detaillierte Funktion der cop-Gene in S. meliloti noch aufgeklärt werden.

Promotoraktivitäsmessungen des $\operatorname{copC}$-Gens zeigten, daß sich die durch 2D-Gel-Analyse gemachten Beobachtungen bestätigen lassen (siehe Abb. 25). Im Biotin-supplementierten Medium wurden 1,5- bis 5,0-fach erhöhte relative gusA-Aktivitäten einer PromotorReportergenfusion in $S$. meliloti gemessen. Wird $S$. meliloti analog zu den Anzuchtbedingung für die Proteomanalyse inkubiert, kann nach 35-tägiger Inkubation unter Biotinlimitierung und anschließender Biotinsupplementation eine 18-fach erhöhte Expression bestimmt werden. Vermutlich handelt es sich bei der verstärkten Expression des $\operatorname{copC}$-Gens nach Biotinsupplementation um einen sekundären Effekt im Rahmen des wiederaufgenommenen Wachstums, um die Zelle vor Kupfer aus dem Medium zu schützen oder den Kupfer-Bedarf Kupfer enthaltender Enzyme zu sichern.

Offensichtlich handelt es sich bei B und C um isoforme Proteine, die in ihrer Masse annähernd identisch sind und sich in ihrem isoelektrischen Punkt unterscheiden, so daß ein anderes Laufverhalten in der ersten Dimension beobachtet werden konnte. Isoforme Proteine können Produkte posttranslationaler Modifikationen wie Phosphorylierung, Glycosylierung oder Acetylierung sein. Sogenanntes „Protein-Stottern“, also das Auftreten mehrerer Protein-Spots nebeneinander, kann aber auch durch den fehlerhaften Einbau von Aminosäuren in das Protein verursacht werden. Eine verminderte Translationsgenauigkeit tritt z. B. in E. coli Zellen auf, die aufgrund C-Quellen-Limitierung nicht mehr teilungsfähig sind (Ballesteros et al., 2001). Man schätzt, daß $18 \%$ der Proteine aus E. coli als isoforme Proteine vorliegen (Link et al., 1997). In S. meliloti lagen von 400 
untersuchten Proteinen $10 \%$ als isoforme Proteine vor. Unter diesen isoformen Proteinen war das PII-Protein, GroEL mit jeweils zwei Isoformen oder auch NifH, von dem es im Bacteroid vier Formen gab, obwohl es nur durch ein Gen codiert wird (Natera et al., 2000). Protein D: Dieses Protein wurde als Omega-Untereinheit der RNA-Polymerase (RpoZ) identifiziert. Sigma-Faktoren sind generell für die Sequenzspezifität bakterieller RNAPolymerasen essentiell. Die Funktion des RpoZ-Proteins in S. meliloti und damit auch Gene, die in Abhängigkeit dieses Sigma-Faktors reguliert werden, wurden bisher nicht charakterisiert. In $R$. leguminosarum befindet sich rpoZ in 3'-Richtung eines Operons, welches an der Aufnahme von Haemen als Eisenquelle beteiligt ist. RpoZ hat keinen Einfluß auf die Expression dieses Transporters, wird aber für seine eigene Transkription benötigt. Mutationen von rpoZ führen zu keiner veränderten symbiontischen StickstoffFixierung in Vicia sp. und bisher konnten keine regulierten Zielgene identifiziert werden (Wexler et al., 2001). Da rpoZ in E. coli im selben Operon lokalisiert ist wie spoT, ging man zunächst davon aus, daß RpoZ eine Rolle bei der stringenten Kontrolle übernimmt. Weitere Arbeiten zeigten aber, daß RpoZ in vivo nicht für die stringente Kontrolle essentiell ist (Gentry et al., 1991). In S. meliloti liegt rpoZ auch unmittelbar stromaufwärts des relA/spoT-Gens. Das RpoZ-Protein aus E. coli bindet an die B'-UE der RNAPolymerase, die Funktion ist bisher ebenfalls unbekannt (Traviglia, 1999). In dem Grampositiven Bakterium Streptomyces aureofaciens ist RpoZ der sporulationsspezifische Sigmafaktor, welcher Sporulationsgene aktiviert (Kormanec et al., 1999). In welcher Weise die Induktion des rpoZ-Gens durch Biotin erfolgt ist unklar. Denkbar wäre auch hier, daß im Rahmen des aufgenommenen Wachstums die Transkription generell gesteigert wird und daß für die Transkription bisher unbekannter Gene die Omega-Untereinheit der RNA-Polymerase benötigt wird.

Proteine E, F, H, I, K, L: Da die sechs Proteine als periplasmatische ABC-TransporterBindeproteine identifiziert wurden, werden sie im folgenden zusammen diskutiert. Protein $E$ ist ein generelles Bindeprotein für Aminosäuren (AapJ) und die Proteine $\mathrm{K} / \mathrm{L}$ sind isoforme Proteine (siehe oben) des Vorläufers eines Leucin-spezifischen Bindeproteins. Bei Protein I handelt es sich um das Vorläufer-Bindeprotein für Glycerol-3-Phosphat UgpB. Glycerol-3-Phosphat kann als Vorstufe in der Phospholipidsynthese dienen. Für die Proteine $\mathrm{F}$ und $\mathrm{H}$ wird die Art des Substrates in der S. meliloti Datenbank nicht näher spezifiziert ( $\mathrm{F}=$ Bindeprotein für Zucker, $\mathrm{H}=$ Bindeprotein). Zusätzliche Blast-Analysen der Proteinsequenzen zeigten, daß beide Proteine Homologien zu D-Ribose-Bindeproteinen 
aus verschiedenen Organismen wie E. coli, Salmonella typhymurium oder Bacillus subtilis haben, wobei Protein H mit 107 höhere Score-Werte erreicht als Protein F mit 79.

In Bakterien bestehen $\mathrm{ABC}$-Transporter aus einem Bindeprotein für das Substrat, zwei integralen Membranproteinen und zwei membranassoziierten ATP-Bindekassetten. Die Translokation des Substrates über die Cytoplasmamembran wird mit der Hydrolyse von ATP gekoppelt und die Substratspezifität wird durch die Bindproteine determiniert. Wichtig sind die Bindeproteine auch für die Signalerkennung bei der Chemotaxis (Ehrmann et. al., 1998). Bisher wurden die Transportsysteme für Ribose oder Glycerol-3Phosphat und deren Regulation in S. meliloti nicht charakterisiert. Andere periplasmatische Bindeproteine wie AgpA aus S. meliloti, welches $\alpha$-Galactoside bindet, werden durch ihr Substrat induziert. Glucose, Succinat und das Regulatorprotein SyrA, welches besonders stark während der Symbiose exprimiert wird, reprimieren die Expression des agpA-Gens (Gage und Long, 1998). Das Bindeprotein ThuE aus S. meliloti 1021 ist am Transport von Trehalose, Maltose und Sucrose beteiligt. ThuE-lacZ-Fusionen werden nur durch Trehalose und nicht durch Cellobiose, Glucose, Maltose, Mannitol oder Sucrose induziert. Das aglEFGAK Operon aus S. meliloti 1021 transportiert dieselben Zucker, wird aber primär durch Sucrose und nur schwach durch Trehalose induziert (Jensen et al., 2002). Da das hier verwendete GTS-Minimalmedium nur Glucose und Succinat als C-Quellen enthält, ist es fraglich, ob diese Moleküle die Expression von Ribose- und Glycerol-3Phosphat-Transportern regulieren, da Ribose und Glycerol-3-Phosphat als Induktoren nicht vorhanden sind. Möglicherweise sind die beiden C-Quellen Glucose und Succinat nach der langen Inkubationsdauer der Kulturen und erneutem Wachstum bis zur exponentiellen Phase nach Biotinsupplementation nur noch in geringen Mengen im Medium vorhanden. Daher liegt es nahe, daß andere Zucker transportierende Proteine synthetisiert werden, um potentielle weitere C-Quellen des Mediums auszuschöpfen. In Proteomanalysen von E. coli wurden die Proteinmuster von Zellen verglichen, die nach Anzucht unter GlucoseSuffizienz (0,5-1,0 g/l) in Medium transferiert wurden, welches nur 0,1 g/l Glucose enthielt. Unter diesen limitierenden Bedingungen werden zwölf Proteine verstärkt exprimiert. Interessanterweise sind acht dieser Proteine periplasmatische Bindeproteine von $\mathrm{ABC}$-Transportern, darunter auch UgpB (siehe Protein I), RbsB, ein periplasmatisches Bindeprotein für D-Ribose (siehe Proteine F und H) und LivJ (Bindeprotein für Leucin, Isoleucin und Valin; siehe Proteine $\mathrm{K} / \mathrm{L}=\mathrm{LivK}$ ). Obwohl Glucose die einzige Energie- und C-Quelle des Mediums war, wurden auch Bindeproteine anderer Transportsysteme induziert, die nicht am Transport von Glucose beteiligt sind (Wick et al., 2001). Auch 
ältere Studien in E. coli zeigten, daß C-Quellen-Limitierung zur Induktion von Zuckerund Peptid bindenden Proteinen und Transportsystemen führt, darunter $r b s B$ (periplasmatisches Ribose-Bindeprotein; siehe Proteine F und H), ein Glycerol-3-Phosphat Transportsystem (siehe Protein I) oder cstA, welches an der Peptidaufnahme beteiligt ist (Alexander et al., 1993; Su et al., 1991; Schultz und Matin, 1991). Dabei werden die Gene für den Transport alternativer C-Quellen durch steigende Konzentrationen von cAMP induziert (Alexander et al., 1993). Zyklisches AMP erreicht bereits relativ hohe Konzentrationen und wirkt regulatorisch, bevor die C-Quelle im Medium auf ein Minimum reduziert ist und bevor die Wachstumsraten sinken (Notley-McRobb et al., 1997). Es interagiert mit dem Rezeptorprotein Crp (cAMP-Rezeptor-Protein) und aktiviert so die Promotoren des crp-Regulons. Biotinsupplementation von Biotin-limitierten S. melilotiKulturen führt zur Wachstumsaufnahme und damit zu einem Verbrauch von C-Quellen des Mediums, welches möglicherweise analog zu E. coli zu erhöhter cAMP Konzentration führt. Dies könnte die Induktion verschiedener periplasmatischer Bindeproteine verursachen. Analysen des S. meliloti Genoms zeigten, daß ORF [SMa1245] für einen Crp/Fnr-ähnlichen Transkriptionsregulator codiert, der $23 \%$ identische und $49 \%$ ähnliche AS enthält wie Crp aus E. coli, und daß weitere nicht klassifizierte Proteine mit Homologie zu Crp vorhanden sind (http://sequence.toulouse.inra.fr/meliloti.html). In der Literatur wurde bisher nicht über Crp oder die Rolle von cAMP in $S$. meliloti berichtet. Daß in $S$. meliloti unter den Versuchsbedingungen auch Bindeproteine für Aminosäuren induziert werden, kann damit zusammenhängen, daß diese ebenfalls als $\mathrm{C}$ - oder $\mathrm{N}$-Quelle genutzt werden. Rhizobien können auf einer Reihe von Aminosäuren als alleiniger C- oder NQuelle wachsen (Kahn et al., 1998). In Brucella melitensis wird die Expression des AapJProteins nach Hitzeschock, aber nicht nach Oxidationsstreß oder niedrigem $\mathrm{pH}-\mathrm{Wert}$ induziert (Teixeira-Gomes et al., 2001). Zwei der identifizierten Proteine wurden als Vorläufer-Bindeproteine (isoforme K/L und I) identifiziert. Auch in E. coli sind nach Glucoselimitation zwei der acht induzierten Bindeproteine als Vorläuferproteine identifiziert worden. Die Autoren gehen davon aus, daß es aufgrund der vielen zu exportierenden Bindeproteine zur Konkurrenz um die Signalpeptidase kommt und daher auch Vorläuferproteine im 2D-Gel auftauchen (Wick et al., 2001).

Protein G: Protein G wurde als 2-Keto-3-Desoxy-6-Phosphogluconat-Aldolase identifiziert (EC 4.1.3.16). Dieses Enzym, welches durch das eda2-Gen codiert wird, ist neben der 6-Phosphogluconat-Dehydratase ein Schlüsselenzym des Entner-DoudoroffWeges. Der Entner-Doudoroff-Weg gilt als Hauptabbauweg von Kohlenstoffverbindungen 
in Rhizobien (Kahn et al., 1998). Nach Biotinsupplementation kommt es zum Wachstum der S. meliloti 1021-Kulturen und damit zum Verbrauch der C-Quellen aus dem Medium und der Mobilisierung von PHB. Daß unter diesen Bedingungen Enzyme exprimiert werden, die an der Degradation der Zucker beteiligt sind, entspricht den Erwartungen. Obwohl die Expression der verschiedenen Bindeproteine darauf hinweist, daß Glucose zum Zeitpunkt der Zellernte limitierend ist (siehe oben), zeigt die Expression von eda2, daß offensichtlich noch Glucose -wenn auch möglicherweise schon in geringen Mengenabgebaut wird.

Protein J: Protein $\mathbf{J}$ ist ein konserviertes Protein mit bisher unbekannter Funktion. BlastAnalysen zeigten, daß das Protein aus S. meliloti $77 \%$ Identität zu einem Protein aus Agrobacterium tumefaciens und $53 \%$ Identität zu einem Protein aus Agrobacterium vitis hat. Beide Proteine wurden in diesen Organismen nicht charakterisiert.

Durch Zugabe von Biotin zu Biotin-limitierten Stationärphasekulturen kommt es zu einer Induktion von etwa 70 Proteinen. Die Kulturen nehmen wieder Wachstum auf, was sich auch in der Expression von Proteinen widerspiegelt, welche an grundlegenden Funktionen wie der Transkription (RpoZ) oder der Translation (L7/L8) beteiligt sind. Beim Wachstum verbrauchen die Bakterien die C-Quellen des Mediums (KDPG-Aldolase), was dazu führt, daß die Konzentration dieses Nährstoffes abnimmt. Dies verursacht möglicherweise die erhöhte Expression verschiedener Bindeproteine, um potentielle andere C-Quellen des Mediums ausnutzen zu können.

\subsection{Expressionsanalysen}

\subsubsection{Erhöhte Expression von $\sin I$ und $\sin R$ unter Biotin-limitierenden Bedingungen}

Wachstum von S. meliloti 1021 ist unter Biotin-limitierenden Bedingungen eingeschränkt und nur bis zu geringen Populationsdichten möglich. Da Biotinmangel im Medium bei $S$. meliloti zur Synthese des Reservepolysaccharides PHB führt (Hofmann et al., 2000) und das LuxR-Regulatorprotein aus Vibrio harveyi die Synthese von PHB kontrolliert (Miyamoto et al., 1998), wurde untersucht, ob in S. meliloti die Biotinkonzentration des Anzuchtmediums einen Einfluß auf die Expression der Autoinduktor-Synthase und den entsprechenden Transkriptionsregulator hat. Datenbankanalysen des S. meliloti Genoms zeigten, daß ein chromosomaler ORF SMc00168 Homologien zu Autoinduktor-Synthasen der LuxI-Familie anderer Mikroorganismen wie Agrobacterium tumefaciens aufweist. Unmittelbar stromaufwärts von SMc00168 ist ein ORF mit Homologien zu HSL- 
abhängigen Transkriptionsregulatoren lokalisiert (SMc00170). Erst kürzlich wurden diese beiden Gene in Anlehnung der luxI- und luxR-Gene als sinI und sinR bezeichnet (Marketon und Gonzales, 2002). Während bereits seit längerem bekannt war, daß S. meliloti 1021 ein Autoinduktor-Molekül produziert (Gray et al., 1996; Cha et al., 1998), ergaben neuere Untersuchungen, daß bis zu sieben verschiedene Autoinduktoren in S. meliloti 1021 vorhanden sind (Marketon und Gonzales, 2002). Ihre chemische Struktur wurde bisher nicht aufgeklärt und auch über die Rolle von Acyl-Homoserinlactonen, den regulierten Zielgenen und damit auch der Funktion der Autoinduktion in S. meliloti 1021 ist bisher nichts bekannt.

Zur Charakterisierung der sinI- und sinR-Gene und zur Untersuchung ob es eine Verbindung zwischen Biotinlimitation und Autoinduktion gibt, wurde die Expression der S. meliloti sinI- und sinR-Gene mit Hilfe von Promotoraktivitätsmessungen in Abhängigkeit verschiedener Wachstumsbedingungen, wie An- oder Abwesenheit von Biotin und Variation der C-Quellen im Medium, untersucht. Dabei konnte gezeigt werden, daß unter Biotin-limitierenden Bedingungen die Expression des sinI-Gens um den Faktor 2,9 gegenüber Wachstum bei Biotinsuffizienz höher war, sofern Glucose und Succinat im Medium als C-Quellen vorhanden waren. Mit Succinat als alleiniger C-Quelle im Anzuchtmedium stieg die Expression insgesamt an und unter Biotin-limitierenden Bedingungen war eine 4,3-fach erhöhte Aktivität als unter Biotinsuffizienz meßbar (Abb. 19 und 20). Erwartungsgemäß stiegen die rel. gusA-Aktivitäten mit zunehmender Populationsdichte und damit auch mit zunehmender Inkubationsdauer der Kulturen an (Abb. 19), jedoch waren zu jedem Zeitpunkt der Messung die rel. gusA-Aktivitäten der Biotin-limitierten Kulturen höher als die der unter Biotinsuffizienz angezogenen Kulturen. Auch eine weitere Reduktion von Succinat im Anzuchtmedium führte zu einer verstärkten Expression des sinI-gusA-Konstruktes (siehe Abb. 21).

Die Expression der Transkriptionsregulators SinR dagegen wurde weniger stark von Biotin im Medium beeinflußt. In Biotin-limitierten Kulturen konnte nur eine bis zu 1,5-fach erhöhte Expression des Reportergens bestimmt werden als unter Biotinsuffizienz. Auch hier wurden höhere Aktivitäten gemessen, sofern die Anzucht der Kulturen mit Succinat als alleiniger C-Quelle erfolgte (Abb. 24). Während die sinI-Expression mit zunehmender Inkubationsdauer der Kulturen in allen getesteten Medien anstieg, war die Expression von $\sin R$ weniger stark Wachstumsphasen-abhängig. Lediglich in der frühen Wachstumsphase konnte eine leicht erhöhte Aktivität unter Biotin-limitierenden Bedingungen beobachtet werden, als zu anderen Zeitpunkten der Messungen (Abb. 23). 
Da Anzucht unter Biotin-limitierenden Bedingungen zu einer erhöhten Expression des sinI-Gens führten, ist davon auszugehen, daß eine erhöhte Autoinduktor-Synthase Expression auch zu einer vermehrten Bildung des Autoinduktor-Moleküls selbst führen. Daher wurde untersucht, ob sich aus einer definierten Menge Überstand einer Biotinlimitierten Kultur mehr Autoinduktoren extrahieren ließen als aus dem Überstand Biotinsupplementierter Kulturen (siehe 3.3.8). Nach Extraktion der Autoinduktoren aus dem Überstand verschiedener Kulturen, Chromatographie und Detektion durch einen Agrobacterium tumefaciens-Reporterstamm, konnte bei den Extrakten der Biotinlimitierten Kulturen ein intensiveres Signal beobachtet werden, als bei den Extrakten der Biotin-supplementierten Kultur gleicher OD (vgl. Abb. 29). In anderen Studien wurde ermittelt, daß die Intensität des Signals proportional zur Menge der chromatographierten Autoinduktor-Moleküle ist (Shaw et al., 1997). Daher kann man die Aussage treffen, daß sich aus einer definierten Menge Überstand einer unter Biotinlimitierung angezogenen $S$. meliloti 1021-Kultur mehr Autoinduktor-Moleküle isolieren ließen, als aus demselben Volumen einer Biotin-supplementierter Kultur gleicher optischer Dichte. Die Expression der SinI-Autoinduktor Synthase ist in S. meliloti 1021 daher nicht nur eine Funktion der optischen Dichte der Kulturen. Wurden Extrakte Biotin-limitierter und Biotinsupplementierter Kulturen mit gleicher Wachstumszeit verglichen (siehe 3.3.8), trat das intensivere Signal bei den Kulturen mit den höheren optischen Dichten, nämlich den Biotin-supplementierten Kulturen, auf. Das heißt, daß unter diesen Bedingungen in den Biotin-supplementierten Kulturen die Konzentration der Autoinduktoren im Überstand höher war. Dies scheint auf den ersten Blick den Expressionsdaten des sinI-Gens zu widersprechen. Es muß aber angemerkt werden, daß bei der Berechnung der rel. gusAAktivitäten die optischen Dichten der Kulturen berücksichtigt werden, während dies bei der Extraktion der Autoinduktoren nicht möglich ist. Zum einen hängt das Phänomen der Autoinduktion in S. meliloti 1021 in Übereinstimmung mit anderen Organismen von der Zelldichte der Kulturen ab. Andererseits weisen die Expressionsdaten des sinI-Gens und auch das intensivere Signal der Extrakte Biotin-limitierter Kulturen bei vergleichbarer $\mathrm{OD}_{600}$ darauf hin, daß Biotinlimitierung $\mathrm{zu}$ einer vermehrten Produktion von Autoinduktoren führt.

Die Ergebnisse dieser Arbeit lassen vermuten, daß Wachstum unter suboptimalen Bedingungen zu einer vermehrten Produktion von Acyl-HSL-Molekülen auch schon bei relativ geringen Populationsdichten führt. 
In der Regel tritt Autoinduktion und damit die Expression spezifischer Gene in Abhängigkeit der Zelldichte bei verschiedenen Bakterien auf, darunter viele, die in Assoziation mit höheren Organismen stehen. Entdeckt wurde dieses Phänomen bei Photobacterium fischeri, welches über das LuxI/LuxR-System Biolumineszenzgene induziert. Diese werden aber nur dann aktiviert, wenn die Bakterien hohe Zelldichten erreichen, wie in Assoziation mit dem Wirtsorganismus innerhalb des Lichtorgans (Gray und Greenberg, 1992; Meighen, 1991). Viele pathogene Bakterien regulieren Virulenzfaktoren oder die Synthese von Antibiotika über Autoinduktion. Dazu gehören pflanzenpathogene Organismen wie Erwinia carotovora oder auch Humanpathogene wie Pseudomonas aeruginosa. Bei Agrobacterium tumefaciens wird der Transfer des Tumor induzierenden Plasmides durch TraI und TraR reguliert. Auch das freilebende Bakterium Rhodobacter sphaeroides verfügt über quorum sensing. Wird das System durch Mutation der Autoinduktor-Synthase cerI gestört, führt das zur Bildung großer Zellaggregate in Flüssigkultur und schleimigen Kolonien bei Anzucht auf Agar (Puskas et al., 1997).

Vielfältig und noch nicht vollständig aufgeklärt ist Funktion von Acyl-HSL-Molekülen bei anderen Rhizobien, wie beispielsweise bei $R$. leguminosarum bv. viciae. In diesem Organismus existieren verschiedene Regulatoren vom LuxR-Typ. RhiR beispielsweise aktiviert einerseits ein Operon von Genen, die in der Rhizosphäre exprimiert werden (rhiABC), welche eine noch nicht definierte Rolle bei der Nodulation spielen (Cubo et al., 1992; Wisniewski-Dye et al., 2002) und andererseits aktiviert RhiR noch nicht identifizierte Gene auf dem Sym-Plasmid pRL1JI, was zur Inhibierung von Wachstum und $\mathrm{zu}$ einem frühen Beginn der stationären Wachstumsphase in R. leguminosarum-Kulturen mit dem symbiontischen Plasmid pRL1JI führt (Gray et al., 1996). Auch das Produkt von CinI inhibiert Wachstum von manchen $R$. leguminosarum bv. viciae Stämmen und ist auch unter dem Namen small bacteriocin bekannt (Hirsch, 1979; Wisniewski-Dye et al., 2002). Ein dritter dem CinI/R-System untergeordneter Regulator RaiR spielt möglicherweise eine Funktion bei der Anpassung von R. leguminosarum an verschiedene Umweltbedingungen. Regulierte Zielgene von RaiR wurden noch nicht identifiziert (Wisniewski-Dye et al., 2002). Neuere Arbeiten identifizierten weitere LuxR-Typ Regulatorproteine (BisR und TriR) in R. leguminosarum, welche für den Plasmidtransfer benötigt werden (Wilkinson et al., 2002). Das Überleben von R. leguminosarum unter C-Quellen und N-Quellen Mangel im Medium ist abhängig von der Zelldichte beim Eintreten in die stationäre Wachstumsphase. Werden nur geringe optische Dichten beim Eintreten in die Stationärphase erreicht, ist das Überleben schlechter als in Kulturen, welche beim 
Eintreten in die Stationärphase hohe optische Dichten aufweisen. Die Autoren gehen davon aus, daß Acyl-HSL-Moleküle die Anpassung an die stationäre Wachstumsphase ermöglichen, welche bei geringen Populationsdichten noch keine Schwellenkonzentration zur Aktivierung bisher unbekannter Zielgene ermöglichen. Die Überlebensfähigkeit von Kulturen mit geringer Populationsdichte konnte durch die Zugabe von Acyl-HSL zum Medium erhöht werden (Thorne und Williams, 1999). Daß Homoserin-Lactone möglicherweise eine Funktion bei der Anpassung von Bakterien an limitierende Bedingungen übernehmen (starvation response) und nicht unbedingt immer direkt an Prozessen der Bakterien-Wirt Interaktion beteiligt sein müssen, zeigen auch weitere Beispiele aus der Literatur. In E. coli werden nicht acetylierte Homoserin-Lactone als Reaktion auf limitierende Wachstumsbedingungen synthetisiert. Diese sich anhäufenden starvation-Signale können dann über den Stationärphase-Sigmafaktor und unabhängig von der Zelldichte weitere Stationärphasegene aktivieren (Huisman und Kolter, 1994; Salmond et al., 1995) Desweiteren ist quorum sensing in E. coli an der Inhibierung der chromosomalen Replikation involviert und man vermutet allgemein eine Beteiligung dieses Systems beim Zellteilungs-Zyklus unter Streß und limitierenden Wachstumsbedingungen, allerdings bewirkt Glucoseapplikation dort eine Erhöhung der Produktion des Autoinduktors AI-2 (Withers und Nordström, 1998; DeLisa et al., 2001).

Bei Vibrio sp. 14 werden als Antwort auf C-Quellen Limitierung verschiedene Proteine verstärkt produziert, sogenannte carbon starvation induzierte Proteine. Durch Zugabe von Überstand aus Stationärphase-Kulturen zu logarithmisch wachsenden Zellen, werden ebenfalls dieselben Proteine induziert, wobei extrazelluläre Signalmoleküle an dieser Antwort beteiligt sind und man vermutet, daß es sich um Acyl-HSL-Moleküle handelt (Srinivasan et al., 1998).

In Vibrio fischeri führt Zugabe von Glucose zum Medium einerseits zu einem schnelleren Wachstum, gleichzeitig aber auch zu einer Verzögerung der Autoinduktion der Lumineszenz. Limitierung von Eisen führt dagegen zu langsameren Wachstum und einer früheren Autoinduktion bei bereits geringeren Zelldichten (Dunlap und Kuo, 1992; Haygood und Nealson, 1985). Dies entspricht den in dieser Arbeit gemachten Beobachtungen, da Glucose im Medium zu einer verminderten sinI Expression führte und schlechtes Wachstum durch Biotinlimitierung zu einer induzierten Expression bei bereits geringen Zelldichten. In Ralstonia solanacearum ist die Produktion der Acyl-HSLSignalmoleküle von einem dem Stationärphase-Sigmafaktor homologen Protein abhängig, welches selbst maximale Aktivität unter limitierenden Wachstumsbedingungen hat (Flavier 
et al., 1998). In Pseudomonas aeruginosa dagegen aktiviert das rhl quorum sensingSystem, welches an der Rhamno-Lipid-Synthese beteiligt ist, die Expression des Stationärphase-Sigmafaktors (Latifi et al., 1996). Van Delden und Mitarbeiter (2001) vermuten, daß in $P$. aeruginosa die stringente Kontrolle beide quorum sensing-Systeme aktivieren kann, unabhängig von der Zelldichte der Kulturen. Letztlich sprechen viele Daten dafür, daß in einigen Bakterien Acyl-Homoserinlactone auch den Übergang in die stationäre Wachstumsphase regulieren und daß bei der Regulation dieses Überganges Autoinduktoren nicht nur bei hohen Populationsdichten von Bedeutung sind. Über Autoinduktion werden auch Gene in Kulturen reguliert, die unter limitierenden Bedingungen geringere optischen Dichten erreichen, so daß eine Anpassung an die Stationärphase ermöglicht wird (Lazazzera, 2000). Desweiteren wird spekuliert, daß die Zelldichte, bei der quorum sensing maximal exprimiert wird, das Wachstumspotential der Umwelt widerspiegelt. Dieses Wachstumspotential ist unter limitierenden Bedingungen eher ausgeschöpft, was durch geringe Populationsdichten deutlich wird. Auch die unter Biotin-limitierenden Bedingungen angezogenen S. meliloti 1021-Kulturen erreichen nur geringe optische Dichten. Biotinlimitierung führt möglicherweise über die erhöhte Expression des sinI-Gens zu einer Aktivierung von unbekannten Genen, die eine Anpassung der Rhizobien an die gegebenen schlechten Umwelt- und WachstumsBedingungen erlauben. Möglicherweise signalisieren Autoinduktoren auch in S. meliloti, daß das Wachstumspotential der Umwelt, wie zum Beispiel während der Anzucht im Biotin-limitierten Medium, ausgeschöpft ist. Zusätzliche Limitierung durch geringere Konzentrationen an C-Quellen im Medium, erhöhen die sinI Expression, was ebenfalls ein Hinweis darauf ist, daß Autoinduktoren in S. meliloti an der Vermittlung von schlechten Wachstumsbedingungen beteiligt sein könnten. Da die Sequenzierung des Genoms gezeigt hat, daß es in S. meliloti 1021 keinen dem rpoS-Gen homologen StationärphaseSigmafakor gibt, und bisher nicht bekannt ist, ob andere Sigmafaktoren seine Funktion übernehmen können, könnten alternativ über den Mechanismus der Autoinduktion Gene aktiviert werden, die den Eintritt in die stationäre Wachstumsphase erlauben.

Beim Nachweis der aus dem Überstand von S. meliloti 1021 extrahierten Autoinduktoren durch den Reporterstamm A. tumefaciens NTL4 (pCF218) (pCF372) konnte in dieser Arbeit nur ein Signal detektiert werden. Die geringe Mobilität läßt auf ein stark hydrophobes Autoinduktor-Molekül schließen, welches vermutlich einen langkettigen Acylrest besitzt. Dies ist vergleichbar mit Ergebnissen anderer Arbeitsgruppen, die im Überstand von S. meliloti 1021 ebenfalls nur ein Autoinduktor-Molekül mit geringer 
Mobilität isolierten (Cha et al., 1998). Auch Shaw und Mitarbeiter (1997) konnten durch andere A. tumefaciens-Reporterstämme nur einen Autoinduktor mit geringer Mobilität im Überstand von S. meliloti L5-30 und S. meliloti YA2 detektieren. Sinorhizobium meliloti AK631 dagegen produziert mindestens neun verschiedene Acyl-HSL-Moleküle und in neueren Untersuchungen konnten im Überstand von S. meliloti 1021 sechs verschiedene Acyl-HSL-Moleküle durch einen A. tumefaciens Reporterstamm und ein AutoinduktorMolekül durch einen $C$. violacearum Reporterstamm identifiziert werden (Marketon und Gonzales, 2002). Allerdings wurden bei diesen Experimenten Überstand von S. melilotiKulturen verwendet, die bis zur Sättigung gewachsen waren. Die Extraktion der in Abb. 29 dargestellten Autoinduktoren erfolgte aus Überstand von Zellen mit einer optischen Dichte von etwa 0,3. Außerdem wurden bei Marketon und Gonzales größere Mengen chromatographiert (etwa 20-fache Menge). Fraglich ist, ob diese zusätzlichen Signale auch durch die Aktivität von SinI produziert werden. In S. meliloti AK631 findet man neben dem $\sin I / \sin R$-Locus auch eine Autoinduktor Synthase vom TraM-Typ, welche für die Produktion der zusätzlichen Autoinduktoren verantwortlich gemacht wird und in $S$. meliloti 1021 nicht vorhanden ist (Marketon und Gonzales, 2002). Auch bei anderen Organismen wie $R$. leguminosarum und $P$. aeruginosa existieren mehrere Regulationssysteme nebeneinander oder auch in übergeordneter Weise und man spricht man von einem quorum sensing Netzwerk oder einer quorum sensing Regulationskaskade. Dabei kann die Expression eines Autoinduktor-Systems weitere LuxI/LuxR-ähnliche Systeme unter verschiedenen Bedingungen aktivieren (Wisniewski-Dye et al., 2002; Parsek und Greenberg, 2000; Blosser-Middleton und Gray, 2001). Denkbar ist daher, daß es bei S. meliloti 1021 weitere Proteine gibt, die für die Synthese der durch Marketon und Gonzales detektierten Autoinduktoren in Frage kommen, die aber unter den in dieser Arbeit dargestellten Bedingungen nicht oder nur sehr wenig aktiv waren. Weitere Synthasen wären vermutlich nicht vom luxI-Typ, da Analysen zeigten, daß es im Genom von S. meliloti 1021 nur eine Autoinduktor Synthase vom luxI-Typ gibt, während mehrere Gene vom luxR-Typ vorhanden sind (Wisniewsky-Dye et al., 2002; Sourjik et al., 2000). Es bleibt noch zu klären, ob S. meliloti weitere Autoinduktor Synthasen vom LuxM-Typ oder HtdS-Typ besitzt, von denen letztere bei Pseudomonas fluorescens identifiziert werden konnten (Laue et al., 2000). 


\subsubsection{Expression der nodD1- und nodD3-Reportergenfusion}

Flavonoide wie Luteolin werden von Leguminosen in den Boden exsudiert. Diese aktivieren zusammen mit bakteriellen NodD-Proteinen die Expression der nod-Gene, deren Genprodukte den nod-Faktor synthetisieren. Ob die Expression der NodD-Regulatoren selbst auch unter Biotin-limitierenden Bedingungen, einer Umweltbedingung, die einen Aspekt der Abwesenheit einer Pflanze unter Laborbedingungen simulieren könnte, möglich ist, wurde bisher noch nicht dokumentiert. Die Ergebnisse dieser Arbeit zeigen, daß die Expression der nodD3- und nodD1-Gene von der Biotinkonzentration des Mediums unbeeinflußt ist. Der nodD1-Promotor war unter allen getesteten Bedingungen auf relativ hohem Niveau aktiv, unverändert von der Verfügbarkeit von Biotin oder dem Flavonoid Luteolin. Andere Studien zeigten ebenso, daß das nodD1-Gen selbst konstitutiv exprimiert wird und NodD1 in Anwesenheit von pflanzlichen Induktoren wie Luteolin und 4,4'-Hydroxy-6-Methoxychalcon nod-Gene aktiviert, (Dusha et al., 1989; Mulligan und Long, 1989; Schlaman et al., 1992). Neuere Arbeiten weisen darauf hin, daß NodD1 nicht aber NodD3 in Anwesenheit von Luteolin und dem GroESL-Chaperonin-System verbesserte DNA-Bindeeigenschaften an die nod-box des nodF-Gens zeigt. Inwieweit die Aktivität des nodD1-Promotors selbst durch Luteolin und GroESL beeinflußt wird, wurde nicht präsentiert (Yeh et al., 2002). Im natürlichen System verhindert das Repressorprotein NolR eine Überexpression der nodD1- und nodD2- Gene (Kondorosi et al., 1991).

Der nodD3-Promotor war unter den getesteten Bedingungen nicht aktiv. Die gemessenen ß-Glucuronidaseaktivitäten der pPR-nodD3-kurz- (mit einem Transkriptionsstartpunkt) und pRP-nodD3-lang-Konstrukte (mit beiden Transkriptionsstartpunkten) entsprachen denen des leeren Vektors und wurden nicht durch Zugabe von Luteolin zum Anzuchtmedium erhöht. In der Literatur wird die Regulation des nodD3-Gens unterschiedlich diskutiert. Bekannt ist, daß das nodD3-Genprodukt auch in Abwesenheit von pflanzlichen Induktoren die Expression der nod-Gene aktiviert (Mulligan und Long, 1989). Das nodD3-Gen selbst soll aber nicht wie nodD1 konstitutiv exprimiert werden, sondern durch das Flavonoid Luteolin induzierbar sein (Dusha et al., 1989). Andere Studien belegten, daß die nodD3-Expression durch den Transkriptionsregulators SyrM aktiviert wird und daß NodD3 wiederum syrM-Expression fördert, während der Effekt von pflanzlichen Induktoren auf diesen Regelkreis minimal ist (Swanson et al, 1993; Maillet et al., 1990). Neuere Arbeiten zeigten, daß zwei verschieden lange Transkripte in Abhängigkeit von verschiedenen Umweltbedingungen synthetisiert werden. Das längere Transkript wird nur bei einem günstigen Stickstoffstatus in der Zelle und unabhängig von 
Luteolin gebildet, während das kurze Transkript unter Stickstoffmangel und wahrscheinlich in Abhängigkeit von $\sigma^{54}$ synthetisiert wird. Von diesem Transkriptionsstartpunkt soll auch eine Luteolin induzierbare und durch NodD1 verstärkte Expression stattfinden, wobei der Mechanismus noch unklar ist (Dusha et al., 1999). Unter den in dieser Arbeit durchgeführten Anzuchtbedingungen, konnte nodD3 nicht induziert werden.

\subsubsection{Expression des bioM-Operons}

Das bioM-Gen wurde bereits in früheren Arbeiten dieser Arbeitsgruppe untersucht (Entcheva et al., 2002). BioM ist möglicherweise ein ATP bindendes Protein aus der Familie der $\mathrm{ABC}$-Transporter. In Biotinaufnahmestudien mit ${ }^{14} \mathrm{C}$-markiertem Biotin konnte festgestellt werden, daß die Aufnahme von markiertem Biotin im Wildtyp und der bioM-Mutante zunächst zwar in identischer Weise verlaufen, mit zunehmender Meßdauer aber die Mutantenzellen weniger Biotin enthalten als der Wildtyp. Dies legt die Vermutung nahe, daß BioM daran beteiligt ist, den zellulären Bestand an Biotin zu erhalten. Stromabwärts von BioM liegt BioN, ebenfalls ein möglicher Bestandteil eines ABCTransporters. Unmittelbar in 3'-Richtung der beiden Gene ist bioB lokalisiert, dessen Genprodukt den letzten Schritt der Biotinsynthese vom Desthiobiotin zu Biotin katalysiert. Exogenes Desthiobiotin fördert Wachstum von S. meliloti 1021, nicht aber von der bioMMutante Rm1021-B3 oder der bioN-Mutante 1021-B6. Offensichtlich haben die Mutationen polare Effekte auf bioB. Liegt bioB extrachromosomal vor, können auch die bioM- und die bioN-Mutante auf Desthiobiotin gut wachsen. Dies läßt darauf schließen, daß bioB mit bioM und bioN cotranskribiert wird (Entcheva et al., 2002). Durch die in dieser Arbeit durchgeführten Promotoraktivitätsmessungen des bioM-Gens wurde untersucht, ob Biotin im Anzuchtmedium einen Einfluß auf die Expression des bioM-Gens hat. Die Messungen zeigten, daß unter Biotinsupplementation die Expression des bioMGens zu allen Zeitpunkten um das 2,1 bis 2,4-fache erhöht waren. Biotin im Anzuchtmedium induzierte folglich die Expression des bioM-Gens. Allerdings ist fraglich, ob diese relativ schwache Induktion ein direkter Effekt des Biotin selbst ist oder indirekt durch verbessertes Wachstum von $S$. meliloti und damit durch allgemein erhöhte Stoffwechselaktivitäten verursacht wurde. Wenn BioM daran beteiligt ist, den intrazellulären Biotinbestand zu erhalten scheint es plausibel, daß Biotin die Expression dieses Gens aktiviert. Geht man aber davon aus, daß bioB mit bioM und bioN cotranskribiert wird, bleibt es eher unerklärlich, warum Biotin und damit das Produkt der 
bioB-Aktivität letztlich die Expression der Biotinsynthase induziert. Wenn genug Biotin in der Zelle vorhanden ist, scheint die Expression des bioB-Gens nicht essentiell zu sein, um mehr Biotin zu synthetisieren. Dies und die letztlich schwache Induktion des bioMPromotors legen die Vermutung nahe, daß die erhöhte Expression eher eine Folge erhöhter physiologischer Aktivität unter Biotinsupplementation ist und nicht ein unmittelbarer Effekt des Biotins.

\subsection{Charakterisierung des surE- und pcm-Gens aus S. meliloti 1021}

SurE-, $p c m$ - und $n l p D / l p p B$-Gene sind weit verbreitet und ihre Anordnung ist in vielen Gram-negativen Mikroorganismen konserviert (siehe Abb. 30). Einzig in S. meliloti und Rhizobium NGR234 befindet sich in 3'-Richtung des pcm-Gens das Biotin-regulierte Stationärphasegen bioS. Mutationen des bioS-Gens führen zu einer verlängerten lag-Phase von Zellen, die nach Inkubation unter Biotin-limitierenden Bedingungen mit Biotin supplementiert werden. BioS ist offensichtlich ein Regulatorprotein, welches möglicherweise daran beteiligt ist, exogenes Biotin wahrzunehmen (Heinz et al., 1999).

\subsubsection{SurE- und pcm-Gene und ihre Funktion}

Proteine können durch spontane Konformationsänderungen und kovalente chemische Veränderungen Schaden nehmen und so ihre Funktionalität verlieren. Die Rate dieser schädigenden Reaktionen wird durch Streß wie Hitze, oxidative Agenzien oder pH-Wert Änderungen erhöht (Visick und Clarke, 1995). Als Antwort auf diese Veränderungen kann die Zelle de novo Proteine synthetisieren, geschädigten Proteine reparieren oder abbauen. $\mathrm{Da}$ in der stationären Wachstumsphase und unter limitierenden Bedingungen die generelle Proteinsynthese -oft nach einer initialen Induktion von verschiedenen Streß- und Stationärphase-Proteinen- reduziert ist, sind verschiedene Reparatursysteme daran beteiligt, Proteine zu erhalten, welches letztlich zu einem besseren Überleben führen kann (Östling et al., 1993; Weichart et al., 1993; Herbert und Foster, 2001).

Eine spontane Veränderung in Proteinen ist die Bildung von L-Isoaspartylresten direkt aus Aspartat oder nach Deamidierung von Asparagin. Die Peptidkette bekommt durch Bildung von L-Isoaspartylresten einen „, Knick“, da nun ein bisheriges Seitenketten C-Atom an der neuen Peptidbindung beteiligt ist. Außerdem wird die Ladung eines Proteins verändert, wenn aus einem neutralen Asparaginrest ein saurer Aspartyl- oder Isoaspartyl-Rest entsteht. Enzyme mit L-Isoaspartylresten können eine verringerte Aktivität haben (Visick 
und Clarke, 1995). Pcm-Gene sind ubiquitär und codieren für eine L-Isoaspartyl-ProteinCarboxymethyltransferase (EC 2.2.2.77), welche spezifisch an L-Isoaspartylreste bindet und das C-Atom der Seitenkette methyliert. Die Methylierung erleichtert die Bildung eines Succinimid-Intermediates, welches hydrolytisch zwar wieder zu L-Isoaspartat umgewandelt aber in signifikanten Mengen auch zu L-Aspartat gespalten werden kann (Visick und Clarke, 1995). Mutationen dieses sehr weit verbreiteten Reparaturenzyms führen in E. coli unter Streß (siehe unten) und auch in Nematoden zu einer verminderten Überlebensfähigkeit (Visick et al., 1998; Kagan et. al, 1997). In den Nematoden häufen sich im Larvenstadium in pcm-Mutanten zweifach mehr geschädigte Proteine an als im Wildtyp (Niewmierzycka und Clarke, 1999). In pcmt-knockout-Mäusen (pcmt entspricht pcm) wies man in verschiedenen Gewebetypen eine 2-6-fach höhere Menge an LIsoaspartylresten in den Proteinen nach und die Mäuse sind unter anderem kleiner und sterben früher als gesunde Tiere (Kim et al., 1997). Transgene Mäuse, in denen ein pcmt1Gen unter Kontrolle eines Neuronen spezifischen Promotors eingeführt wurde, akkumulierten in Proteinen des Gehirns $50 \%$ weniger geschädigte Isoaspartylreste (Lowenson et al., 2001). Überexpression dieses Reparaturenzyms in Drosophila melanogaster resultiert in einer temperaturabhängigen Verlängerung der Lebensdauer um bis zu $39 \%$ (Chavous et al., 2001).

SurE-Gene findet man bei vielen Eubakterien und Archaeen aber bisher konnte die physiologische Funktion innerhalb der Zelle nicht genau aufgeklärt werden. Erste Hinweise auf die Funktion gaben Experimente von Treton und Mitarbeitern (1992), in denen festgestellt wurde, daß ein dem surE homologes Gen aus Yarrowia lipolytica einen Saccharomyces cerevisiae Stamm komplementieren kann, in dem zwei saure Phosphatasen mutiert vorlagen. Annähernd zeitgleich klärten unlängst zwei Arbeitsgruppen die Struktur des SurE-Proteins aus Thermotoga maritima auf und wiesen eine Magnesium-abhängige Phosphataseaktivität nach (Lee et al., 2001; Zhang et al., 2001). Daß die surE- und pcmGene eine Rolle bei der Streßantwort spielt, implizieren auch Daten aus E. coli Bc251. Die Bakterien wurden 2000 Generationen lang unter hohen Temperaturen inkubiert, was zu mehreren Genduplikationen führte, darunter auch die der surE- und pcm-Gene (Riehle et al., 2001). Dabei ist Genduplikation in Bakterien ein verbreiteter Prozeß, um auf verschiedene Selektionsdrücke zu reagieren. 


\subsubsection{Expressionsanalyse des pcm-Gens}

Reportergenanalysen in dieser Arbeit zeigten, daß das pcm-Gen aus S. meliloti 1021 in TYVollmedium mit Beginn der stationären Wachstumsphase am stärksten exprimiert wurde. Die relativen ß-Glucuronidaseaktivitäten erreichten in dieser Phase einen durchschnittlichen Wert von 1979, welcher 3,8-fach über dem Wert der frühen exponentiellen Phase und 1,9-fach über dem Wert der mittleren exponentiellen Wachstumsphase lag. In GTS-Minimalmedium war die Expression des pcm-Gens in den ersten 14 Tagen der Inkubation unter Biotin-limitierenden Bedingungen und unter Biotinsupplementation annähernd identisch (siehe Abb. 37). In den Biotinsupplementierten Kulturen fiel die Aktivität danach deutlich $a b$, während unter Biotinlimitierenden Bedingungen das Maximum mit durchschnittlich 2031 und 2024 rel. Einheiten erst nach 21 bzw. 23 Tagen Inkubation erreicht wurde. Die Expressionsstudien in allen Medien zeigten, daß das pcm-Gen aus S. meliloti maximal in der Stationärphase induziert wurde. Interessanterweise war die Expression unter Biotin-limitierenden Bedingungen in Langzeitexperimenten (bis 70 Tage) signifikant höher als unter Biotinsupplementation (siehe Abb. 37). Bisher wurde für kein $p c m$-Gen eine Abhängigkeit der Expression vom Biotingehalt des Mediums beschrieben, was möglicherweise eine Besonderheit des S. meliloti pcm-Gens ist und mit seiner Lokalisation unmittelbar vor dem Biotin-induzierbaren bioS-Gen zusammenhängt, obwohl bioS im Gegensatz zu pcm durch Biotin in der Stationärphase induziert wird. Allerdings sollte in weiteren Experimenten untersucht werden, ob diese Beobachtungen auch unter anderen limitierenden Wachstumsbedingungen gemacht werden können. In E. coli wird das pcm-Gen auch in der stationären Wachstumsphase maximal exprimiert, wobei im Minimalmedium geringere Gesamtaktivitäten erreicht werden. Die Induktion in der Stationärphase ist im Vollmedium 12-15-fach und im Minimalmedium 3,5-5,0-fach (Li et al., 1997). Die Aktivität des PcmProteins ist in der Stationärphase um den Faktor 1,7 höher als in der exponentiellen Wachstumsphase (Li und Clarke, 1992b). Nicht untersucht wurde in E. coli die Expression unter limitierenden Anzuchtbedingungen.

\subsection{3 Überleben der pcm- und surE-Mutante Rm1021-EH45 und Rm1021-EH47}

Die Überlebensfähigkeit der pcm-Mutante Rm1021-EH45 und der surE-Mutante Rm1021EH47 wurde unter verschiedenen Anzuchtbedingungen untersucht. Die Ausplattierung der Kulturen erfolgte nach verschieden langen Inkubationszeiten. Durch Auszählung der Platten wurde der Titer unter Berücksichtigung der optischen Dichte der Kulturen zur 
besseren Vergleichsmöglichkeit als Lebendzellzahl/ml * $\mathrm{OD}_{600}{ }^{-1}$ bestimmt und als Maß für die Überlebensfähigkeit betrachtet.

Die surE-Mutante zeigte unter allen getesteten Bedingungen das gleiche Wachstumsverhalten wie der Wildtyp, was darauf schließen läßt, daß das Gen für das Überleben in der stationären Wachstumsphase keine Bedeutung hat. Bei der pcm-Mutante Rm 1021-EH45 wurde unter Biotin-limitierenden Bedingungen in GTS-Minimalmedium eine verringerte Überlebensfähigkeit im Vergleich zum Wildtyp beobachtet, sofern es sich um mindestens 6 Tage alte Stationärphasekulturen handelte (Abb. 39). Der größte Unterschied trat dabei nach 35 Tagen Inkubationszeit auf. Die pcm-Mutante hatte eine 29-fach schlechtere Überlebensfähigkeit als der Wildtyp. Daher läßt sich folgern, daß das Überleben (survival), welches als die Erhaltung der Lebensfähigkeit definiert wird (Barer und Harwood, 1999), in S. meliloti 1021 durch ein nicht funktionales $p c m$-Gen eingeschränkt ist. Während der über zwei Monate andauernden Inkubation des Wildtyps und der pcm-Mutante in GTSMinimalmedium verringerten sich die optischen Dichten der Kulturen nur leicht und es war auch keine stärkere Abnahme bei der pcm-Mutante beobachtbar, so daß nicht davon auszugehen ist, daß die Zellen signifikant schneller lysierten und aus diesem Grund eine verminderte Überlebensfähigkeit gemessen wurde. In diesem Zusammenhang zeigten auch stichprobenartig durchgeführte Bestimmungen des Titers mit Hilfe einer Zählkammer keine signifikante Abnahme der Zellzahlen während der langen Inkubationsdauer beim Wildtyp und der Mutante. Desweiteren wurden auch keine wesentlichen Unterschiede in der Zellzahl bei gegebener optischen Dichte zwischen dem Wildtyp und der Mutante Rm1021-EH45 beobachtet. Die durch die Zählkammer bestimmten Titer lagen jedoch beim WT und der Mutante in der Regel über denen der durch Ausplattierung bestimmten Titer und zwar stieg die Diskrepanz zwischen den beiden Titern mit zunehmendem Alter der Kulturen an. Während Titer, die durch Auszählen bestimmt worden waren bis zu fünf Monate nahezu konstant blieben, verringerten sich die durch Ausplattierung ermittelten Titer im selben Zeitraum erheblich. Die Titerbestimmung mit Hilfe der Zählkammer lieferte bis zu 2600-fach höhere Werte als die Titerbestimmung nach Ausplattierung. Generell wird die Fähigkeit einer Bakterienpopulation Kolonien zu bilden als zuverlässiges Maß betrachtet, die Lebensfähigkeit zu bestimmen. Andererseits muß eine Bakterienzelle, die keine Kolonie auf Agarplatten bilden kann, nicht zwangsläufig tot sein, da solche Zellen trotzdem Metabolite aufnehmen und verstoffwechseln können (Siegele et al., 1993; Nyström, 2001). 
Offensichtlich führt die Mutation des $p c m$-Gens nicht $\mathrm{zu}$ einem generell schlechterem Wachstum oder schnellerer Lyse der Zellen, sondern zu einem verringerten Überleben. Möglicherweise häufen sich in S. meliloti über diesen langen Inkubationszeitraum Proteine mit L-Isoaspartylresten an, die durch ein nicht funktionales Pcm-Protein nicht repariert werden können. Es stand kein rekombinantes Pcm-Protein zur Verfügung mit dem man erhöhte Isoaspartylmengen hätte nachweisen können. Da die Proteinsynthese in der Stationärphase wie auch unter limitierenden Bedingungen eingeschränkt ist, ist die Reparatur von degenerierten L-Isoaspartylresten ein Mechanismus, um Proteine biologisch aktiv zu halten. Fehlt dieses Reparatursystem könnten auch Proteine geschädigt sein, die eine Wiederaufnahme des Wachstums ermöglichen. Warum der Phänotyp nur nach Anzucht unter Biotin-limitierenden Bedingungen auftrat ist unklar, könnte aber mit den geringen Populationsdichten und damit einer anderen Zusammensetzung der limitierten Kulturen zusammenhängen $\left(\mathrm{OD}_{600}<0,8\right.$; unterschiedlicher Nährstoffgehalt, An- oder Abwesenheit verschiedener Signalmoleküle etc.). Im TY-Vollmedium und im Biotinsupplementierten GTS-Minimalmedium erreichten die Kulturen hohe optische Dichten, was eventuell andere Regelkreise und damit andere Wege der Proteinerhaltung induziert. Sicherlich setzt die Inkubation unter Biotin-limitierenden Bedingungen Mechanismen in Gang, die es der Zelle ermöglichen, Gene zu aktivieren, die eine bessere Anpassung an die vorherrschenden Wachstumsbedingungen erlauben, darunter zum Beispiel eine verstärkte Expression von Reparaturenzymen, wie das Pcm-Protein. Dies würde auch die Hypothese stützen, daß die Abwesenheit von Biotin möglicherweise einer der Faktoren ist, der die Abwesenheit des Symbiosepartners signalisiert. Im unbepflanzten Boden kann S. meliloti lange unter limitierenden Bedingungen überleben und eine erhöhte Expression von Reparaturenzymen könnte dabei die zellulären Proteine schützen.

\subsection{4 Überleben unter Streß}

Streßapplikationen führten zu keiner verminderten Überlebensfähigkeit der S. meliloti pcm-Mutante oder der surE-Mutante. In früheren Arbeiten wurde zunächst vermutet, daß in E. coli pcm- und auch surE-Mutationen zu einer verminderten Überlebensfähigkeit unter diversen Streßbedingungen führten ( $\mathrm{Li}$ und Clarke, 1992b). Neuere Ergebnisse sprechen dafür, daß die beobachteten Phänotypen auf eine zweite Mutation im StationärphaseSigmafaktor-Gen zurückzuführen waren (Visick und Clarke, 1997) und eine neu konstruierte $p c m$-Mutante zeigte auch keinen Überlebensphänotyp nach Hitzeinkubation. Lediglich Zugabe von 0,5 \% (v/v) Methanol zu Stationärphasezellen oder Inkubation von 
Kulturen in Anwesenheit von $0,1 \mathrm{mg} / \mathrm{ml}$ Paraquat führte $\mathrm{zu}$ einem verminderten Überleben bis auf 20-40\% des Wildtypniveaus. Eine E. coli surE-Mutante zeigte unter keinen Bedingungen einen Überlebensphänotyp und bisher wurde auch in keinem Organismus über einen Phänotyp einer surE-Mutation berichtet. Die Genduplikation des surE-Gens in E. coli unter Temperaturstreß, deutet dennoch auf eine Beteiligung des surE-Gens an einer Streßantwort hin (Riehle et al., 2001). Außerdem kompensiert eine surE-pcmDoppelmutante den Phänotyp der pcm-Mutante in E. coli. Erstaunlich dabei ist, daß zwar in 10 Tage alten Stationärphasezellen von E. coli erhöhte Mengen an L-Isoaspartylresten im Vergleich zu $24 \mathrm{~h}$ alten Zellen auftreten, die Menge der angehäuften Reste jeweils in der pcm- und in der surE-Mutante nicht erhöht ist, wohl aber in der surE-pcmDoppelmutante (Visick et al., 1998).

$\mathrm{Da}$ bei verschiedenen Streßapplikationen kein Phänotyp zu beobachten war, könnte auch daran liegen, daß es in $S$. meliloti weitere pcm-Gene gibt, die möglicherweise unter anderen Bedingungen als das pcm-Gen aus dem survival operon induziert werden und Reparaturfunktionen übernehmen. Blast-Analysen mit der pcm-Sequenz aus dem survival operon lassen auf die Existenz von mindestens zwei weiteren pcm-Genen schließen. Dabei handelt es sich um ORF SMa1547 (26\% identische AS und $47 \%$ ähnliche AS) und ORF SMc02083 (27\% identische AS und $44 \%$ ähnliche AS), die bisher nicht charakterisiert wurden, aber als potentielle Protein-L-Isoaspartat-Methyltransferase (EC 2.2.2.77) und als Transmembrane Methyltransferase (pcm-like) (EC 2.1.1.-) annotiert wurden (http://sequence.toulouse.inra.fr).

\subsubsection{Phosphataseaktivität des SurE-Proteins}

Da man schon lange vermutete, daß SurE-Proteine Phosphataseaktivitäten haben und dieses auch kürzlich für das rekombinante SurE-Protein aus T. maritima nachgewiesen werden konnte, wurde überprüft, ob das rekombinante $S$. meliloti SurE-Protein, welches noch an die Histidinreste des Vektoranteiles fusioniert war, ebenfalls diese Enzymaktivität besitzt. Es konnte gezeigt werden, daß SurE aus S. meliloti p-Nitrophenyl-Phosphat (pNPP) und $\alpha$-Naphtyl-Phosphat ( $\alpha$-NP) hydrolysiert und somit Phosphataseaktivität besitzt. In dieser Arbeit wurde keine detaillierte Analyse des SurE-Proteins durchgeführt, sondern nur das pH-Optimum bestimmt. Es lag in Anwesenheit von $20 \mathrm{mM} \mathrm{MgCl} 2$ und 6 mM p-Nitrophenyl-Phosphat im Reaktionsansatz bei pH 6,5. Alle Reaktionen wurden bei $37^{\circ} \mathrm{C}$ durchgeführt. Die Enzymaktivität lag unter diesen Bedingungen bei 5,05 $\mu \mathrm{mol}^{*} \mathrm{~min}^{-}$

$1 * \mathrm{mg}^{-1}$, wurde aber nicht im Substratoptimum bestimmt. In Abwesenheit von $\mathrm{MgCl}_{2}$ 
wurden geringere Aktivitäten ermittelt (Abb. 33). Nativ-PAGE zeigte, daß das SurEProtein im Eluat sowohl als Monomer als auch als Dimer enthalten war (Abb. 32 B). Das SurE-Protein aus dem thermophilen Organismus T. maritima, dessen codierendes Gen nicht in der Nähe eines pcm-Gens lokalisiert ist, wurde kürzlich in zwei verschiedenen Studien charakterisiert. Während eine Arbeitsgruppe davon ausgeht, daß SurE als Dimer vorliegt und ein $\mathrm{pH}$-Optimum von 7,0-7,2 besitzt, zeigten die anderen Forscher, daß sich zwei Dimere zu einem Tetramer assemblieren und das $\mathrm{pH}$-Optimum bei $\mathrm{pH}$ 5,5-6,2 liegt (Lee et al., 2001, Zhang et al., 2001). Die maximale Reaktionsgeschwindigkeit lag mit $\alpha$ NP als Substrat bei $147 \mu \mathrm{mol} / \mathrm{min} / \mathrm{mg}$ und die Aktivität unter diesen Bedingungen wurde = $100 \%$ gesetzt. Mit pNPP als Substrat wurde nur $4 \%$ dieser Aktivität erreicht (Lee et al., 2001). In der anderen Studie wurde Vmax mit $233 \mu \mathrm{mol} / \mathrm{min} / \mathrm{mg}(\alpha-\mathrm{NP})$ und 51,6 $\mu \mathrm{mol} / \mathrm{min} / \mathrm{mg}$ (pNPP) bestimmt. Einig sind sich beide Forschergruppen, daß die Phosphataseaktivität von divalenten Metallionen abhängig ist, und daß das SurE-Protein strukturell keine Sequenzhomologien zu Proteinen bisher bekannten Phosphatase-Familien aufweist und somit eine neue Familie von Phosphatasen darstellt. SurE aus S. meliloti ist mit 256 Aminosäuren um 9 Reste länger als das Protein aus T. maritima. Blast-Analysen des rhizobiellen SurE-Proteins zeigten, daß $32 \%$ der Proteinsequenz identisch und $52 \%$ ähnlich zur Sequenz aus T. maritima sind. Ein Sequenzvergleich ist in Abb. 42 dargestellt. Über die physiologische Funktion des SurE-Proteins in der Zelle und das natürliche Substrat konnten beide Forschergruppen keine Aussage machen. Man spekulierte, daß SurE möglicherweise an Prozessen der Signaltransduktion, konnte aber keine experimentellen Beweise dafür liefern (Lee et al., 2001).

S. meliloti

M. loti

T. maritima

E. coli

$P$. aeruginosa

$x$. fastidiosa

Clustal Consensus

S. meliloti

M. loti

T. maritima

E. coli

$P$. aeruginosa

$X$. fastidiosa

Clustal Consensus
MRILLTNDDGIHAEGLSVLERIARTISDDVWVVA EVDQSGLAHSLTLSE 50 MRILLTNDDGIHAEGLASLERVARTLSDDVWVVA EQDQSGYAHSLSISE 50 MRILVTNDDGIQSKGIIVLAELLS-EEHEVFVVA DKERSATGHSITIHV 49 MRILLSNDDGVHA GIQTLAKALR-EFADVQVVA DRNRSGASNSLTLES 49 MRILIANDDGVTA GIAALYDALA-DHADCVVIA DQDKSGASSSLTLDR 49 MRVLVSNDDGVDA GIKILADALRNAGHEVMVVA DRDRSGASNSLTLDT 50

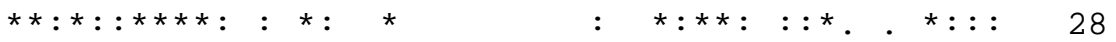

LRLR VSERRFALR----GT TDCVIMAVKKILDRK DLVLSGVNVGAN 96 LRLRKIGEKHFAVR----GT TDCVIMGVKKIL GA DVILSGINSGAN 96 LWMKKVFISERVVAYSTTGT ADCVKLAYNVVMDKRVDLIVSGVNRG N 99 SLRTFTFENGDIAVQ---MGT TDCVYLGVNALMR R DIVVSGINAG N 96 LH QRLDNGF ISL----NGT TDCVHLGLNGLLEEL DMVVSGINLGAN 95 IRAKQIDMHTYSV----AGT TDCVHLALTGLLNYD DIVVSGINNTGN 96

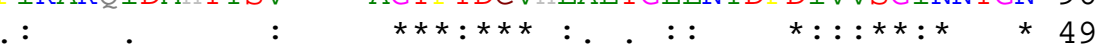




\begin{tabular}{|c|c|c|}
\hline S. meliloti & LADDVTYSGTVAGAIEGTLQGIRSIALSQAYQHAVG-RDV WDVAETHA & 145 \\
\hline M. $\operatorname{loti}$ & IADDVTYSGTVAGAMEGALLGIRS IALSQGYSYVGEDRIV YETTEALA & 146 \\
\hline T. maritima & MGMD I LHSGTVSGAMEGAMMNI SIAISS-----ANYES DFEGAARFLI & 144 \\
\hline E. coli & LGDDVIYSGTVAAAMEGRHLGF ALAVSL-----DG--HKHYDTAAAVTC & 9 \\
\hline P. aeruginosa & LGDDVLYSGTVAAAIEGRFLKG AFAFSL-----VSRLTDNL TAMHFAR & 140 \\
\hline X. fastidiosa & LGDDVIYSGTVSAAMEGRFLGL AVAVSLVTLYREGQQA QYETAAHAAI & 146 \\
\hline Clustal Consensus & $\therefore{ }^{\star}::{ }^{\star \star \star \star}: .^{\star}: \star \star$ & 66 \\
\hline s. meliloti & ALIRTLMGVDL DGTLINLNF NCAVDAVAGVEVTSQGKLEFGLSIDERT & \\
\hline M. loti & ALLKKLVAT L DGVLLNVNF NCL EEVVGTVVTMQGKLVHSLWVDERR & 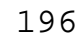 \\
\hline T. maritima & DFLKEFDFSLLD FTMLNINV ---AGEIKGWRFTRQSRRRWNDYFEERV & 91 \\
\hline E. coli & SILRALCKE LRTGRILNINV DL LDQIKGIRVTRCGTRH ADQVI QQ & 18 \\
\hline P. aeruginosa & LLVSAHERLAV RTVLNVNI NL LDRVRGIQLTRLGHRARAAA VKVV & 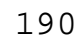 \\
\hline x. fastidiosa & NIVAQLKTD L ADTILNVNV DVTWQQMRGFKVTRLGNRHRSA CLTQT & 196 \\
\hline Clustal Consensus & $: \star * *$. & 78 \\
\hline S. meliloti & DGRGF YFWLRFGERAGDFRSGTDIRALRDNRISVT LKLDMTDHAAQER & \\
\hline M. $\operatorname{loti}$ & DGRGL YYWLRFGRE VEGKQGTDLHALRNRLVSVT LQLDLTAHEIRDQ & 246 \\
\hline T. maritima & S FGEKYYWMMGEVIEDDDRDDVDYKAVREGYVSIT IH FLTNEQCLKK & 241 \\
\hline E. $\operatorname{coli}$ & D RGNTLYWIG GGKCDAG GTDFAAVDEGYVSIT LHVDLTAHSAQDV & 23 \\
\hline P. aeruginosa & N RGKEGYWIAAAGDAEDGG GTDFHAVMQGYVSIT LQLDRTFHEAFGG & 24 \\
\hline x. fastidiosa & D RGHTIYWIG AG EQDAG GTDFDAVRNTYISIT IHVDLTRYQALEN & 24 \\
\hline Clustal Consensus & 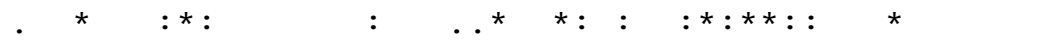 & 95 \\
\hline s. meliloti & IAQALREGSVA----- 256 & \\
\hline M. $\operatorname{lot} i$ & LSKALA---------- 252 & \\
\hline T. maritima & LREVYD---------- 247 & \\
\hline E. $\operatorname{col} i$ & VSDWLNSVGVGTQW-- 253 & \\
\hline P. aeruginosa & LDEWLGGLT------- 249 & \\
\hline$x$. fastidiosa & VTRWTDRLTAHMDW T 262 & \\
\hline Clustal Consensus & 96 & \\
\hline
\end{tabular}

Abb. 42 CLUSTALW-alignment von SurE-Aminosäuresequenzen

Aminosäure-Sequenzvergleiche von SurE-Proteinen aus Sinorhizobium meliloti, Mesorhizobium loti, Thermotoga maritima, Escherichia coli, Pseudomonas aeruginosa und Xylella fastidiosa mit dem Programm CLUSTALW. Mit Sternchen unterlegt sind identische, mit zwei Punkten unterlegt sehr ähnliche und mit einem Punkt unterlegt sind leicht ähnliche Aminosäuren.

\subsubsection{Wachstum von $S$. meliloti unter Biotin-limitierenden Bedingungen}

Nach 20 minütiger Inkubation der $S$. meliloti Kulturen bei $39{ }^{\circ} \mathrm{C}$ fiel auf, daß die unter Biotin-limitierenden Bedingungen angezogenen und gestreßten Kulturen relativ gesehen eine bessere Überlebensfähigkeit hatten, als die Kulturen, welche in Minimalmedium mit $40 \mathrm{nM}$ Biotin angezogen wurden (Abb. 41). Setzte man den Titer der unbehandelten Kulturen als $100 \%$, so zeigten die hitzegestreßten und Biotin-limitierten WT-Kulturen eine Überlebensfähigkeit von $185 \%$ und die gestreßten Biotin-supplementierten Kulturen eine Überlebensfähigkeit von $113 \%$. Die Biotin-limitierten Kulturen waren offensichtlich besser in der Lage, mit zusätzlichem Streß umzugehen. In Vibrio sp. wird unter limitierenden Wachstumsbedingungen eine allgemeine Streßresistenz gegenüber Hitze, 
UV-Bestrahlung und Cadmium-Chlorid beobachtet (Nyström et al.,1992). Generell sind viele Bakterien in der stationären Wachstumsphase resistenter gegenüber schädigenden Umweltbedingungen als in anderen Wachstumsphasen (Hengge-Aronis, 1993). Möglicherweise führt Biotinlimitierung zu einer Aktivierung von Genen, die es der Zelle ermöglichen, schnell auf zusätzliche schlechte Umweltbedingungen $\mathrm{zu}$ reagieren. Außerdem konnte schon in früheren Experimenten unserer Arbeitsgruppe beobachtet werden, daß Biotin-supplementierte Zellen relativ gesehen schneller absterben als Biotinlimitierte Zellen (Belling, 1998). Diese Beobachtungen wurden durch Daten dieser Arbeit unterstützt. So zeigten die Wachstumsversuche in GTS-Minimalmedium mit supplementiertem Biotin, daß vom 2. bis zum 12. Tag der Inkubation beim WT der

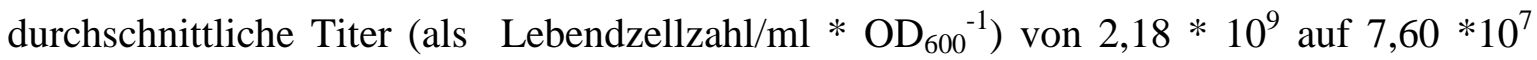
zurückging. Das heißt, daß vom 2. bis 12. Tag der Inkubation der Titer um 96,5\% zurückging. Bei der pcm-Mutante waren die Werte im Biotin-supplementierten Medium über den gleichen Zeitraum vergleichbar (Rückgang um 96,6 \%).

Unter Biotin-limitierenden Bedingungen gingen die Titer im gleichen Zeitraum weniger stark zurück, beim Wildtyp auf $61 \%$ und bei der pcm-Mutante, bei der eine verringerte Überlebensfähigkeit unter Biotinlimitierung festzustellen war, auf 18,5\%.

\subsection{Biotinlimitierung als ein spezielles Streß-Signal für $S$. meliloti ?}

Exogenes Biotin stimuliert rhizobielles Wachstum und spielt eine Schlüsselfunktion bei der Besiedlung der Rhizosphäre durch den Mikrosymbionten (Watson et al., 2001; Streit et al., 1996). Obwohl im Genom von S. meliloti verschiedene Biotinbiosynthesegene vorliegen, konnte die Funktionalität von einigen dieser Gene bisher nicht nachgewiesen werden, so daß davon auszugehen ist, daß die endogene Biotinsynthese limitierend auf rhizobielles Wachstum wirkt (Entcheva et al., 2002). Wie der rhizobielle Stoffwechsel auf molekularer Ebene auf Biotinlimitierung und Biotinsupplementation reagiert, wurde bisher wenig untersucht. Erste Hinweise darauf, daß es in S. meliloti spezielle Anpassungsmechanismen an die Verfügbarkeit von exogenem Biotin gibt, lieferte die Identifizierung des Biotin-regulierten Stationärphasegens bioS aus dem Survival-Locus, die Synthese von PHB unter Biotinlimitierung oder das Vorhandensein von extrem affinen Aufnahmemechanismen für Biotin (Heinz et al., 1999; Entcheva et al., 2002; Hofmann et al., 2000). 
Die Ergebnisse dieser Arbeit zeigen, daß in Abhängigkeit der Biotinkonzentration des Mediums eine Reihe von Veränderungen im Stoffwechsel von S. meliloti auftreten, wobei letztendlich noch zu klären bleibt, ob diese direkt oder indirekt durch Biotin reguliert werden. Aufgrund der Vielfältigkeit dieser Prozesse kann man von einem Biotinregulatorischen Netzwerk in S. meliloti sprechen. Unter Biotin-limitierenden Bedingungen kommt es zu einer erhöhten Expression der Autoinduktor-Synthase SinI und des AcylHomoserin-Lacton-abhängigen Transkriptionsregulators SinR und damit $\mathrm{zu}$ einer vermehrten Bildung eines langkettigen Acyl-Homoserin-Lactons. Es ist bekannt, daß in verschiedenen Mikroorganismen über die Autoinduktion der Übergang in die stationäre Wachstumsphase reguliert werden kann (Lazazzera, 2000). Offensichtlich führt Biotinlimitierung in S. meliloti zur Aktivierung von Mechanismen, die es den Bakterien ermöglichen in die stationäre Wachstumsphase überzugehen, um so im unbepflanzten Boden und damit auch unter Biotinlimitierung überlebensfähig zu bleiben. Dies könnte erklären, warum S. meliloti auch in Laborkulturen eine bessere relative Überlebensfähigkeit unter Biotin-limitierenden Bedingungen als unter Biotinsuffizienz hat und warum Biotin-limitierte Kulturen eine erhöhte Überlebensfähigkeit nach Hitzestreß aufweisen. Die erhöhte Expression des Pcm-Reparaturenzyms unter Biotinlimitation in der stationären Wachstumsphase spricht ebenfalls für eine weitere Anpassung an das Überleben unter Biotinmangel. Biotinmangel könnte daher ein spezielles Streßsignal sein, das eine Anpassung an Hungerzustände im Boden erlaubt, um in Abwesenheit eines potentiellen Symbiosepartners besser zu überdauern. Nach Biotinsupplementation nehmen die Zellen wieder Wachstum auf, was sich in einer erhöhten Expression von Proteinen zeigt, welche an der Transkription, der Translation, dem katabolen Stoffwechsel oder dem Transport von verschiedenen potentiellen Nährstoff-Quellen beteiligt sind. Welche Prozesse unter Biotinlimitierung und Biotinsuffizienz in S. meliloti 1021 eine Rolle spielen ist in Abb. 43 zusammengefaßt. Dabei sind Vorgänge, die durch experimentelle Daten dieser Arbeit unterstützt werden, unterstrichen. Grüne Pfeile symbolisieren aktivierende Funktionen, während rote Pfeile inhibierende Funktionen darstellen. 
A

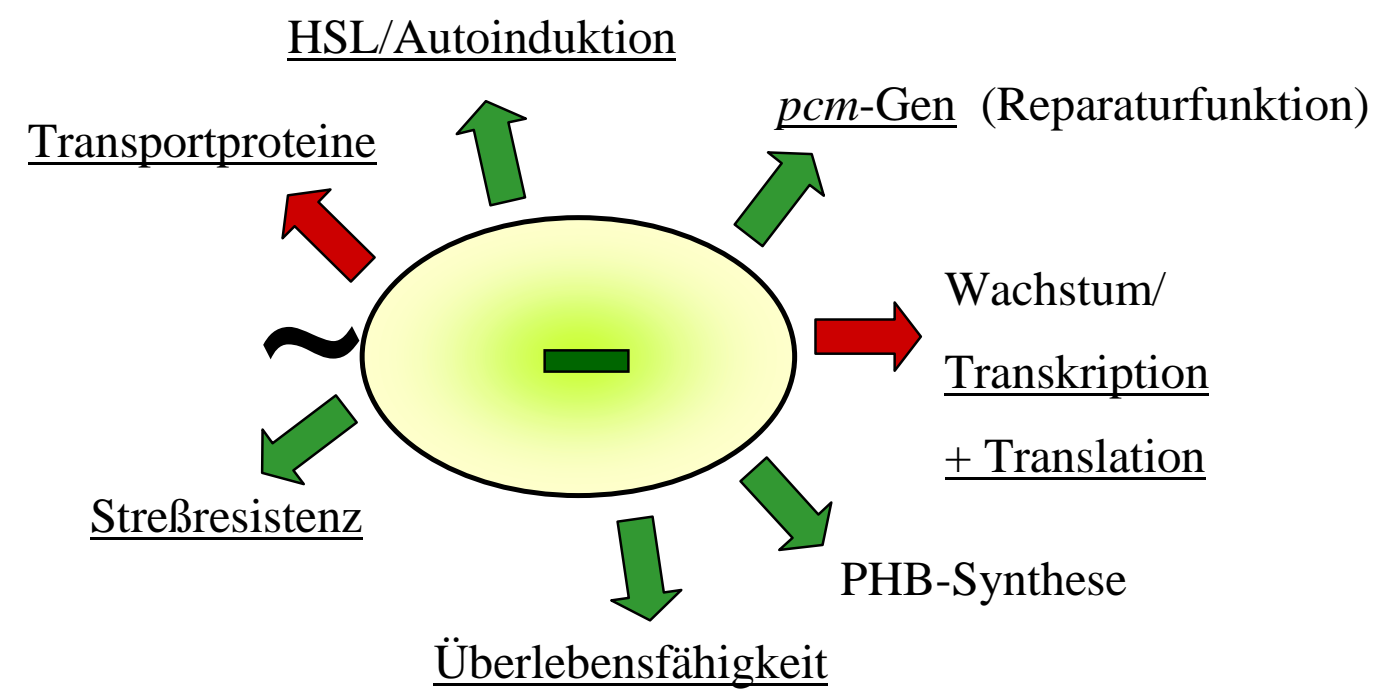

B

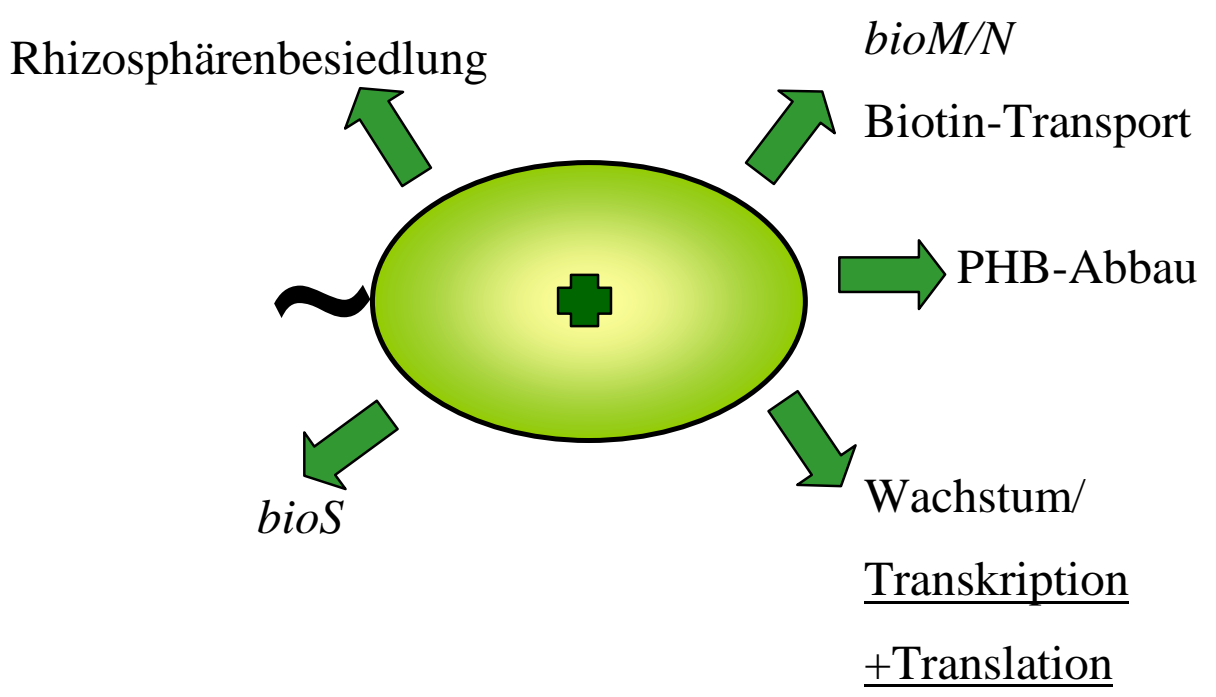

Abb. 43 Zusammenfassende Darstellung von Biotin-abhängigen Prozessen in $S$. meliloti 1021

Diese Abbildung zeigt die Prozesse, welche im Biotin-regulatorischen Netzwerk von Bedeutung sind. Unter $\mathbf{A}$ sind Vorgänge dargestellt, die unter Biotinlimitierung eine Rolle spielen und unter B solche, die unter Biotinsuffizienz von Bedeutung sind. Aktivierende Effekte sind durch grüne Pfeile markiert, inhibierende Effekte durch rote Pfeile. Prozesse, welche durch experimentelle Daten dieser Arbeit unterstützt werden, sind unterstrichen. 


\section{ZUSAMMENFASSUNG}

Bakterien der Gattung Sinorhizobium sind nicht in der Lage Biotin selbst zu synthetisieren. Daher führt Biotinlimitierung zu einer deutlichen Reduktion von Stoffwechselaktivitäten, wohingegen Biotinsuffizienz einen allgemein positiven Einfluß auf Wachstum und Proteinbiosynthese nimmt.

Ziel dieser Arbeit war es mit molekularen Methoden mögliche regulatorische Phänomene zu identifizieren, die an der Wahrnehmung von Biotin, welches sowohl Biotinlimitierung und Biotinsuffizienz umfaßt, beteiligt sein könnten. Dazu wurden drei unterschiedliche Strategien verfolgt:

(i) 2D-Gelanalyse und MALDI-TOF-MS

(ii) Promotoraktivitätsmessungen mit Hilfe von Reportergenen

(iii) Mutagenese und molekulare Charakterisierung von Genen aus dem Survival-Locus

(i) Durch vergleichende Proteomanalyse konnte gezeigt werden, daß die Expression von etwa 70 Proteinen im pI-Bereich 4-7 nach Biotinsupplementation des Mediums induziert wurde. Durch massenspektrometrische Analyse wurden 12 von 18 untersuchten ProteinSpots mit erhöhter Expression eindeutig identifiziert. Zu diesen zählten das ribosomale Protein L7/L12, das CopC-Protein, welches möglicherweise an der Resistenz gegenüber Kupfer beteiligt ist, die Omega-Untereinheit der RNA-Polymerase, ein konserviertes Protein mit unbekannter Funktion und mehrere Bindeproteine von ABC-Transportern mit unterschiedlicher Substratspezifität.

(ii) Mit Hilfe von Reportergenen erfolgte die Expressionsanalyse von Genen, die gezielt aus den Datenbanken ausgewählt wurden, in Abhängigkeit vom Biotingehalt des Anzuchtmediums. Leicht aktivierend wirkte Biotin auf die Expression des bioM-Gens, welches an der Aufrechterhaltung des intrazellulären Biotin-Pools beteiligt ist (2,4-fach erhöhte Expression). Promotoraktivitätsmessungen des $\operatorname{cop} C$-Gens, welches bereits durch die 2D-Gelelektroporese als Biotin-induziert identifiziert werden konnte, zeigten, daß die Expression in Anwesenheit von Biotin bis zu 5-fach erhöht war. Nach andauernder Inkubation unter Biotin-limitierenden Bedingungen, analog zu den Versuchsbedingungen der 2D-Gelelektrophorese, bewirkte Biotinzugabe eine 18-fach erhöhte Expression dieses Gens. 
Unter Biotin-limitierenden Bedingungen konnte eine bis zu 4,3-fach erhöhte Expression des $\sin I$-Promotors und eine bis $\mathrm{zu}$ 1,7-fach erhöhte Expression des $\sin R$-Promotors gemessen werden. Erhöht wurden die Promotoraktivitäten zusätzlich durch Verringerung der Kohlenstoff-Quellen des Mediums. Die sinI- und sinR-Gene codieren für eine Autoinduktor-Synthase bzw. einen Acyl-Homoserin-Lacton-abhängigen Transkriptionsregulator des LuxI- bzw. LuxR-Typs.

Diese Expressionsdaten wurden durch weitere Experimente bestätigt. Aus dem Überstand von unter Biotin-limitierenden Bedingungen angezogener Kulturen ließen sich größere Mengen eines Acyl-Homoserin-Lactons extrahieren und nach Dünnschichtchromatographie durch einen Reporterstamm nachweisen, als aus dem Überstand Biotinsupplementierter Kulturen mit vergleichbaren optischen Dichten. Dabei handelte es sich um einen Autoinduktor mit geringer Mobilität. In S. meliloti ist Autoinduktion daher nicht nur abhängig von der Populationsdichte, sondern auch vom Biotingehalt des Mediums.

(iii) Die Analyse von Genen aus dem Survival-Locus von S. meliloti zeigte, daß die Mutation des surE-Gens unter keiner getesteten Bedingungen $\mathrm{zu}$ einer reduzierten Überlebensfähigkeit führte. Das rekombinante SurE-Protein hatte eine Magnesiumabhängige Phosphataseaktivität mit einem pH-Optimum von 6,5. Die Mutation des pcmGens, welches für das Reparaturenzym L-Isoaspartyl-Protein-Carboxymethyltransferase codiert, resultierte in einer verminderten Überlebensfähigkeit von S. meliloti unter Biotinlimitierenden Bedingungen in der stationären Wachstumsphase. Durch Hitze, Methanol und Oxidationsmittel gestreßte pcm-Mutanten zeigten keinen Phänotyp. Das pcm-Gen wurde unter Biotin-limitierenden Bedingungen maximal exprimiert, wobei die Meßwerte bis zu 13,6-fach über denen von Biotin supplementierten Kulturen lagen. Dies deutet somit auf eine Biotin-abhängige Expression hin. 


\section{LITERATURVERZEICHNIS}

Ballesteros, M., Fredriksson, A., Henriksson, J., Nyström, T. (2001): Bacterial senescence: protein oxidation in non-proliferating cells is dictated by the accuracy of the ribosomes, EMBO J. 20: 5280-5289

Barer, M. R., Harwood, C. R. (1999): Bacterial viability and culturability, Advances in microbiological physiology, 41: 93-137

Barnett, M. J., Fisher, R. F., Jones, T., Komp, C., Abola, A. P., Barloy-Hubler, F. et al., (2001): Nucleotide sequence and predicted functions of the entire Sinorhizobium meliloti pSymA megaplasmid, Proc. Natl. Acad. Sci. USA 98: 9883-9888

Belling, G. (1998): Untersuchungen zum Biotin-abhängigen Wachstum und Überleben von Sinorhizobium meliloti, Diplomarbeit, Universität Bielefeld

Birnboim, H., Doly, J. (1979): A rapid alkaline extraction procedure for screening recombinant plasmid DNA, Nucleic Acids Res. 7: 1513-1518

Bjellqvist, B., Ek, K., Rhigetti, P. G., Gianazza, E., Görg, A., Westermeier, R., Postel, W. (1982): Isoelectric focusing in immobilized pH gradients: Principle, methodology and some applications, J. Biochem. Biophys. Methods 6: 317-339

Blanco, G., Rodicio, M. R., Puglia, A. M., Mendez, C., Thompson, C. J., Salas, J. A. (1994): Synthesis of ribosomal proteins during growth of Streptomyces coelicolor, Mol. Microbiol. 12: 375-385

Blosser-Middleton, R. S., Gray, K. M. (2001): Multiple N-acyl homoserine lactone signals of Rhizobium leguminosarum are synthesized in a distinct temporal pattern, J. Bacteriol. 183: 6771-6777

Blum, H., Beier, H., Gross, H. J. (1987): Improved silver staining method of plant proteins, RNA and DNA in polyacrylamide gels, Electrophoresis 8: 93-99

Bottomley, P. J., Maggard S. P. (1992): Determination of viability within serotypes of a soil population of Rhizobium leguminosarum bv. trifolii, Appl. Environ. Microbiol. 56: 533-540

Bradford, M. M. (1976): A rapid and sensivive method for the quantitation of microgramm quantities of protein utilizing the principle of protein dye-binding, Anal. Biochem. 72: 248-254

Bullock, W., Fernandez, J., Short, J. (1987): XL1-blue: a high efficiency plasmid transforming recA Escherichia coli strain with beta-galactosidase selection, Bio Techniques 5: 376-378

Capela, D., Barloy-Hubler, F., Gouzy, J., Bothe, G., Ampe, F., Batut, J. et al. (2001): Analysis of the chromosome sequence of the legume symbiont Sinorhizobium meliloti strain 1021, Proc. Natl. Acad. Sci. USA 98: 9877-9882 
Cha, C., Gao, P., Chen, Y-C., Shaw, P. D., Farrand, S. K. (1998): Production of acylhomoserine lactone quorum-sensing signals by Gram-negative plant associated bacteria, Molec. Plant-Microbe Interact. 11: 1119-1129

Chatterji, D., Ojha, A. K. (2001): Revisitising the stringent response, ppGpp and starvation signaling, Curr. Opin. Microbiol. 4: 160-165

Chavous, D. A., Jackson, F. R., O'Connor, C. M. (2001): Extension of the Drosophila lifespan by overexpression of a protein repair methyltransferase, Proc. Natl. Acad. Sci. USA 98:14814-14818

Chester, N., Marshak, D. R. (1993): Dimethyl sulfoxide-mediated primer Tm reduction: a method for analyzing the role of renaturation temperature in the polymerase chain reaction, Anal. Biochem. 209: 284-290

Cooksey, D. A. (1994): Molecular mechanisms of copper resistance and accumulation in bacteria, FEMS Microbiol. Rev. 14: 381-386

Cubo, M. T., Economou, A., Murphy, G., Johnston, A. W., Downie, J. A. (1992): Molecular characterization and regulation of the rhizosphere-expressed genes rhiABCR that can influence nodulation by Rhizobium leguminosarum biovar viciae, J. Bacteriol. 174: $4026-4035$

Davey, M. E., de Bruijn, F. J. (2000): A homologue of the tryptophan-rich sensory protein $\mathrm{TspO}$ and FixL regulates novel nutrient deprivation-induced Sinorhizobium meliloti locus, Appl. Environ. Microbiol. 66: 5353-5359

DeLisa, M. P., Vades, J. J., Bentley, W. E. (2001): Mapping stress-induced changes in Autoinducer AI-2 production in chemostat-cultivated Escherichia coli K-12, J. Bacteriol. 183: $2918-2928$

Dunlap, P. V., Kuo, A. (1992): Cell density-dependent modulation of the Vibrio fischeri luminescence system in the absence of autoinducer and LuxR protein, J. Bacteriol. 174: 2440-2448

Dunn, M. F., Araiza, G., Finan, T. M. (2001): Cloning and characterization of pyruvate carboxylase from Rhizobium strain 1021, Arch. Microbiol. 176: 355-363

Dunn, M. F., Araiza, G., Cevallos, M. A., Mora, J. (1997): Regulation of pyruvat carboxylase in Rhizobium etli, FEMS Microbiol. Lett. 157: 301-306

Dusha, I., Austin, S., Dixon, R. (1999): The upstream region of the nodD3 gene of Sinorhizobium meliloti carries enhancer sequences for the transcriptional activator NtrC. FEMS Microbiol. Lett. 179: 491-499

Dusha, I., Bakos, A., Kondorosi, A., de Bruijn, F. J., Schell, J. (1989): The Rhizobium meliloti early nodulation genes $(\operatorname{nod} A B C)$ are nitrogen regulated: Isolation of a mutant strain with efficient nodulatin capacity on alfalfa in the presence of ammonium, Mol. Gen. Genet. 219: 89-96 
Egener, T., Hurek, T., Reinhold-Hurek, B. (1998): Use of green fluorescent protein to detect expression of nif genes of Azoarcus sp. BH72, a grass-associated diazotroph, on rice roots, Mol. Plant-Microbe Interact. 11: 71-75

Ehrmann, M., Ehrle, R., Hofmann, E., Boos, W., Schlosser, A. (1998): The ABC maltose transporter, Mol. Microbiol. 29: 685-694

Entcheva, P., Phillips, D. A., Streit, W. R. (2002): Functional analysis of Sinorhizobium meliloti genes involved in biotin synthesis and transport, Appl. Environ. Microbiol. 68: 2843-2848

Finan, T. M., Weidner, S., Wong, K., Buhrmester, J., Chain, P. et al. (2001): The complete sequence of the $1,683-\mathrm{kb}$ pSymB megaplasmid from the $\mathrm{N}_{2}$-fixing endosymbiont Sinorhizobium meliloti, Proc. Natl. Acad. Sci. USA 98: 9889-9894

Finkel, S. E., Kolter, R. (1999): Evolution of microbial diversity during prolonged starvation, Proc. Natl. Acad. Sci. USA 96: 4023-4027

Flavier, A. B., Schell, M. A., Denny, T. P. (1998): A RpoS $\left(\sigma^{\mathrm{S}}\right)$ homologue regulates acylhomoserine lactone-dependent autoinduction of Ralstonia solanacearum, Mol. Microbiol. 28: 475-486

Fuqua, W. C., Winans, S. C. (1996): A LuxI-LuxR type regulatory system activates Agrobacterium $\mathrm{Ti}$ conjugal transfer in the presence of a plant tumor metabolite, $\mathrm{J}$. Bacteriol. 178: 2796-2806

Gage, D. J., Long, S. R. (1998) alpha-Galactoside uptake in Rhizobium meliloti: isolation and characterization of agpA, a gene encoding a periplasmic binding protein required for melibiose and raffinose utilization, J. Bacteriol. 180: 5739-5748

Gay, P., Le Coq, D., Steinmetz, M., Ferrari, E., Hoch, J. A. (1983): Cloning structural gene $s a c B$, which codes for exoenzyme levansucrase of Bacillus subtilis: expression of the gene in Escherichia coli, J. Bacteriol. 153: 1424-1431

Gentry, D., Xiao, H., Burgess, R., Cashel, M. (1991): The omega subunit of Escherichia coli K-12 RNA polymerase is not required for stringent RNA control in vivo, J. Bacteriol. 173: $3901-3903$

Gong, L., Takayama, K., Kjelleberg, S. (2002): Role of spoT-dependent ppGpp accumulation in the survival of light-exposed starved bacteria, Microbiology 148: 559-570

Gonzales, J. E., York, G. M., Walker, G. C. (1996): Rhizobium meliloti exopolysaccharides: synthesis and symbiotic function, Gene 179: 141-146

Gray, K. M., Greenberg, E. P. (1992): Physical and functional maps of the luminescence gene cluster in an autoinducer-deficient Vibrio fischeri strain isolated from a squid light organ, J. Bacteriol. 174: 4384-4390 
Gray, K. M., Pearson, J. P., Downie, J. A., Boboye, B. E., Greenberg, E. P. (1996): Cell-to-cell signaling in the symbiotic nitrogen-fixing bacterium Rhizobium leguminosarum: Autoinduction of a stationary phase and rhizosphere-expressed genes, J. Bacteriol. 178: 372-376

Guerreiro, N., Djordjevic, M. A., Rolfe, B. G. (1999): Proteome analysis of the model microsymbiont Sinorhizobium meliloti: Isolation and characterization of novel proteins, Electrophoresis 20: 818-825

Guerreiro, N., Redmond, J. W., Rolfe, B. G., Djordjevic, M. A. (1997): New Rhizobium leguminosarum flavonoid-induced proteins revealed by proteome analysis of differentially displayed proteins, Mol. Plant-Microbe. Interact. 10: 506-516

Haygood, M. G., Nealson, K. H. (1985): Mechanisms of iron regulation of luminescence in Vibrio fischeri, J. Bacteriol. 162: 209-216

Heinz, E., Phillips, D. A., Streit, W. S. (1999): BioS, a biotin-induced stationary phase and possible LysR-type regulator in Sinorhizobium meliloti, Mol. Plant-Microbe Interact. 12: $803-812$

Hengge-Aronis, R. (1993): The role of rpoS in early stationary phase gene regulation in Escherichia coli K12, In: Starvation in bacteria, Kjelleberg (ed.), pp: 171-194, ISBN 0306-44430-5, Plenum Press, New York

Hengge-Aronis, R. (1999): Interplay of global regulators and cell physiology in the general stress response of Escherichia coli, Curr. Opin. Microbiol. 2: 148-152

Herbert, K. C., Foster, S. J. (2001): Starvation survival in Listeria monocytogenes: characterization of the response and the role of known and novel components, Microbiology 147: 2275-2284

Hirsch, P. R. (1979): Plasmid-determined bacteriocin production by Rhizobium leguminosarum, J. Gen. Microbiol. 113: 219-228

Hofmann, K., Heinz, E. B., Charles, T. C., Hoppert, M., Liebl, W., Streit, W. R. (2000): Sinorhizobium meliloti strain 1021 bioS and bdhA gene transcription are both affected by biotin available in defined medium, FEMS Microbiol. Lett. 182: 41-44

Honeycutt, R.J., McClelland, M., Sobral, B. W. (1993): Physical map of the genome of Rhizobium meliloti 1021, J. Bacteriol. 175: 6945-6952

Howorth, S. M., England, R. R. (1999): Accumulation of ppGpp in symbiotic and freeliving nitrogen-fixing bacteria following amino acid starvation, Arch. Microbiol. 171: 131134

Huisman, G. W., Kolter, R. (1994): Sensing starvation: a homoserine lactone-dependent signaling pathway in Escherichia coli, Science 5171: 537-539 
Jäger, W., Schäfer, A., Kalinowski, J., Pühler, A. (1995): Isolation of insertion elements from Gram-positive Brevibacterium, Corynebacterium, and Rhodococcus strains used in the Bacillus subtilis $s a c B$ gene as a positive selection marker, FEMS Microbiol. Lett. 126: $1-6$

Jefferson, R. A., Burgess, S. M., Hirsch, D. (1986): B-Glucuronidase from Escherichia coli as a gene-fusion marker, Proc. Natl. Acad. Sci. USA 83: 8447-8451

Jensen, J. B., Peters, N. K., Bhuvaneswari, T. V. (2002): Redundancy in periplasmic binding protein-dependent transport systems for trehalose, sucrose, and maltose in Sinorhizobium meliloti, J. Bacteriol. 184: 2978-2986

Kagan, R. M., Niewmierzycka, A., Clarke, S. (1997): Targeted gene disruption of the Caenorhabditis elegans L-isoaspartyl protein repair methyltransferase impairs survival of dauer stage nematodes, Arch. Biochem. Biophys. 348: 320-328

Kahn, M. L., McDermott, T. R., Udvardi, M. K. (1998): Carbon and nitrogen metabolism in Rhizobia. In: The Rhizobiaceae, Molecular biology of model plantassociated bacteria, Spaink, H. P., Kondorosi, A., Hooykaas, P. J. J., (eds.) $1^{\text {st }}$ ed; pp. 461485, Kluwer Academic Publishers, Dordrecht, The Netherlands

Kim, E., Lowenson, J. D., MacLaren, D. C., Clarke, S. Young, S. G. (1997): Deficiency of a protein-repair enzyme results in the accumulation of altered proteins, retardation of growth, and fatal seizures in mice, Proc. Natl. Acad. Sci. USA 94: 6132-6137

Kiss, G.B., Vincze, E., Kalman, Z., Forrai, T., Kondorosi, A. (1979): Genetic and biochemical analysis of mutants affected in nitrate reduction in Rhizobium meliloti, J. Gen. Microbiol. 113: 105-118

Kondorosi, E., Buire, M., Cren, M., Iyer, N., Hoffmann, B., Kondorosi, A. (1991): Involvement of the syrM and nodD3 genes of Rhizobium meliloti in nod gene activation and in optimal nodulation of the plant host, Mol. Microbiol. 5: 3035-3048

Kormanec, J., Homerova, D., Barak, I., Sevcikova, B. (1999): A new gene, sigG, encoding a putative alternative sigma factor of Streptomyces coelicolor A3(2), FEMS Microbiol. Lett. 172: 153-158

Kovach, M. E., Elzer, P. H., Hill, D. S., Robertson, G. T., Farris, M. A., Roop, R. M. 2nd, Peterson, K. M. (1995): Four new derivatives of the broad-host-range cloning vector pBBR1MCS, carrying different antibiotic-resistance cassettes, Gene 166: 175-176

Kusian, B., Bednarski, R., Husemann, M., Bowien, B. (1995): Characterization of the duplicate ribulose-1,5-bisphosphate carboxylase genes and $c b b$ promoters of Alcaligenes eutrophus, J. Bacteriol. 177: 4442-4450

Kutchma, A. J., Hoang, T. T., Schweizer, H. P. (1999): Characterization of a Pseudomonas aeruginosa fatty acid biosynthetic gene cluster: purification of acyl carrier protein (ACP) and malonyl-coenzyme A:ACP transacylase (FabD), J. Bacteriol. 181: 5498-5504 
Kvint, K., Farewell, A., Nyström, T. (2000): RpoS-dependent promotors require guanosine tetraphosphate for induction even in the presence of high levels of $\sigma^{\mathrm{S}}$, J. Biol. Chem. 275: 14795-14798

Lange, R., Hengge-Aronis, R. (1991): Growth phase regulated expression of bolA and morphology of stationary-phase Escherichia coli cells are controlled by the novel sigma factor $\sigma^{\mathrm{S}}$, J. Bacteriol. 173: 4474-4481

Latifi, A., Foglino, M., Tanaka, K., Williams, P., Lanzdunski, A. (1996): A heirarchical quorum sensing cascade in Pseudomonas aeruginosa links the transcriptional activator LasR and Rhl (VsmR) to expression of the stationary phase sigma factor RpoS, Mol. Microbiol. 21: 1137-1146

Laue, B. E., Jiang, Y., Chhabra, S. R., Jacob, S., Stewart, G. S., Hardman, A., Downie, J. A., O'Gara, F., Williams, P. (2000): The biocontrol strain Pseudomonas fluorescens F113 produces the Rhizobium small bacteriocin, N-(3-hydroxy-7-cistetradecenoyl) homoserine lactone, via HdtS, a putative novel $\mathrm{N}$-acylhomoserine lactone synthase, Microbiology 146: 2469-2480

Lazazzera, B. A. (2000): Quorum sensing and starvation: signals for entry into stationary phase, Curr. Opin. Microbiol. 3: 177-182

Lee, J. Y., Kwak, J. E., Mooe, J., Eom, S. H., Liong, E. C., Pedelacq, J.-D., Berendzen, J., Suh, S. W. (2001): Crystal structure and functional analysis of the SurE protein identify a novel phosphatase family, Nat. Struct. Biol. 8: 789-794

Li, C., Clarke, S. (1992b): A protein methyltransferase specific for altered aspartyl residues is important in Escherichia coli stationary-phase survival and heat-shock resistance, Proc. Natl. Acad. Sci. USA 89: 9885-9889

Li, C., Wu, P.-Y., Hsieh, M. (1997): Growth-phase dependent transcriptional regulation of the pcm and surE genes required for stationary-phase survival of Escherichia coli, Microbiology 143: 3513-3520

Link, A. J., Robinson, K., Church, G. M. (1997): Comparing the predicted and observed properties of proteins encoded in the genome of Escherichia coli K-12, Elecrophoresis 18: $1259-1313$

Loewen, P. C., Hu, B., Strutinsky, J., Sparling, R. (1998): Regulation of the rpoS regulon of Escherichia coli, Can. J. Microbiol. 44: 707-717

Lowenson, J. D., Kim, E., Young, S. G., Clarke, S. (2001): Limited accumulation of damaged proteins in L-isoaspartyl (D-aspartyl) O-methyltransferase-deficient mice, J. Biolog. Chem. 276: 20695-20702

Maillet, F., Debelle, F., Denarie, J. (1990): Role of the nodD and syrM genes in the activation of the regulatory gene nodD3, and of the common and host-specific nod genes of Rhizobium meliloti, Mol. Microbiol. 4: 1975-1984

Marketon, M. M., Gonzales J. E. (2002): Identification of two quorum-sensing systems in Sinorhizobium meliloti, J. Bacteriol. 184: 3466-3475 
Marquard, R. (2000): Stickstoffassimilation und die Symbiose mit Knöllchenbakterien. www.bibd.uni-giessen.de/gdoc/2000/uni/p00003/sticksto.htm

Matin, A., Auger, A., Blum, P. H., Schultz, J. E. (1989): Genetic basis of starvation survival in nondifferentiating bacteria, Annu. Rev. Microbiol. 43: 293-316:

Meade, H. M., Long., S. R., Ruvkun, G. B., Brown, E. E., Ausubel, F. M. (1982): Physical and genetic characterization of symbiotic and auxotrophic mutants of Rhizobium meliloti induced transposon Tn5 mutagnesis, J. Bacteriol. 149: 114-122

Meighen, E. A. (1991): Molecular biology of bacterial bioluminescence, Microbiol. Rev. 55: $123-142$

Milcamps, A., de Bruijn, F. J. (1999): Identification of a novel nutrient-deprivationinduced Sinorhizobium meliloti gene ( $h m g A)$ involved in the degradation of tyrosine, Microbiology 145: 935-947

Miyamoto, C. M., Sun, W., Meighen, E. A. (1998): The LuxR regulator protein controls synthesis of polyhydroxybutyrate in Vibrio harveyi, Biochim. Biophys. Acta 1384: 356364

Mulligan, J. T., Long, S. R. (1989): A family of activator genes regulates expression of Rhizobium meliloti nodulation genes, Genetics 122: 7-18

Natera, S. H., Guerreiro, N., Djordjevic, M. A. (2000): Proteome analysis of differentially displayed proteins as a tool for the investigation of symbiosis, Mol. PlantMicrobe Interact. 13: 995-1009

Niewmierzycka, A., Clarke, S. (1999): Do damaged proteins accumulate in Caenorhabditis elegans L-isoaspartate methyltransferase (pcm-1) deletion mutants ? Arch. Biochem. Biophys. 364: 209-218

Nomura, M. (1999): Regulation of ribosome biosynthesis in Escherichia coli and Saccharomyces cerevisiae: diversity and common principles, J. Bacteriol. 181: 6857-6864

Notley-McRobb, L., Death, A., Ferenci, T. (1997): The relationship between external glucose concentration and cAMP levels inside Escherichia coli: implications for models of phosphotransferase-mediated regulation of adenylate cyclase, Microbiology 143: 19091918

Nyström, T. (2001): Not quite dead enough: on bacterial life, culturability, senescence, and death, Arch. Microbiol. 176: 159-164

O'-Farell, P.H. (1975): High resolutional two-dimensional electrophoresis of proteins, J. Biol. Chem. 250: 4007-4021

Östling, J., Holmquist, L., Flärdh, K., Svenblad, B., Jouper-Jaan, A., Kjelleberg, S. (1993): Starvation and recovery of Vibrio; In: Starvation in bacteria, Kjelleberg (ed.), pp: 103-123, ISBN 0-306-44430-5, Plenum Press, New York 
Parsek, M.R., Greenberg, E. P. (2000): Acyl-homoserine lactone quorum sensing in gram-negative bacteria: a signaling mechanism involved in associations with higher organisms, Proc. Natl. Acad. Sci. USA 97: 8789-8793

Peoples, M. B., Herridge, D. F., Ladha, J. K. (1995): Biological nitogen fixation: an efficient source of nitrogen for sustainable agricultural production, Plant soil 174: 3-28

Peters, N. K., Frost, J. W., Long, S. R. (1986): A plant flavone luteolin induces expression of Rhizobium meliloti nodulation genes, Science 233: 977-980

Phillips, D. A., Streit, W. R. (1996): Legume signals to rhizobial symbionts: A new approach for defining rhizosphere colonization. In: G. Stacey, N. Keen (eds.), PlantMicrobe Interactions, Vol. 1. Chapmann \& Hall, New York, 236-271

Puskas, A., Greenberg, E. P., Kaplan, S., Schaefer, A.L. (1997): A quorum-sensing system in the free-living photosynthetic bacterium Rhodobacter sphaeroides, J. Bacteriol. 179: $7530-7537$

Riehle, M. M., Bennett, A. F., Long, A. D. (2001): Genetic architecture of thermal adaptation in Escherichia coli, Proc. Natl. Acad. Sci. USA 98: 525-530

Rovira, A. D., Harris, J. R. (1961): Plant root excretions in relations to the rhizosphere effect.V. The excretion of B-group vitamins, Plant Soil 14: 199-214

Sadowsky, M. J., Graham, P. H. (1998): Soil biology of the Rhizobiaceae. In: The Rhizobiaceae, Molecular biology of model plant-associated bacteria, Spaink, H. P., Kondorosi, A., Hooykaas, P. J. J., (eds.) $1^{\text {st }}$ ed; pp. 155-172, Kluwer Academic Publishers, Dordrecht, The Netherlands

Salmond, G. P. C., Bycroft, B. W., Stewart., G. S. A. B., Williams, P. (1995): The bacterial „enigma“: cracking the code of cell-cell communication, Mol. Microbiol. 16: 615-624

Sambrook, J., Fritsch, E. F., Maniatis, T. (1989): Molecular cloning: a laboratory manual, $2^{\text {nd }}$ ed., Cold Spring Harbour laboratory Press, Cold Spring Harbour, N. Y.

Schäfer, A., Tauch, A., Jäger, W., Kalinowski, J., Thierbach, G., Pühler, A. (1994): Small mobilizable multi-purpose cloning vectors derived from the Escherichia coli plasmids pK18 and pK19: selection of defined deletions in the chromosome of Corynebacterium glutamicum, Gene 145: 69-73

Schlaman, H. R. M., Okker, R. J. H., Lugtenberg, B. J. J. (1992): Regulation of nodulation gene expression by NodD in Rhizobia, J. Bacteriol. 174: 5177-5182

Schmeißer, C. (2001): Molekulare Charakterisierung von birS, einer potentiellen SensorKinase aus Sinorhizobium meliloti, Diplomarbeit am Institut für Mikrobiologie und Genetik der Georg-August-Universität Göttingen

Schrattenholz, A. (2001): Methoden der Proteomforschung, Spektrum Akademischer Verlag, Heidelberg Berlin 
Schultze, M., Quiclet-Sire, B., Kondorosi, E., Virelizer, H., Glushka, J. N., Endre, G., Gero, S. D., Kondorosi, A. (1992): Rhizobium meliloti produces a family of sulfated lipooligisaccharides exhibiting different degrees of plant host specifity, Proc. Natl. Acad. Sci. USA 89: 192-196

Shaw, P. D., Ping, G., Daly, S. L., Cha, C., Cronan, J. E. Jr, Rinehart, K. L., Farrand, S. K. (1997): Detecting and characterizing N-acyl-homoserine lactone signal molecules by thin-layer chromatography, Proc. Natl. Acad. Sci. USA 94: 6036-6041

Siegele, D. A., Almiron, M., Kolter, R. (1993): Approaches to the study of survival and death in stationary-phase Escherichia coli, In: Starvation in bacteria, Kjelleberg (ed.), pp: 151-167, ISBN 0-306-44430-5, Plenum Press, New York

Simon, R., Priefer, U., Pühler, A. (1983): A broad host range mobilization system for in vivo genetic engineering: transposon mutagenesis in Gram-negative bacteria, Bio/Technology 1: 784-791

Sourjik, V., Muschler, P., Scharf, B., Schmitt, R. (2000): VisN and VisR are global regulators of chemotaxis, flagellar and motility genes in Sinorhizobium (Rhizobium) meliloti, J. Bacteriol. 182: 782-788

Southern, E. M. (1975): Detection of specific sequences among DNA fragments separated by gel electrophoresis, J. Mol. Biol. 98: 503-517

Spector, M. P. (1998): The starvation stress response (SSR) of Salmonella, Adv. Microb. Physiol. 40: 233-279

Srinivasan, S., Östling, J., Charlton, T., de Nys, R., Takayama, K., Kjelleberg, S. (1998): Extracellular signal molecule(s) involved in the carbon starvation response of marine Vibrio sp. strain S14, J. Bacteriol. 180: 201-209

Streit, W. R., Hofmann, K., Liebl, W. (2000): Molecular characterization of the Sinorhizobium meliloti nlpD gene, Arch. Microbiol. 174: 292-295

Streit, W. R., Joseph, M. C., Phillips, D. A. (1996): Biotin and other water-soluble vitamins are key growth factors for alfalfa root colonization by Rhizobium meliloti 1021, Mol. Plant-Microbe Interact. 9: 330-338

Streit, W. R., Phillips, D. A. (1997): A biotin regulated DNA locus (bioS) in a possible survival operon of Rhizobium meliloti strain 1021. Mol. Plant-Microbe Interact. 10: 933937

Swanson, J. A., Mulligan, J. T., Long, S. R. (1993): Regulation of syrM and nodD3 in Rhizobium meliloti, Genetics 134: 435-444

Teixeira-Gomes, A. P., Cloeckaert, A., Zygmunt, M. S. (2001): Characterization of heat, oxidative, and acid stress responses in Brucella melitensis, Infect. Immun. 68: 2954-2961 
Thorne, S. H., Williams, H. D. (1997): Adaption to nutrient starvation in Rhizobium leguminosarum bv. phaseoli: analysis of survival, streß resistance and changes in macromolecular synthesis during entry to and exit from stationary phase, J. Bacteriol. 179: 6894-6901

Thorne, S. H., Williams, H. D. (1999): Cell densitiy-dependent starvation survival of Rhizobium leguminosarum bv. phaseoli: identification of the role of $\mathrm{N}$-acyl homoserine lactone in adaptation to stationary-phase survival, J. Bacteriol. 198: 981-990

Traviglia, S. L., Datwyler, S. A., Yan, D., Ishihama, A., Meares, C. F. (1999): Targeted protein footprinting: where different transcription factors bind to RNA polymerase, Biochemistry 38: 15774-15778

Treton, B. Y., Le Dall, M. T., Gaillardin, C. M. (1992): Complementation of Saccharomyces cerevisiae acid phosphatase mutation by a genomic sequence from the yeast Yarrowia lipolytica identifies a new phosphatase, Curr. Genet. 22: 345-355

Uhde, C., Schmitt, R., Jording, D., Selbitschka, W., Pühler, A. (1997): Stationary-phase mutants of Sinorhizobium meliloti are impaired in stationary-phase survival or in recovery to logarithmic growth, J. Bacteriol. 179: 6432-6440

van Delden, C., Comte, R., Bally, A. M. (2001): Stringent response activates quorum sensing and modulates cell density-dependent gene expression in Pseudomonas aeruginosa, J. Bacteriol. 83: 5376-5384

Vance, C. P. (1998): Legume symbiotic nitrogen fixation: agronomic aspects. In: The Rhizobiaceae, Molecular biology of model plant-associated bacteria, Spaink, H.P., Kondorosi, A., Hooykaas, P. J. J., (eds.) $1^{\text {st }}$ ed; pp. 509-530, Kluwer Academic Publishers, Dordrecht, The Netherlands

Visick, J. E., Clarke, S. (1997): RpoS and OxyR-independent induction of HPI catalase at stationary phase in Escherichia coli and identification of rpoS mutations in common laboratory strains, J. Bacteriol. 179: 4158-4163

Visick, J. E., Cai, H., Clarke, S. (1998): The L-isoaspartyl protein repair methyltransferase enhances survival of aging Escherichia coli subjected to secondary environmental stresses, J. Bacteriol. 180: 2623-2629

Visick, J. E., Clarke, S. (1995): Repair, refold, recycle: how bacteria can deal with spontaneous and environmantel damage to proteins, Mol. Microbiol. 16: 835-845

Visick, J. E., Ichikawa, J. K., Clarke, S. (1998): Mutations in the Escherichia coli surE gene increase isoaspartyl accumulation in a strain lacking the $p c m$ repair methyltransferase but suppress stress-survival phenotypes, FEMS Microbiol. Lett. 167: 19-25

Wai, S. N., Mizunoe, Y., Yoshida, S. (1999): How Vibrio cholerae survive during starvation, FEMS Microbiol. Lett. 180: 123-131

Wei, X., Bauer, W. D. (1998): Starvation-induced changes in motility, chemotaxis and flagellation of Rhizobium meliloti, Appl. Environ. Microbiol. 67: 3767-3770 
Weichart, D., Lange, R., Henneberg, N., Hengge-Aronis, R. (1993): Identification and characterization of stationary phase-inducible genes in Escherichia coli, Mol. Microbiol. 10: $407-420$

Wells, D. H., Long, S. R. (2002): The Sinorhizobium meliloti stringent response affects multiple aspects of symbiosis, Mol. Microbiol. 43: 1115-1127

Wexler, M., Yeoman, K. H., Stevens, J. B., de Luca, N. G., Sawers, G., Johnston, A. W. (2001): The Rhizobium leguminosarum tonB gene is required for the uptake of siderophore and haem as sources of iron, Mol. Microbiol. 41: 801-816

Wick, L. M., Quadroni, M., Egli, T. (2001): Short- and long-term changes in proteome composition and kinetic properties in a culture of Escherichia coli during transition from glucose-excess to glucose-limited growth conditions in continuous culture and vice versa, Environ. Microbiol. 3: 588-599

Wilkins, M. R., Gasteiger, E., Sanchez, J. C., Bairoch, A., Hochstrasser, D. F. (1998): Two-dimensional gel electrophoresis for proteome projects: the effects of protein hydrophobicity and copy number, Electrophoresis 19: 1501-1505

Wilkinson, A., Danino, V., Wisniewski-Dye, F., Lithgow, J. K., Downie, J. A. (2002): $\mathrm{N}$-acyl-homoserine lactone inhibition of rhizobial growth is mediated by two quorumsensing genes that regulate plasmid transfer, J. Bacteriol. 184: 4510-4519

Wilson, K. J., Sessitsch, A., Corbo, J. C., Giller, K., Akkermans, A. D. L., Jefferson, R. A. (1995): ß-Glucuronidase (GUS) transposons for ecological and genetic studies of rhizobia and other Gram-negative bacteria, Microbiology 141: 1691-1705

Wisniewski-Dye, F., Jones, J., Chhabra, S. R., Downie, J. A. (2002): rai genes are part of a quorum-sensing netwerk controlled by $\operatorname{cinI}$ and cinR in Rhizobium leguminosarum, J. Bacteriol. 184: 1597-1606

Withers, H. L., Nordström, K. (1998) Quorum-sensing acts at initiation of chromosomal replication in Escherichia coli, Proc. Natl. Acad. Sci. USA 95: 15694-15699

Yeh, K. C., Peck, M. C., Long, S. R. (2002): Luteolin and GroESL modulate in vitro activity of NodD, J. Bacteriol. 184: 525-530

Yildiz, F. H., Schoolnik, G. K. (1998): Role of $r p o S$ in stress survival and virulence of Vibrio cholerae, J. Bacteriol. 180: 773-784

Zhang, Y., Cronan, J. E. Jr. (1998): Transcriptional analysis of essential genes of the Escherichia coli fatty acid biosynthesis gene cluster by functional replacement with the analogous Salmonella typhimurium gene cluster, J. Bacteriol. 180: 3295-3303

Zhang, R.-G., Skarina, T., Katz, J. E., Beasley, S., Khachatryan, A., Vyas, S., Arrowsmith, C. H., Clarke, S., Edwards, A., Joachimiak, A., Savchenko, A. (2001): Structure of the Thermotoga maritima stationary phase survival protein SurE: A novel acid phosphatase, Structure 9: 1095-1106 


\section{DANKSAGUNGEN}

Prof. Dr. Wolfgang Liebl danke ich für die Ermöglichung dieser Arbeit.

Bei Herrn Prof. Dr. Gerhard Gottschalk möchte ich mich für die Übernahme des Korreferats meiner Arbeit bedanken.

Als Betreuer meiner Arbeit möchte ich PD Dr. Wolfgang Streit für die Überlassung des Themas und die Bereitschaft, jederzeit für Fragen zur Verfügung zu stehen, danken.

Ganz herzlich danke ich allen ehemaligen und jetzigen Labormitgliedern Cati, Christel, Mladen, Moni, Julia, Kai, Nina, Manuela, Jörg, Christian, Maike, Alex, Birgit, Sonja, Plamena, Patrick, Angel, Kiki, Krassi, Arnim, Katrin und Schmul für die gute Atmosphäre im Labor 37/44. Besonders möchte ich mich bei Ute bedanken, für ihre sehr nette Art und die kleinen Gespräche an der Laborbank, bei Martin, für das tiefgehende Verständnis in Gesprächen über den schönen Laboralltag, bei Meike, als würdige Nachfolgerin im Geschicklichkeitsbereich und für die guten Filmempfehlungen, bei unserem „Chemiker“ Volker, für seine Hilfsbereitschaft, bei Ole, für die freundliche Aufnahme in Göttingen und die Fähigkeit die Dinge optimistischer zu betrachten und andere mit dieser Sichtweise (manchmal) anstecken zu können und natürlich bei Carsten, für die Organisation des Sportprogramms innerhalb und außerhalb des Labors, für den Spaß, für das Korrekturlesen und für seine „Weisheiten, die die Welt nicht braucht“.

Danken möchte ich auch Nicole, Bianca und Gunnar, dafür, daß Ihr mich nicht im „Exil“ vergessen habt.

Bei Marc-Oliver Luther bedanke ich mich für die Einführung in die Welt der Massenspektrometrie.

Bedanken möchte ich mich außerdem bei der Werkstatt-Crew, für die Lösung aller Probleme mechanischer und elektronischer Natur und bei allen weiteren Mitgliedern des Instituts, die mir mit Rat und Tat behilflich waren.

Besonders bedanke ich mich bei meinem Freund Tom, für die Unterstützung, die kleinen Aufmunterungen zwischendurch und für den monatelangen Verzicht auf seinen Computer.

Schließlich möchte ich meinen Eltern und Großeltern danken, die mich während der Studien- und Promotionszeit ideell und finanziell unterstützt haben. 


\section{LEBENSLAUF}

$14 / 09 / 1972$

1979-1983

1983-1989

1989-1992

$06 / 1992$

$10 / 92$

$11 / 93,04 / 94,10 / 94$

$12 / 96,5 / 97,11 / 97$

$11 / 97-11 / 98$

$01 / 99$
Geburt in Arad/Rumänien

Besuch der Grundschule in Bielefeld

Besuch der Marienschule der Ursulinen in Bielefeld

Besuch des Bavink-Gymnasiums in Bielefeld

Abitur

Immatrikulation an der Universität Bielefeld im

Studiengang Biologie (Diplom)

Vordiplom in den Fächern Chemie, Physik,

Neurophysiologie und Tierphysiologie

Diplomprüfungen in den Fächern Chemie,

Tierphysiologie, Pflanzenphysiologie und Genetik

Anfertigung der experimentellen Diplomarbeit unter

Anleitung von Prof. Dr. A. Pühler und Dr. W. Streit mit dem Titel: Überexpression, Reinigung und immunologischer Nachweis von BioS1, einem Biotinabhängigen LysR-Typ Rezeptor in Rhizobium meliloti 1021

Beginn der experimentellen Arbeiten zur vorliegenden Dissertation 